\title{
After the rehabilitation centre : a study into the course of functioning after discharge from rehabilitation
}

Citation for published version (APA):

de Witte, L. P. (1991). After the rehabilitation centre : a study into the course of functioning after discharge from rehabilitation. [Doctoral Thesis, Maastricht University]. Swets \& Zeitlinger. https://doi.org/10.26481/dis.19910906lw

Document status and date:

Published: 01/01/1991

DOI:

10.26481/dis.19910906lw

Document Version:

Publisher's PDF, also known as Version of record

\section{Please check the document version of this publication:}

- A submitted manuscript is the version of the article upon submission and before peer-review. There can be important differences between the submitted version and the official published version of record.

People interested in the research are advised to contact the author for the final version of the publication, or visit the DOI to the publisher's website.

- The final author version and the galley proof are versions of the publication after peer review.

- The final published version features the final layout of the paper including the volume, issue and page numbers.

Link to publication

\footnotetext{
General rights rights.

- You may freely distribute the URL identifying the publication in the public portal. please follow below link for the End User Agreement:

www.umlib.nl/taverne-license

Take down policy

If you believe that this document breaches copyright please contact us at:

repository@maastrichtuniversity.nl

providing details and we will investigate your claim.
}

Copyright and moral rights for the publications made accessible in the public portal are retained by the authors and/or other copyright owners and it is a condition of accessing publications that users recognise and abide by the legal requirements associated with these

- Users may download and print one copy of any publication from the public portal for the purpose of private study or research.

- You may not further distribute the material or use it for any profit-making activity or commercial gain

If the publication is distributed under the terms of Article $25 \mathrm{fa}$ of the Dutch Copyright Act, indicated by the "Taverne" license above, 
AFTER THE REHABILITATION CENTRE 


\section{CIP-gegevens Koninklijke Bibliotheek, Den Haag}

Witte, Lucas. Petrus de

After the rehabilitation centre : a study into the course of functioning after discharge from rehabilitation / Lucas Petrus de Witte. - Amsterdam [etc]: Swets \& Zeitlinger

Ook verschenen in handelseditie: Amsterdam [etc]: Swets \& Zeitlinger, 1991 - (IRV Series in Rehabilitation Research. ISSN 0925-8396 : vol. 3). - Proefschrift Maastricht.

- Met lit. opg. - Met samenvatting in het Nederlands.

ISBN 90-265-1207-4

NUGI 742

Trefw.: revalidatie : sociaal-wetenschappelijk onderzoek.

Cover design: Rob Molthoff

Cover printed in the Netherlands by Casparie IJsselstein

Typesetting: Shift-Key Produkties, Utrecht

Printed in the Netherlands by Offsetdrukkerij Kanters B.V., Alblasserdam

\section{Copyright (C) 1991 Swets \& Zeitlinger B.V., Amsterdam/Lisse}

All rights reserved. No part of this publication may be reproduced, stored in a retrieval system, or transmitted in any form or by any means, electronic, mechanical, photocopying, recording, or otherwise, without the prior written permission of the publisher.

ISBN 9026512074

NUGI 742 


\section{AFTER THE REHABILITATION CENTRE}

\section{A STUDY INTO THE COURSE OF FUNCTIONING} AFTER DISCHARGE FROM REHABILITATION

\section{PROEFSCHRIFT}

ter verkrijging van de graad van Doctor aan de Rijksuniversiteit Limburg te Maastricht op gezag van de Rector Magnificus,

$$
\text { Prof.Mr. M.J. Cohen, }
$$

volgens het besluit van het College van Dekanen, in het openbaar te verdedigen op vrijdag, 6 september 1991 om 16.00 uur

door

Lucas Petrus de Witte 
Promotores:

Prof.dr. H. Philipsen

Prof.dr. C.A. de Geus

Co-promotor:

Dr. F.G. van der Horst

Beoordelingscommissie:

Prof.dr. G.J. Kok (voorzitter)

Prof.dr. G.J. Lankhorst (Vrije Universiteit Amsterdam)

Prof.dr. J.M.J.P. van der Linden

Dr.ir. M. Soede (Instituut voor Revalidatie-Vraagstukken te Hoensbroek)

Prof.dr. J. van der Zee 


\section{Dankwoord}

Op een proefschrift prijkt veelal slechts de naam van één auteưr. In de meeste gevallen, ook in dit geval, is dat een onjuiste weergave van de werkelijkheid. En gelukkig maar. Het wetenschappelijk genie, dat solitair op een stoffige zolderkamer grootse ontdekkingen doet, past niet goed meer in het huidige onderzoeksapparaat. Onderzoek doen wordt steeds meer een gezamenlijke activiteit, waarbij ook de grenzen tussen disciplines vervagen. Ik ben blij te kunnen zeggen dat ook dit proefschrift in intensieve samenwerking met anderen tot stand is gekomen. Het is dan ook heel bewust dat het woor dje 'ik' alleen in het curriculum vitae en in dit dankwoord voorkomt. Helaas is het (nog?) niet zo ver dat voor al die anderen die aan zo'n produkt meewerken, meer dan een vernoeming in het dankwoord is weggelegd. Die minimale plaats wil ik aan iedereen graag geven.

De basis voor al het in dit boek beschrevene is gegeven door 146 patiënten, 175 bij hen betrokkenen, 115 huisartsen, 99 wijkverpleegkundigen, en door de verpleegkundigen en artsen in revalidatiecentrum en ziekenhuis, die voor het onderzoek een of meerdere malen geinterviewd zijn. $\mathrm{Zij}$ hebben de meest wezenlijke bijdrage geleverd. Vooral de patiënten en de mensen uit hun so- 
ciaal netwerk bedank ik daarvoor hartelijk: zij hebben veel en vaak intieme informatie gegeven. De gemiddelde lezer van dit proefschrift zou zeer waarschijnlijk niet bereid zijn geweest om hetzelfde te doen.

Een tweede groep van mensen zonder wie dit proefschrift er niet zou zijn, betreft de teams van de afdelingen I en IV in het revalidatiecentrum "Hoensbroeck" ( $\mathrm{RCH}$ ) en de afdelingen reumatologie van het De Wever Ziekenhuis en het Maasland Ziekenhuis. Vooral wil ik noemen de heer C. Pons, revalidatie-arts op afdeling I van het $\mathrm{RCH}$, mevrouw A. BakkerBoerrigter, reumatologe op afdeling IV van het $\mathrm{RCH}$, en de heer $\mathrm{H}$. Goei Thè, reumatoloog in de genoemde ziekenhuizen. Zij waren zeer bereidwillig om dit onderzoek steeds te steunen. Vooral in de eerste drie jaar van het onderzoek werden zij frequent door een van de projectmedewerkers 'bestookt'. Dat laatste geldt nog meer voor de verpleging van de betrokken afdelingen en wellicht het meest voor de afdelingssecretaresses. Marijke Scheijen en Yvonne Jegers zullen onze bijna dagelijkse telefoontjes en bezoeken zeker gemist hebben toen de interviews voorbij waren.

De derde groep van mensen die ik hier wil bedanken zijn diegenen die bij de uitvoering van het onderzoek, bij de analyse, bij de frustraties en bij de verslaglegging een rol hebben gespeeld: de 'projectgroep'. Dominique Tilli, Liesbeth van Hoef, Vonka Schaffers en later ook Anneke Bogaerts deden de zeer vele interviews, verzorgden de afspraken, en hielpen met de verwerking van alle gegevens. Vooral Dominique en Liesbeth zijn vrijwel dagelijks in alle facetten van het project betrokken geweest. Frans van der Horst, co-promotor bij dit proefschrift, was vanaf het allereerste begin tot en met het laatste moment mijn vaste 'praatmaat'. In eerste instantie alleen voor dit proefschriftproject, maar later ook voor allerlei andere projecten en ideeën. Deze hele projectgroep ben ik zeer dankbaar. Collegialiteit, enthousiasme, creativiteit, werklust, gezelligheid en vriendschap zijn woorden die de samenwerking karakteriseren.

Bij de projectgroep moet ik nog drie mensen noemen, die een bijdrage hebben geleverd aan de uitvoering van het onderzoek. De eerste is Peter Bakker, revalidatie-arts. Hij is in zekere zin de 'aanstichter' van het onderzoek doordat hij de oorspronkelijke vraagstelling voor een keuzeblok bij de vakgroep Huisartsgeneeskunde neerlegde. Dat keuzeblok heeft later (mede) geleid tot het onderzoek waarop dit proefschrift is gebaseerd. Later heeft Peter Bakker mij met zijn grote enthousiasme 'warm' gemaakt voor de revalidatie en mij ervan overtuigd met iets zinvols bezig te zijn.

De tweede is Jan Joosten. Die speelde vooral in de beginfase een rol, onder andere bij de vele avonden discussie over te gebruiken vragenlijsten. Als 
derde noem ik Ineke Kortland, die als student-assistente puzzelde aan de gegevens over overdracht van zorg.

Tenslotte bedank ik Henk Lebens voor zijn voortdurende bereidheid om computerklusjes op te knappen en Jos Diederiks voor zijn adviezen en suggesties bij de eindanalyses.

Mijn beide promotoren, Hans Philipsen en Cees de Geus, verdienen ook zeker een plaats in dit dankwoord. Hans is altijd op de achtergrond aanwezig geweest. De samenwerking met hem heb ik altijd erg plezierig gevonden. Ik kreeg volop de ruimte, maar als het nodig was kon ik steeds bij hem terecht en, nog belangrijker, kreeg ik ook steeds goede ideeën en suggesties mee. Ik ben blij dat we inmiddels ook in enkele andere projecten op eenzelfde manier samenwerken. Cees de Geus speelde vooral in het begin en aan het eind van het project een rol. In het begin als belangrijke adviseur, vooral met betrekking tot zorgoverdracht en nazorg. Later was hij een zeer kritisch en secuur lezer van het eerste concept van dit proefschrift. Zijn opmerkingen hebben het geheel op belangrijke punten verfraaid.

Een groep van mensen die op een meer indirecte wijze aan dit proefschrift hebben bijgedragen, betreft mijn naaste collega's en de stagiair(e)s die ik in de afgelopen jaren heb mogen begeleiden. De interactie en samenwerking met anderen op gebieden die buiten het promotie-onderzoek sec liggen is mijns inziens wezenlijk voor de ontwikkeling als onderzoeker. Ik ben in ieder geval door die contacten steeds gemotiveerd en (opnieuw) enthousiast gemaakt. Zonder namen te noemen bedank ik al die collega's en stagiaires daarvoor hartelijk.

Mevrouw E. Stek en de heer B. Wilkinson bedank ik voor hun opmerkingen en suggesties over het engels. Nauwgezet hebben zij zich in dit boek ver diept en hebben zij grammaticale en stijlsuggesties gedaan, die ik vervolgens graag overgenomen heb.

De leden van de beoordelingscommissie zijn de laatsten die professioneel aan dit boek hebben bijgedragen, in de eerste plaats door het manuscript goed te keuren, maar zeker ook door hun opmerkingen en suggesties voor verbetering. Ook hen bedank ik voor hun bijdrage.

Hoewel het haast een cliché lijkt, wil ik aan het eind van dit dankwoord stil staan bij het 'thuisfront'. Het schrijfwerk voor dit proefschrift heeft zich grotendeels thuis in de avonduren en de weekends afgespeeld. Zonder de volledige steun van mijn partner Bernice, en vooral zonder haar vele lange 
wandelingen met de kinderen, zonder mij dus, was dit boek nooit afgekomen. Het kost als promovendus veel zelfdiscipline om steeds opnieuw achter het buro te kruipen, maar het kost als moeder van twee kleine kinder en met je eigen werk minstens evenveel energie om het steeds zonder vader en partner te doen. Ik ben haar voor haar steun zeer dlankbaar.

Tenslotte bedank ik mijn ouders voor het feit dat ze mij de ontplooiingsmogelijkheden hebben geboden, die de basis van mijn ontwikkeling vormen. 


\section{Contents}

Dankwoord

PART I INTRODUCTION, A RESEARCH MODEL AND
METHODOLOGY

1 Introduction

1.1 A general description of the issue

1.2 Why this study?

1.3 The structure of this book

2 Towards a research model

2.1 Measurement of rehabilitation outcome 10

$\begin{array}{lll}2.2 & \text { Selected factors of study } & 12\end{array}$

2.3 Personal factors in relation to functioning 13

2.4 Social factors in relation to functioning $\quad 15$

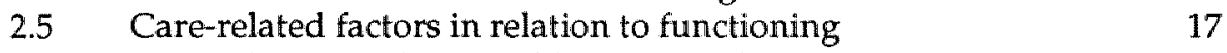

2.6 Social-demographic variables and disability-related characteristics in relation to functioning

3 A specification of the research questions and the research model

3.1 The research questions and the research model 23

3.2 Expectations

$4 \quad$ Research design, methods and operationalisations 29

$\begin{array}{ll}4.1 & \text { Design of the study } \\ 29\end{array}$

4.2 Methods used 33

4.3 Operationalisation of the core variables in the research model 36

4.3.1 The dependent variables 36

4.3.2 The independent variables 41

$\begin{array}{ll}\text { 4.3.2.1 Personal characteristics } & 42\end{array}$

4.3.2.2 Social network characteristics 44

4.3.2.3 Continuity of professional care 46

4.3.3 Social-demographic and disability-related characteristics $\quad 51$

4.3.3.1 Social-demographic characteristics 51

4.3.3.2 Disability-related characteristics 51

4.3.4 An overview of the variables and their operationalisation 54

4.4 Statistical methods $\quad 55$ 
5.1 Potential populations and non-response

5.2 A description of the research populations in terms of socialdemographic and disability-related characteristics

5.3 Drop-out during phase 2 of the study

$6 \quad$ Functioning of patients after discharge $\quad 73$

6.1 The view of the patient 73

6.2 The view of professionals and social network members 76

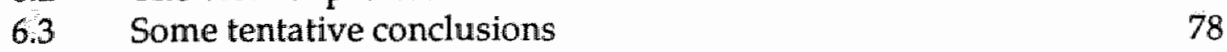

$7 \quad$ Factors related to the course of functioning after discharge $\quad 79$

7.1 Overall functioning and social-demographic characteristics $\quad 80$

7.2 Overall functioning and disability-related characteristics $\quad 82$

$\begin{array}{lll}7.3 & \text { Overall functioning and personal characteristics } & 83\end{array}$

7.4 Overall functioning and social network characteristics $\quad 85$

7.5 Overall functioning and continuity of professional care 86

$\begin{array}{lll}7.6 & \text { A summary and some tentative conclusions. } & 89\end{array}$

PART III A LONGITUDINAL ANALYSIS

$8 \quad$ Functioning of patients after discharge 93

8.1 The course of physical functioning : 94

8.2 The course of psychosocial functioning 98

8.3 The relationships between the different measures used 101

8.4 The view of professionals and social network members 103

$\begin{array}{ll}8.5 & \text { Some conclusions } \\ & 106\end{array}$

$\begin{array}{ll}\text { 9 Creating groups for the further analysis } & 109\end{array}$

9.1 Regression to the mean 110

9.2 Solving the problem of differences between the diagnostic groups 111

9.3 Combining the self-assessment scales and the SIP 112

9.4 A brief summary and an outline of the analysis later on 115

10 Social-demographic characteristics, disability-related characteristics and their relationship to the course of functioning

10.1 Social-demographic characteristics related to the course of functioning 
10.1.1 Physical functioning

10.1.2 Psychosocial functioning

10.2 Characteristics of the disability related to the course of functioning

10.2.1 Physical functioning

10.2.2 Psychosocial functioning

10.3 A summary and some conclusions

11 Personal characteristics and the course of functioning

11.1 Personality traits, health locus of control and self-image in a time-perspective

11.2 Personal characteristics related to the course of physical functioning

11.3 Personal characteristics related to the course of psychosocial functioning

11.4 A summary and some conclusions

12 Social network characteristics and the course of functioning

12.1 Social networks in a time-perspective

12.2 Social network characteristics related to the course of physical functioning

12.3 Social network characteristics related to the course of psychosocial functioning

12.4 A summary and some conclusions

13 Continuity of professional care and the course of functioning

13.1 Continuity of professional care after discharge

13.2 Continuity of care related to the course of functioning

13.3 A summary and some conclusions

14 A multivariate analysis: explaining the course of functioning

14.1 A selection of the variables to be included in the multivariate analysis and a description of the method

14.2 The relationships between the explanatory variables 166

$\begin{array}{lll}\text { 14.3 Explaining the course of physical functioning } & 167\end{array}$

14.4 Explaining the course of psychosocial functioning 171

14.5 A check on the results and an alternative analysis 174

14.6. A summary and some conclusions 
$\begin{array}{lll}15 & \text { Conclusions } & 187\end{array}$

15.1 Some problems encountered in the study 188

15.2 The course of functioning after discharge 191

15.3 Explaining the course of functioning 192

15.4 Continuity of professional care 199

15.5 Possible implications for rehabilitation practice 202

15.6 Recommendations for further research 205

$\begin{array}{lll}16 & \text { Summary } & 207\end{array}$

$\begin{array}{ll}\text { References } & 215\end{array}$

Appendices 225

I Scores of the total groups of patients involved in the study on the most central variables $\quad 226$

II The items of the health locus of control scales (in Dutch) 228

III The items of the scales measuring aspects of the self-image (in Dutch)

IV Aspects of continuity of care related to the course of functioning: tables

V Social-demographic and disability-related characteristics of the two subgroups of RA patients in phase II of the study

Samenvatting in het Nederlands 


\section{PART I}

\section{Introduction, a research model and methodology}

The first part of this book, comprising five chapters, is devoted to a description of the background of this study, the research questions to be answered and the way the study was planned and carried out. Chapter 1 provides a short introduction, chapter 2 offers an overall view of the literature relevant within the framework of this study, and in chapter 3 the research questions are formulated, together with a set of expectations.

In chapter 4 the methodology is described, while chapter 5 describes the patient populations involved in the study.

'Quick' readers may confine themselves to chapters 1 and 3, to get an idea of what the study is about. Those who, on the contrary, want to know the details on methodology, measures and patient populations cannot do without chapters 4 and 5 . 



\section{CHAPTER 1}

\section{Introduction}

\subsection{A general description of the issue}

This book is about people with a chronic disability who were treated in a rehabilitation centre. It is a report of a partly retrospective and partly prospective follow-up study, which attempts to throw some light on the way these people cope with chronic disease and disability in their daily life once discharged from rehabilitation. Firstly we describe how people assess their own functioning after clinical rehabilitation and to what extent they, in their own perception, succeed in keeping the functional level they have reached in the rehabilitation centre. Secondly we investigate the role of social, personal and care-related factors in explaining why some people experience a more positive course of functioning than others.

The initiative for this study lies in a question posed by the medical staf $f$ of the rehabilitation centre where the study was conducted. They had developed a standardised letter for primary health care workers to inform them when a patient was discharged from their centre. This letter it was hoped would stimulate the quality and especially the continuity of care around and after 
discharge. After a few years, however, some staff members felt that the letter was not having the desired result. They asked us to evaluate their discharge procedure and the letter. In response to this request we performed a small study, consisting of in-depth interviews with 9 patients with dif ferent disabilities, and with some of the health professionals involved in the care for these patients. With respect to the discharge letter, all professionals interviewed were very positive. They also gave a rather positive judgement of the quality of care after discharge. The patients, however, all reported experiencing a vacuum after discharge from the rehabilitation centre. They had difficulty in implementing what they had learned in their daily life and they all mentioned a lack, or sometimes even an absence, of support in this respect from health professionals. We were surprised by the generality of this experience, although it is an experience that will probably be recognised by many rehabilitation professionals. In practice-based textbooks it is sometimes described as an important area for special attention after rehabilitation (Verkuyl, 1981; Huygen, 1977). It has not been the object of systematic research, however.

In the same study we were struck by the experience that there can be large differences in daily activities and well-being between people with, from a strictly medical perspective, a comparable disability. We met two young men of about the same age, who both had had a swimming pool-accident, r esulting in a cervical spinal cord lesion. They were both unmarried and they both stayed in the same rehabilitation centre for about a year. Person A had a slightly higher lesion than person $B$. We saw them about two years after the rehabilitation period. They lived in comparable houses and they were still unmarried. There was a tremendous difference between these two men in their daily activities and in their well-being. Person $A$ was very active. He had a lot of friends, had a part-time job, and told us he was happy with his life. Person $B$, the one with the lower lesion, had very few outdoor activities, did not have many friends, and told us he would rather be dead. Medically speaking, there was no obvious reason for the lack of success B showed in living with his disability; both had no other diseases and there were no medical complications. During rehabilitation $B$ had reached a better functional level than $\mathrm{A}$.

These two experiences, the vacuum after discharge, and the observed discrepancy between objective level of disability on the one hand and long-term functioning and well-being on the other, prompted us to conduct the study described in this book. The objective was to discover how patients get along and how many do not get along well, and to gain more insight into some factors related to or influencing the course of functioning after a rehabilitation 
period, with a special interest in the care process.

The study focuses on the role of social network characteristics, personal factors, and organisational aspects of professional care around and after discharge, all factors expected to have a possible influence on functional status and well-being. In addition we include some social-demographic and disability-related characteristics. One of the aims of the study is to provide insight into the relative importance of all these factors in explaining the long-term course of functioning or, in other words, long-term rehabilitation outcome. It was decided to perform the study in a population of patients with different diagnoses and disabilities, because we are explicitly interested in factors that play a role in general, independent of the diagnostic category.

\subsection{Why this study?}

As described above, an important stimulus to conducting this study was a kind of personal interest or curiosity on the part of the researchers. We were concerned by the practical experience that a number of patients report difficulty in maintaining their functional level after discharge and especially by the fact that non-medical factors seemed to play an important role in explaining this course of functioning. We wanted to know to what extent deterioration really occurs and what specific factors are important. But this was not the only reason. A more fundamental ground for this study has to do with the theoretical and practical development of rehabilitation, especially rehabilitation medicine, and the counselling and supporting of people with chronic diseases or disabilities in general. In Dutch health care, rehabilitation is a rather recent field of professional activity. This relatively new branch of health care finds its basis in practical experience, not well supported by scientific theory. Rehabilitation is, in a sense, a reaction to what is often called the 'medical model'. It can be seen as an attempt to form a counterweight to the medical-biological approach in health care. As one of the first professional groups in health care, rehabilitation workers recognised the importance of personal, social and other environmental factors in living with a chronic disease or disability. In this they followed the argument of social scientists, who stressed the importance of such factors (for example Bloom, 1965). In the last few decades rehabilitation has grown to become a considerable part of Dutch health care, stimulated by the increasing number of chronically ill or disabled people and a tendency towards a welfare state in the 1960s. (For a review of the development of Dutch rehabilitation medicine see Bangma, 1984, 1989).

The essence of rehabilitation lies in a patient-centered and problem-oriented approach. The ultimate goal is not to cure disease, but to help the patient 
reach an optimal level of activity and functioning, given his impairments and functional disabilities. Obviously this goal must be placed in the total context of the life of the patient, and rehabilitation efforts must thus aim at functioning in 'real life', after the patient has left the rehabilitation centre or similar facility. To extend this field in health care it is important to obtain knowledge about how rehabilitation works and to what extent its effects take root in daily life and why it sometimes does not work or its effects fade away. There is a need for knowledge that makes it possible to construct programmes with a greater chance of being effective in the long term, and to refine and adjust existing programmes. Such knowledge could also make it possible to identify dif ferent types of patients in psychosocial and medical terms, who might need dif ferent types of treatment, counselling and support.

With this study wre hope to make a contribution to the understanding of how and why people in different diagnostic categories are more or less successful in living with a chronic disease or disability after rehabilitation and thus to the understanding of the long-term outcome of rehabilitation. The results of this study should make it possible for rehabilitation workers and other health professionals working with chronically ill or disabled people to reflect on their own work and routine. The study also aims to give clues for a further improvement of rehabilitation practice, in the sense that we might identify factors that can be influenced to enhance the long-term outcome of rehabilitation efforts. Furthermore, the results should contribute to the theoretical development of rehabilitation and help to direct future research.

\subsection{The structure of this book}

Following this introduction, chapter 2 discusses the literature relevant within the framework of this study, in order to determine the variables to be included in the research model. Firstly we discuss the question of what rehabilitation aims at and how rehabilitation outcome can be measured. Secondly we try to determine what specific factors or characteristics are most relevant for our research model, and how and to what extent these factors are related to functioning or rehabilitation outcome. On the basis of this literature, and taking practical considerations into account, the research questions are specified and a research model defined. A set of expectations with respect to our research questions is also formulated. These questions, the model and the expectations are presented in chapter 3. Chapter 4 gives a description of the design of the study, the methods used in the study and the operationalisation of the variables in the research model. It also briefly describes the statistical techniques 
used. In chapter 5 the research population and non-response and drop-outs are described.

The results of the study are presented in the parts II and III.

Part II, which consists of two chapters, gives the results from the first, transversal or retrospective phase of the study. In chapter 6 the results regarding the course of functioning experienced after discharge are presented. Chapter 7 deals with the question of which of the factors investigated are related to the course of functioning. The results from the transversal study are discussed from the perspective of the expectations formulated in chapter 3 .

In part III, which consists of 7 chapters, the results from the prospective part of the study are given. In chapter 8 the results regarding the course of functioning are presented. The course of functioning is dealt with from different perspectives, using different measures of functioning. Chapter 9 deals with the creation of groups of patients to be compared in the analysis of the factors explaining the course of functioning; it forms a kind of bridge between chapter 8 and the later chapters. The four subsequent chapters, 10 to 13 , each deal with the relationship of one group of variables with the different measures of the course of functioning distinguished in chapters 8 and 9. Chapter 10 is about social-demographic and disability-related characteristics, chapter 11 deals with the personal characteristics selected for this study. In chapter 12 social network characteristics are analysed, while chapter 13 deals with the care-related factors studied (i.e. continuity of professional care).

In each of these chapters only bivariate relationships are described. In chapter 14 we describe a multivariate analysis with a limited selection of the variables studied in the previous chapters. Together with 8 , this chapter forms the crux of part III.

The book concludes in part IV with a discussion of the results. In chapter 15 we first discuss some problems encountered in the study. Subsequently the results from the two phases of the study are reviewed and some final conclusions formulated. Finally the possible implications of this study for r ehabilitation practice are discussed, and some recommendations for further research are given.

Those readers who do not have the opportunity to read this whole book but want to know more than what is described in the summary, might restrict themselves to the most important chapters. We suggest those 'quick' readers to read chapter 3 , paragraph 4.1 in chapter 4 , chapters 8 and 9, chapter 14 and of course the concluding chapter 15. 



\section{CHAPTER 2}

\section{Towards a research model}

As described in chapter 1 the central question to be answered has two elements: a description of the course of functioning of patients after clinical rehabilitation and an investigation of the role of the social network, personal characteristics and care-related factors in explaining why some people show a more positive course than others. This chapter focuses on the literature regarding the second element of our question. First of all we discuss the question of how rehabilitation outcome can best be measured, from the perspective of the goals of rehabilitation medicine. The discussion in paragraph 2.1 culminates in the choice of a focus of measurement for our study and the clarification of what is meant with 'the course of functioning'.

Paragraph 2.2 presents the reasons for choosing to restrict the study to the groups of factors mentioned before as potential explanatory factors. The subsequent four paragraphs each deal with one of the groups of factors mentioned. Here we discuss the literature regarding these factors and identify a set of explicit variables to be incorporated in the research model. Paragraph 2.3 deals with personal characteristics, 2.4 with social network characteristics and 2.5 with care-related factors. In paragraph 2.6 attention is payed to the possible role of social-demographic and disability-related variables in explaining the course of functioning. 
Reading reports on studies concerning rehabilitation results or outcome, one can see many different definitions and within these definitions many different operationalisations of outcome. Instead of 'simply' choosing one or some of these, we first tried to define a focus of measurement on the basis of the goals of rehabilitation medicine. This should enable a considerate choice for measurement instruments later on.

The goals of rehabilitation can be clearly described with the help of the classification system ICIDH (International Classification of Impairments, Disabilities and Handicaps), published by the World Health Organisation (WHO, 1980). This classification is built upon three central concepts - impairment, disability and handicap - standing for three essentially different levels on which diseases can have consequences. 'Impairment' is defined as a restriction in physical or mental capacities. Impairments are generally disturbances at the organ level; they need not be visible and may not have adverse consequences for the individual (for example impaired vision, corrected by wearing glasses). When the effects of an impairment are not corrected, a 'disability" may result. Disability refers to restrictions in a person's ability to perform a function in a manner considered normal. Disability may or may not limit the ability to fulfill a normal social role, depending on the severity of the disability and on what a person wants to do. This is the level of 'handicap': the social disadvantage that may arise from disability. The classical 'medical model' focuses on the level of the pathological processes and on their consequential impairments. Rehabilitation medicine is essentially different: it primarily aims at the other levels in this conceptual model: disability and handicap. The central goal is to prevent or reduce functional disabilities and handicaps, given the impairments. Rehabilitation aims at optimal functioning of the patient with a role fulfilment which is as normal as possible, and at optimal social integration. Most of the therapeutic programmes in rehabilitation have their point of application at the levels of impairment and disability: with the help of prostheses, orthoses and technical aids, impairments are reduced or compensated. Together with extensive training and exercise this is meant to lead to a maximum reduction of the disability. It is assumed then that this leads to optimal functioning in 'real life' and thus reduces or prevents handicap.

Probably unnoticed we have introduced a distinction between disability and actual functioning in daily life. In our opinion it is important to make this distinction because the ability to perform a function does not guarantee that the function will actually be used. Discrepancies between what a person 'can do' and what he or she 'does do' can often be seen in rehabilitation practice. 
The ICIDH model does not distinguish these aspects; the definition of disability is not clear in this respect. We suggest the extension of the model with these aspects: 'objective" disability and actual functioning.

The strength of the rather simple ICIDH model is that it clearly shows the essence of rehabilitation medicine; it is a very clear model of thought that can help to direct rehabilitation practice as well as research. It also shows that success criteria in rehabilitation must be on different levels, the ultimate criteria being at the levels of actual functioning and handicap. As already illustrated by the example in the introduction of this book, success at the level of objective disability does not automatically imply success at these other levels. Success criteria defined at the level of objective disability are therefore not sufficient in rehabilitation research. They need to be complemented with criteria at the levels of functioning in daily life and handicap.

Although the basic philosophy of rehabilitation is oriented to achieving outcomes at the levels of personal functioning and handicap, instruments measuring at these levels are not common in rehabilitation literature. ADL self-care measures and other measures of 'objective' disability are the type of outcome measures most frequently used, assuming that successful interventions at that level will have positive effects at the levels of actual daily functioning and handicap. McDowell and Newell (1987) give an excellent overall view of the most commonly used and thoroughly tested instruments in this field. Examples are, among many others, the PULSES profile (Moskowitz and McCann, 1957), the Index of Independency in Activities in Daily Living (Katz et al., 1963, 1979), The Functional Status Index (Jette, 1980) and the Kenny Self-care Evaluation (Schoening et al., 1965). What most of these instruments have in common is that they measure what a patient 'can do', in the sense of skills, rather than actual functioning. They are therefore not sufficient as outcome measures in rehabilitation. As already stated, we consider it essential that actual functioning in daily life is part of outcome measurement as well.

Operationalisation and measurement of the concept of handicap is difficult. There are no instruments available which are specifically designed for measuring at this level. The most essential difficulty is that handicap is a strongly normative concept. It is the reflection of difficulties in social integration, that can be caused by the disabilities of a person, but also by the reaction of the social environment, health policy, etc. Another problem in measuring handicap is that it has an individual character: it is strongly dependent on the perceived possibilities, expectations and wishes of the person involved. A minor injury can severely handicap a musician, but not give any problem to another person. Not being able to work can be an enormous handi- 
cap, but some people experience it as a liberation. This essentially individual character of handicap implies that a subjective evaluation by the "handicapped' person himself or herself should be part of its measurement. That is the reason why two different elements of handicap are often distinguished: professionally assessed handicap and experienced or personal handicap (see also Bangma, 1989). The subjective element comes, in our opinion, quite close to concepts like life-satisfaction and well-being.

From the perspective of our central research question, described in the introductory chapter, it is clear that our interest in this study lies at the levels of actual functioning and experienced or personal handicap. We have explicitly chosen to focus on these aspects.

So far we have given a frame of reference for the measurement of rehabilitation outcome: we have mentioned some basic considerations. We have stated that success criteria at the level of objective disability alone are not sufficient, because the ultimate goal is at the level of actual functioning and handicap. We have chosen to focus on actual functioning and on the subjective element of handicap. In our approach to measurement there are two aspects which can be distinguished: (reported) actual behaviour and activities in daily life ('does do' instead of 'can do'), and an evaluation of functioning by the patients themselves. In this way important areas in which the ultimate goals of rehabilitation lie would seem to be covered.

The focus of measurement described puts the emphasis on subjective evaluative aspects, as opposed to an objective approach. In order to get an impression of the extent to which the subjective evaluation of patients conforms to more 'objective' information, we also included professional assessments and assessments of people who are close to the patient. Details on the operationalisation are described in chapter 4.

\subsection{Selected factors of study}

There is no generally accepted theory with respect to the explanation of the course of functioning after discharge from rehabilitation, that would give direct clues for the choice of specific variables to be investigated in this study. The literature on this subject in the field of physical rehabilitation is limited and, as far as literature is available, it is very diverse: it is about very different diagnostic categories, and, as already discussed, many different operationalisations of outcome or success have been used. Furthermore very different sets of predictors or explanatory variables have been investigated. This diversity and the lack of an obvious theory on which to build made us decide to limit 
the scope of the study to some basic groups of factors or variables, in which we were particularly interested and/or which we expected might play a role. This selection was mainly based upon the literature about more general healthrelated concepts that have been the object of more thorough research.

The first group of factors to be investigated, care-related factors, is a logical consequence of one of the reasons for starting this study, described in the introduction: we have a particular interest in the care-process around and after discharge, based on the experience of patients that a kind of vacuum arises at that time.

The three other groups of factors chosen for investigation are already mentioned in the introduction. Firstly, factors relating to aspects characterising the person, secondly, factors covering aspects characterising the direct social environment of the patient (the social network) and, of course, finally those concerning social-demographic characteristics and characteristics of the disability. This choice, which has an almost self-evident character, provides a first important restriction criterion for those variables to be taken into consideration when choosing the set of variables to be investigated as explanatory or predictor variables for the course of functioning after discharge.

There was another important criterion that played a role in the considerations regarding the variables to be incorporated in the study. Besides a contribution to the theoretical development of rehabilitation, this study should also give clues for a further improvement of rehabilitation practice. We are therefore particularly interested in factors that potentially can be positively influenced.

The discussion of the literature in the following four paragraphs provides further support for our choice of these groups of explanatory variables. It also permits a selection of more specific variables to be incorporated in the study and the formulation of expectations regarding these variables in relation to the course of functioning.

\subsection{Personal factors in relation to functioning}

Personality characteristics have often been proposed as important variables in the explanation of individual differences in the response to disease and illness conditions. Personality characteristics are mostly defined in terms of individual, psychological factors that consist of deep-lying, early learned and largely unconscious traits. They are assumed to be rather stable over time. These traits have often been associated with illness, functioning, well-being, patient-compliance and other health-related concepts. The description given 
is rather broad; it may include a large variety of characteristics. Indeed, many different personality characteristics are reported in the literature, all with their own operationalisations. This means that it is hard to indicate a limited set of specific characteristics, found to be related to aspects of health in a systematic way. Nevertheless some general tendencies can be recognised in the literature. In a review of the literature on subjective well-being, Diener (1984) mentions the following personality characteristics as important: self-esteem, extraversion and neuroticism. He also mentions internal control, but this might be considered as a more social psychological concept, as will be discussed later on.

The characteristics mentioned, and related ones, are found rather consistently to be related to several health-related concepts. They especially seem to play a role in the subjective evaluation of health, well-being, etc., high neuroticism being a negative factor and high self-esteem and extraversion being positive factors.

Besides these 'classic' personality traits, defined as stable, deep-rooted and primarily unconscious, a growing emphasis has been laid on socially learned cognitive systems, sometimes called the 'sociall personality'. These cognitive systems are as much the result of learning in later life as they are of earlier learning. They are, therefore, more liable to change. Various models of health behaviour that have been successfully used in research, emphasize such psychological and sociocultural characteristics. Good examples are the "Health Belief Model' (Becker, 1974) and the 'Theory of reasoned action' (Ajzen and Fishbein, 1980). DiMatteo and DiNicola (1982) give a good overview of the theory and research findings in this area.

A central construct in this field is 'Locus of control'. This is what Diener referred to as internal control. The construct Locus of Control was introduced by Rotter, Seeman and Liverant in 1962. It was described as the degree to which a person considers events following his own behaviour as contr ollable or as controlled by external factors like chance or powerful others. Using this concept, two types of people can be distinguished: internally oriented and externally oriented people. Later on the content of the concept alter ed under the influence of research and theoretical developments. Initially the central question was whether the person thinks he can control things himself or not. Later the central question became who or what he thinks controls things and to what extent; it was looked upon as multi-dimensional.

A second important shift in the content of the concept is that a differentiation in behavioural areas has been made. Measurement instruments have been developed for specific areas of behaviour, for example achievement behaviour, affection, alcohol-use and, most relevant for our study, health and 
illness. Research shows that the locus of control for these areas can be different and sometimes even independent (for an overview of the history of the construct see Halfens, 1985; Lefcourt, 1981).

In empirical research on health behaviour, the locus of control construct has proved to be important in explaining various health behaviours (e.g. Wallston and Wallston, 1981; Levenson, 1981; Halfens, 1985). Also in other health-related contexts it has been found to be important (e.g. Diener, 1984). Rather consistently an internal orientation appears to be a positive factor, while an external orientation appears to be a more negative factor:

For the purpose of our study these social psychological characteristics are potentially more promising than the 'classic' personality traits mentioned, since they have a better chance to be influenced by specific interventions.

Consequently we decided to include both the personality traits mentioned or related characteristics, and locus of control, as a more social psychological characteristic. The measurement instruments are described in chapter 4.

Besides these characteristics, special attention is paid to another personal characteristic, closely related but not identical to self-esteem: self-image. Charmaz (1983) describes changes in self-image as one of the important consequences of chronic illness. She states 'chronically ill persons frequently experience a crumbling away of their former self-images without simultaneous development of equally valued new ones'. She considers this a fundamental form of suffering in the chronically ill. There are some findings in the literature indicating that a positive self-image is related to positive outcome in rehabilitation (Litman, 1962; Andersson and Berg, 1975). We expect a positive selfimage to be related to a positive course of functioning. How the self-image is operationalised is also described in chapter 4.

\subsection{Social factors in relation to functioning}

In the past few decades social support and other social network characteristics have emerged as major variables in health-related research in many different contexts. Personal networks and especially social support provided by the networks have gained prominence as having potentially protective properties for psychological as well as physical well-being. Personal networks are found to have an important influence on health status and even predict life span (e.g. Nuckolls et al., 1972; Lin et al., 1979; Berkman and Syme, 1979; Caplan, 1974; Cassell, 1976; Cobb, 1976; Van Eijk, 1980).

In the field of patient compliance, social support has been recognised as an important variable enhancing or, if the social network disencourages the pa- 
tient, impeding the patient's cooperation with a certain regimen (Haynes, Taylor and Sackett, 1979; DiMatteo and DiNicola, 1982; Van der Steen, 1987). Although relatively rare, studies of social support in relation to recovery from disease and rehabilitation also provide fairly consistent evidence of positive effects on adaptation and recovery (e.g. Finlayson, 1976; Hyman, 1972; Litman, 1966; Croog and Levine, 1977; Finlayson and McEwen, 1977; Smith, 1979; Ben-Sira, 1981; Wortman and Conway, 1985; Patrick et al., 1986).

For an overview of the literature regarding social networks and health we refer to the many reviews that have been published (e.g. Cohen and Syme, 1985; Wallston et al, 1983; Israel, 1983; Cobb, 1976).

Although there seems to be considerable consensus about the potentially positive effects of social support, there is also some criticism (e.g. Broadhead et al, 1983; Wallston et al., 1983). The criticism is based mainly upon the fact that an enormous variety of different measurement instruments, measuring very different network characteristics, has been used and that relationships found are not very strong. Another point of critique is the fact that there is only weak proof of a causal relationship of network characteristics with aspects of health. Despite these critical remarks in the literature, it is clear that social network characteristics should be included in our study. We want to investigate whether these characteristics play a role in the process we want to study; the literature suggests it is very likely that they do.

An important question at this point is what aspects are most likely to be important and thus should be measured. Social networks can be described in many different aspects. In general, two kinds of aspects can be distinguished: structural and functional aspects. Structural aspects refer to 'descriptive' characteristics like size, composition or structure (relatives/non-relatives etc.), frequency of contacts, geographical distance between network-members, etc. Functional aspects are mostly denoted as social support. They stand for the qualitative aspects of social relations. The most commonly distinguished functional aspects are emotional support and practical (or instrumental) support. Another aspect, more recently given more attention, is reciprocity; the balance between receiving and giving support.

There are indications in the literature that both structural and functional aspects have an influence on health status, each in a specific manner. Structural characteristics (the social network) might be seen as indicators of the degree of social integration and they probably have a direct effect on health. Social support is probably of special importance in stressful situations. Here it might act as a 'buffer' against stress (for a review of the literature on the working mechanism of social support, see Cohen and Wills, 1985). The answer 
to the question of how social network characteristics and social support influence health is not yet fully clear and beyond the scope of the present study. The focus in our study is on the investigation of whether these aspects play a role in explaining or predicting the course of functioning, and, if so, to what extent. Because of the fact that structural and functional aspects of the social network both seem to have their own specific ef fect, we decided to include elements of both in our study. We confined ourselves to the most basic aspects: size and structure on the one hand and emotional and practical support on the other. In chapter 4 the operationalisation of these aspects is described in detail.

On the basis of the foregoing, we expect that people with larger networks will show a more positive course of functioning, especially when this network contains relatively many non-relatives. We expect that social support positively influences the course of functioning. It must be said, however, that social support might also have negative effects, for example when excessive support leads to overprotection and consequently to dependence of the patient.

If a relationship between social network characteristics and the course of functioning is shown to exist in this study, it is very likely to be complicated. So far we have only discussed these characteristics as independent variables, potentially influencing functioning. This is, however, a drastic simplification. The social network is very likely to change under the influence of changes in functioning or other important changes in life. Staying in a rehabilitation centre and coming back home are most certainly situations in which social relations change. This complex relationship between network characteristics and functioning means that we should not be surprised when ambiguous results are found. Again, unravelling this complexity falls outside the scope of the study. We shall describe changes in the network characteristics studied over time, but we look upon these characteristics as independent variables. In a separate study on a largely comparable patient population, some of our colleagues investigated social network changes following chronic illness (Janssen et al., 1990).

\subsection{Care-related factors in relation to functioning}

In the introduction it was noted that patients experienced a lack and sometimes an absence of support from health professionals after discharge from rehabilitation. The relatively intensive care in the rehabilitation centre stops and, as far as necessary, has to be taken over by professionals in primary health care or by non-professionals. Some people describe this as a real gap. 
This experience is far from unique: problems in coordination or continuity of care are widely recognised in Dutch health care, at almost all the borders' between different professionals and institutions and between primary health care and institutional care (e.g. De Melker, 1973; Jacobs and De Melker, 1983; Buys, 1984; Soeters, 1983; Jansen et al, 1985). In the field of rehabilitation and care for the 'handicapped', it is also a well known problem (Schoemaker and Hessing, 1987; Gehandicaptenraad, 1986). In recent years a large number of working papers, articles and other reports have been published on the subject of continuity of care and related concepts like aftercare and coordination of care. Organisations of general practitioners as well as community nurses have declared that coordination of care is a central element of their task.

In order to determine which specific factors should be incorporated in our research model, it is necessary to understand the nature and background of the problem described. As in many other countries, Dutch health care has developed in a direction that can be characterised in terms such as heterogenity, differentiation, specialisation and rationalisation. This development can be seen theoretically as a manifestation of modernisation of our society (Philipsen, 1985, 1988; Zijderveld, 1983). For the individual patient it means that he has to deal with different, highly specialised professionals and agencies. On the one hand this is a positive development: the patient is likely to get; within the specialism of the professional he is dealing with, the best possible care. On the other hand this development carries with it potential problems in at least two fields:

1. There is a potential conflict of values between functional rationality of health care and the life sphere of the patient. In simple terms this means that highly efficient professional procedures do not automatically fit in with the feelings and experienced needs of the patient. The communicative distance between patient and care-providers tends to grow.

2. There is a growing need for coordination and integration between a growing number of different professionals and agencies, while at the same time communication between them becomes more difficult: they speak their own specialist professional languages (Philipsen, 1985, 1988; Ris and Diederiks, 1974).

It becomes more difficult for professionals to coordinate and integrate their activities, and even when they succeed in doing so, there is a considerable chance that the patient does not feel understood and supported. From this perspective it is not surprising that problems in coordination occur and that patients experience a discontinuity.

The problems mentioned must be dealt with in close relation to each other. Coordination is not a goal in itself; it must be derived from the mutual goal to 
provide the care the patient needs. First of all, health care workers should make an effort to reduce the distance between functional rationality and the life sphere of the patient; good coordination and integration of care activities is a necessary condition to do so. Our study focuses on the potential problems described above, summarised in the term continuity of care. We distinguish two separate, but related, aspects: coordination, and tuning of care to patient needs. From the line of thought presented we define continuity of care as the degree in which professional care is provided as a coordinated and uninterrupted succession of activities, in accordance with (experienced) patient needs.

It is important to note that continuity of care is mostly defined in terms of the number of contacts with the same physician (Ejlertsson and Berg, 1984; Eriksson and Mattsson, 1983; Grol et al., 1987; IJzerman and Oskam, 1990). Our definition is essentially different; it includes more qualitative aspects of care and it includes care from all professionals involved.

Although there seems to be consensus about the fact that problems in this field exist, only relatively rarely have they been the object of empirical research. Surprisingly, there is almost no research linking problems in continuity of care with aspects of health and well-being. This is surprising because it seems almost self-evident that a vacuum or gap as described by patients cannot be good for them. There are only some indirect indications in the literature that aspects of the problem as described above are related to aspects of health and outcome of health care interventions. Ben-Sira $(1980,1982,1986)$ for example demonstrated that 'affective' behaviour of rehabilitation staff and agreement upon the goals of a rehabilitation programme (staff not pursuing their own latent goals), were positively related to rehabilitation success. Cassee much earlier (1971) very convincingly argued that what he calls 'thera peutic behaviour ${ }^{\prime}$ has a positive influence on recovery of patients in general hospitals. Experiments in the 1960s and 1970 s suggest that coordination between professionals has a positive influence on quality of care; continuity of practitioner and medical record were found to be associated with better satisfaction of patients, better staff knowledge of patients' problems and needs, better compliance and some other aspects of quality (Becker et al., 1974; Starfield et al., 1976).

In this study we investigate the problem of continuity of care from the perspective of the definition formulated above. As already mentioned we focus on continuity of care around the time of discharge from the rehabilitation centre. Although there is only limited empirical evidence, we expect that continuity of care is related to a relatively positive course of functioning. 

in relation to functioning

It needs little discussion to choose a set of social-demographic variables to be included in the study. We restrict ourselves to a few 'standard' characteristics, the importance of which has been clearly proved in different health-related contexts: age, sex, socio-economic status and marital status. A compact but extensive review of the literature on the relationships of these variables with subjective well-being is given by Diener (1984).

With respect to age, he concludes that there is no evidence of a direct relationship between age and well-being in general; as far as positive relationships are found, they are often likely to be explained by other factors that tend to covary with age. The findings in the field of rehabilitation are not entirely unequivocal. Young age was found to be a positive factor for successful rehabilitation in different patient categories (e.g. Andersson and Berg, 1975; Lehmann et al., 1975; Fugl-Meyer, 1982; Gogstad and Kjellman, 1976; Smith, 1979; Teasdale et al., 1979), but controversial results have been reported as well (Yarkony et al., 1988; Feigenson et al., 1977). It might be questioned whether the relationship between age and outcome found in some studies could not also be explained by covariation with other factors. Age is associated with educational level and income, both variables known to be related to well-being and health. Most studies have not controlled for such factors. On the basis of these findings we expect to find a relationship between age and the course of functioning, younger people being better off. Whether this relationship still exists after controlling for other variables is a question about which we have no expectations.

About the possible influence of sex on the course of functioning the literature does not give a clear answer. In his review, Diener concludes that differences in well-being between sexes are, if they exist, never large. Sex-differences are also likely to be explained by other factors, like educational level and social psychological variables (e.g. Meddin, 1986). In specific rehabilitation literature, we found little information about the importance of sex. There tends to be no relationship between sex and outcome-criteria. On the basis of this, we expect to find no relationship either.

With respect to socio-economic status, the literature is quite unequivocal. Income, which can be considered a central indicator of socio-economic status, is without doubt related to well-being and health (e.g. Diener, 1984; Larson, 1978; Andrews and Withey, 1976). The same goes, although somewhat less obviously, for educational level, which can also be seen as an indicator of socio-economic status. High income and high education are positive factors. In the field of physical rehabilitation, these variables have also, more than 
once, been found to be positively related to rehabilitation success (e.g. Andersson and Berg, 1975; Dew, 1985; Mackenzie, 1987). We expect a similar result in our study.

The last social-demographic variable to be studied is marital status. Marriage or having a love relationship appeared to be strong predictors of wellbeing and life satisfaction in many studies (see Diener, 1984). One of the possible explanations for this is the fact that life partners are an important source of social support (Waltz, 1986). In the field of rehabilitation we found very little data on the role of marital status as a predictor of success. On the basis of the foregoing we expect that having a life partner exerts a positive influence.

When studying functioning of people with disabilities after rehabilitation, it is selfevident that characteristics of the disability have to be included in the research model. Defining which characteristics these should be, however, is less obvious. The literature gives no clear indications. We restricted ourselves to three basic aspects, roughly describing the character of the disability: the diagnosis, the objective level of disability and the duration of the disability.

The importance of diagnosis is obvious; each diagnosis has its own 'natural course", directly influencing functioning. Diseases causing progressive disability, for example, will most likely lead to a more negative course of functioning than non-progressive diseases. Since this study is concerned with different diagnostic categories (see chapters 3 and 4), diagnosis is a basic variable in this study. We are, however, specifically interested in factors related to the course of functioning independent of the diagnosis. This means that diagnosis is registered in order to be able to control for its influence and not to use it as a predictor variable. We therefore formulate no expectations with respect to diagnosis.

The impairment-disability-handicap model described in paragraph 2.1, implies that objective level of disability is a major predictor of the level of actual functioning and handicap. As argued above, however, it is most likely not the only predictor. We mentioned a series of other factors likely to contribute to the development of handicap and to actual functioning as well. Within the specific framework of our study, focusing on the course of functioning, it can be even questioned whether the level of disability plays a role at all. This study is concerned with the course of functioning after discharge in terms of (experienced) changes in activities and the evaluation of functioning. Unless the level of disability changes as well, we find little reason to believe that changes in (experienced) functioning are predicted by the level of disability. This is strongly supported by a study of Ben-Sira (1981), who found severity of the impairment to be irrelevant in predicting rehabilitation success. 
We expect to find no relationship between objective level of disability and the course of functioning after discharge, unless the disability changes.

Following this line of thought, we decided to include the presence of complicating diseases or impairments in our research model as well. We expect that chronic diseases, already present before start of the rehabilitation period, do not relate to the course of functioning after discharge. Diseases or impairments occurring after discharge, however, are expected to have a negative influence on the course of functioning.

The last disability-characteristic included is its duration. Although we found no clear indications in the literature about the role of this variable, we consider it potentially important. One could argue that longer duration increases the chance that the things learned in the rehabilitation centre will fade away more easily, in favour of old habits and behaviour patterns. This leads to the expectation that longer duration is related to a more negative course of functioning after discharge. The basis for this expectation is, however, small. 


\section{CHAPTER 3}

\section{A specification of the research questions and the research model}

In chapter 1 we described our central research question in global terms. In chapter 2 we presented the arguments for our choice for a particular focus of measurement of rehabilitation outcome, and we determined the variables to be studied. We also discussed what is known about the relationship of these variables to outcome. In this chapter we further specify our central question and present the research model in paragraph 3.1, as a visual representation of the research questions. In paragraph 3.2 we formulate some expectations, based on the literature discussed in chapter 2 .

\subsection{The research questions and the research model}

We are interested in long-term rehabilitation outcome at the level of actual funtioning and experienced handicap in different patient categories and in factors explaining and/or predicting this outcome. In paragraph 2.1 we indicated outcome as daily functioning, in terms of reported actual behaviour and the personal evaluation or self-assessment of functional status. We discussed the role of relevant social-demographic variables (age, sex, socio-economic 
status, marital status) and disability-related characteristics (objective severity, duration, complicating diseases) in predicting or explaining outcome. As specific factors to be explored we mentioned personal characteristics (personality traits, locus of control, self-image), social network characteristics (size, structure, emotional and practical support), and the degree of continuity of professional care. Now the research questions can be specified as follows.

1a. How is the course of daily functioning, in terms of reported actual behaviour and personal evaluation of functional status, of different patient categories in a period of two years after admission to a rehabilitation centre?

1b. To what extent do self-assessments of the patients conform to professional assessments of the course of functioning and to the assessments of relevant others?

2. What is the role of social-demographic variables and disability-related characteristics in explaining the course of daily functioning as described under $1 \mathrm{a}$ ?

3. What is the role of personal characteristics, social network characteristics, and the degree of continuity of professional care in explaining the course of daily functioning?

4. What is the relative importance of the factors mentioned in explaining the course of daily functioning after rehabilitation?

As part of the third question this investigation also provides a purely descriptive study of the personal and social network characteristics and their development over time, and of the care-process after discharge. This serves as a necessary background for the analysis of their relationship with (experienced) changes in functioning.

The questions to be answered with this study can be represented in the model shown in figure 3.1. This simple model contains the variables of inter est in this study and shows the relationships between them which are to be investigated. We primarily investigate the relationships of the groups of possible predictor variables with daily functioning. This means that we do not deal with the relationships between these predictor variables. It is more than likely that such relationships exist. For example, personality might determine one's social network, self-image is influenced by social contacts, locus of control might influence the way patients deal with the professional care they receive, the level of disability and the occurrence of complicating diseases obviously determine the care someone receives, marital status influences the social network; and so forth. It is not the purpose of this study to investigate thoroughly 


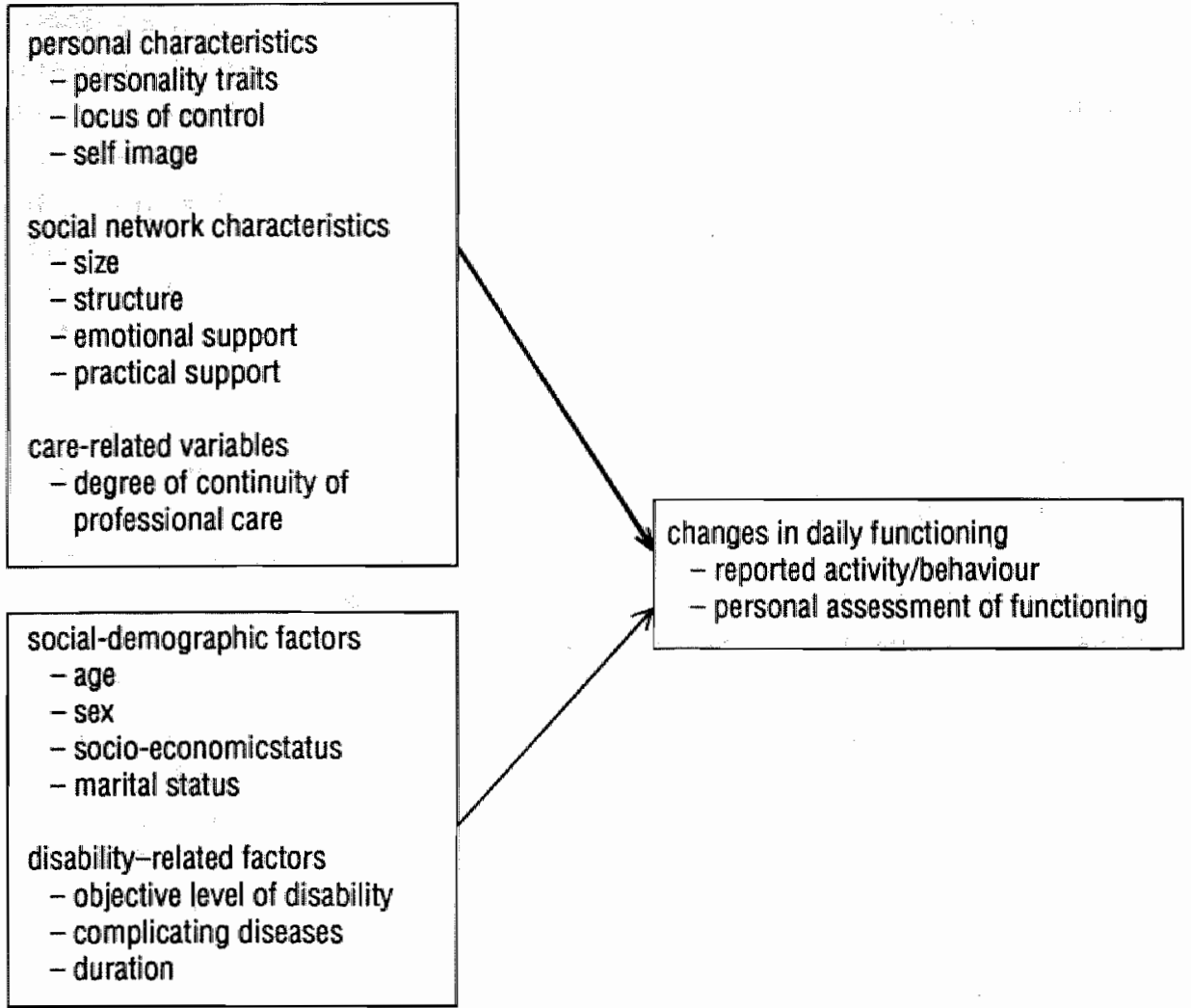

such relationships. The primary aim is to determine the variables that play a role in explaining the course of functioning after discharge. Only in the analysis regarding the fourth research question, presented in chapter 14, are interrelationships between a selection of the predictor variables at issue. Here we perform a multivariate analysis. This analysis is, however, not aimed at describing and understanding these interrelationships, but at assessing the relative importance of the variables studied in the explanation.

At this point it is important to describe one of the choices made in this study, somewhat anticipating the description of the research design and methods in chapter 4 . We decided to study three different patient categories: people with spinal cord injuries, people with definitive rheumatoid arthritis, and patients with ankylosing spondylitis. As already mentioned in the introduction, we explicitly wanted to study different diagnostic categories, but we did not want to create too diffuse a mixture. In chapter 4 these categories are further 
described and specified. Here it is sufficient to indicate why these and not others were chosen. Firstly we wanted to be able to distinguish progressive and non-progressive diseases and disabilities, and secondly we wanted to distinguish disabilities and diseases in different stages of life. Roughly speaking the category of spinal cord injury contains relatively young people and it generally is a stable disability. Rheumatoid arthritis mostly concerns somewhat older people and it tends to be progressive. Ankylosing spondylitis mostly concerns younger people while also tending to be progressive. We had tended to include patients with a cerebrovascular accident, who are generally older and mostly suffering from a stable disability (after a few months). After a pilot-study with this patient category we had to abandon this idea, however, because of specific problems in interviewing, due to common phatic and cognitive impairments. Thus, our research questions concern spinal cord injury, rheumatoid arthritis and ankylosing spond ylitis.

Another important choice made in this study is the restriction to one rehabilitation centre, mainly for practical reasons.

We want to stress the fact that this study is not an evaluation or ef fectivity study of a rehabilitation programme. Our main interest is to understand how and why people are more or less successful in living with a chronic disease or disability after rehabilitation. We want to determine some of the factors influencing this success.

\subsection{Expectations}

Most of the literature mentioned in chapter 2 does not originate from the field of physical rehabilitation. The reason for this is simple: only very little empirical research focused on the things we want to know has been done in this field. As far as research data are available they are almost incomparable; a great variety of outcome criteria have been used with an even greater variety of predicting or explanatory variables. The specific rehabilitation literature gives very little basis on which to formulate explicit hypotheses with respect to our research questions. We therefore decided to formulate a set of expectations for the questions formulated in paragraph 3.1, but we do not give them the formal status of hypotheses to be tested.

\section{The course of functioning}

On the basis of experiences reported by patients and rehabilitation professionals we expect that a considerable number of patients deteriorate in functioning 
after discharge from rehabilitation. We have no specific expectations about the degree of deterioration and the number of cases in which deterioration occurs. With respect to question $1 \mathrm{~b}$ we have no specific expectation.

2. The role of social-demographic variables and disability-related characteristics

On the basis of paragraph 2.6 we formulate four expectations with respect to the social-demographic characteristics included in the study:

2.1 Younger people show a more positive course of functioning after discharge.

2.2 Sex is not related to the course of functioning after discharge.

2.3 People with a relatively high socio-economic status show a more positive course of functioning.

2.4 People having a life partner show a more positive course of functioning than people without a life partner.

With respect to the disability-related characteristics the considerations described in paragraph 2.6 give rise to the following expectations:

2.5 The objective level of disability is not connected with the course of functioning after discharge.

2.6 Longer duration of the disability is related to a negative course of functioning.

2.7a Having other (chronic) diseases or impairments at the time of admission to the rehabilitation centre is not related to the course of functioning after discharge.

$2.7 \mathrm{~b}$ Complicating diseases or impairments developing after discharge have a negative influence on the course of functioning.

3. The role of personal characteristics, social network characteristics and continuity of care

Personal characteristics

The personal characteristics included in the study are personality characteristics related to extraversion, self-esteem and neuroticism, the locus of control and the self-image. Building upon paragraph 2.3 we formulate the following expectations with respect to the personality traits:

3.1a High neuroticism is related to a negative course of functioning.

3.1b High extraversion is related to a positive course of functioning.

3.1c A high self-esteem is related to a positive course of functioning. 
With respect to the locus of control, paragraph 2.3 leads to the following expectations:

3.2a A strong internal locus of control is related to a pasitive course of functioning.

$3.2 \mathrm{~b}$ A strong external locus of control is related to a negative course of functioning.

The last personal characteristic is the self-image. Although there is only limited empirical evidence, we expect that:

3.3 A positive self-image is related to a positive course of functioning.

Social network characteristics

Paragraph 2.4 presented the reasons for measuring some structural network characteristics, as indicators of social integration, as well as social support. The structural aspects included are size of the network and its structure, specifically the number of non-family members. With respect to these characteristics the literature described in paragraph 2.4 leads to the following expectations:

3.4 A large social network is related to a positive course of functioning.

3.5 A network with relatively many non-family members is related to a positive course of functioning.

Our expectation regarding social support is that:

3.6 Strong social support (emotional and practical) is related to a positive course of functioning.

Continuity of care

In paragraph 2.5 we already stated that, in spite of the limited empirical evidence, we expect continuity of care to have a positive influence on the course of functioning:

3.7 Continuity of professional care is related to a positive course of functioning.

4. The relative importance of the factors mentioned in explaining the course of functioning

We have no specific expectations regarding this question. 


\section{CHAPTER 4}

\section{Research design, methods and operationalisations}

In the preceding chapters we formulated our research questions and some expectations regarding these questions. We already made a few choices, anticipating the description of the design of the study and the methods used. The present chapter further describes and justifies the design and methods. In paragraph 4.1 we describe and discuss the design of our study and in paragraph 4.2 we describe our methods of data-gathering. Paragraph 4.3 is devoted to a description and discussion of the precise measures and instruments used to operationalise the variables in the study. Finally, in paragraph 4.4, we briefly describe the statistical methods used to analyse the data.

\subsection{Design of the study}

The study is divided into two phases. The first phase has a transversal design. The second, much larger and more extensive phase has a longitudinal design. The latter is without doubt the most appropriate design to answer our questions. It has, however, some important disadvantages of a practical nature: it is very time-consuming, it requires a lot of work and administration, change of 
instruments and methods during the course of the study is problematic, and there is the problem of drop-outs. Therefore we started with a retrospective transversal study to test the feasability of the design and methods chosen, and to assess some aspects of the validity and reliability of the measurement instruments. Also, we wanted to gain an impression of the answer to our first research question regarding the course of functioning. The study was built upon the expectation that a considerable number of patients experience a deterioration after discharge, but we had no empirical proof of this.

In this first phase, in the summer of 1985 , we interviewed 37 patients from two of the three patient categories of interest (spinal cord lesion and rheumatoid arthritis), who had been discharged from the rehabilitation centre between a half and one and a half years before. We also interviewed 21 patients who were hospitalized at the time we conducted this part of the study, but the data from these interviews will not be used in the analysis. From this first phase we obtained a good idea of the practical feasability of our plan, the reactions of patients and professional workers to it, and of the quality and usefulness of the instruments and methods chosen.

The results of this first phase were satisfactory. There was a rather high degree of cooperation from the patients and professional workers approached, the instruments and methods proved workable. Tests for validity and reliability were positive. More importantly, the results from the first analysis showed that a number of patients had indeed experienced some degree of deterioration since discharge, and also suggested that the questions we asked ourselves had a chance to be, at least partially, answered after the second phase of this study. The results from the post-discharge interviews in this phase are presented in part II of this book.

The second phase started in the spring of 1986 . From that time on we approached every newly admitted patient in the three categories described, who met the criteria described in chapter 5 , for the longitudinal study. On the basis of admission figures during the five years before the study we aimed at a number of 150 patients, but there were only 109 patients available who agreed to cooperate in the period during which we could include new patients in the study ( 1.5 years). The patients cooperating were followed for 2 years. In these 2 years there were four assessments: the first as soon as possible after admission (t1), the second at the time of discharge ( $(2)$, the third 3 months after discharge ( $t 3$ ), and the fourth 2 years after admission ( $t 4)$. The choice of a final assessment two years after the first is based on the expectation that after such a period most patients will have reached a certain balance in their life. In a study among heart patients, Finlayson and McEwen (1977) found that after two years $84 \%$ had a stable pattern of life (after 1 year this was $71 \%$, after 4 
years $88 \%$ ). Another consideration for this choice was of a practical nature: a longer follow-up period would make the study impracticable. Completion of the study following the design as described would already take almost 5 years.

In our study organisational aspects of professional care and support from the social network are areas for special attention. We decided to gather information on these areas not only from the point of view of the patient, but also from the point of view of professional helpers and persons from the social network. This enables firstly two-sided information to be obtained on the patients' contacts with professional helpers, and on coordinating contacts among professionals, and secondly it enables this objective information to be related to the reported experience of the patients. Another important advantage of this approach is that we could obtain a professional assessment of the level of disability, information on complicating diseases and disorders, and a professional assessment of functioning of the patients over a period of time (r esearch question 1b).

Regarding the social network, this approach gives two-sided information on the contents and significance of supportive social relations. Besides, it provides the opportunity to obtain an evaluation of the patients' functioning by people who are close to them, which is also necessary to answer question $1 \mathrm{~b}$.

These considerations led to a decision to approach the following persons at each assessment mentioned above:

- the rehabilitation specialist or rheumatologist

(in phase 1 only for the patients admitted)

- the rehabilitation nurse who was closest to the patient

(only the first and second assessment of phase 2)

- the general practitioner

- the community nurse

- the two people from the social network who were, according to the patient, the most important relevant others at the time of assessment.

Of course, these persons were only approached when the patient gave permission to do so. This list was based on the following considerations.

- The rehabilitation specialist and nurse are the best informed at the time of the first and second assessment and play a central role in coordinating or handing over care at the moment of discharge. At the time of the fourth assessment, we approached the treating specialist who was, according to the patient, the best informed. 
- The general practitioner is, in Dutch health care, the official coordinating person outside the hospital; he gets the letter of discharge, he is expected to coordinate care at home and, if necessary, to refer the patient to a specialist, physiotherapist or other health care worker.

- When a patient needs nursing care at home, the community nurse is the proper person to deliver this care.

- The choice of two persons from the social network is arbitrary: it is mainly based on practical considerations.

In two cases one of the most important members of the social network appeared to be the general practitioner and the community nurse respectively. In these cases, they were interviewed in both capacities.

Consideration was given to adding the physiotherapist to the list of people to be interviewed. For reasons of feasibility we decided not to do so. In the course of phase 2 this was seen to be an omission, because the physiotherapist often appeared to play an important role.

The design described above implies that we had to approach seven people at the first and second assessment for every patient, and six at the thir $d$ and fourth assessment. This brings a total (maximum) of 311 interviews for phase 1 and 2834 for phase 2, not taking into account drop-outs and non-response. Schematically, the design of the study can be represented as in table 4.1.

Table 4.1 A schematic representalion ol the research design

\begin{tabular}{|c|c|c|c|c|c|c|}
\hline & Phase 1 & & Phase 2 & & & \\
\hline & $\begin{array}{l}\text { admission } \\
\mathrm{N}=21^{*}\end{array}$ & $\begin{array}{l}1 / 2-11 / 2 \\
\text { years after } \\
\text { admission } \\
N=37\end{array}$ & $\begin{array}{l}\text { admission } \\
\mathrm{N}=109\end{array}$ & discharge & $\begin{array}{l}3 \text { months } \\
\text { after } \\
\text { discharge }\end{array}$ & $\begin{array}{l}2 \text { years } \\
\text { after } \\
\text { admission m }\end{array}$ \\
\hline patients & $x$ & $x$ & $x$ & $x$ & $x$ & $x$ \\
\hline $\begin{array}{l}\text { rehabilitation specialist } \\
\text { rheumatologist }\end{array}$ & $x$ & - & $x$ & $x$ & $x$ & $x$ \\
\hline rehabilitation nurse & - & - & $x$ & $x$ & - & - \\
\hline general practitioner & $x$ & $x$ & $x$ & $x$ & $x$ & $x$ \\
\hline district nurse & $x$ & $x$ & $x$ & $x$ & $x$ & $x$ \\
\hline $\begin{array}{l}2 \text { persons from the } \\
\text { social network }\end{array}$ & $x$ & $x$ & $x$ & $x$ & $x$ & $x$ \\
\hline
\end{tabular}


In paragraph 3.1 we have already mentioned two choices made in the design of our study: the choice for three patient categories and the restriction to one rehabilitation centre. The first choice implies on the one hand a complication for the analysis, because the research population is far from homogeneous and diagnosis is likely to partly predict the course of functioning by itself. On the other hand this choice implies a likelihood of finding results that can be generalised to other patient categories as well. The research model and the expectations presented in chapter 3 were based on general literature, and it was decided to cover diseases and disabilities of different origins and in different stages of life.

The second choice might adversely effect the generalisation of results regarding the care-related factors. Two comments are in order here. The first is that, as already mentioned, this is not a study on the effect of a specific rehabilitation programme. The influencing care-related factors to be studied concern the coordination of care between rehabilitation centre and primary health care and within primary health care. The information needed for this was gathered from primary health care workers, the rehabilitation centre, and the patients. Since patients in this rehabilitation centre come from a rather large area (up to $150 \mathrm{~km}$ away), and primary health care workers formally have no influence on the decision to admit a patient to the rehabilitation centre, there is a high degree of likelihood to obtain a random sample of general practitioners and community nurses from the area mentioned. This in turn implies a likelihood to obtain a random sample of care-situations. The second comment is that there is very little reason to believe that patients with a spinal cord lesion or a rheumatic disease in one part of the Netherlands are very different from those in other parts.

\subsection{Methods used}

The information required was mainly gathered by means of personal interviews and partly by means of self-administered questionnaires. The personal interviews can be divided into face-to-face and telephonic interviews. The patients were always interviewed face to face. At the time of the fourth assessment in phase 2 we asked the patients to fill in some parts of the questionnaire in advance. This concerned the personality-inventory and the questionnaire on the health locus of control, as described in paragraph 4.3. Patients did not always want to do this. In such cases, these parts were administered by the interviewer, as at the other assessments.

We had intended to interview the rehabilitation specialist or rheumatologist personally. In the first phase this appeared to be too time-consuming for 
them, so we developed a written questionnaire for them. The rehabilitation nurse was interviewed personally at $t 1$ and also at $t 2$ if possible. Sometimes, for example when the person concerned was on night duty, we asked them to fill it in themselves. In phase 1 the rehabilitation nurses were not approached at all, because we did not expect that they would have information about their patients more than a year after discharge. The general practitioners and the community nurses were always interviewed personally in phase 1 and at $t 1$ of phase 2. At 12 we approached them by telephone. At $t 3$ we intended to interview them personally again, but sometimes they said they would rather fill in the questionnaire themselves, mostly citing lack of time as a reason. With a view to not inciting resistance to cooperation, as a rule we accepted such reactions, and sent the questionnaire by post. The persons from the social network of the patient were always interviewed personally.

Table 4.2 gives an overall view of the methods of data-gathering in both phases of the study for every person approached.

Tabie 4.2

An overviaw of methods of daia-gathering

\begin{tabular}{|c|c|c|c|c|c|}
\hline & Phase 1 & Phase 2 & t? & t. & 14 \\
\hline patient & 1 & 1 & $\|$ & 1 & 1 \\
\hline $\begin{array}{l}\text { rehabilitation specialist } \\
\text { rheumatologist }\end{array}$ & 1 & 0 & $a$ & $Q$ & 0 \\
\hline rehabilitation nurse & - & 1 & $1 / 0$ & - & - \\
\hline general praclitioner & 1 & I & $\mid-$ te $\mid$ & $1 / 0$ & 1 \\
\hline district nurse & 1 & 1 & $|-t e|$ & $1 / 0$ & 1 \\
\hline $\begin{array}{l}\text { persons from the } \\
\text { social network }\end{array}$ & 1 & 1 & $\|$ & 1 & 1 \\
\hline $\begin{aligned} 1 & =\text { face-to-face in } \\
|-t \theta| & =\text { telephone inte } \\
0 & =\text { self-administe }\end{aligned}$ & & & & & \\
\hline
\end{tabular}

The interviews were all pre-structured. There were, however, a lot of open questions and the interviewers were instructed to let the interviews take as natural a course as possible. This meant that questions were not always asked in exactly the same order, but depended on the course of conversation. The formulation of the questions was, however, strictly prescribed. All the answers to open questions were written down by the interviewer and later put together in a summarising report, which served as a qualitative background for the more quantitative data. 
Since coordination and tuning of care is a field of special interest in this study, we developed a diary in which patients, participating in phase 2 of the study, were asked to report all contacts they had with professional helpers during the first three months after discharge from the rehabilitation centre. During the second interview (at the time of discharge) we asked the patient to cooperate in this part of the study. Although nearly everybody agreed, only a small number of the respondents filled in the diary completely. The first three months at home after a rehabilitation period appeared to be rather difficult for most people; they had too much on their minds to think about our diary. Regrettably this part of the study turned out to be a disappointment.

The interviews were administered by five interviewers, about $65 \%$ of all the interviews by two of them. The interviewers had very different backgrounds: there was a community nurse, a youth welfare worker, a health educator and a social worker. The fifth was the author of this book, a physician.

With only a few exceptions all the interviews regarding one patient at one assessment were done by the same interviewer. In phase 2 we also tried to let the same interviewer follow a patient throughout the study. In almost $80 \%$ of the cases this scheme succeeded. It did not succeed completely because one of the interviewers retired during the course of the study, and another had to be in a hospital for a considerable time.

All interviewers were experienced in interviewing; there was no specific interview training for this study. In order to ensure the quality and especially the comparability of the interviews, we had, especially in the first two years of the study, intensive discussions after the interviews, in which all the interviewers together discussed their experiences and problems. Here we tried to reach agreement on matters like the approach of patients or professionals, formulation of questions and coding of the answers. Later on, such discussions were organised on a more ad hoc basis. In order to ensure sufficient commitment and because we wanted to make full use of their experience, all interviewers were involved in the development of the questionnaires for the subsequent assessments. In this way we hope to have created maximal conditions to obtain reliable data.

The design of this study demanded a very good organisation and coordination. Organisation was in the hands of two people, who could always replace each other. For safety's sake they also kept a double diary. More than once this appeared not to be an unnecessary luxury. 
Chapter 3 gave an overview of the variables measured in this study. This paragraph describes and discusses the way they were operationalised. First we discuss the dependent variables, then the independent or explanatory variables and the social-demographic and disability-related variables.

\subsubsection{The dependent variables}

Earlier the reasons were discussed for the decision to focus on daily functioning and to analyse it in terms of reported actual behaviour and the self-assessment of functioning. Functioning has three main aspects: physical, psychological and social. The dependent variables were, naturally, measured most extensively in the interviews with the patients themselves. The professionals and the persons from the social network interviewed were also asked to assess the functional status of the patient. Operationalisation was as follows.

\section{Reported actual behaviour:}

Actual behaviour in physical, psychological and social respect was measured with the Sickness Impact Profile (SIP). The SIP was developed in the United States in the 1970 s by Bergner et al. (Bergner et al., 1976a, 1976b). It was conceived as a behaviourally based measure of health status. It measures changes in behaviour and activities, which, according to the respondent, are related to his health. In other words, it measures the consequences of disease or disability on daily activities and behaviour. Formulated this way, it is obvious that it might be of special interest for outcome measurement in rehabilitation. It fits well into our description of the focus of outcome measur ement. From this perspective it is surprising that it has rarely been used in rehabilitation research, while very often in other fields of health-related research.

In addition, there were two other reasons for choosing the SIP. The first is that we needed a measure that can be used in different patient categories: the SIP has been explicitly developed for such use (Bergner et al., 1976a, 1976b, 1980, 1981). Most other instruments of a similar kind are developed for specific diagnostic categories. The second reason is that there is a lot of experience with this instrument in different areas of research, and thus the validity and reliability are very well tested and described. Results on validity and reliability are positive (Bergner et al, 1976a, 1976b, 1981; Bergner and Gilson, 1980; Pollard et al., 1976; Gilson et al., 1975; Carter et al., 1976; Deyo et al., 1983; McDowell and Newell, 1987). 
1. Sleep and rest

- I sit during much of the day

- I sleep less at night, for example, wake up too early, don't fall asleep for a long time, awaken frequently

2. Emotional behaviour

- I act nervous or restless

- I keep rubbing or holding areas of my body that hurt or are uncomfortable

3. Body care and Movernent

- I change position trequently

- I get in and out of bed or chairs by grasping something for support or using a cane or walker

4. Home management

- I am not doing heawy work around the house

- I am doing less of the regular daily work around the house than I would usually do

5. Mobility

- I stay away from home only for brief periods of time

- I am getting around only within one building

6. Social interaction

- I am going out less to visit people

- My sexual activity is decreased

7. Ambulation

- I do not walk at all

- I walk more slowly

8. Alertness behaviour

- I have difficulty reasoning and solving problems, for example, making plans; making decisions, learning new things

- I react slowly to things that are said or done

9. Communication

- I am having trouble writing or typing

- I have difficuity speaking, for example, get stuck, stutter, stammer, slur my words

10. Work

- I am not working at all

- I am working at my usual job with some changes, for example, using different tools or special aids, trading some tasks with other workers

11. Recreation and pastimes

- I lam going out for entertainment less often

- I am doing more inactive pastimes in place of my other usual activities

12. Eating

- I am eating much less than usuai

- I am eating special or different food, for example, soft food, bland diet, low-salt, low-fat, lowsugar

On the basis of these considerations we decided to translate the American version of the SIP into Dutch. We did this in collaboration with the Department of General Practice of the University of Utrecht (Luttik et al., 1985). We tested the Dutch version for aspects of validity and reliability in several 
studies. Results of these tests were positive and strongly suggested that this Dutch version was as valid and reliable as the original (de Witte et al., 1987; De Bruin et all, 1990; De Melker et al., 1990).

The SIP contains 136 statements about sickness-related dysfunction, divided into twelve categories of activities. In table 4.3 these categories are listed and two examples of statements in each category are given.

From each category a category-score can be computed. Also, an overall score and two subscores can be computed: physical dysfunction and psychosocial dysfunction. These scores give a percentage of the total maximum level of dysfunction in the respective categories or dimensions: a high score means dysfunction. A score of ' $O$ ' indicates that there is no sicknessrelated dysfunction at all. For more details on the scoring procedure and information on validity and reliability, we refer to the literature already mentioned. In our study we primarily use the two subscores (physical and psychosocial). In appendix I the average scores of the total groups of patients involved in the study are presented, together with some information about the distribution.

At this point a special problem concerning the SIP must be mentioned. There have been some publications in which the ability of the SIP to measure change in functioning over a period of time is doubted. MacKenzie et al.(1986) did a study to evaluate the performance of the SIP as a measure of within-patient change. They interviewed 22 medical and 21 surgical patients within 24 hours of their admission to a hospital. Follow-up interviews were performed by telephone at 1,2,4 and 6 weeks post-discharge. They compared the changes in SIP-scores with self-assessments of change. They found that the SIP was unable to detect improvements and deteriorations equally, and concluded the use of the SIP for following individuals over some time might be limited. On the basis of this study and a similar investigation of Deyo and Inui (1984), we conducted a study ourselves to evaluate the performance of our Dutch version in this respect. In this study 18 patients with rheumatoid arthritis filled in an activity-diary for two weeks. In these two weeks the SIP was scored five times at different intervals. We investigated the relationship between SIP scores and information from the diaries. In accordance with Mackenzie et al. and Deyo and Inui we found that SIP scores were rather stable during a period of two weeks, and did not follow day-to-day changes in the diary accurately. They, however, correlated strongly with average information from the diaries. This means that it is better not to use the SIP for short-term follow-up. For our study this characteristic of the SIP is positive: It means that the scores we find at follow-up assessments are not likely to be influenced by daily variations in 
functioning or discomfort, they reflect the average level of functioning during a period of a few weeks. Especially for the rheumatic patient categories this is important, since these are characterised by fluctuating complaints and discomfort.

\section{Personal evaluation of functioning:}

Personal evaluation of physical, psychological and social functioning was in both phases of the study measured with a set of self-assessment questions, in the form of 5-point rating scales. Each rating scale had as possible answers: very good/good/ moderate/ bad/ very bad, or" not at all/ a little/ moderate/ much/ very much. The aspects of functioning to be assessed in the dif ferent phases of the study are given in table 4.4. The set of questions for the second phase was repeated at each assessment, except for an accidental omission of the psychological aspect 'being able to cope with daily problems'.

In order to reduce the number of variables we conducted a cluster analysis, with the self-assessment questions as units for analysis, and a principal components analysis on the data of the first assessment in phase 2. Both types of analysis revealed an obvious group of questions referring to the physical aspects of functioning: severity of disability, hindrance in daily activities, physical functioning and general health. This was in accordance with our expectations. The expected division of the remaining questions into social and

Table 4.4

Aspecis of functioning to be assessed in different phases of the siudly

Physical aspects:

- Severity

- hindrance in daily activities

- physical functioning

- generall health

Psychological aspects:

- being able to cope with daily practical problems

- psychological functioning

- success in coping with disability

$\begin{array}{cc}x & x \\ x & x \\ x & x \\ x & x\end{array}$

Social aspects:

- contacts with others

- difficulty in contacts with strangers

- difficulty in cantacts witn known people

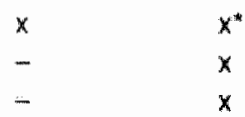

" only at first assessment 
psychological aspects did not come out of the analysis clearly. Neither the principal components analysis nor the cluster analysis gave a clear division of social and psychological aspects. On the basis of these results we decided to create two sumscores. The first represents the personal evaluation of physical functioning, with the four questions already mentioned. The second represents the personal evaluation of psychosocial functioning. The internal consistency, according to Cronbach's alpha, of both scales was acceptable (.74 and 69). An important advantage of this solution is that the contents of these sumscores generally fit the subscores of the Sickness Impact Profile. Both scales were used in all the other assessments of phase 2. Cronbach's alpha was good at each assessment $(.79, .79$ and .80 for the physical scale and $.76, .74$ and 70 for the psychosocial scale). For the data of phase 1 we could only compute the score on physical functioning. Cronbach's alpha here was also high (.84). In appendix I the average scores of the total groups of patients involved in the study are presented, together with information about the distribution.

In a survey among 372 patients with rheumatic diseases, independent of the study reported in this book, we used the same set of self-assessments developed for this study. Here a principal components analysis revealed exactly the same structure: Cronbach's alpha of the physical scale was .79 and of the psychosocial scale .78 (de Witte et al., 1989).

In the first phase and at the third and fourth assessment of phase 2 we added a question to some of the ratings mentioned above, in which we asked for comparison of functioning at that time with functioning at the time of discharge from the centre. In phase 1 this was done for the aspects hindrance, physical functioning, general health, being able to cope with daily problems and social contacts. In phase 2 we took psychological functioning in exchange for being able to cope with daily problems, and we added severity of disability. These questions were also presented as 5-point rating scales with possible answers ranging from much better to much worse.

We conducted a principal components analysis on these retrospective selfassessment questions as well, with a view to data reduction. For the data of the first phase of the study this analysis distinguished two clearly interpretable factors, parallel to those described above: the three physical aspects together and the two psychosocial aspects together. For the data of the fourth assessment of the second phase of the study exactly the same structure was found. The analysis on the data of the third assessment in phase II, three months after discharge, revealed a one-factor structure. This difference between the data three months after discharge and the data regarding a longer period after discharge, indicates that the evaluation of change over a shorter period is 
more diffuse than over a longer period: in the long term a differentiation of physical and psychosocial aspects appears.

On the basis of these analyses we decided to compute two sumscores in both phases of the study. The first represents experienced change in physical aspects of functioning (hindrance, general health, physical functioning and, in phase II, severity of disability). The second represents experienced change in psychosocial aspects of functioning (being able to cope with problems and social contacts in phase $I_{i}$ psychological functioning and social contacts in phase II).

The internal consistency of these scales was good: the physical scale has a Cronbach's alpha of .86 in phase $I$, and .81 and .89 at the third and fourth assessment respectively in phase If; the items of the psychosocial scale have intercorrelations of .48 in phase I and .35 and .53 respectively in phase II. Just as for the other scales described before, appendix I gives some basic characteristics of these scales.

All the self-assessment questions mentioned above were primarily asked as open questions. The patient was given the opportunity to answer freely and the interviewer was expected to ask for further elucidation or illustration. When the subject was closed, the interviewer presented the 5-point rating scale to the patient who was then asked to choose an answer. With this approach we tried to ensure good contact between interviewer and respondent (the respondent could tell his own story), and to get an impression of the reliability of the answers.

Assessment of functional status by professionals and network-members:

The professionals and social network-members interviewed were asked to evaluate different aspects of patient-functioning as well. For this purpose the same questions as described above under 'personal evaluation of functioning' were used. This whole set was repeated at every assessment. They were also asked to retrospectively evaluate the course of functioning since discharge, in the same way as described above for the patients.

\subsubsection{The independent variables}

The way we operationalised the independent variables mentioned in our research model is described below. 


\subsubsection{Personal characteristics}

Personality traits:

For measuring personality traits we used the Dutch Personality Inventory (Luteijn et al, 1975,1985 ). This inventory, with its 133 items, measures 7 personality traits:

- Inadequacy

- Social Inadequacy

- Rigidity

- Resentfulness

- Self-satisfaction

- Dominance

- Self-recognition

There were two other possibilities to measure personality traits, the Dutch version of the Minnesota Multiphasic Personality Inventory (MMPI) and the Amsterdam Biographic Inventory. The Dutch MMPI consists of over 400 items. We thought that this was too much because the interviews were already very long. The Amsterdam Biographic Inventory has an important disadvantage in that it only measures three aspects of personality, namely neurotic lability, extraversion-introversion, and self-defence-self-criticism (Wilde, 1970). The Dutch Personality Inventory seemed to be the best choice. Some of the traits measured with it come very close to the characteristics mentioned in chapter 2: self-recognition is closely related to self-esteem, low social inadequacy might be considered similar to extraversion and inadequacy may stand for neuroticism. The psychometric characteristics and qualities of the inventory are satisfactory (Luteijn et al., 1975, 1985).

The patients filled in the complete inventory, but we did not include all seven aspects in the study, because only three of the traits measured are clearly related to the aspects identified as important. The other subscales are therefore not included in the research model, except for rigidity. On the basis of common sense we expect that people with a high score on this scale have more difficulty in changing their lifestyle and habits, and are thus more likely to present a negative course of functioning; they will have the tendency to 'fall back' to earlier behaviour patterns. Although rigidity was not mentioned in chapter 2, we decided to explore its relationship to the course of functioning.

Scores on the seven scales are compared with a norm table and converted to a relative score, ranging from "very low" $(-3)$ to "very high' $(+3)$. In these relative scores the influence of age, sex, and educational level are taken into consideration. For this study we used these 'corrected' scores. In appendix I the average scores of the total groups of patients in the study are presented.

It is important to realize that, as a consequence of the measurement instrument chosen, the personality characteristics measured are not exactly those 
mentioned in chapter 2 and in the expectations in chapter $3(3.1 \mathrm{a}, \mathrm{b}$ and $\mathrm{c})$. They are, however, closely related. Inadequacy stands for neuroticism, social inadequacy stands for (low) extraversion and self-recognition stands for selfesteem.

\section{Locus of Control:}

As described in chapter 2, research shows that the locus of control for different areas of behaviour can be different and sometimes even independent. Since our study regards health and illness, we chose to measure the health-related locus of control. On the basis of the work of Halfens (1985), who made a comparison of a number of measurement instruments available to measure health-related locus of control, we chose to use an adapted version of a Dutch translation of the Multi-dimensional Health Locus of Control Scale (MHLC) (original version by Wallston, Wallston and DeVellis, 1978; translation by Burink-Withaar, Jansen, Jonkers and Pruyn, 1981; adaptation by Halfens, 1985). In this scale three different controlling agencies are distinguished: the person himself, doctors and chance. For each agency a scale is developed. Each scale consists of 6 items with a 6-point Likert-type answering possibility. In Halfens' study (1985), internal consistency of these scales was satisfactory. Principal components analysis on the data of the first assessment in phase 2 of our own study revealed the same structure as described by Halfens. Cronbach's alphas of the three scales in our study were also satisfactory: .69 for the internal scale, 79 for the doctor scale and .75 for the chance scale. The items of the scales used are presented in appendix II. Appendix I gives the average scores and information on the distribution of the patients in the study.

The scales measuring doctor-orientation and chance-orientation can be seen as two specifications of the external orientation mentioned in chapter 2 and in expectation $3.2 \mathrm{~b}$. They are both included in the study.

\section{Self-image:}

Operationalisation of the concept of self-image is difficult. There is no obvious and generally accepted instrument for measuring it. We used two instruments:

1. a circle to which the respondent had to draw the degree to which he was damaged by the disability (in both phases of the study).

2. a semantic differential (only in phase 2).

In both phases of the study we presented a circle to all patients. We asked them to imagine this circle represented them. Then we asked them to draw the place and degree in which they felt damaged by their disease or disability. We derived the idea for this approach from the title page of Dijkstra's book on 
stigmatization (Dijkstra, 1979). On this title page a damaged apple is printed onto the face of a young man. The percentage of the circle filled correlated highly with scores on the Sickness Impact Profile and on the scales on evaluation of functioning, and also with a 5-point rating scale asking for the degr ee of damage. Although these findings suggest so, we did not feel certain enough of the validity of this instrument as a measure of damage to the self-image, due to the disability. We also could not fall back on literature about this instrument or on the experience of others. Therefore we decided not to use this as the only measure of self-image in phase 2. For the analysis of the data from phase 1 of the study, it is the only available measure, since we did not use the semantic differential there.

The semantic differential is an old and often used instrument. It is an instrument for studying the psychological meaning of different stimuli (Osgood, Suci and Tannenbaum, 1957). It consists of a series of rating scales with two contrasting adjectives at the extremities. The respondents in the second phase of our study were asked at every assessment to place themselves on a 5-point scale between each contrasting pair of adjectives. We used a list of 32 pairs, largely copied from other studies and partly adjusted to follow our own interest. In this way we obtained a kind of self-evaluation in terms of the polarities used. With the help of a principal components analysis and a cluster analysis on the data of the first assessment, it was possible to construct two scales, interpretable as positive evaluation and negative evaluation. Both scales had a satisfactory internal consistency (.71 and .68). The items of the scales are presented in appendix III. Appendix I gives some information on the scores of the patients involved in the study. We decided to use these scales as measures of self-image for the second phase of the study, in addition to the circle described.

\subsubsection{Social network characteristics}

As described in chapter 2 , we wanted information concerning str uctural characteristics, like size and type of relationships, and functional characteristics, like emotional and practical support. Because of the varied information needed, and because we wanted to be able to use the data on social networks in another study, oriented especially on changes in social networks of handicapped or chronically ill people, we developed a rather detailed and comprehensive instrument to measure the different characteristics of the social network. We considered that none of the instruments available in the literature was completely suitable for our purpose. Besides, the choice of instruments available in Dutch was very limited: there had not been much Dutch research on social networks at the time we started planning this study. Therefore we decided to develop an instrument for this study, that also could be 
used in the other study mentioned above (Janssen et al., 1990). Of course this was based on elements of instruments available and tested in the literature, for example the Norbeck Social Support Questionnaire (Norbeck, 1981) and the Social Network Index (Berkman and Syme, 1979).

At every assessment we asked the respondent to name the people with whom he had good personal ties. We set a maximum of 20 persons to be named. We did not direct the mentioning of persons in any way. After we got a list of these persons, we asked for the following aspects of the relationship to every person named*

- kind of relationship (partner, close family, friend, etc.)

- sex

- duration of relationship (years and months)

- house-mate or not

- frequency of face-to-face contacts (per month)

- frequency of telephone contacts (per month)

- most frequent initiator of contacts (patient, the other, equal)

- accessibility (5-point rating scale, ranging from very good to not at all)

- importance of relationship (although the opening question implies that persons mentioned are important, we asked here how important they really were (very important/important/not really important))

- the amount of emotional support received from this person (5-point rating scale, ranging from no support to very much)

- the amount of practical support received from this person (5-point rating scale as above)

- the perception of how important the patient is to the person mentioned

- the amount of emotional support given to this person

- the amount of practical support given to this person

- frequency of talking about the disability or disease.

With this information on every person named as a close personal relationship, it is possible to compute a number of variables, describing dif ferent aspects of the network. As discussed in chapter 2 (par. 2.4) we confine ourselves in this study to the following variables.

\section{Structural characteristics:}

- size of the network (number of people named)

- number of friends and other non-relatives

\section{Functional characteristics:}

- number of people giving (very) much emotional support

- number of people giving (very) much practical support 
- number of people with whom the patient talks (very) often about the disability (this is seen as a specific aspect of emotional support).

Following this method, it is possible that professional workers would be mentioned as social network members. This appeared to be the case only very infrequently. Therefore this category of network members is included in the category of non-relatives.

The method described above was used in phase 2 of the study. In phase 1 we used a slightly different method, giving comparable measures. The differences were the following:

- A limit of 15 was set instead of 20 persons.

- Face-to-face contacts were not distinguished from telephonic contacts.

- Accessibility and the most frequent initiator of contacts were not asked about.

- To measure the functional aspects rating scales were not used for every person named, but the patient was asked to rank the persons he received support from in order of decreasing amount of emotional and practical support, and the same for the persons he gave support to. As measures of number of people supporting, we counted the persons mentioned in these rankings.

These differences mean that figures from both phases are not directly comparable. They do, however, stand for the same aspects of the network. The average scores of the patients in both phases of the study are presented in appendix $I$, together with information on distribution.

At the last assessment of phase 2 of the study we added a loneliness scale, developed by De Jong-Gierveld et al. (1984, 1985), to the questionnair e. Loneliness involves situations in which the number of achieved relationships is smaller than desired, or when the existing relationships fail to attain the desired degree of intimacy. We considered it important to distinguish these subjective feelings of loneliness from the more descriptive registration of number and kind of social relationships. The scale of De Jong-Gierveld et al. is a short (11 items) Rash-type scale with good psychometric properties. It has been used in several Dutch studies in recent years, with good results (Van Tilburg, 1988).

\subsubsection{Continuity of professional care}

In chapters 2 and 3 continuity of care was mentioned as an important factor to be explored in this study. At the time we started our study there was, as far as we know, no generally accepted instrument available to measure the different 
aspects of continuity of care we distinguished. Therefore we had to develop our own method, without much support from the literature. Below we shall describe our operationalisation. Some of the considerations leading to this operationalisation have already been described in chapter 2 . The two central aspects distinguished in our definition are dealt with separately: firstly the degree of coordination and integration of professional care, secondly the degree of tuning to perceived patient needs.

Degree of coordination and integration of professional care:

For this study our interest is focused on the level of the primary care process: the coordination and integration of patient-directed activities. The object was to study care at an operational level, that is operational coherence. The focus of the investigation was on continuity of care around the time of discharge from the rehabilitation centre (handing over care to primary health care workers) and on coordination within primary care. Our primary approach to this aspect of continuity of care is very similar to the approach to operational coherence described by Jansen et al. (1985). They mentioned four conditions for operational coherence:

1. Care activities must connect in time, meaning that duration of time between activities is not longer than necessary and there is no unnecessary overlap.

2. Care activities must be functionally complementary, meaning no unnecessary repeats and the right thing at the right moment.

3. Care activities may not be contradictory.

4. Care activities must preferably reinforce each other, meaning that the careprocess as a whole is purposeful and that one care-provider builds upon what others have already done.

These four aspects enabled us to operationalise the concept of operational coherence. We intended to do this with the care-diary described in paragraph 4.2. In phase 2 of this study we asked the patients to fill in a diary during the first three months after discharge (between the second and third assessment), in which they were asked to note and describe every contact with professionals. This would give detailed information on aspects regarding time and content of contacts with professionals. With such information it should have been possible to construct a measure for operational coherence of professional care during these three months. Regrettably, this part of the study must be considered a fallure, as already mentioned in paragraph 4.2 . For this reason we have no direct measure for operational coherence. We can only use two indirect measures, which can be expected to be related to operational coherence: the degree in which coordinating activities between professional care-providers 
take place and the degree of agreement on each other's tasks and duties. We suppose that when care-providers have mutual contacts regarding a patient and agree on each other's tasks and duties, there is a better chance that care activities are coherent than when there are no mutual contacts and there is no agreement on tasks and duties. In a study by Coolen (1986) on health care and welfare for elderly people, the relationship between coordinating contacts and integration of care was found to be positive. Following this line of thought we developed one measure for coordination between care-providers and another for agreement on tasks and duties. The patients were asked which professionals and agencies they had contacted and how frequently this was. All the professionals interviewed were asked how often they had had contact with any other professional involved. We also asked for the character of these contacts (informative or policy planning) and for the initiator of each contact between professionals. The measure for coordination was meant to be computed by simply dividing the number of pairs of professionals between whom a contact took place by the number of pairs of professionals between whom a contact could be considered desirable or advisable. In this respect we had to make some basic assumptions: a contact between two professionals was assumed desirable or advisable when both had had contact with the patient more than once, and every contact mentioned by any of the professionals was considered relevant, even when the other professional of the pair did not mention it. The character of the contacts was not incorporated in the computation. This means that a telephonic, purely informative contact is treated in the same way as a face-to-face contact about the treatment policy for the next few months. As will become obvious later on such a refinement was not meaningful because of the small number of coordinating contacts. The small number of contacts found even led to a further simplification of the measure. For the analysis in phase 2 (described in chapter 13) we only distinguished cases in which any contact between professionals took place and cases in which no contact was mentioned. Contacts with alternative helpers, pastoral workers and patient associations were not taken into account in computing the measure.

The measure for agreement on tasks and duties was constructed as follows. The professionals were presented with a list of tasks and duties and were asked who they thought was primarily responsible for each of the tasks. There were four possible answers for every task: the general practitioner, the community nurse, the rehabilitation centre or 'another' professional. Comparing the answers gives an indication of the agreement on each other's tasks and duties. The number of tasks on which a pair of professionals gave the same answer was used as the measure of agreement on tasks and duties. The follow- 
ing tasks were used to construct the measure, all referring to the period after discharge:

- guiding the patient through health care and procedures

- surveillance of care

- arbitration and help with agencies and difficult procedures

- counselling of the family

- counselling of the patient

- coordinating care.

For phase 2 both measures, the one for coordination and the one for agreement on tasks and duties, can be computed for the period between the second and the third assessment and for the period between assessments 3 and 4 . For the data from phase 1 we can only compute the measure for coordination, because we did not ask for the professional's opinions on tasks and duties here.

Tuning of care to patient needs:

As described in chapter 2 this aspect of continuity of care has to do with the distance between professional activities and the life sphere of the patient. It can also be seen as the communicative distance between care-providers and the patient. We approached operationalisation in two different ways. Firstly we constructed a measure for agreement between the patient's self-assessment of physical functioning and the assessment of the same functional aspects by the professionals. We restricted this to the general practitioners and community nurses. As already described in paragraph 4.3.1, we presented these professionals with the same 5-point rating scales as the patients were asked. In phase 2 we added a series of questions on how they thought the patient would have scored on these rating scales. In phase 1 the degree of similarity of the answers of the professionals to the answers of the patient is considered to be a measure of how well the professional knows the life sphere of the patient. In phase 2, the degree of similarity between the answers of the patients and the answers of the professionals on how they thought the patient would answer is considered as such. In both phases high correspondence of answers is considered to indicate a small communicative distance. As a measure the absolute difference on the sumscore measuring the evaluation of physical functioning was used (see paragraph 4.3.1).

The second line of approach is the measurement of satisfaction of patients and people closely related to them with professional care. For this purpose we presented each patient and each social network member interviewed with a 5point rating scale (ranging from very satisfied to very dissatisfied) and asked them to give a report mark (from 0 to 10 ). The answers of the social network members were combined. When two of them were unterviewed, their answers were averaged, when only one was interviewed, we used his/her answer. The 
answers on the rating scale and the report marks were also combined into one measure. When a report mark above 7 was given, together with an answer 'satisfied' or "very satisfied', this resulted in a code (3): high satisfaction. A report mark below 6, together with an answer 'dissatisfied' or 'very dissatisfied', resulted in a code (1) for low satisfaction. Any other combination resulted in a code (2) for moderate satisfaction.

These measures together would appear to be satisfactory indicators for the tuning of professional care to perceived patient needs, although we would have preferred to use the results from care-diaries.

To conclude this paragraph we give a schematic summary of the operationalisation of the concept of continuity of care in figure 4.1. Unlike the other measures described in this chapter, the scores on these measures are not presented in appendix $I$, because they are quite extensively described in chapters 7 and 13.

Flgure 4.1 Aspects of continuity of care distinguished in this sludy

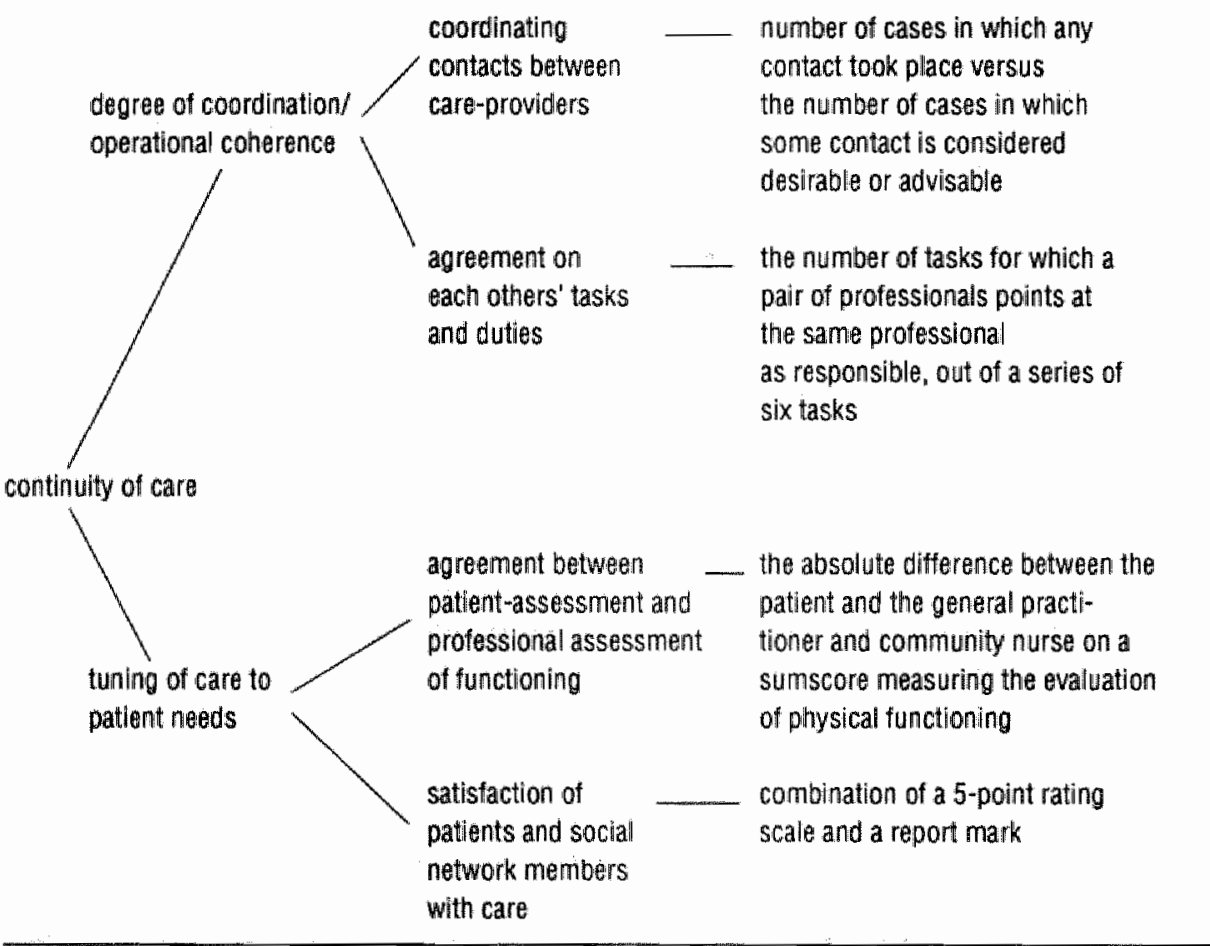




\subsubsection{Social-demographic and disability-related characteristics}

In this paragraph the operationalisation of the social-demographic and disability-related characteristics in the research model is described.

\subsubsection{Social-demographic characteristics}

age: self-explanatory.

sex: self-explanatory.

socio-economic status: we used educational level of the patient and the net family income as indicators for socio-economic status. For both variables a threecategory classification was made. The highest of these two classifications was used as an indicator of socio-economic status. Thus there are three levels to be distinguished: low, middle and high. The exact criteria for classification are given in table 4.5. Occupational status was not used as an indicator of socioeconomic status because we expected that most of the patients would not have an occupation because of their age and sex (older women in the rheumatoid arthritis group and young men in the spinal cord group).

marital status: we distinguished people having a regular partner (married and/or living together) and people without a regular partner (unmarried and not living together, widow or widower, divorced). Thus a dichotomous variable was obtained.

Table 4.5

low

middle

high
Criteria lor classiflcation of socio-economic status

educational level

andor net family income*

up to and including

below minimum

lower vocational training

up to and including

secondary vocational training

up to and including

university between minimum and

$1.5 \times$ standard Income

above $1.5 \times$ standard income

- based upon figures from the note on income policy 1989, belonging to the Budget 1989 from the Ministry for Social Affairs and Employment, Lower House, 1988-1989, 20808, nrs. 1-2.

\subsubsection{Disability-related characteristics}

Objective level of disability:

For the patient category with spinal cord lesion the measurement of the level of disability seems rather obvious. The height of the lesion, as reported by the rehabilitation specialist, could be used as an indicator for the level of disabil- 
ity. A special problem, however, is caused by the incomplete lesions. Here an exact determination of the level of disability is not unequivocal: motorically the lesion can be at a level other than sensory, and it is hard to measure how incomplete or complete a lesion is. To get an objective assessment, we asked 5 members of the rehabilitation team (2 physiotherapists, the rehabilitation specialist, the occupational therapist and the head nurse) to rank all patients in order of increasing disability at the time of their discharge. The average rankorder correlation between these five rankings was .90 in phase 1 and .93 in phase 2 of the study, indicating that this procedure gives a reasonably reliable relative measure. The five rankings were averaged.

The measurement of the objective level of disability in the other two ( $r$ heumatic) patient categories was different. For both diagnoses there is no hard or objective measure available. Laboratory data like erythrocyte sedimentation rate or hematocrit, or roentgenologic anatomic changes do not give sufficient information about functional disability. They are parameters of the severity of inflammation, which do not necessarily correlate with disability. The often used, more functional ARA classification, a 4-point ordinal scale with classes ranging from no functional problems to largely or wholly incapacitated, is not useful for our study, because nearly all the patients would be classified in the third or second class (Steinbröcker et al., 1949). To provide a rather simple solution to this problem, in the second phase of the study the treating rheumatologist in the rehabilitation centre was asked to classify all the patients at the time of their discharge on the same 5-point rating scales we used in the patient interviews to operationalise the personal evaluation of physical functioning. Thus our operationalisation of the level of disability in both rheumatic patient categories is the same as the scale developed for the patients' own evaluation of physical functioning. The internal consistency of this scale on the data obtained from the treating rheumatologists in phase 2 was satisfactory (Cronbach's alpha .66).

In the first phase we only asked the general practitioners and the community nurses to classify the patients by this method. Internal consistency here was satisfactory, though not very high (alpha .62 and .63). The assessments of the general practitioners and the community nurses were averaged.

In this way, for all patient categories in both phases of the study, a relative professional assessment of the level of disability was obtained. Next, three groups were formed within each patient category on the basis of the statistical distribution, creating three more or less equally sized groups within each category. Thus we distinguish three levels of disability. 
Besides a professional assessment of the disability at the time of discharge, we also wanted to obtain a similar assessment of changes at the level of disability after discharge. Given the stable character of spinal cord lesions, we considered this only necessary for the RA and AS groups. Thus we asked the rheumatologists of the patients, at the last assessment (t4), whether a progression of the disease had occurred since discharge, functionally and/or radiologically. This was done with the help of two five-point rating scales. Regrettably, this assessment could only be obtained in slightly more than half of the cases, because the rheumatologists did not return the questionnaire or did not have information about the patient. In those cases in which the assessment was obtained, only very few times was progression reported. This aspect was therefore not included in the analysis.

\section{Complicating diseases:}

In the first phase of the study we only asked the patient whether he had any other disease or impairment. Thus a dichotomous variable was created, without a distinction between diseases existing since before the rehabilitation period and those developed later.

In the second phase we asked the patient, the general practitioner and the rehabilitation specialist or rheumatologist at the first assessment whether the patient had any other chronic disease or impairment and, if so, what kind of disease or impairment. All the problems mentioned were assessed by two independent physicians and classified into two classes: not influencing longterm functioning and possibly or certainly influencing long-term functioning. When the two physicians did not agree, it was classified into the latter category. Only diseases and impairments classified as possibly or certainly influencing functioning, were taken into consideration. In this way probably irrelevant impairments are omitted.

At the third and fourth assessments in phase 2, we also asked the patient and the professional involved whether any intercurrent disease had occurred since discharge. These were treated in the same way.

Thus, we distinguished two kinds of complicating diseases in the second phase of the study: those already present at the time of admission and those occurring after discharge.

\section{Duration:}

The operationalisation of this variable is quite simple. For the group with spinal cord lesion we asked the patient and the rehabilitation specialist how long the lesion had existed at the time of the first assessment. We asked the patients in the rheumatic groups how long they had had complaints as a result of their disease. 
In table 4.6 a summarising overview of the variables and their operationalisation as described earlier in this paragraph is given. These are the variables used in our analysis. As already mentioned, appendix I gives additional information about these variables, except for the social-demographic and disability-related characteristics. The latter are described in chapter 5.

\section{Table 4.6 An overviev of the central variables and their operattonalisation}

\section{Dependent variables}

- daily functioning in terms of actual behaviour

- personal evaluation of functloning.

- personal evaluation of chiange in functioning over time

+ Health Locus of Contral

+ Self-Image
Sickness Impact Profile

- physical subscore

- psychosocial subscore

Sell-assessments on a series of 5point rating scalles

- sumscore on physical functioning

- sumscare on psychosocial functioning

Seli-assessment on a series of 5point rating scales: experienced change of functioning since discharge

- sumscore on physical functioning

- sumscore on psychosacial functioning phase 1 phase 2

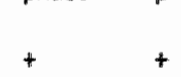

$+*$

宣

Dutch Personality Inventory

- inadequacy

- social inadequacy

- rigidity

- self-recognition

Adaptation of the Multidimensional

HLOC-scale

- Internal orientation

- orientation on dactors

- chance-orientation

Circlle

- percentage damaged by the disease or disability

Semantic differential

- positive self-evaluation

- negative self-evaluation 
- Social network characteristics structural

functional

- Continuity of professional care

- Disability related variables
- size

- number of friends and other non-relatives

- number of people giving emotional support

- number of people giving practical support

- number of people with whom patient talks about disability

- Ioneliness

- coordinating contacts between care-providers

- agreement on tasks and duties

- agreement between patient assessment and professional assessment

- (patient) satisfaction with care

- Social-demographic variables -age

$-\operatorname{sex}$

- socio-economic status

- marital status

- objective level of disability

- complicating diseases

- duration

* Operationalisation slightly different in both phases of the study.

\subsection{Statistical methods}

An important part of the statistical techniques used in this study has already been described earlier in this chapter. With the help of principal components analyses, cluster analyses and the Cronbach's coefficient alpha, we created two scales measuring the self-assessment of physical and psychosocial functioning respectively, and two scales measuring the assessment of the course of functioning retrospectively. The same techniques were used to create two scales measuring aspects of the self-image on the basis of the semantic dif ferential, and to check the internal structure and consistency of the health locus of control scales. The aim of using these techniques was only data reduction. We consider these techniques familiar.

In the following chapters up to and including 13 , complicated statistical techniques are not used. At some places a correlation coefficient is computed; this is always Pearson's product-moment coefficient. The structure of the analysis further only implies statistical tests of differences between groups of patients. 
For both phases of the study we create groups of patients with a relatively positive, average or negative course of functioning (in phase I only two groups are created). These groups are then compared with respect to all the possible predictor variables in the research model. Until chapter 14 only bivariate relationships are investigated. Dependent on the number of groups compared and the kind of variable, we made a choice out of 4 tests:

1. T-Test for independent samples: this test is used to test the difference between the means of two groups when the dependent variable is at an interval level. All sumscores that consist of a series of similar five- or sixpoint rating scales are treated as interval scales.

2. Chi-Square Test: this is used to test differences in proportions in 2 or 3 groups when the dependent variable is at nominal level. When computation of Chi-Square is not allowed, because of a small number of cases, we used the Fisher Exact probability test instead.

3. Mann-Whitney $U$ Test: this is the nonparametric parallel of the $t$-Test. It is used to test the difference in the ranks of scores of two groups. This is done when the dependent variable is at ordinal level.

4. One-way analysis of variance: this is used to test the dif ference among the means of three groups when the dependent variable is at an interval level. The sumscores computed are treated as interval scales here as well. This analysis only shows whether a difference exists or not. We used Scheffe's procedure for contrasts to detect which of the groups actually differ from each other.

In each table presented, regarding the comparison of groups of patients, the tests used are mentioned, together with the level of significance of the differences. The tests are indicated with one of the above mentioned numbers.

Besides comparisons of the groups created, we also describe longitudinal changes in the personal and social network characteristics in chapters 11 and 12. Changes in the scores between subsequent assessments are tested with the $\mathrm{t}$-Test for paired samples.

In chapter 14 more complicated multivariate techniques are mentioned. Here we describe a series of discriminant analyses, followed by a series of multiple regression analyses. These analyses were performed on a limited selection of the variables. This selection is made on the basis of the results from the bivariate analyses. The purpose of using these techniques is to determine the relative importance of the variables selected in explaining or predicting the course of functioning. Details on these techniques and the way we used them are given in the paragraphs concerned. 
One of the main purposes of this study is to determine which variables out of the groups of variables investigated play a role in explaining the course of functioning. The study has a largely explorative character, although we formulated some expectations. Because of this explorative character we adapted a significance level alpha of .10; we would rather wrongfully conclude that a variable plays a role than wrongfully conclude that it is not important. We only computed two-tailed tests.

All statistical analyses were carried out with the statistical computer package SPSS- $X$. 



\section{CHAPTER 5}

\section{The research populations}

In this chapter we describe the populations of patients, professional workers and social network members, participating in the study. In paragraph 5.1 we describe the selection criteria and the way we approached the patients and other people to be questioned. Information on non-response is also given. In paragraph 5.2 a description of the groups participating is given in terms of social-demographic and disability-related characteristics.

Phase 1 and phase 2 of the study are dealt with separately. Paragraph 5.3 treats the problem of drop-out during the study.

\subsection{Potential populations and non-response}

\section{Phase 1}

In phase 1 we needed patients with a spinal cord lesion (SC) or rheumatoid arthritis (RA) who had been discharged from the rehabilitation centre about a half to one and a half years before. This roughly corresponds with admission 1-2 years before. From the administration of the rehabilitation centre we obtained the names and addresses of all the patients in these categories who 
had been admitted for the first time between 1-1-1983 and 1-9-1983. This gave a list of 37 patients with a spinal cord lesion and 36 with rheumatoid arthritis. Two spinal cord lesion patients were excluded because they had died. The following step was a comparison of all the people on the list with the following criteria: not older than 75 years, living in the Netherlands, and, for the RA group, having classical rheumatoid arthritis (ARA criteria, Ropes et al, 1958). Using these criteria 53 patients remained: 25 with rheumatoid arthritis and 28 with a spinal cord lesion. The addresses of these patients were checked in the phone book. Only 37 addresses appeared to be correct. In the other cases we tried to reach someone at the address we had, asking how the patient concerned could be reached. Following this procedure we finally obtained correct addresses of 45 patients. The remaining 8 could not be traced. These 45 received a letter with the request to cooperate with our study. Only 5 patients told us they did not want to participate, 2 had died, and 1 lived in a nursing home because of dementia. Thus we had 37 patients participating in the first phase of the study: $16 \mathrm{RA}$ and $21 \mathrm{SC}$. This corresponds with a response rate of $88 \%(37 / 42)$. We know nothing about the patients not participating. We can therefore not say anything about a possible selection ef fect. We asked the patients to allow us to approach their general practitioner and, if they had had contact, their community nurse for an interview. We also asked them to name the two persons from their social network who were closest to them, and to allow us to approach these for an interview as well.

Table 5.1 gives the numbers of different interviews held. The figures regarding the group admitted to the rehabilitation centre are not mentioned, because the data from this group is not used for this study.

\section{Table 5.1}

Numbers of post-discharge interviews held in phase 1 for both patienl categories

\begin{tabular}{lccl} 
& RA & SC & Total \\
patients & 16 & 21 & 37 \\
general practitioner & 13 & 12 & $25(=68 \%)$ \\
Community nurse & 12 & 8 & $20(=54 \%)$ \\
person 1 from social network & 15 & 17 & $32(=87 \%)$ \\
person 2 from social network & 12 & 12 & $24(=65 \%)$ \\
\hline
\end{tabular}


As can be seen in this table there were quite a lot of general practitioners and community nurses not interviewed. The reasons for this were several:

-4 times the patient did not allow us to interview the general practitioner; for the community nurse this was 5 times the case

- 6 times the general practitioner refused cooperation;

1 community nurse refused

- once the patient had never seen the general practitioner; for the community nurse this was 8 times the case

- 1 interview with a general practitioner and 3 with community nurses did not give any information at all.

Phase 2

Phase 2 of the study started in the spring of 1986. From that time on we approached every newly admitted patient in the three categories described in chapter 3 .

For the spinal cord injury group (SC) selection criteria were: not younger than 16 years and having an acute spinal cord lesion, which is unlikely to progress. The criteria for the patients with ankylosing spondylitis (AS) were: not younger than 16 and having a proven diagnosis of AS. For the patients with rheumatoid arthritis (RA) we used comparable criteria: not younger than 16 and having a proven diagnosis of classical RA. For all three categories it had to be the first admission to a rehabilitation centre.

We had a maximum period of one and a half years to let new patients enter the study. We started with the SC and RA groups. For the AS group we started half a year later. The reason for starting in phases was of a practical nature: we wanted to be sure that the large number of interviews could be organised and carried out with the available research team.

A special remark must be made regarding the RA group: contrary to our expectations and figures from earlier years the number of new RA patients admitted was low. Therefore we decided, in the spring of 1987, to approach RA patients from a rheumatological clinic nearby. This clinic cooperates very closely with the rehabilitation centre, and the treatment of patients in this clinic is roughly comparable to the treatment in the rehabilitation centre. They use, for example, the same exercise programme, developed by physiotherapists of both clinic and centre together. The two subgroups of RA patients obtained in this way are of course not completely equal. They differ with respect to some of the social-demographic variables and also with respect to characteristics of the disease. In appendix $V$ both subgroups are described in terms of social-demographic and disability-related characteristics. The patients in the rehabilitation centre tend to have a slightly higher level of disability, more often another disease and especially a longer disease-duration. In 
this group there are relatively more men, more patients live alone and the educational level is slightly higher; the net family income is a bit lower and they are a few years younger. These differences are not very impressive. We therefore consider it justifiable to treat these two subgroups as one in this study. They do not differ with respect to the course of functioning; in the groups of patients distinguished in chapters 8 and 9 both subgroups are equally distributed.

In the period mentioned there were 145 patients who met our criteria. After consulting the rehabilitation specialist, ten of these patients were not approached because of severe psychosocial problems (for example spinal cord lesions due to attempted suicide). The interviews were rather penetrating and possibly confronting. We felt that we could not guarantee sufficient support and counselling in the event serious problems would rise during or following the interview.

The remaining 135 patients were approached personally by one of the researchers, after they had been generally informed by the rehabilitation staff. After the talk with the researcher they received a letter with information on the design and purposes of the study. One or two days later they were asked for an answer. Of these 135 patients 26 did not want to cooperate. In table 5.2 the figures on non-response are given, specified for each patient category.

Table 5.2

Non-response of patlents in phase 2 lor the three palient categories

$\begin{array}{llll}\text { meeting the } & \text { not approached } & \text { non- } & \text { actual } \\ \text { criteria } & \text { because of } & \text { cooperation } & \text { partici- } \\ & \text { severe psycho- } & & \text { pation } \\ & \text { soc. problems } & & \end{array}$

AA RC

30

9

21

RA clinic

22

4

18

AS

48

3

7

38

SC

45

7

6

32

145

10

26

109

Table 5.2 shows that $75 \%$ of the patients meeting the criteria participated in the study, or $81 \%$ of the patients asked to cooperate. This is satisfactory. We do not know much about the noncooperative group. Our impression is that they 
are mostly people with psychosocial difficulties, who were afraid to reveal too much. We are, however, not certain if this was the reason. It is an impression gained during our short talks when asking the patients to cooperate.

As in phase 1 we asked the patients to allow us to approach their general practitioner and the community nurse working in the neighbourhood in which the patient lived. When the patient agreed to this, the general practitioner and/or community nurse received a letter with information about the project, and the request to cooperate. We also approached the rehabilitation nurse who was closest to the patient, and asked the rehabilitation specialist to fill in the questionnaire mentioned in chapter 4 . The two social network members named by the patient as most important to him or her, were, if the patient agreed, approached by telephone or personnally.

In table 5.3 the numbers of different interviews held at the first assessment of phase 2 in the three patient categories are given.

\begin{tabular}{|c|c|c|c|c|c|}
\hline \multirow[t]{2}{*}{ Table 5.3} & \multicolumn{5}{|c|}{$\begin{array}{l}\text { Numbers of interviews held in phase } 2 \text { tor the three patient calegories (first: } \\
\text { assessment) }\end{array}$} \\
\hline & & RA & AS & $\mathrm{SC}$ & Total \\
\hline patients & & 39 & 38 & 32 & 109 \\
\hline \multicolumn{2}{|c|}{$\begin{array}{l}\text { rehabilitation specialist/ } \\
\text { rheumatologist }\end{array}$} & 37 & 38 & 30 & $105(=96 \%)$ \\
\hline \multicolumn{2}{|c|}{ rehabilitation nurses } & 36 & 35 & 31 & $102(-94 \%)$ \\
\hline \multicolumn{2}{|c|}{ general practitioners } & 31 & 29 & 30 & $90(=83 \%)$ \\
\hline \multicolumn{2}{|c|}{ community nurses } & 30 & 24 & 23 & $77(=71 \%)$ \\
\hline \multicolumn{2}{|c|}{ person 1 from social network } & 22 & 22 & 23 & $67(=62 \%)$ \\
\hline \multicolumn{2}{|c|}{ person 2 from soclal network } & 19 & 17 & 16 & $52(=48 \%)$ \\
\hline
\end{tabular}

We are satisfied to have reached more general practitioners than in phase 1 ( $83 \%$ instead of $68 \%$ ). We have no obvious explanation for this difference. Noncooperation by general practitioners was for different reasons: in two cases the patient did not want us to approach the general practitioner, two others did not know the patient, one had been admitted to a hospital, the remaining 14 refused cooperation, mostly citing shortage of time as a reason.

The number of community nurses interviewed is relatively low, although higher than in phase 1. The difference between both phases can be easily explained: in phase 1 we only approached the community nurse if the patient 
had ever had contact; in phase 2 we approached the community nurse as a rule. The relatively large percentage of noncooperating nurses is mainly due to the office in one region nearby; here we were not allowed to approach any nurse. This led to 13 missing interviews. The remaining cases of noncooperation had the following reasons: in two cases the patient did not want us to approach the community nurse, in $\mathbb{1 1}$ cases the nurse did not know the patient, in five cases we could not find out who the responsible nurse was, one refused to cooperate.

The low percentage of social network members is in all cases due to the fact that the patient did not want us to talk to these persons, mostly because he or she did not want to overburden them. As a rule we did not push too hard to change this.

The missing information from the rehabilitation specialists and nurses is due to practical or organisational problems in the centre. Sometimes it took several weeks before an appointment could be made. When more than 2 weeks late, we considered the information missing.

The numbers of interviews given in table 5.3 posed an important problem for our study: when combining data from different interviews regarding the same patient in one analysis, we have a constantly fluctuating number of cases. Really complete sets of data are rare in our study.

\subsection{A description of the research populations in terms of social- demographic and disability-rellated characteristics}

Paragraph 5.1 described the selection criteria and gave the numbers of patients participating. To give an idea of what sort of patients we are dealing with in this study, the populations are now described in terms of the socialdemographic variables mentioned in the research model in chapter 3 and some characteristics of the disability. The aspects described are:

- age

- sex

- marital status

- socio-economic status (educational level and family-income are described separately)

- objective level of disability

- complicating diseases

- duration

- evaluation of physical functioning by the patient.

The figures are given for the different patient categories seperately and for the total groups in both phases of the study. 
Social-demographic characteristics:

In table 5.4 the patient populations of both phase 1 and 2 are described in terms of age, sex, marital status, educational level and net family-income. Although the number of patients is low some of the figures are presented in percentages. This is done to make a comparison more easy and to reduce the number of figures in the table.

Table 5.4

Social-demographic characteristics of the palient populations in both phases of the
study

Phase 1

Phase 2

\begin{tabular}{|c|c|c|c|c|c|c|c|}
\hline & $\begin{array}{l}R A \\
(N=16)\end{array}$ & $\begin{array}{l}S C \\
(N=21)\end{array}$ & $\begin{array}{l}\text { Total } \\
(N=37)\end{array}$ & $\begin{array}{l}R A \\
(N=39)\end{array}$ & $\begin{array}{l}\text { AS } \\
(N=38)\end{array}$ & $\begin{array}{l}S G \\
(N=32)\end{array}$ & $\begin{array}{l}\text { Total } \\
(\mathbb{N}=109)\end{array}$ \\
\hline $\begin{array}{r}- \text { mean age } \\
\text { (+ range })\end{array}$ & $\begin{array}{l}57.7 \\
(35-73)\end{array}$ & $\begin{array}{l}38.7 \\
(17-72)\end{array}$ & $\begin{array}{l}47.6 \\
(17-67)\end{array}$ & $\begin{array}{l}51.9 \\
(17-77)\end{array}$ & $\begin{array}{l}36.9 \\
(21-61)\end{array}$ & $\begin{array}{l}35.1 \\
(16-76)\end{array}$ & $\begin{array}{l}41.8 \\
(16-77)\end{array}$ \\
\hline$-\%$ male & $25 \%$ & $83 \%$ & $56 \%$ & $31 \%$ & $66 \%$ & $81 \%$ & $58 \%$ \\
\hline $\begin{array}{l}\text { - \% married } \\
\text { and/or living } \\
\text { together }\end{array}$ & $63 \%$ & $58 \%$ & $54 \%$ & $71 \%$ & $76 \%$ & $53 \%$ & $67 \%$ \\
\hline $\begin{array}{c}\text { - mean educa- } \\
\text { tional leve|* }\end{array}$ & 2.1 & 3.1 & 2.6 & 2.1 & 3.3 & 3.0 & 28 \\
\hline $\begin{array}{l}\text { - mean family } \\
\text { income } \\
\text { (monthly) }\end{array}$ & $\begin{array}{l}2131- \\
(360- \\
3900)\end{array}$ & $\begin{array}{l}1855-- \\
(300- \\
3100)\end{array}$ & $\begin{array}{l}1993,- \\
(300- \\
3900)\end{array}$ & $\begin{array}{l}1954,- \\
(1094 \\
3700)\end{array}$ & $\begin{array}{l}2260_{1}^{-} \\
(700- \\
4500)\end{array}$ & $\begin{array}{l}2250- \\
(1100- \\
5000)\end{array}$ & $\begin{array}{l}2148- \\
(700- \\
5000)\end{array}$ \\
\hline
\end{tabular}

* In phase 1 we used slightly different categories from those in phase 2. Therefore these figures are not exactly comparable. To give an impression it is, however, sufficient.

Table 5.4 shows that the different patient categories differ in many respects and that within each group there is a wide range of age and socio-economic status. The variables sex and marital status show a good differential in the total groups.

There are some differences between the comparable patient categories in phase 1 and phase 2. The RA and SC groups in phase 1 are somewhat older than those in phase 2, and there are small differences in the percentage of patients living alone and in average family income.

Disability-related characteristics:

Tables 5.5 and 5.6 give information on some characteristics of the disability of the different patient categories in both phases of the study. 
Table 5.5 Disabillty-related characteristics of the patieni populations in both phases of the study

Phase 1 Phase 2, first assessment

\begin{tabular}{|c|c|c|c|c|c|c|c|}
\hline & RA & $\mathrm{SC}$ & Total & RA & AS & SC & Total \\
\hline $\begin{array}{l}\text { - mean duration } \\
\text { (weeks) }\end{array}$ & $\begin{array}{l}1047 \\
104 \\
2132)\end{array}$ & $\begin{array}{l}357 \\
(104- \\
3068)\end{array}$ & $\begin{array}{l}655 \\
(104 \\
3068)\end{array}$ & $\begin{array}{l}530 \\
(1- \\
2028)\end{array}$ & $\begin{array}{l}485 \\
(13- \\
1300)\end{array}$ & $\begin{array}{l}6 \\
12- \\
20)\end{array}$ & $\begin{array}{l}378 \\
(1- \\
2028)\end{array}$ \\
\hline $\begin{array}{l}\text { - \% with any } \\
\text { complicating } \\
\text { disease }\end{array}$ & $63 \%$ & $33 \%$ & $46 \%$ & $36 \%$ & $37 \%$ & $38 \%$ & $37 \%$ \\
\hline $\begin{array}{c}- \text { level of } \\
\text { disability }\end{array}$ & $\begin{array}{l}15.6 * \\
(12-18)\end{array}$ & $* *$ & - & $\begin{array}{l}13.6 \\
(7-19)\end{array}$ & $\begin{array}{l}11.9 \\
(9-16)\end{array}$ & 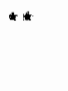 & $\begin{array}{l}R A+S A 12.7 \\
(7-19)\end{array}$ \\
\hline $\begin{array}{l}\text { - evaluation of } \\
\text { physiccal } \\
\text { functioning by }\end{array}$ & $\begin{array}{l}14.9 \\
(10-19)\end{array}$ & $\begin{array}{l}12.7 \\
(7-20)\end{array}$ & $\begin{array}{l}13.7 \\
(7-20)\end{array}$ & $\begin{array}{l}13.5 \\
(8-18)\end{array}$ & $\begin{array}{l}12.2 \\
(7-18)\end{array}$ & "nt" & $\begin{array}{l}R A+S A 12.9 \\
(7-18)\end{array}$ \\
\hline
\end{tabular}

functioning by

the patient

* Assessed by the general pracitioner and/or the community nurse (see chapter 4).

** information on height of lesions is given in table 5.6.

*** not available because at the first assessment these patients were not asked these questions; mostly they had had their lesion only for a few weeks.

Table 5.6

Height of lesion in the palient calegory with spinal cord lesion in phase 1 and 2

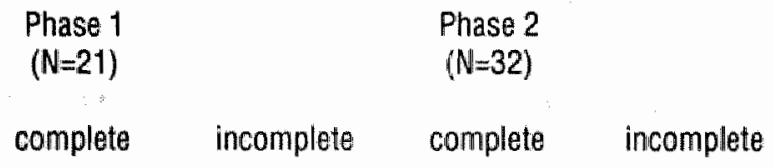

low lumbar

low thoracic

1

high thoracic

2

Iow cervical

3

mid cervical

high cervical

not to be classified

1

3

4

5

31

1

4

1

2 
Tables 5.5 and 5.6 show again large differences between the patient groups and a wide range in duration, level of disability and evaluation of physical functioning within each group. There are some remarkable differences between the groups in both phases of the study, which might be important for a correct interpretation of the results. The SC group in phase 1 has a longer history as a patient, partly explained by the fact that patients were interviewed about 1-2 years after admission. This, however, only accounts for a difference of about 100 weeks. The RA group in phase 1 also has a longer patient history and there are relatively more patients with complicating diseases. This may explain the fact that they assess their physical functioning less positively than the RA group in phase 2 . It is uncertain what the importance of these differences is for the interpretation of the results in both phases, but it is good to realise they exist.

\subsection{Drop-out during phase 2 of the study}

Executing a longitudinal study with patients almost inevitably entails the problem of drop-out. In this paragraph the size and nature of this problem in our study is described. Information is given on how many and why patients dropped out of the study. Then the drop-outs are compared with the patients cooperating longer, in terms of the same variables as shown in paragraph 5.2. Table 5.7. gives the information on number of drop-outs between the subsequent assessments in phase 2.

Table 5.7 Drop-out during the course of phase 2 of the sludy

$\begin{array}{cccccc}N & N & N & N & 3 & 4 \\ \text { at } & \text { at } & \text { at } & \text { at } & \text { assessments assessments } \\ \text { start } & \text { second } & \text { third } & \text { fourth } \\ \text { assessment } & \text { assessment } & \text { assessment } & & \end{array}$

$\begin{array}{lcccccc}\text { RA } & 39 & 36 & 27 & 24 & 27 & 21 \\ \text { AS } & 38 & 30 & 34 & 31 & 30 & 27 \\ \text { SC } & 32 & 28 & 24 & 22 & 23 & 19 \\ \text { Total } & 109 & 94 & 85 & 77 & 80 & 67\end{array}$

This table shows that at 13 we were able to interview about $78 \%$ of the starting number and at $t 471 \%$. Most drop-outs occur in the category of rheumatoid arthritis, followed by the group with spinal cord lesion. There are only 67 
patients of whom all four assessments are available. This is $62 \%$. This is the group available for complete analysis.

For a correct interpretation of the final results of the study it is important to know why people stopped and who stopped. We want to know what kind of selection occurred during the study. Therefore the drop-outs are compared with the 'stayers'. Table 5.8 gives a comparison of the patients of whom all 4 assessments are available and the drop-outs.

\begin{tabular}{|c|c|c|}
\hline \multirow[t]{2}{*}{ Table 5.8} & \multirow[b]{2}{*}{$\begin{array}{l}\text { drop-outs } \\
(N=42)\end{array}$} & \multirow[b]{2}{*}{$\begin{array}{l}\text { remaining group } \\
(N=67)\end{array}$} \\
\hline & & \\
\hline - mean age & $\begin{array}{l}48.5 \\
(16-77)\end{array}$ & $\begin{array}{l}37.5 \\
(16-76)\end{array}$ \\
\hline$-\%$ male & 60 & 57 \\
\hline $\begin{array}{l}\text {-\% married and/or } \\
\text { living together }\end{array}$ & 80 & 60 \\
\hline $\begin{array}{l}\text { - mean educational } \\
\text { level }\end{array}$ & 2.1 & 3.1 \\
\hline $\begin{array}{l}\text { - mean family-income } \\
\text { (monthly) }\end{array}$ & $\begin{array}{l}2120,- \\
(1033-5000)\end{array}$ & $\begin{array}{l}2160,- \\
(700-4500)\end{array}$ \\
\hline $\begin{array}{l}\text { - duration of } \\
\text { disability (weeks) }\end{array}$ & $\begin{array}{l}424 \\
(3-2028)\end{array}$ & $\begin{array}{l}348 \\
(1-1976)\end{array}$ \\
\hline $\begin{array}{l}\text { - \% with any compli- } \\
\text { cating disease }\end{array}$ & 45 & 33 \\
\hline - level of disability* & $\begin{array}{l}13.4 \\
(7-19)\end{array}$ & $\begin{array}{l}12.4 \\
(9-16)\end{array}$ \\
\hline $\begin{array}{l}\text { - evaluation of physical } \\
\text { functioning by the } \\
\text { patient * }\end{array}$ & $\begin{array}{l}13.6 \\
(9-18)\end{array}$ & $\begin{array}{l}12.5 \\
(7-18)\end{array}$ \\
\hline
\end{tabular}

* not available for spinal cord lesion; these figures only concern the RA and AS group.

In table 5.8 we see that the drop-outs tend to be somewhat older and less educated than the remaining group. Among drop-outs there are slightly more married people. Other important differences between both groups are the 
higher level of disability, the higher percentage of complicating diseases and a more negative self-assessment of physical functioning among the drop-outs.

The reasons for drop-out at the subsequent assessments are, as far as they

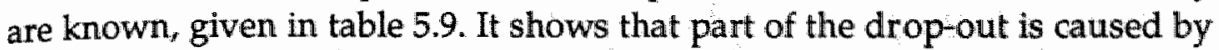
illness or severe difficulties of the patients, by death or dementia. This might explain part of the differences found in table 5.8. It is a pity that at the second assessment 5 patients were 'missed'. The reason for this was that they had been discharged without notifying the research team. The main cause for drop-out was that patients did not want to talk about their disability so intensively, especially not after discharge.

The information on drop-out during the study presented here, is in line with our impression about initial non-cooperation. It indicates that the population for the longitudinal analysis in this study consists of relatively 'good' patients. The consequences of this selection for the interpretation of the results of the study will be discussed in chapter 15 .

\section{Table 5.9 Reasons lor drop-out at subsequent assessments $(\mathrm{N}=109)$}

\begin{tabular}{|c|c|c|c|}
\hline & +2 & 13 & t4 \\
\hline - deceased & - & - & 2 \\
\hline - dementia & - & - & 2 \\
\hline $\begin{array}{l}\text { - sewere disability/ } \\
\text { illiness }\end{array}$ & 1 & 5 & $5^{\circ}$ \\
\hline $\begin{array}{l}\text { - retusal for different } \\
\text { reasons (time, intimacy) }\end{array}$ & 9 & 19 & 23 \\
\hline \multirow{2}{*}{$\begin{array}{l}\text { - administrative mistake } \\
\text { in rehabilitation centre }\end{array}$} & 5 & - & - \\
\hline & 15 & 24 & 32 \\
\hline
\end{tabular}

Until now we have only discussed the problem of drop-out among patients. Complete description of drop-out in the other categories of people interviewed would be very space-consuming. Therefore we confine ourselves to the presentation of the numbers of people in all categories interviewed at the four assessments for the three patient categories together. These figures are given in table 5.10. The reason for drop-out among the non-patient groups is mostly drop-out of the patients or the fact that patients did not want us to talk 
with others. The very low number of community nurses interviewed at the fourth assessment is caused by the fact that only a few patients appear ed to have contact with a community nurse at that time.

\section{Table 5.10 Numbers of interviews heid in phase 2, at every assessment}

\begin{tabular}{|c|c|c|c|c|}
\hline & t1 & t2 & 13 & t4 \\
\hline - patients & 109 & 94 & 85 & 77 \\
\hline $\begin{array}{l}\text { - rehabilitation specialist } \\
\text { rheumatologist }\end{array}$ & 105 & 91 & 72 & 57 \\
\hline - rehabilitation nurses & 102 & 86 & - & - \\
\hline - general practitioners & 90 & 78 & 74 & 54 \\
\hline - community nurses & 77 & 65 & 40 & 12 \\
\hline - person 11 from sacial network & 67 & 46 & 55 & 45 \\
\hline - person 2 from soclal network & 52 & 35 & 39 & 31 \\
\hline
\end{tabular}

From table 5.10 it is obvious that the problem of a fluctuating number of cases in different analyses is even greater when looking longitudinally. There are only a few cases in which a complete data-set is available. 


\section{PART II}

\section{A retrospective analysis}

In the second part of this book, the results of the first phase of the study are presented. Chapter 6 describes the results regarding the experienced course of functioning after discharge. In chapter 7 the relationships between the independent variables in the research model and the course of functioning as experienced by the patients are investigated.

Both chapters close with some tentative conclusions, to be confirmed or rejected in part III.

The 'quick' reader may skip this part. The most important results are summarised again in chapter 14 in part III and also in the final discussion in part IV. 



\section{CHAPTER 6}

\section{Functioning of patients after discharge}

The first question to be answered in this study concerns a description of the course of daily functioning of patients after clinical rehabilitation. We want to know to what extent patients succeed in maintaining the functional level they reached in the rehabilitation centre. In this chapter the results from the first phase of the study regarding this question are presented. The data presented were obtained retrospectively. They concern the experienced change in functional status after discharge from the rehabilitation centre. Paragraph 6.1 presents data from the patients themselves, whereas paragraph 6.2 deals with the view of the health professionals interviewed and the social network members.

\subsection{The view of the patient}

As described in paragraph 4.3 , the patients were asked in this phase of the study to compare their functional status at the time of assessment with their functioning at the time of discharge from the centre a half to one and a half years before. Patients were asked to assess the following aspects of functioning: hindrance in daily activities, general health, physical functioning, social 
contacts and being able to cope with daily practical problems as a result of the disability. Answering possibilities ranged from 'much worse' to 'much better'. Table 6.1 specifies the answers of the patients for both diagnostic categories, and also presents the sumscores of the total group on the two scales described in chapter 4 (page 41 ).

Talle 6.1

Self-assessmenl of the course of functionino since discharpe for RA and SC patients a hall to one and hall years alter discharge

much worse the better much
warse

\begin{tabular}{|c|c|c|c|c|c|c|}
\hline \multirow[t]{3}{*}{$\begin{array}{l}\text { hindrance in } \\
\text { activities }\end{array}$} & $\begin{array}{l}\text { total group } \\
(N=37)\end{array}$ & 8 & 10 & 5 & 10 & 4 \\
\hline & $\mathrm{RA}(\mathrm{N}=16)$ & 3 & 6 & 4 & 2 & 1 \\
\hline & $\mathrm{SC}(\mathrm{N}=21)$ & 5 & 4 & 1 & 8 & 3 \\
\hline \multirow[t]{3}{*}{ general health } & total group & 1 & 9 & 20 & 4 & 3 \\
\hline & RA & & 5 & 9 & 2 & \\
\hline & SC & 1 & 4 & 11 & 2 & 3 \\
\hline \multirow{3}{*}{$\begin{array}{l}\text { physical } \\
\text { functioning }\end{array}$} & total group & 3 & 11 & 12 & 9 & 2 \\
\hline & RA & 3 & 4 & 6 & 3 & \\
\hline & $\mathrm{SC}$ & & 7 & 6 & 6 & 2 \\
\hline \multirow[t]{3}{*}{ social contacts } & total group & 1 & 2 & 28 & 5 & 1 \\
\hline & RA & & & 13 & 2 & 1 \\
\hline & SC & 1 & 2 & 15 & 3 & \\
\hline \multirow{3}{*}{$\begin{array}{l}\text { being able to } \\
\text { cope with } \\
\text { daily practical } \\
\text { problems }\end{array}$} & total group & 2 & 5 & 17 & 10 & 3 \\
\hline & RA & & 3 & 8 & 4 & 1 \\
\hline & $\mathrm{SC}$ & 2 & 2 & 9 & 6 & 2 \\
\hline & & average & std. dev. & range & & \\
\hline \multirow{2}{*}{\multicolumn{2}{|c|}{$\begin{array}{l}\text { physical sumscore } \\
\text { psychosocial sumscore } 6.3\end{array}$}} & 8.6 & 3.0 & $4-15$ & & \\
\hline & & 1.4 & $2-9$ & & & \\
\hline
\end{tabular}

The table shows that, in both patient categories and for every aspect of functioning asked for, there are both patients who experience a deterioration and those experiencing an improvement in functioning. As expected, there are a 
considerable number of patients experiencing some degree of deterioration in physical and/or psychosocial aspects.

Among the patients with a spinal cord lesion there are about equal numbers of patients with deteriorated and improved conditions. Among the arthritics deterioration seems to prevail, especially on the physical aspects. This could be expected given the generally progressive character of rheumatoid arthritis. The fact that people with spinal cord injuries report deterioration as well, however, suggests that the deterioration found in the rheumatic group is not likely to be caused by progression of the disease alone. After all, a spinal cord lesion generally causes a stable disability.

It is striking that in both groups most change is reported on the physical aspects of functioning; the psychosocial aspects are mostly stable or subject to positive change. It is especially the fact that only very few patients report a deterioration on being able to cope with daily practical problems' which indicates that in general patients succeed fairly well in living with their disabilities.

When using the sumscores as criteria for the course of functioning, there appear to be 18 patients reporting some degree of deterioration in physical functioning ( $49 \%$ ) versus 13 reporting improvement $(35 \%)$ and 7 patients reporting psychosocial deterioration (19\%) versus 15 reporting improvement (41\%). Six report no physical change and 15 no psychosocial change.

Although we already found that two dimensions have to be distinguished when studying the experienced course of functioning (paragraph 4.3.1), it is interesting to pay more attention to the relationship between physical and psychosocial functioning at the aggregated level of the sumscores computed. Table 6.2 shows the relationship between the scores on the two scales.

Table 6.2

Relalionship between sumscores of sell-assessments of the course of physical and psychosacial functioning since discharge

$\begin{array}{lll}\text { psychosocially } & \text { psychosocially } & \text { psychosocially } \\ \text { better } & \text { the same } & \text { worse }\end{array}$

$\begin{array}{lcccc}\text { physically better } & 10 & 3 & - \\ \text { physically the same } & 1 & 5 & 7 \\ \text { physically worse } & 4 & 7 & (7) \\ & (15) & (15) & \end{array}$


As could be expected, it is evident that psychosocial and physical deterioration not necessarily occur together, but also that there is a positive relationship between them. The correlation between both scales is .46. There are only four cases in which the directions of both scores really contrast (physically worse and psychosocially better).

\subsection{The view of professionals and social network members}

This paragraph focuses on the course of functioning from the point of view of the health professionals and social network members interviewed. While in 6.1 we saw that a considerable number of patients perceived some deterioration, we now investigate whether this result is supported by professional assessments and/or assessments from people who are close to the patient. The analysis is conducted at the level of the sumscores for change in physical and psychosocial functioning. Paragraph 4.3.1 already reported that the professionals and network members were presented with the same scales as used in

Table 6.3

Assessment of the course of physical and psychosocial functioning after discharge by beneral practitioners, community nurses and social network members

number of patients ${ }^{*}$

$+\quad$ - ?

physical functioning

general practitioners

community nurses

socilal network member 1

social network member 2

psychosocial finctioning

generall practitioners

communty nurses

social natwork member

social network member 2
$(\mathrm{N}=25)$

$(\mathrm{N}=20)$

$(\mathrm{N}=32)$

$(N=24)$
11

6

15

14

6

3

3

1
9

$?$

14

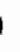

$6 \quad(2)$

8 (3) 
the patient interviews. This makes comparison easy. The only problem is the unequal number of judges in the different groups. Table 6.3 gives the results from the groups of general practitioners, community nurses and the first and second important network member.

Clearly, also in the perception of professionals involved and social network members who are close to the patient, there are a considerable number of patients physically deteriorating after discharge. Just as the patients themselves did, the psychosocial course of functioning is evaluated more positively.

\section{Table 6.4 Correlation between assessments of the course of physical and psychosocial} funclioning by different judpes
1.
2.
3.
4.

physical functioning

1. general practitioner

2. community nurse .44

3. social network member 1

4. social network member 2

.36

.70

.31

(20)

.62

(14)
.69
.89

(22)

psychosocial functioning

1. general practitioner

2. community nurse

3. social network member 1

4. social network member 2 
Because of the unequal numbers of judges the scores of the different groups are not directly comparable with each other and with the scores of the patients themselves. To investigate the degree of agreement between the different judges and the patients, we computed correlation coefficients between the scores of the different judges and the patients. These are presented in table 6.4. Statistically significant correlations are italicized ( $\mathrm{p} \leq .10)$.

The table shows that there is a relatively strong correlation between the answers of the patients and those of the social network members, especially regarding the physical aspects of functioning. The general practitioners assess the functional course very differently from the patients; regarding psychosocial functioning there is even a negative correlation. The assessments of the community nurses appear to be much closer to those of the patients. The fact that there is a strong correlation between the patients and the social network members and also the community nurse, convinces us of the credibility of the assessment made by the patients themselves of their physical functioning. This might be seen as an indication of the validity. For this reason this selfassessment has been used as an indicator for the course of functioning in the analysis later on. We feel somewhat less certain about the assessment of the psychosocial aspects.

\subsection{Some tentative conclusions}

The results presented in this chapter already allow an initial general answer to our first research question, regarding the course of functioning after discharge. We had no specific hypotheses regarding the course of functioning. We expected that there would be a considerable number of patients deteriorating after discharge from rehabilitation. The results confirm this expectation. Almost half of the patients reported some degree of physical deterioration and about $20 \%$ some degree of psychosocial deterioration; health professionals and relevant others reported similar data. We expect to find comparable results in the second phase.

It is important to conclude that on average the experienced course of functioning is not negative. Most of the patients appear to be quite successful in keeping their functional level. It is a specific group of patients who experience some deterioration. In chapter 7 we try to identify and characterize this gr oup. 


\section{CHAPTER 7}

\section{Factors related to the course of functioning after discharge}

Chapter 6 described the changes in functioning experienced after discharge from the rehabilitation centre. We saw that patients, a half to one and a half years after discharge, on average report having the same functional level as at the time of discharge, but that a considerable number experiences some degree of deterioration on one or the other aspect of functioning. This was supported by assessments of the course of functioning by social network members and community nurses. This chapter investigates the relationships between the course of functioning and the other variables mentioned in the research model. Only the course of functioning as perceived by the patient is dealt with. We want to find out what characteristics the deteriorated patients have in comparison to the stable or improved patients. In this way we try to provide partial answers to the second, third and fourth research questions. As already described in chapter 4 , we follow a typological approach for this analysis: by means of a comparison of groups of deteriorated and non-deteriorated patients we try to gain an insight into the factors which are related to the experienced course of functioning.

Although physical and psychosocial functioning appeared to be separate dimensions of functional status, we decided not to study them separately in 
this phase of the study. Chapter 6 already reported a positive correlation between the physical and psychosocial scales. Table 6.2 showed that a classiffcation into three groups (improved, unchanged or deteriorated) on the basis of both scales only rarely leads to really contrasting results. Because of the small number of patients in this phase of the study, it is not very meaningful to use a distinction of three categories for the analysis in this chapter. An analysis with two groups -unchanged or improved together versus deteriorated-is more appropriate. At that level distinguishing both dimensions does not seem very relevant. Therefore it was decided to compute a sumscore of the physical and psychosocial scales together. Cronbach's alpha of this new scale was .80 , indicating that this decision is not likely to have a strong effect on the results of the analysis of factors related to the course of functioning.

When using this 'overall' sumscore, there appear to be 15 patients experiencing some degree of improvement and 17 some degree of deterioration. Five patients experience no overall change. On average there is no change: the mean score is 14.9 with a theoretical range of 5-25 (much better-much worse).

In this chapter we shall compare the deteriorated and the improved or unchanged groups on all the variables in the research model. The comparison reveals the factors related to how patients perceive the course of functioning retrospectively. The sequence in which the variables are discussed is as follows: social-demographic variables, disability-related characteristics, personal characteristics, social network characteristics and, finally, continuity of professional care. Interrelationships between the independent variables are only discussed in passing; they are not taken into account in the analysis. Given the small number of patients such a multivariate statistical analysis does not seem very meaningful.

\subsection{Overall functioning and social-demographic characteristics}

In table 7.1 the social-demographic characteristics of both the unchanged or improved and the deteriorated group are given.

The figures speak for themselves: improvement is mainly reported by young patients and by men. Careful interpretation of this result is required, since there are only a few young women in this population. The differences in age and sex are also likely to be related to the differences in diagnoses, presented in the following paragraph (table 7.3). There are relatively fewer patients with rheumatoid arthritis in the improved or unchanged group than in the deteriorated group. These rheumatic patients are older and mainly female (see chapter 5, table 5.4). In order to examine whether age and sex are independently related to the course of functioning, the data on these variables for the 

pattenis

$\begin{array}{llll} & \begin{array}{l}\text { the same } \\ \text { or better } \\ (\mathrm{N}=20)\end{array} & \begin{array}{l}\text { worse } \\ (\mathrm{N}=17)\end{array} & \begin{array}{l}\text { significance } \\ \text { of difference }\end{array} \\ \text { mean age (years) } & 39.5 & 58.7 & \mathrm{p}=.000^{1} \\ \operatorname{sex}(\% \text { male) } & 75 \% & 35 \% & \mathrm{p}=0.036^{2}\end{array}$

socio-economic status

$\begin{array}{lrrr}\text { high } & 3 & 4 & \\ \text { middle } & 10 & 11 & \text { n.s. }{ }^{2} \\ \text { low } & 5 & 2 & \\ \text { unknown } & 2 & - & \end{array}$

marital status

RA and SC groups are given separately in table 7.2. This table shows that the significant differences observed in table 7.1 appear within each diagnostic group as well. The difference in age, however, is somewhat less obvious in the RA group, since there are really no young patients in this group (range 35-73 years). These results support expectation 2.1 , that younger people would show a more positive course of functioning. The difference in sex is in contrast to our expectation 2.2. We expected to find no relationship between sex and the course of functioning, but in both diagnostic categories men appear to experience an improvement more often.

The fact that table 7.1 shows no significant difference in socio-economic status is also somewhat surprising. We expected that high socio-economic status would be positively related to the course of functioning (2.3). The results shown here do not support this expectation.

Marital. status appears not to be related to the course of functioning, in contrast to our expectation 2.4. The results even tend in the opposite direction: people living alone tend to report a more positive course of functioning. This difference might partly be explained by differences in age between those who live alone and those who have a regular partner, but it is unlikely that such factors explain the difference completely. 
Table 7.2 Social-demographic characteristics of unchanged or improved and deteriorated patients for both diagnostic groups separately

$\begin{array}{llll}\text { RA } & & \text { SC } & \\ \text { the same } & \text { worse } & \begin{array}{l}\text { the same } \\ \text { or better }\end{array} & \text { worse } \\ \begin{array}{l}\text { or better } \\ (N=7)\end{array} & (N=9) & (N=13) & (N=8)\end{array}$

$\begin{array}{lcccc}\text { mean age } & 54 & 60 & 32 & 57 \\ \text { sex (male/female) } 3 / 4 & 1 / 8 & 12 / 1 & 5 / 3 & \end{array}$

\subsection{Overall functioning and disability-related characteristics}

Table 7.3 gives information on the diagnosis, objective level of disability, duration of the disability and complicating diseases of both the unchanged or improved and the deteriorated group.

The figures in this table show that there is no significant difference in the distribution of the diagnoses in both groups, although as already seen in chapter 6 deterioration is somewhat more prevalent in the RA group. Because the difference is not significant, we decided not to make a distinction between the two diagnostic groups for the analysis in this chapter.

Consistent with our expectation 2.5 , there is no clear relationship between the course of functioning and the level of disability. There is a significant difference in distribution, but the direction of the relation is unclear. People with relatively severe as well as people with relatively light disabilities have a greater chance of experiencing a deterioration.

\section{Table 7.3}

Disability-related characteristics of unchanged or improved and deteriorated patients

\begin{tabular}{|c|c|c|c|c|}
\hline & & $\begin{array}{l}\text { the same } \\
\text { or better } \\
(\mathrm{N}=20)\end{array}$ & $\begin{array}{l}\text { worse } \\
(\mathrm{N}=17)\end{array}$ & $\begin{array}{l}\text { significance } \\
\text { of difference }\end{array}$ \\
\hline diagnosis: RA/SG & & $7 / 13$ & $9 / 8$ & $n . s^{2}$ \\
\hline \multicolumn{5}{|l|}{ lovel af disability } \\
\hline (relatively high/ & RA & $1 / 5 / 1$ & $5 / 1 / 3$ & $p=022^{i}$ \\
\hline moderate/relatively (ow) & SO & $4 / 6 / 3$ & $3 / 1 / 4$ & \\
\hline $\begin{array}{l}\text { duration of disability } \\
\text { (inyears) }\end{array}$ & & 8.3 & 17.7 & $p=.037^{1}$ \\
\hline complicating disorders & & $35 \%$ & $59 \%$ & $n . s^{2}$ \\
\hline
\end{tabular}


Furthermore table 7.3 shows that patients who have had their disability for a long time have a greater chance of deterioration than those who have a shorter patient history; the deteriorated group is disabled for a longer time than the improved or unchanged group. This is in line with expectation 2.6.

Since we did not distinguish pre-existing diseases from those that developed after discharge, it is not clear whether the results confirm our expectation 2.7 or not. Although the difference in complicating disorders between the groups is not significant, the data suggest that complicating disorders might have a negative influence on the experienced course of functioning.

\subsection{Overall functioning and personal characteristics}

The results regarding the personal characteristics are presented in table 7.4. This table shows important differences between both groups. The improved group has a low score on the scales measuring the personality traits inadequacy and social inadequacy, and a high score on self-recognition, which is generally in line with our expectations ( $3.1 \mathrm{a}, \mathrm{b}$ and $\mathrm{c})$. The difference with respect to rigidity also accords with the expectation formulated in chapter 4 (page 42). Also in line with expectation 3.2, the improved group has a relatively high internal health locus of control and a low orientation on doctors. The difference in chance-orientation is significant as well, although not strongly.

The deteriorated group is characterised by a significantly higher external health locus of control, high inadequacy, social inadequacy, rigidity and low self-recognition.

There is also an interesting difference in self-image between the two groups: the improved group experiences less damage to the self. This confirms expectation 3.3 .

Correct interpretation of table 7.4 is strongly hampered by the fact that there are a considerable number of missing scores. In 10 out of the 37 patients there are no complete Health Locus of Control scores and for 9 patients there is no complete personality inventory as well. Missing scores mainly appear in the deteriorated group, indicating that people with a poor functional status have more difficulties answering or filling in such questionnaires (for Health Locus of Control this is even statistically significant.) How this influences the results cannot be determined. 
Table 7.4 Personal characteristics of unchanged or improved and deteriorated palienis

Personality traits

\begin{tabular}{|c|c|}
\hline $\begin{array}{l}\text { the same } \\
\text { or better } \\
(N=20)\end{array}$ & $\begin{array}{l}\text { worse } \\
(N=17)\end{array}$ \\
\hline
\end{tabular}

$\begin{array}{lccc}\text {-inadequacy } & -0.8 & 0.7 & p=010^{3} \\ \text {-social inadequacy } & -0.5 & 0.7 & p=0.049^{3} \\ \text {-rigidity } & -0.2 & 0.6 & p=0.065^{3} \\ \text {-self-recognition } & 0.4 & -0.8 & p=.007^{3}\end{array}$

Heaith locus of control

$\begin{array}{llll}\text {-internal orientation } & 22.2(\mathrm{~N}=17) & 16.2(\mathrm{~N}=10) & p=.004^{1} \\ \begin{array}{l}\text {-orientation on } \\ \text { doctors }\end{array} & 18.4(\mathrm{~N}=18) & 24.5(\mathrm{~N}=11) & \mathrm{p}=.012^{1} \\ \begin{array}{l}\text {-Chance-orientation } \\ \text { - }\end{array} & 21.5(\mathrm{~N}=17) & 25.8(\mathrm{~N}=11) & \mathrm{p}=.072^{\prime}\end{array}$

Selt-image

-percentage of self damaged

39.1

$(\mathrm{N}=17)$
62.1

$(\mathbb{N}=14)$ $p=0851$

The differences in health locus of control could be influenced by age-differences, since it is known that older people are more externally oriented (Halfens, 1985; Halfens and Philipsen, 1988). The differences here, however, are unlikely to be explained by age, because all scores presented come from patients younger than 26 years. The considerable number of missing scores originate from older patients. This also makes it unlikely that these patients would have scored much higher on the internal scale or much lower on the external scales.

The differences in personality traits are not related to social-demographic variables, because the scores used have already been corrected for such influences (see page 42).

The results presented in this paragraph suggest that the personal characteristics measured are important determinants of the course of functioning. When looking at the overall picture, they provide strong support for our expectations regarding these variables. 
Table 7.5 gives the social network characteristics of the unchanged or improved and the deteriorated group.

\section{Table 7.5 Social nelwork characteristics of unchanged or Improved and deleriorated patients}

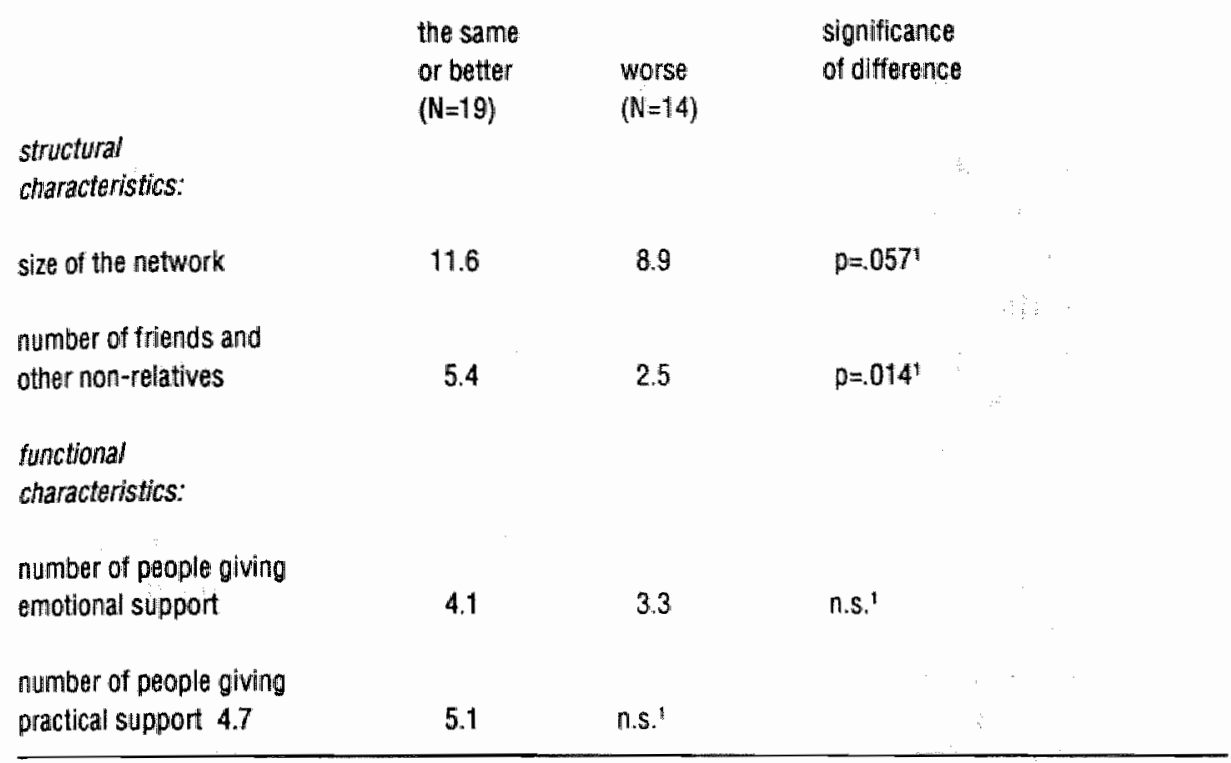

Completely in line with expectations 3.4 and 3.5, the deteriorated group has smaller networks, mainly caused by a significantly smaller number of nonrelatives. In contrast to expectation 3.6, regarding social support, there are no significant differences in functional characteristics of the network.

Interpretation of the differences found is not unequivocal. As mentioned in chapter 2 , a small network with few non-relatives $\mathrm{can}_{f}$ on the one hand, be the result of deterioration in functioning. Disability can cause changes in the balance of relationships in the sense that patients receive more than they can return. On the basis of exchange and interaction theories it could be hypothesised that family members are more likely to keep such a relationship going than non-relatives are (e.g. Adams, 1967; Bruhn, 1977; Lin, 1982; Flap, 1987; Broese van Groenou, 1989; Coleman, 1988). On the other hand, a small network with few non-relatives could be one of the factors influencing experienced deterioration, as we already discussed in chapter 2 . The difference in personality traits described in table 7.4 lends some support for such a relationship. The deteriorated group scores higher on the scale measuring social 
inadequacy. This score indicates difficulties in social relationships. It measures a personality trait which is said to be rather stable over time (Luteijn et al., 1985). This makes it likely that the smaller network already existed and is one of the causes or risk factors for experienced deterioration. Regrettably we cannot investigate the direction of the relationship. For the moment we presuppose that both explanations are true.

\subsection{Overall functioning and continuity of professional care}

The last group of independent variables in our research model are the carerelated variables. Four different aspects were distinguished, together indicating the degree of continuity of professional care. Table 7.6 gives the results on three of these aspects. The fourth, agreement on tasks and duties, is not available for this phase of the study. The table presents the measures described in chapter 4 , together with some additional information.

The figures in this table cannot be easily interpreted. Patients in the deteriorated group have more frequent contacts with slightly more different professionals than patients in the unchanged or improved group. It is not obvious that there are more coordinating contacts between professionals involved, also not when the number of contacts that took place is related to the number of contacts considered necessary or advisable.

The figures regarding agreement between patients and professionals about functional status show no significant difference at all. Only the number of cases in which a community nurse is involved is higher in the deteriorated group.

With respect to patient satisfaction too, no significant differences appear. The patients in the deteriorated group seem to be more satisfied with care. This is likely to be at least partly explained by differences in age and the degree of dependence on professional care; it is known that older people in general are more satisfied with care than younger people and that people who are more dependent on professionals tend to answer more positively to questions about their satisfaction with care (Visser, 1984). Since the deteriorated group is much older than the improved, and consists of patients evaluating their functioning as worse, this means that the differences observed are unlikely to be related to the course of functioning. In the age-group below 26 years the improved or unchanged group indeed has exactly the same average score on satisfaction and gives the same average report mark. In the group older than 26 the numbers are too small to be interpretable.

In sum, we conclude that the figures in table 7.6 give no support for a relation- 


$\begin{array}{lll}\text { the same } & \text { physically } & \text { significance } \\ \text { or better } & \text { worse } & \text { of difference } \\ (N=20) & (N=15) & \end{array}$

Coordination between care-providers

number of professionals involved

n.s.

number of professionals contacted

more than once

coordinating contacts:

-no contacts necessary

-no contacts

-same degree of communication

-total degree of coordination**

ffor those cases in which some

contact was considered necessary)

-no information available

$6 \quad 1$

$4 \quad 6$

8

n.s. ${ }^{2}$

number of cases in which there were contacts between rehabilitation centre and primary care

\section{Agreement between patient and} professionals about functioning

patient - general practitioner number of cases in which disagreement could not be computed

average disagreement

patient - community-nurse number of cases in which disagreement could not be computed

average disagreement

patient satisfaction with care

satisfaction with care since discharge

report mark for care since discharge

* for a description of the measures used see chapter 4 , paragraph 4.3.2.3.

* number of pairs of professionals between whom a contact took place, divided by the number of pairs between whom a contact is considered desirable or advisable. 
ship between care-related factors and functional deterioration or improvement. However, they are also not really in conflict with our expectation 3.7. Interpretation of the results is hampered by the fact that some of the measures cannot always be computed. We think we have insufficient information to reject or to confirm our expectation.

When looking at the figures in table 7.6 as a description of aspects of care for the whole population, ignoring the differences between the two groups distinguished, they do not give a very positive picture. Only in 16 of the 26 cases in which any contact between professionals could be considered necessary did a contact actually take place. The total number of contacts between professionals related to the total number of necessary or advisable contacts, gives an average percentage of only $21 \%$. In only 6 out of 35 cases was there a personal (telephonic) contact between professionals from the rehabilitation centre or hospital and primary health care workers. The figures on agreement fit into this not very positive picture. The average absolute difference between patients and general practitioners as well as community nurses on the sumscore measuring the evaluation of physical functioning is 2.2. The corr elation between the patient-assessment and the assessment of the general practitioners is .51, for the community nurse this is .48. Cohen's Kappa between the evaluation by the patient and the general practitioner of the four specific aspects constituting the sumscore ranges from .16 for severity to .37 for physical functioning. For the community nurses this measure varies from -.21 for hindrance to .22 for severity. These figures indicate that there is a quite large communicative distance between professionals and patients. In the light of these data it is not very surprising that 22 patients complained about the care they received. The most frequent complaints concern an experienced lack of counselling and support from professional health care workers and the competent authorities' long and complicated procedures for providing aids and house adaptations. Another category of problems concerns insufficient and incorrect information from different professionals. A lack of counselling and support is also mentioned by 32 of the 56 social network members interviewed (See also De Witte et al., 1986.).

Although table 7.6 does not give clearcut answers to the question whether there is a relationship between continuity of care and the course of functioning, it does give ground for the conclusion that coordination and tuning of professional care after discharge from clinical rehabilitation is far from perfect. In part III (chapter 13) we shall elaborate further on this subject.

The fact that no clearly interpretable relationship between care-related fac- 
tors and functioning is found in this retrospective study might bedue to the fact that there is insufficient differentiation found within each factor investigated.

\subsection{A summary and some tentative conclusions}

The results presented in this chapter allow a general tentative answer to the second and third research questions. Of course the final conclusions must be

Table 7.7

A schematic summary af the results in relation to the expectalions

relationship

found?

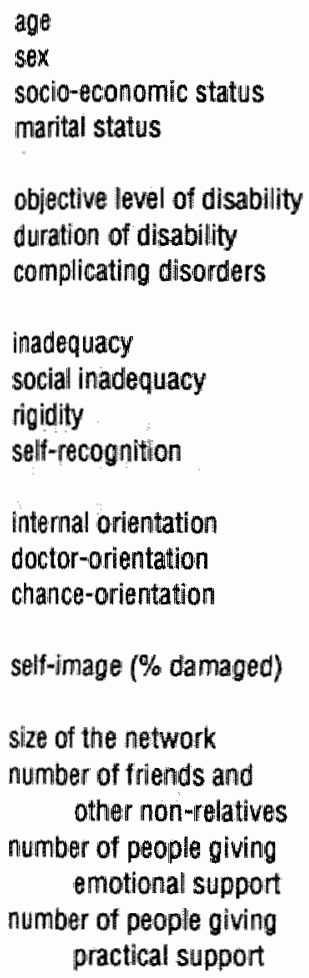

in line with expectation?

yes

ก10

no

no

yes

yes

unclear

yes

yes

yes:

yes

yes

yes.

yes.

yes

yes

yes

no

no

no 
saved until after the analyses of the data from the second phase of the study. In table 7.7 we give a schematic summary of the results from the analysis in the preceding paragraphs, in relation to the expectations. For each variable investigated we indicate whether a significant relationship to the course of functioning is found and whether this supports the expectation or not.

From this table, it is clear that patients experiencing a deterioration are in many respects different from those who give a more positive assessment of the course of functioning. In very global terms, the differences found are in line with, or at least not in contrast to, what we expected.

The results presented also give rise to some expectations with respect to our fourth research question, regarding the relative predictive value of the factors investigated for the course of functioning. We add the following expectations to the set in chapter 3 , on the basis of the results described:

4.1 Social-demographic variables play a minor role in predicting the course of functioning.

4.2 Disability-related characteristics play a minor role in predicting the course of functioning.

4.3 Personal characteristics and social network characteristics are important predictors of the course of functioning.

Another tentative conclusion to be drawn from the results discussed in this chapter is that there appear to be some problems in the continuity of care after discharge. Tuning and coordination of care seem far from optimal. A judgement of the importance of these problems for the course of functioning of patients is not possible on the basis of the data. We, however, consider them important enough to pay special attention to the description of the aspects of continuity of care in part III of this book, in order to enable a considerate judgement of the problems found in this phase of the study. 


\section{PART III}

\section{A longitudinal analysis}

In the seven chapters of this part of the book the results from the longitudinal phase of the study are presented. The first chapter (8) deals with the course of functioning, measured in different ways. Chapter 9 deals with the creation of groups of patients to be compared in the analysis later on. Chapters 10 to 13 are about the bivariate relationships of the groups of independent variables studied with different measures of the course of functioning. Chapter 14 describes a multivariate analysis with a selection of the variables described in the preceding chapters.

The 'quick' reader may skip chapters 10 to 13 or only read the summarising paragraphs. 



\section{CHAPTER 8}

\section{Functioning of patients after discharge}

As was done for the retrospective part of the study in chapter 6, we shall now describe the course of functioning after discharge from the rehabilitation centre, as measured in the prospective part of the study. This description will be restricted to the 67 patients of whom four assessments are available (see chapter 5). Figures, similar to those in chapter 6 , are presented regarding the experienced course of functioning after discharge. Changes in the self-assessment of functioning over time and changes in reported activities, measured with the Sickness Impact Profile, are also reported. In chapter 4 (page 40) it was already emphasised that at one point in time a distinction must be made between physical and psychosocial functioning. Paragraph 8.1 ther efore deals with the physical aspects of functioning and paragraph 8.2 with the psychosocial aspects. In paragraph 8.3 the relationships between the different measures of functioning employed and also between physical and psychosocial functioning are investigated, in order to gain an insight into the correspondence between the approaches of the course of functioning used, and thus into the comparability of the retrospective findings in chapters 6 and 7 and the longitudinal findings further on. The investigation of these relationships is also a necessary preliminary step to deciding how the analysis of 
factors related to the course of functioning is best performed, more specifically for the choice of the ultimate dependent variables. Paragraphs 8.1 to 8.3 all deal with the view of the patients themselves. In paragraph 8.4 the results in these paragraphs are compared with the view of the health professionals and social network members interviewed. Although the view of the patient is central in this study, it is important to know to what extent it is supported by the judgement of other people involved. In the last paragraph in this chapter (8.5), the results are briefly discussed from the perspective of the first research question and the related expectations, and from the perspective of the necessary further analyses.

\subsection{The course of physical functioning}

In chapter 4 we described the way we operationalised daily functioning. We distinguished physical and psychosocial functioning and for each of these aspects we developed three different measures. Table 8.1 summarises the available measures and gives some of their characteristics.

Table 8.2 presents the mean scores on the scale measuring the self-assessment of physical functioning, together with the scores on the physical subscale

Table 8.1 The available measures of functional status

$\begin{array}{clll}\begin{array}{c}\text { Number of } \\ \text { items }\end{array} & \begin{array}{l}\text { Thearetical Direction } \\ \text { range }\end{array} & \begin{array}{l}\text { Available } \\ \text { at }\end{array} & \begin{array}{l}\text { Alpha at } \\ \text { subsequent } \\ \text { assessments }\end{array}\end{array}$

1 Selt-assessment of physical functioning

$4 \quad 4-20$

very goodvery bald

2 Phiysical SIP score

3 Experienced change
in physical functioning
since discharge

4 Self-assessment of psychosocial functioning

5 Psychosocial SIP score

\section{Experienced change in} since discharge very bad

\section{$5 \quad 5-25$}

very good-

very bad

very good-

very bad

$2 \quad 2-10$
$45 \quad 0.100$ very good- as 1

4 4-20 much bettermuch worse

13 and 14

$.78 / .90$

assessments (for SC patients not at t1)

$.88 / .88 / .87 / .87$

$.74 / .79 / .79 / .80$

as 1

as 1

much better-

$t 3$ and $t 4$

much worse
$.69 / .76 / .74 / .70$

$.89 / .83 / .88 / .87$

$.49 / 68$ 
of the SIP and the scores on the scale measuring the experienced change in physical functioning since discharge. Results are presented for the three patient categories separately and for the total group. The data of the first assessment are not presented, since the focus of our study is on the course of functioning after discharge. There appears to be a statistically significant improvement on each measure between admission and discharge, but this is not presented in the table.

Especially at the time of discharge not everyone was able to answer all questions. In the table the number of missing scores is given between brackets. Omitting every case with one or more missing scores from the table does not alter the picture. We choose to present data from the maximum number of patients available.

Table 8.2 Physicall functioning at the subsequent assessments

\begin{tabular}{|c|c|c|c|c|c|c|c|c|}
\hline & & & 12 & t3 & 14 & $\begin{array}{l}\text { signil } \\
\text { of dif }\end{array}$ & $\begin{array}{l}\text { ince } \\
\text { ence }\end{array}$ & \\
\hline & & & & & & $12-13$ & $13-14$ & $12-14$ \\
\hline $\begin{array}{l}\text { self-assessment } \\
\text { of physical }\end{array}$ & $\begin{array}{l}\text { total group } \\
(N=67)\end{array}$ & $\begin{array}{l}\text { mean } \\
\text { st.dev. }\end{array}$ & $\begin{array}{l}10.9(8) \\
3.0\end{array}$ & $\begin{array}{r}11.6 \\
3.1\end{array}$ & $\begin{array}{c}\| 1.1(3) \\
2.9\end{array}$ & .041 & n.s. & n.s. \\
\hline & $\mathrm{RA}(\mathrm{N}=21)$ & & $12.4(5)$ & 13.2 & $12.3(1)$ & n.s. & n.s. & n.s. \\
\hline & AS $(N=27)$ & & $9.8(2)$ & 10.6 & $10.2(1)$ & .051 & n.s. & n.s. \\
\hline & $\operatorname{SC}(N=19)$ & & $11.0(1)$ & 11.2 & $11.1(1)$ & n.s. & n.s. & n.s. \\
\hline physical sub- & total group & mean & $19.7(2)$ & $20.1(2)$ & $18.5(2)$ & n.s. & n.s. & n.s. \\
\hline score of the SIP & $(N=67)$ & st.dew & 14.3 & 13.9 & 13.0 & & & \\
\hline & $R A(N=21)$ & & $26.3(1)$ & $24.8(1)$ & $23.2(1)$ & n.s. & n.s. & n.s. \\
\hline & AS $(\mathbb{N}=27)$ & & $8.8(1)$ & $9.6(1)$ & $10.8(1)$ & M.s. & n.s. & n.s. \\
\hline & $\operatorname{SC}(N=19)$ & & 27.6 & 29.3 & 24.2 & M.s. & .030 & n.s. \\
\hline $\begin{array}{l}\text { experienced } \\
\text { change after- }\end{array}$ & $\begin{array}{l}\text { total group } \\
(N=67)\end{array}$ & $\begin{array}{l}\text { mean } \\
\text { st.dew. }\end{array}$ & ** & $\begin{array}{c}12.3(1) \\
2.4\end{array}$ & $\begin{array}{l}11.8(3) \\
3.5\end{array}$ & & n.s. & \\
\hline & $\mathrm{RA}(\mathrm{N}=21)$ & & $* *$ & 12.1 & $11.6(1)$ & & n.s. & \\
\hline & $\operatorname{AS}(\mathbb{N}=27)$ & & $*$ & $12.8(1)$ & $12.6(1)$ & & n.s. & \\
\hline & $\operatorname{SC}(\mathbb{N}=19)$ & & $* * *$ & 118 & $10.7(1)$ & & n.s. & \\
\hline * T-test & & & & & & & & \\
\hline not available & & & & & & & & \\
\hline
\end{tabular}

Table 8.3 reveals a tendency of the scores of the total group to become less positive between $t 2$ and $t 3$. For the self-assessment scale this tendency is statistically significant. The average score on experienced change afterwards also indicates a slight deterioration between $t 2$ and $t 3$. This means that the 
improvement occuring during admiftance only partly endures until three months after discharge. In the long term, at $t 4$, the scores of the total group are somewhat more positive again. The differences between $t 2$ and $t 4$ are not significant. Obviously, the tendency to deteriorate after three months is only temporary, although none of the changes between $t 3$ and $t 4$ are statistically significant.

Separate analysis of the diagnostic categories reveals some important differences. At every assessment the AS group has the most positive scores. The scores of this group on the self-assessment scale are all statistically significantly lower than those of the RA group. They are not different from the SC group and the SC group does not differ significantly from the RA group, except for the third assessment. For the SIP the scores of the AS group are significantly different from both the RA and the SC group, while the latter two are not different from each other (one-way analysis of variance). The change on the self-assessment scale between $t 2$ and $t 3$ found for the whole group is only significant for the AS group, while the SC group does not show an obvious 'dip' on the self-assessment scale at t3. The results of the SIP changes are even more different for the diagnostic categories. Here only the SC group shows a functional 'dip' at $\mathrm{t} 3$, most of all caused by the SIP category ambulation. The RA group tends to improve at every assessment (especially bodycare and movement) while the AS group tends to deteriorate (also especially bodycare and movement).

The scores on the scale measuring experienced change afterwards are in the main consistent with the other results. The AS group reports the most deterioration (scores higher than 12), while the SC group, especially in the long term, has a relatively positive course (lower than 12).

For the total group table 8.2 gives a consistent picture: there is a tendency towards deterioration in the first three months after discharge, followed by a tendency to improvement again.

For this study we are not only interested in trends in the average scores. We are particularly interested in changes at an individual level. We want to distinguish patients who deteriorate from patients who succeed in keeping the functional level they reached in the rehabilitation centre, or who even improve. We therefore now look at the scores at an individual level.

Before a classification of the patients into the categories mentioned can be made, we have to define a criterion for determining whether an individual patient has changed or not. For the experienced change afterwards this is easy: a score 12 indicates no change, any higher score some degree of deterioration, any lower score some degree of improvement. 
For the self-assessment scale and the SIP we computed a standardised measure of change: the score difference between two assessments divided by the standard deviation of the average score-difference (Effect Size Index $\mathrm{d}_{\text {; }}$ Cohen, $1969,1977)$. Following Cohen, we considered a d-value of +0.5 or -0.5 as a criterion for deterioration or improvement respectively ('medium effect size'). In table 8.3 the numbers of improved, unchanged or deteriorated patients, using these criteria for change, are presented for the total group and for the three diagnostic categories separately.

Table $8.3 \quad$ Numbers of physically improved $(+)$, unchanged $(0)$ and deteriarated $(-)$ patients between the subsequent assessments afler discharge

\begin{tabular}{|c|c|c|c|c|c|c|c|c|c|c|c|c|}
\hline & & \multicolumn{3}{|c|}{$t^{2}-t 3$} & \multicolumn{4}{|c|}{$\mathrm{t} 3-\mathrm{t} 4$} & \multicolumn{4}{|c|}{$t 2-14$} \\
\hline & & + & 0 & - & $?$ & + & 0 & - & $?$ & + & 0 & - \\
\hline $\begin{array}{l}\text { self-assessment } \\
\text { of physical } \\
\text { functioning }\end{array}$ & $\begin{array}{l}\text { total group } \\
(N=67)\end{array}$ & 10 & 27 & 22 & (8) & 18 & 32 & 14 & (3) & 13 & 24 & 19 \\
\hline
\end{tabular}

$\begin{array}{lrrrrrrrrrrrr}\text { RA. }(N=21) & 3 & 7 & 6 & (5) & 8 & 7 & 5 & (1) & 4 & 4 & 7 & (6) \\ \text { AS }(N=27) & 3 & 12 & 10 & (2) & 6 & 16 & 4 & (1) & 4 & 13 & 7 & (3) \\ \text { SC }(N=19) & 4 & 8 & 6 & (1) & 4 & 9 & 5 & (1) & 5 & 7 & 5 & (2)\end{array}$

$\begin{array}{llllllllllllll}\text { physical SIP } & \text { total group } & 15 & 33 & 17 & \text { (2) } & 19 & 32 & 14 & \text { (2) } & 19 & 31 & 14 & \text { (3) }\end{array}$

score

$\begin{array}{lrrrrrrrrrrrr}\text { RA } & 6 & 10 & 4 & (1) & 6 & 8 & 6 & (1) & 8 & 6 & 5 & (2) \\ \text { AS } & 4 & 17 & 5 & (1) & 2 & 20 & 4 & (1) & 4 & 15 & 7 & (1) \\ \text { SC } & 5 & 6 & 8 & & 11 & 4 & 4 & & 7 & 10 & 2 & \end{array}$

$\begin{array}{llllllllllllll}\text { experienced } & \text { total group } & 18 & 21 & 27 & \text { (1) } & 18 & 30 & 15 & \text { (4) } & 26 & 12 & 26 & \text { (3) }\end{array}$

change after-

wards

$\begin{array}{rrrrllrrrrrr}\text { RA } & 7 & 4 & 10 & & 6 & 7 & 7 & (1) & 9 & 2 & 9 \\ \text { AS } & 3 & 11 & 12 & (1) & 5 & 15 & 5 & (2) & 5 & 6 & 15 \\ \text { SC } & 8 & 6 & 5 & & 7 & 8 & 3 & (1) & 11 & 5 & 2\end{array}$

$+=$ improved; $D=$ unichanged; $-=$ deteriorated; $?=$ unknown

This table shows, even more obviously, the same tendency as in table 8.2. Between $t 2$ and $t 3$ a considerable number of patients deteriorated, especially on the self-assessment scales. A relatively small number improved in this period. Between $\mathrm{t} 3$ and $\mathrm{t} 4$ this picture is partly reversed, and in the long term $(\mathrm{t} 2-\mathrm{t} 4)$ there are about as many improved as deteriorated patients. 
As we expected, there are a considerable number of patients deteriorating in every period. Most of them, however, keep the same functional level or even improve. These results are consistent with those in the first phase of the study. The self-assessment scales indicate a deterioration slightly more often than the SIP does.

Looking at the three diagnostic categories separately, some differences catch the eye. The AS group shows the most deterioration in the first three months after discharge, except for the changes on the SIP. Only a few patients in this group improve. They apparently experience a deterioration and feel worse, but this is not reflected in activities and behaviour. The SC group has a relatively positive course of functioning, especially in the long term. The RA group is the most stable; they, as a group, do not show an obvious tendency to change in a certain direction.

The profile found in this table is globally consistent with the figures in table 8.2. The differences between the diagnostic groups are only statistically significant for the SIP between $\mathrm{t} 3$ and $\mathrm{t} 4\left(\mathrm{Chi}^{2}=18.1 ; \mathrm{df}=4 ; \mathrm{p}=.001\right)$ and for the experienced change in the period $\mathrm{t} 2-\mathrm{t} 4\left(\mathrm{Chi}^{2}=11.4 ; \mathrm{df}=4 ; \mathrm{p}=.023\right)$. The other figures in the table are not statistically significantly different for the diagnostic categories, but the tendency is often obvious. Therefore we shall have to take the differences between the diagnostic categories into account in the analysis of factors related to the course of functioning.

\subsection{The course of psychosocial functioning}

Table 8.1 summarises the available measures of physical and psychosocial functioning. Table 8.4 presents the same data for psychosocial functioning as 8.2 did for physical functioning. The data of the first assessment are not presented here either. There is a statistically significant improvement on each measure between admission and discharge. Just as in table 8.2 there is no obvious effect on the score-pattern if the patients with one or more missing scores are omitted.

The figures for the whole group show exactly the same tendency as seen for physical functioning in table 8.2. After discharge there tends to be a 'dip' in functional status three months after discharge. Only for the self-assessment scale is this statistically significant. The dip in the SIP scores is mainly caused by the category alertness behaviour, and to a lesser extent by the category social interaction. The average score on experienced change afterwards does not indicate deterioration nor improvement between $t 2$ and $t 3$.

Separate analyses of the diagnostic categories show important dif ferences here as well. Just as for physical functioning, the AS group has relatively 
Psychosocial functioning at the subsequent assessments

\begin{tabular}{|c|c|c|c|c|c|c|c|c|}
\hline & & & & & & & & \\
\hline & & & 12 & 13 & 14 & $\begin{array}{l}\text { signifi } \\
\text { of diff }\end{array}$ & $\begin{array}{l}\text { ance } \\
\text { ence: }\end{array}$ & \\
\hline & & & & & & $+2-13$ & $13-14$ & $+2-14$ \\
\hline $\begin{array}{l}\text { self-assessment } \\
\text { of psychosocial }\end{array}$ & $\begin{array}{l}\text { total group } \\
(\mathbb{N}=67)\end{array}$ & $\begin{array}{l}\text { mean } \\
\text { st.dev. }\end{array}$ & $\begin{array}{l}9.6(5) \\
2.7\end{array}$ & $\begin{array}{l}10.9(8) \\
3.1\end{array}$ & $\begin{array}{l}10.4(2) \\
2.9\end{array}$ & .001 & n.s. & ns \\
\hline & $\begin{array}{l}\text { RA }(N=21) \\
\text { AS }(N=27) \\
\text { SC }(N=19)\end{array}$ & & $\begin{array}{r}10.6(2) \\
8.4(1) \\
10.3(2)\end{array}$ & $\begin{array}{l}11.5(5) \\
10.7(1) \\
10.6(2)\end{array}$ & $\begin{array}{l}12.1(2) \\
9.4 \\
10.2\end{array}$ & $\begin{array}{l}n . s . \\
.000 \\
n . s\end{array}$ & $\begin{array}{l}\text { n.s. } \\
.013 \\
\text { n.s. }\end{array}$ & $\begin{array}{l}\text { n.s. } \\
.046 \\
\text { n.s. }\end{array}$ \\
\hline $\begin{array}{l}\text { psychosocial } \\
\text { subscore of the }\end{array}$ & $\begin{array}{l}\text { total group } \\
(N=67)\end{array}$ & $\begin{array}{l}\text { mean } \\
\text { st.dev }\end{array}$ & $\begin{array}{l}9.2(2) \\
9.2\end{array}$ & $\begin{array}{r}9.9(1) \\
10.5\end{array}$ & $\begin{array}{l}8.5(3) \\
9.9\end{array}$ & n.s. & n.s. & n.s. \\
\hline & $\begin{array}{l}\text { RA }(\mathbb{N}=21) \\
\text { AS }(N=27) \\
\text { SC }(\mathbb{N}=19)\end{array}$ & & $\begin{array}{r}12.5(1) \\
5.8(1) \\
10.4\end{array}$ & $\begin{array}{c}13.3 \\
6.5(1) \\
10.7\end{array}$ & $\begin{array}{c}12.4(2) \\
6.9(1) \\
6.6\end{array}$ & $\begin{array}{l}\text { n.s. } \\
\text { n.s. } \\
\text { n.s. }\end{array}$ & $\begin{array}{l}\text { n.s. } \\
\text { n.s. } \\
.030\end{array}$ & $\begin{array}{l}\text { n.s. } \\
\text { n.s. } \\
.039\end{array}$ \\
\hline $\begin{array}{l}\text { experienced" } \\
\text { change after- } \\
\text { ward's }\end{array}$ & $\begin{array}{l}\text { total group } \\
(M=67)\end{array}$ & $\begin{array}{l}\text { mean } \\
\text { st.dev. }\end{array}$ & \#* & $\begin{array}{l}5.9(1) \\
0.9\end{array}$ & $\begin{array}{l}5.8(2) \\
1.2\end{array}$ & & n.s. & : \\
\hline (since discharge) & $\begin{array}{l}\text { RA }(N=21) \\
\text { AS }(N=27) \\
\text { SC }(N=19)\end{array}$ & & $\begin{array}{l}* * \\
* * \\
* *\end{array}$ & $\begin{array}{l}6.1(1) \\
5.6 \\
5.8\end{array}$ & $\begin{array}{l}6.1(1) \\
5.6(1) \\
5.7\end{array}$ & & $\begin{array}{l}\text { n.s. } \\
\text { n.s. } \\
\text { n.s. }\end{array}$ & \\
\hline $\begin{array}{ll}* & \text { T-test } \\
* * & \text { not available }\end{array}$ & & & & & & & & \\
\hline
\end{tabular}

positive scores, but the differences are much smaller than in table 8.2 and the AS group does not always have the lowest score. This indicates that, although the physical consequences of AS are relatively small, the psychosocial consequences are comparable to those of RA or a spinal cord lesion. At $\mathrm{t} 3$ there are no statistically significant differences between the diagnoses (one-way analysis of variance). At $t 2$ and $t 4$ the AS group scores significantly lower than the RA group, but not different from the SC group, except for the self-assessment scale at $\mathrm{t} 2$. At $\mathrm{t} 4$ the $\mathrm{SC}$ group scores significantly lower than the RA group.

The change on the self-assessment scale between $t 2$ and $t 3$ found for the whole group is only significant in the AS group, just as in table 8.2.

The sharp significant improvement in the SC group between $t 3$ and $t 4$ is striking, mainly in the SIP categories social interaction and alertness behaviour.

When using similar criteria for change as was done for physical functioning in paragraph 8.1, individual patients can be categorised as improved, unchanged or deteriorated. The result is presented in table 8.5 . 
Table 8.5

Wumbers of psychosoclatly improved $(+)$, unchanged $(0)$ and deferiorated (-) palients befween the subsequenl assessmenls after discharge

$+0+2+13-14$

self-assessment total group

$5 \quad 28 \quad 21 \quad(13)$

$23 \quad 23 \quad 12$

(9)

112920

of psychosocial ( $N=67)$

functioning

$\begin{array}{lrrr}\text { RA }(N=21) & 4 & 7 & 3 \\ \text { AS }(N=27) & 0 & 10 & 15 \\ \text { SC }(N=19) & 1 & 11 & 3\end{array}$

$\begin{array}{lll}5 & 2 & 8\end{array}$

$\begin{array}{llll}13 & 11 & 2 & \text { (1) }\end{array}$

$\begin{array}{llll}5 & 10 & 2 & (2)\end{array}$

$\begin{array}{rrr}4 & 6 & 7 \\ 1 & 15 & 10 \\ 6 & 8 & 3\end{array}$

$\begin{array}{llllll}\text { psychosocial total group } & 13 & 37 & 15 & \text { (2) }\end{array}$

$21 \quad 31 \quad 12$

$\begin{array}{lll}17 & 33 & 13\end{array}$

SIP score

$\begin{array}{rrrr}\text { RA } & 6 & 8 & 6 \\ \text { AS } & 3 & 19 & 4 \\ \text { SC } & 4 & 10 & 5\end{array}$

$\begin{array}{rrr}6 & 10 & 3 \\ 3 & 16 & 7 \\ 12 & 5 & 2\end{array}$

$\begin{array}{llll}7 & 6 & 5 & (3)\end{array}$

$\begin{array}{lll}4 & 15 & 7\end{array}$

$\begin{array}{llllll}\text { experienced total group } & 14 \quad 42 & 10 & \text { (1) }\end{array}$

$$
17 \quad 33 \quad 14
$$

$\begin{array}{lll}21 & 29 & 15\end{array}$

change atter-

\begin{tabular}{|c|c|c|}
\hline RA & 5 & 8 \\
\hline AS & 5 & 20 \\
\hline SC & 4 & 14 \\
\hline
\end{tabular}

668

$\begin{array}{llll}6 & 18 & 2 & (1)\end{array}$

$\begin{array}{lll}9 & 13 & 4\end{array}$

$6 \quad 10 \quad 3$

$t=$ improved; $0=$ unchanged; $-=$ deteriorated; $?=$ unknown

The figures in this table are consistent with those in table 8.4. They show the 'dip' in the self-assessment of functioning at t 3 very obviously. It is also clear that this is only the case in the AS group. The same goes for the period $t 2-t 4$. The sharp improvement of the SC group on the SIP between $t 3$ and $t 4$ is also clearly visible.

In every period there are a considerable number of patients deteriorating, although most of them are improving or unchanged. This is in line with the results in chapter 6 .

There is a striking difference between the classification on the basis of the SIP and that on the basis of the self-assessment scale: the self-assessment scale more often indicates deterioration.

There are also remarkable differences between the diagnostic categories. The SC group shows the most positive pattern, especially on the SIP. The AS group shows the most negative pattern on the self-assessment scale: many patients deteriorating between $t 2$ and $t 3$, much improvement after $t 3$, but at $t 4$ relatively many patients are worse than they were at discharge. The SIP does not show this pattern so obviously and the scale measuring experienced change afterwards even tends to give an opposite picture. This means that 
longitudinal deterioration is not evaluated as such by the AS patients. In table 8.3 we saw that the AS group experiences deterioration in physical functioning between $t 2$ and $t 3$ as well as between $t 2$ and $t 4$, which was not completely supported by the longitudinal findings. Combination of these findings suggests that in the AS group psychosocial changes are 'translated' physically when asking about change afterwards.

The differences between the diagnostic categories in table 8.5 are often statistically significant: changes in the self-assessment scale for each timeinterval presented $\left(\mathrm{Chi}^{2}=15.4,16.1\right.$ and 8.7 respectively; $\mathrm{df}=4 ; \mathrm{p}=.004, .003$ and .068 respectively), changes in the SIP for the period between $t 3$ and $t 4$ $\left(\mathrm{Chi}^{2}=13.5 ; \mathrm{df}=4 ; \mathrm{p}=.009\right)$ and experienced change afterwards for the period $t 2-t 3\left(\mathrm{Chi}^{2}=10.2 ; \mathrm{df}=4 ; \mathrm{p}=.037\right)$. This means that the differences between the diagnostic groups have to be taken into account in the analysis of factors related to the course of psychosocial functioning as well.

We now investigate the relationships between the different measures used in this chapter. In paragraphs 8.1 and 8.2 we saw that they give a globally comparable picture of the course of functioning for the whole group after discharge. There are, however, also important differences, especially when looking at specific diagnostic groups. We also saw that the pattern found for physical functioning is largely the same as that for psychosocial functioning. For the analysis of factors related to or predicting the course of functioning, it is important to know whether the two dimensions of functioning have to be distinguished or not and whether it is possible to choose one or to combine two or more of the measures used for each dimension.

In table 8.6 the correlations between the measures of functional status at the subsequent assessments are presented in what could be called a multitrait multimethod - multitime - matrix. The experienced change in functioning afterwards is left out of this table, because this is a measure of change over time; the other self-assessment scales and the SIP are measures of functional status at one point in time.

The table shows that the two measures of physical functioning as well as the two measures of psychosocial functioning are positively correlated. The mean correlations over the four assessments are .57 and .65 respectively. The SIP and the self-assessment scales are apparently not independent, but the correlation is not strong enough to say that they are interchangeable. The correlations between the physical and psychosocial measures are also (moder- 


\begin{tabular}{|c|c|c|c|c|c|c|}
\hline & & & 1. & 2. & 3 & 4. \\
\hline \multirow[t]{4}{*}{1} & Self-assessment of & $t 1$ & - & .56 & .38 & .45 \\
\hline & physical functioning & 2 & & .63 & .60 & .47 \\
\hline & & t3 & & .53 & .68 & .67 \\
\hline & & 14 & & .55 & .53 & .63 \\
\hline \multirow[t]{4}{*}{2} & Physical SIP score & & & - & .23 & .50 \\
\hline & & & & & .48 & .39 \\
\hline & & & & & .44 & .56 \\
\hline & & & & & .38 & .50 \\
\hline \multirow[t]{4}{*}{3} & Self-assessment of & & & & - & .59 \\
\hline & psychosocial funct. & & & & & .62 \\
\hline & & & & & & .67 \\
\hline & & & & & & .70 \\
\hline 4 & Psychosocial SIP score & & & & & - \\
\hline
\end{tabular}

ately) positive. They are somewhat weaker than the between-method correlations discussed before. It is striking that they differ considerably at the four assessments, indicating that the relationship between the two dimensions is not very stable or predictable.

In this study the focus is on changes in functioning over time. Table 8.7 therefore presents the correlations of change-scores between the subsequent assessments, as measured with the six available measures. This table is also structured as a multitrait - multimethod - multitime - matrix.

There appear to be only weak to moderate correlations in each block of the matrix. The between-method correlations tend to be slightly stronger than the between-dimension correlations. Within the upper right block, presenting the correlations between the two traits, the correlations on the diagonal (A1 with $B 1, A 2$ with $B 2$ and $A 3$ with $B 3$ ) are somewhat stronger than the rest. This should be expected because they represent the correlation between similar instruments. The conclusion from this table should be that both the dimensions of functioning and the three operationalisations of them ought to be distinguished in a longitudinal investigation. This has important implications for the analysis later on, as will be discussed in paragraph 8.5. 
Inter-instrument correlations of change-scores between the subsequent assessments: after discharge

(total group, pearson $\mathrm{r}, \mathrm{N}=50-64$ )

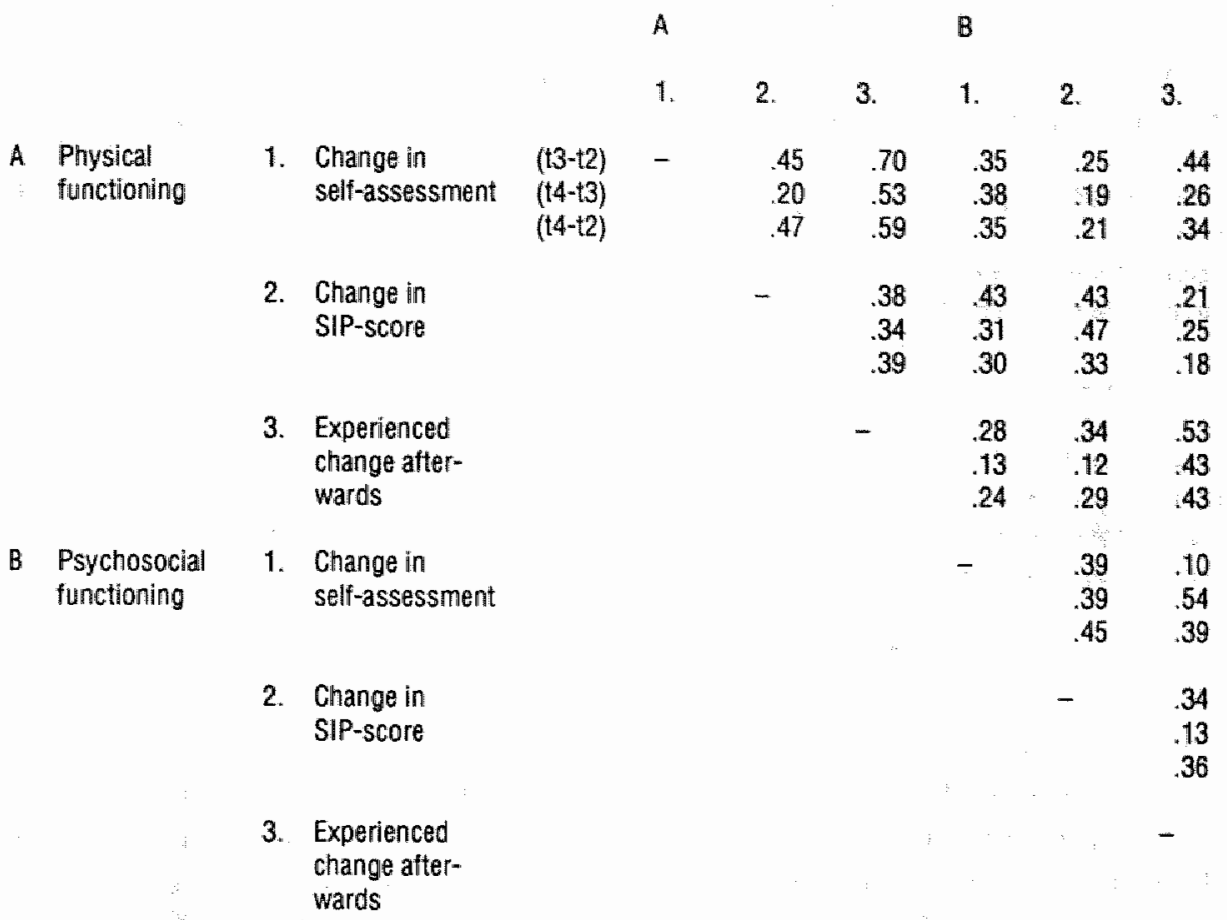

Every correlation above .20 is significant at $p<.05$.

\subsection{The view of professionals and social network members}

The preceding paragraphs dealt with the question of how patients themselves assess the course of functioning after discharge. In this paragraph we describe the view of the health professionals and social network members interviewed. The approach is similar to the one we followed in chapter 6, paragraph 6.2.

At the third and fourth assessment the professionals and network members were presented with the two scales measuring experienced change in physical and psychosocial functioning since discharge, used in the patient interviews as well (see table 8.1 and chapter 4, page 41 ). Table 8.8 gives the results from the groups of all general practitioners, community nurses, and the first and second important network members who were available at the third and fourth assessment. 
Table 8.8

Assessment of the course of physical and psychosocial functioning after discharge by general practilioners, community nurses and social network members

$12-13$

\begin{tabular}{|c|c|c|c|c|c|c|c|c|c|}
\hline $12-13$ & & & & & $12-t 4$ & & & & \\
\hline \multirow{2}{*}{$\begin{array}{l}\text { Nurnber } \\
\text { avallable }\end{array}$} & \multicolumn{4}{|c|}{ Number of patients: } & Number & \multicolumn{4}{|c|}{ Number of patients" } \\
\hline & + & 0 & - & $?$ & availabile & + & 0 & - & $?$ \\
\hline$(N=57)$ & 11 & 16 & 6 & (24) & $(\mathrm{N}=48)$ & 20 & 10 & 4 & (14) \\
\hline$(\mathrm{N}=27)$ & 5 & 4 & 2 & (16) & $(N=10)$ & 4 & 2 & 4 & - \\
\hline$(\mathrm{N}=46)$ & 17 & 11 & 18 & $-\infty$ & $(N=42)$ & 21 & 10 & 11 & - \\
\hline$(N=30)$ & 14 & 5 & 9 & (2) & $(\mathrm{N}=28)$ & 12 & 7 & 9 & - \\
\hline
\end{tabular}

Psychosocial functioning

\section{general practitioners}

community nurses

social network member 1

social network member 2

$\begin{array}{rrrrr}(\mathrm{N}=57) & 11 & 18 & 7 & (22) \\ (\mathrm{N}=27) & 5 & 6 & 1 & (15) \\ (\mathrm{N}=46) & 12 & 24 & 10 & - \\ (\mathrm{N}=30) & 11 & 13 & 5 & (1)\end{array}$

$12-14$

$(\mathrm{N}=28$
* $+=$ improved; $D=$ unchanged; $-=$ deteriorated; ? = unknown

This table shows that especially the network members assess a considerable number of patients as deteriorated. It is striking that the general practitioners and community nurses tend to be more positive. Maybe even more striking is the fact that many general practitioners and community nurses say that they do not know how the functioning of their patients has developed; they ar e not able to answer our questions regarding the course of functioning.

Because of the unequal numbers of judges the scores of the different groups in table 8.8 are not comparable. The degree of agreement between the different judges can be deduced from table 8.9. Here the correlation coefficients between the scores of the different judges and the patients are presented, again regarding the time-periods $t 2-t 3$ and $t 2-t 4$. The number of pairs for which a coefficient could be computed is given between brackets. Where less than 5 pairs were available, no coefficient is printed. Statistically significant correlations are italicized ( $\mathrm{p} \leq .10)$.

It is clear that, just as in chapter 6 , there are relatively strong correlations between the answers of the patients and those of the social network members, especially regarding physical functioning. The two network members also give consistent answers. This indicates again that the self-assessment of the patients is supported by assessments of relevant other persons who know the patient well. Just as in chapter 6 , the general practitioners assess the course of functioning quite differently from the patients. 
Table 8.9

Correlation between assessments of the course of physical and psychosoclal functioning by different judges

\section{Physical functioning}

$t^{2}-13$
$12+4$
1. 2

3. 4.

1. general practitioner

2. community nurse

3. social network member 1 $-.03 \quad .06$
0

(14) (6)

(3)

4. social network member 2

$.43-86$

(2) (21)

.46

$-\quad .75$

5. the patient

$\begin{array}{rrrr}.45 & .20 & .61 & .86 \\ (25) & (8) & (43) & (24)\end{array}$

.43

(27)

(3) (21)

$.74 \quad 63$

(8) (38)

80

Psychosocial functioning
1.
2.
3. 4.

1. general practitioner

2. community nurse

3. social network member 1

4. social network member 2

35
.79

(2) (21)

5. the patient

We decided to confine ourselves in this paragraph to the evaluation retrospectively of the course of functioning by health professionals and network members and not to compute change-scores of their assessments over a period of time. The data presented are sufficient to conclude that the assessment by the patients themselves is trustworthy. Besides, computation of longitudinal change-scores is problematic because of the fact that it was not always the same person who was interviewed at the subsequent assessments. 
With the results presented in this chapter, the answer to the first research question of this study, regarding the course of daily functioning after clinical rehabilitation as perceived by the patients, can be given. It became clear that during rehabilitation both physical and psychosocial functioning improve in each diagnostic group, but that this improvement only partly lasts until three months after discharge. The average scores indicating functional status tend to become less positive after discharge. After a longer period the average functional status tends to improve again. In spite of this rather positive longterm picture, there appear to be a considerable number of patients at the last assessment experiencing a less positive functional status than at the time of discharge, especially in the AS group. The SC group has the most positive course of functioning. These results are in line with the results of the first phase of the study, regarding the course of functioning. When averaging the results of the three measures of the course of physical functioning in table 8.3 , about $35 \%$ of the patients deteriorate between $t 2$ and $t 3$ and somewhat fewer between $t 2$ and $t 4$. For psychosocial functioning these percentages are lower, but slightly higher than expected on the basis of phase 1 of the study. For the period $t 2-t 3$ as well as for $t 2-t 4$ the percentage of patients deteriorating is slightly more than $25 \%$.

The results obtained from the patients are to a large extent supported by health professionals involved and social network members who are close to the patient.

It is important to realise that the figures presented only concern the patients of whom all assessments are available. In chapter 5 we described that this is likely to be a positive selection of the starting population. This gives reason to believe that the 'real' percentages of deteriorated patients are higher.

The 'functional dip' in the first few months after discharge indicates that this is a very critical period. It is likely that the 'dip' found in this study is a relatively positive representation of the 'dip' actually existing; it is unlikely that the deepest point of it lies exactly at three months after discharge. In the interviews three months after discharge we asked the patients to describe the course of functioning during the first month. For this purpose we presented them with a set of questions asking for an assessment of overall functioning at discharge, after 1 week, after 2 weeks, after 1 month and at the time of the interview. They were asked to give their answers on the same 5-point rating scale (very good - very bad). The answers show a slight tendency of deterioration, with the deepest point already after 1 month. Although none of these 
changes are statistically significant, they suggest that the dip found after three months is indeed not the deepest point.

Besides answering our first research question, this chapter was meant as a preparation of the analysis of factors related to or predicting the course of functioning. The results presented have important consequences for this analysis.

1. In order to gain good insight into the factors playing a part in explaining the functional 'dip' three months after discharge, found in paragraphs 8.1 and 8.2, we decided to perform two separate analyses: one for the course of functioning in the first three months after discharge $(\mathrm{t} 2-\mathrm{t} 3)$ and one for the long-term ( $t 2-t 4)$.

2. It became clear that for any analysis a distinction must be made between physical and psychosocial aspects of functioning. These two dimensions will therefore be dealt with separately.

3. It also became clear that the three different measures for these dimensions should be analysed separately as well. This, however, would implicate a series of parallel analyses, which would very likely lead to accidental and uninterpretable differences in the results. The limited scale of this study does not permit such a detailed analysis. The easiest alternative would be to choose one of the measures as the criterion variable to go on with. There are, however, no obvious grounds for arguing that one of them is the best or most valid. Therefore we decided to try to combine the results of the different approaches. On the basis of the figures in table 8.6 we consider it justifiable to make a combination of the results from the self-assessment scale and the SIP for both physical and psychosocial functioning. The precise implementation of this approach will be described in the following chapter. The results of the scales measuring experienced change afterwards will be studied separately. In this way we still have to perform a series of parallel analyses, but the number is restricted as far as possible. The final conclusions will be based upon a combination of the results.

4. The differences between the diagnostic categories regarding the course of functioning have to be taken into account in the analysis.

The decisions mentioned above mean that for the analysis of factors related to the course of functioning, four parallel approaches with different dependent variables will be followed, once for the course of functioning the first three months after discharge and once for the long-term course. 



\section{CHAPTER 9}

\section{Creating groups for the further analysis}

To study the role of the independent variables in our research model in explaining the course of functioning after discharge, we decided to follow a typological approach. We intended to compare the group of patients who did not succeed in keeping the functional level they had at discharge with the group who did and with the group who even improved, in a similar way to that in chapter 7 . In chapter 8 , however, we reported some problems that have to be solved before creating groups of patients suitable for such an analysis. The first problem is that of the differences between the diagnostic groups: when 'simply' making groups of improved, unchanged and deteriorated patients, as in tables 8.3 and 8.5 , some of the diagnostic groups are significantly over- or underrepresented in one or more of the groups created. This makes it difficult to distinguish whether a certain difference found in the analysis is related to the course of functioning or is a characteristic of a diagnostic group. Since we are interested in general factors related to and predicting the course of functioning, independent of the diagnosis, it is necessary to cr eate groups in which the diagnostic categories are equally represented.

The second problem to be solved is the combination of the results from the self-assessment scale and the SIP for both physical and psychosocial functioning. 
A possible third problem, not yet mentioned, is that of the almost inevitable phenomenon of regression to the mean: as almost always in longitudinal research, patients with a good functional status will tend to become worse while patients starting very negative have a greater chance of becoming better.

In this chapter we first examine the phenomenon of regression to the mean. We investigate whether it exists and, if so, to what extent (paragraph 9.1). In 9.2 we deal with the problem of the differences between the diagnostic categories. Paragraph 9.3 deals with the combination of the self-assessment sicales and the SIP.

In paragraph 9.4 we give a brief summary and we describe the approach for the following chapters.

\subsection{Regression to the mean}

As already mentioned, the phenomenon of regression to the mean is an almost inevitable occurence. The effect nearly always exists in longitudinal research and can be simply explained: someone who has only a little money cannot lose much. There is no evident solution for this essentially statistical problem. The effect exists and can be considered as belonging to real life. It is, however, important to know how strong it is and what role it plays in interpreting the results of a study.

For our study this is particularly important, since it is likely to interfere with the differences between the diagnostic groups. In chapter 8 we saw that the AS group initially has the most positive scores and that it is also the group with the most negative course of functioning.

Table 9.1 presents the correlations between the initial scores $(t 2)$ and the change-scores on the self-assessment scales and the SIP for the periods $t 2-13$ and $\mathbf{t 2}-\mathrm{t} 4$. It also presents the correlations between initial scores and the scores on the scales measuring the evaluation of change afterwards, at $t 3$ and $t 4$. The figures very obviously show a regression-effect for the longitudinal changescores: the course of functioning is negatively correlated with the initial scores, especially for long-term functioning. This means that positive scor es become worse and vice versa. The effect does not exist for the assessment of the course of functioning afterwards.

The regression-effect is too evident to be ignored. Since it is likely to interfere with the differences between the diagnostic groups, we shall examine it again after having eliminated these dif ferences and combined the results from the SIP and the self-assessment scales in the following paragraphs. 


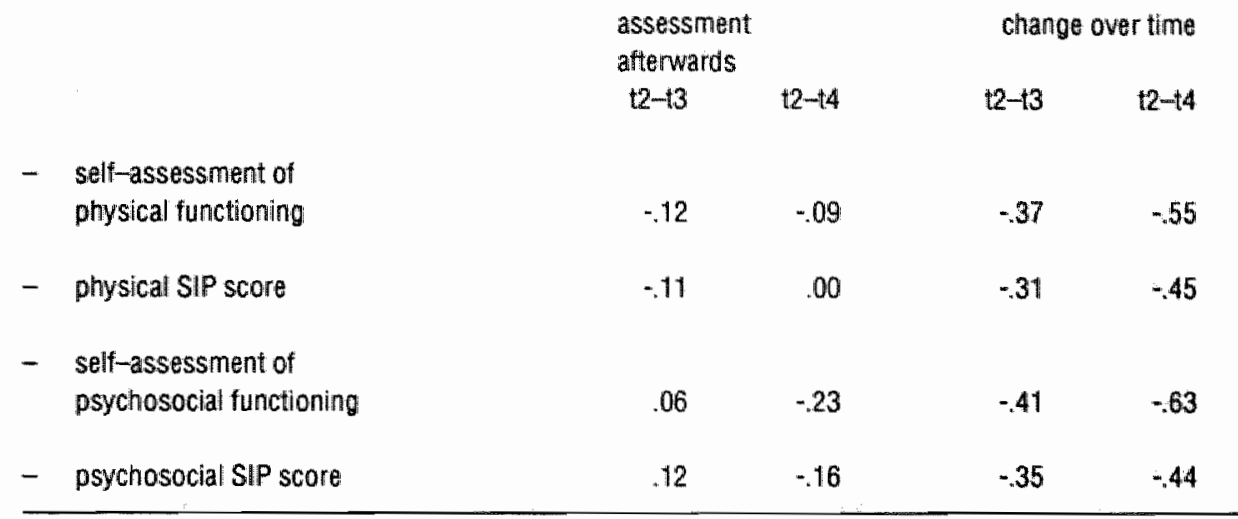

In order to create groups with an equal distribution of the diagnostic categories involved in this study, we decided not to use the tripartite division into improved, unchanged and deteriorated patients, presented in chapter 8 . We made a relative three-way partition instead. Within each diagnostic group we tried to create three equally sized groups of patients, on the basis of the difference-scores between the subsequent assessments. Thus we obtained three groups within each diagnostic group separately: a group with a relatively positive functional course, a group with a relatively negative course and an 'average group'. Of course this was done for every measure available. After having done this for each diagnostic group separately, the diagnostic groups were put together again. Because scores on the different scales tend to group around certain values, especially the scores on the two scales measuring experienced change afterwards, a perfectly equally sized three-partition was not always possible. The procedure, however, resulted in a tripartite division with no significant differences between the diagnostic groups, except for experienced change in psychosocial functioning the first three months after discharge. This is the only scale for which it was impossible to create equally sized groups within each diagnostic category.

The result is shown in table 9.2. The tripartite divisions on the basis of the self-assessment scales and the SIP are to be combined in paragraph 9.3. The three-way partitions on the basis of the scales measuring experienced change afterwards are to be used in the analysis further on. Patients with a missing score are classified into the average group. 
Table 9.2

$A$ relative three-way partition of he patients on the basis of change-scores for each availlable measure

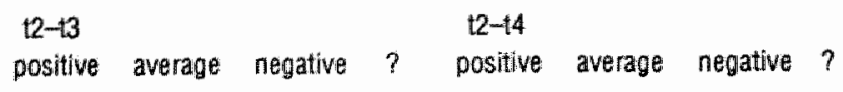

Self-assessment of

physical functioning

$17 \quad 20 \quad 22$

(8) 15

$22 \quad 19$

Physical SIP score

$22 \quad 20 \quad 23$

(2) 22

21

22

Experienced change

afterwards (physical)

$\begin{array}{lll}28 & 15 & 23\end{array}$

(1) 19

23

22

Self-assessment of

psychosocial func-

tioning

14. $22 \quad 18$

(13) 16

22

22

Psychosocial SIP score

$\begin{array}{lll}22 & 24 & 19\end{array}$

(2)

20

23

20

Experienced change

alterwards

14

$42 \quad 10$

(1)

21

29

15

(psychosocial)

Table 9.2 shows another advantage of this procedure instead of the tripartite division in chapter 8 , namely the fact that the groups created have a reasonable size which is useful for the analysis. Given the small number of patients available for the analysis, this is not unimportant.

\subsection{Combining the self-assessment scales and the SIP}

The tripartite divisions described above on the basis of the self-assessment scales and on the basis of the SIP-scores were combined into one new threeway partition, using the scheme given in table 9.3.

This was done separately both for psychosocial functioning and for the periods $12-t 3$ and $t 2-t 4$. Missing scores on either one of the instruments were classified into the average group before combining the classifications. In this way we are able to classify every patient in the study. Table 9.4 gives the final numbers of patients in each group.

After having created this new three-way partition we again checked for differences between the diagnostic groups. There appeared to be no significant differences. 
SIP score

positive average negative

self-assessment

$\begin{array}{llll}\text { positive } & \text { positive } & \text { positive } & \text { average } \\ \text { average } & \text { positive } & \text { average } & \text { negative } \\ \text { negative } & \text { average } & \text { negative } & \text { negative }\end{array}$

Table 9.4

Final classification of patients into groups wilh a relatively positive, negalive or average functional course, on the basis of a combinalion of the SIP and the seltassessment scores

$\mathrm{t} 2-\mathrm{t} 3$
positive average negative $\quad \stackrel{12-14}{ }$ positive average negative

physical functioning

24

18

25

22

21

24

psychosocilal functioning

$23 \quad 23 \quad 21$

23

19

25

The procedure described in a way forces the patients into three distinct groups, assuming that these groups have a different functional course. This is, however, not certain, since the three-way partition is based on a relative criterion. We therefore now investigate whether the groups created actually have a different course of functioning. This is shown in table 9.5. This table shows the scores of the groups created on the self-assessment scales and the SIP at the subsequent assessments.

It is obvious that the three-way partitions made really distinguish people with a relatively positive, negative or average course of functioning. The only possibly doubtful case is the 'average' group for psychosocial functioning over the period $t 2-t 3$. Here the self-assessment score indicates significant deterioration and the SIP a tendency to improvement. Compared with the other groups, however, this group has an average position. The figures in this table indicate that the combination of the SIP and the self-assessment scales is sensible.

We now look at the regression phenomenon again. It is likely that part of the regression effect seen in table 9.1 has disappeared now the diagnostic groups are distributed about equally among the groups distinguished and the SIP and 
Table 9.5 Scores of the groups created on the basis of a combination of the SIP and selfassersment scores on these scales at the subsequent assessments

the first three months

t2 3 long-term functioning

t2

14

Physical functioning

\begin{tabular}{|c|c|c|c|c|c|c|c|}
\hline \multirow[t]{2}{*}{ positive } & selt-ass. & 12.0 & 10.6 & $p=.004$ & 12.9 & 10.4 & $p=.000$ \\
\hline & S\|P & 24.1 & 18.5 & $p=.000$ & 25.1 & 16.8 & $p=.000$ \\
\hline \multirow[t]{2}{*}{ awerage } & self-ass. & 10.2 & 11.1 & n.s. & 9.7 & 10.3 & n.s. \\
\hline & $S \| P$ & 20.1 & 20.1 & n.s. & 18.4 & 15.4 & $p=.055$ \\
\hline \multirow[t]{2}{*}{ negative } & selfo-ass. & 10.4 & 12.9 & $p=000$ & 10.1 & 12.3 & $p=000$ \\
\hline & SUP & 15.4 & 21.6 & $p=000$ & 15.8 & 22.6 & $p=.000$ \\
\hline
\end{tabular}

Psychosocial functioning

\begin{tabular}{|c|c|c|c|c|c|c|c|}
\hline \multirow[t]{2}{*}{ positive } & self-ass. & 10.4 & 10.1 & $p=011$ & 11.5 & 10.2 & $\mathrm{D}=.005$ \\
\hline & $\mathbf{S \| P}$ & 12.4 & 6.7 & $p=003$ & 13.6 & 5.8 & $p=.000$ \\
\hline \multirow[t]{2}{*}{ average } & selt-ass. & 9.1 & 10.3 & $\mathrm{p}=.001$ & 9.0 & 8.9 & n.s. \\
\hline & SIP & 6.7 & 60 & $p=.079$ & 5.5 & 4.8 & n.s. \\
\hline \multirow[t]{2}{*}{ negative } & self-ass. & 9.3 & 12.5 & $p=.000$ & 8.4 & 11.6 & $p=000$ \\
\hline & SIP & 8.1 & 17.3 & $p=.000$ & 7.7 & 13.6 & $p=0.001$ \\
\hline
\end{tabular}

self-assessments are combined. In table 9.6 we present the relationship between the initial scores on the combination of the SIP and the self-assessment scale and the final classification into the positive, average or negative groups. Since the regression effect did not exist for the assessment of the course of functioning afterwards, we do not present figures regarding this. Figures are given separately for physical and psychosocial functioning and for the periods $t 2-t 3$ and $t 2-t 4$. The initial scores are divided into two categories using the following procedure: Z-scores of both the SIP and the self-assessment scales were computed and then added up; scores equal to or above the median of this sumscore are in the 'high' group, the rest is in the "low" group. The number of patients represented in this table is less than 67 , because the initial scor es used are not always both available, and therefore the sumscore could not always be computed.

The figures show that, using this rather rough method, there is a statistically significant regression effect only for the long-term course of psychosocial functioning. When looking more closely, by performing a one-way analysis of 
Tabie 9.6

The relationship between initial scores (12) and the final classificalion inlo groups with a positive, average or negative course of functioning

t2-13

positive average negative positive average negative

\begin{tabular}{|c|c|c|c|c|c|c|c|}
\hline physsical & high at $t 2$ & 11 & 8 & 10 & 12 & 9 & 8 \\
\hline functioning & low at 2 & 8 & 8 & 13 & 7 & 8 & 14 \\
\hline & \multicolumn{4}{|c|}{$\left(X^{2}=0.87 ; n, s.\right)$} & \multicolumn{3}{|c|}{$\left(X^{2}=3.01 ; n . s.\right)$} \\
\hline psychosocial & high at 2 & 12 & 11 & 8 & 16 & 8 & 7 \\
\hline functioning & low at t2 & 8 & 10 & 12 & 4 & 9 & 17 \\
\hline & \multicolumn{4}{|c|}{$\left(x^{2}=1.63 ; n . s\right)$} & \multicolumn{3}{|c|}{$\left(X^{2}=11.41 ; p=003\right)$} \\
\hline
\end{tabular}

variance with the sum of the two Z-scores as a dependent variable, there appears to be a significant difference between the groups for long-term physical functioning as well $(\mathrm{F}=7.08 ; \mathrm{p}=.002)$.

The upshot must be that for the analysis of the short-term functional course a regression effect does not have to be taken into account, but for the analysis of the long-term course on the basis of the change-scores this effect has to be heeded and at least its potential influence on the results has to be discussed.

\subsection{A brief summary and an outline of the analysis later on}

With the procedures described in this chapter we have tried to eliminate the problem of differences between diagnostic categories in the course of functioning. For each time-period to be studied we created groups of patients with a relatively positive, a relatively negative and an average course of functioning after discharge: once on the basis of a retrospective assessment of the patients themselves afterwards, and once on the basis of actual changes over time on self-assessment scales and the SIP.

The analysis in the following four chapters will primarily consist of a comparison of the groups created in terms of the variables in the research model. A chapter is devoted to each group of variables, in which we study the bivariate relationships between them and the different approaches of the course of functioning. Within each chapter we first deal with physical functioning and then with psychosocial functioning. Within these two dimensions we first investigate the relationship of the variables to the assessment of change afterwards. This is similar to the analysis in chapter 7 . Subsequently 
their relationship to changes in the evaluation of functioning over time is investigated.

In chapter 14 we integrate the results of these four chapters and perform a multivariate analysis to answer our fourth research question, regarding the relative importance of the different factors in explaining the course of functioning and their predictive value in this respect. 


\section{CHAPTER 10}

\section{Social-demographic characteristics, disability-related characteristics and their relationship to the course of functioning}

In paragraph 10.1 of this chapter we investigate the relationship of the socialdemographic variables to the course of functioning. Paragraph 10.2 is about the disability-related characteristics. In both paragraphs comparisons are made between the groups of patients described in chapter 9: patients with a relatively positive, an average or a relatively negative course of functioning. Firstly we investigate the relationships between the selected variables and the assessment of change afterwards, at the time of the third as well as the fourth assessment. Then we investigate their relationship to changes in functioning over time. Both paragraphs are divided into two subparagraphs: one regarding physical functioning and one regarding psychosocial functioning. The chapter ends with a brief summary and some conclusions in paragraph 10.3.

10.1 Social-demographic characteristics related to the course of functioning

\section{0:1.1 Physical functioning}

Table 10.1 gives the social-demographic characteristics of the groups of patients who experienced a relatively positive, average or negative course of physical functioning. Data are presented for the period $t 2-t 3$ as well as for the period $\mathrm{t} 2-\mathrm{t} 4$. 
Table 10.1 Social-demographic characteristics of paltents who experienced a relatively positive, averape or relatively negative course of physical functioning at ts and ti (assessment afle rwards)

\begin{tabular}{|c|c|c|c|c|c|c|c|c|}
\hline & $\begin{array}{l}t 2-t 3 \\
1 . \\
\text { positive } \\
(N=28)\end{array}$ & $\begin{array}{l}2 . \\
\text { average } \\
(\mathrm{N}=16)\end{array}$ & $\begin{array}{l}3 \text { negative } \\
(\mathrm{N}=23)\end{array}$ & $\begin{array}{l}\text { silgnifi- } \\
\text { cance of } \\
\text { diffe- } \\
\text { rences }\end{array}$ & $\begin{array}{l}t 2-14 \\
1 . \\
\text { positive } \\
(n=19)\end{array}$ & $\begin{array}{l}2 . \\
\text { average } \\
(N=26)\end{array}$ & $\begin{array}{l}3 . \\
\text { negative } \\
(\mathrm{N}=22)\end{array}$ & $\begin{array}{l}\text { signifi- } \\
\text { cance of } \\
\text { diffe- } \\
\text { rences }\end{array}$ \\
\hline mean age (years) & 32.2 & 39.4 & 42.7 & $\begin{array}{l}1<3^{4} \\
\rho=040\end{array}$ & 35.5 & 35.0 & 42.1 & n.s. \\
\hline $\operatorname{sex}(\%$ male $)$ & $36 \%$ & $50 \%$ & $48 \%$ & n.s. ${ }^{2}$ & $42 \%$ & $35 \%$ & $55 \%$ & n.s. ${ }^{2}$ \\
\hline $\begin{array}{l}\text { socio-economic } \\
\text { status (low/ } \\
\text { middle/high) }\end{array}$ & $2 / 14 / 12$ & $3 / 8 / 5$ & $6 / 12 / 5$ & $n . s^{2}$ & $1 / 8 / 10$ & $4 / 13 / 9$ & $6 / 13 / 3$ & $p=.079^{2}$ \\
\hline $\begin{array}{l}\text { marital status } \\
\text { (\% without partner) }\end{array}$ & $36 \%$ & $44 \%$ & $44^{\%} \%$ & n.s. ${ }^{2}$ & $42 \%$ & $35 \%$ & $46 \%$ & n.s. ${ }^{2}$ \\
\hline
\end{tabular}

Table 10.2 Social-demographic characteristics of patients with a relatively positive, average or relatively negative course of physical functioning (change over time)

\begin{tabular}{|c|c|c|c|c|c|c|c|c|}
\hline & $\begin{array}{l}\mathrm{t} 2-\mathrm{t} 3 \\
1 . \\
\text { positive } \\
(\mathrm{N}=24)\end{array}$ & $\begin{array}{l}\text { 2. } \\
\text { average } \\
(\mathrm{N}=18)\end{array}$ & $\begin{array}{l}3 . \\
\text { negative } \\
(\mathrm{N}=25)\end{array}$ & $\begin{array}{l}\text { signifi- } \\
\text { cance of } \\
\text { diffe- } \\
\text { rences. }\end{array}$ & $\begin{array}{l}t 2-14 \\
1 . \\
\text { pasitiwe } \\
(N=22)\end{array}$ & $\begin{array}{l}2 . \\
\text { average } \\
(\mathrm{N}=21)\end{array}$ & $\begin{array}{l}3 . \\
\text { negative } \\
(N=24)\end{array}$ & $\begin{array}{l}\text { signifi- } \\
\text { cance of } \\
\text { diffe- } \\
\text { rences }\end{array}$ \\
\hline mean age (years) & 34.7 & 40.3 & 38.2 & m.s. & 35.7 & 37.0 & 39.6 & n.s. ${ }^{4}$ \\
\hline sex (\% male) & $46 \%$ & $44 \%$ & $40 \%$ & n.s. ${ }^{2}$ & $46 \%$ & $38 \%$ & $46 \%$ & $n . s^{2}$ \\
\hline $\begin{array}{l}\text { socio-economic } \\
\text { status (low/ } \\
\text { middle/high) }\end{array}$ & $3 / 10 / 11$ & $2 / 12 / 4$ & $6 / 127$ & $7.5 .^{2}$ & $4 / 9 / 9$ & $3 / 10 / 8$ & $4 / 15 / 5$ & n.s. ${ }^{2}$ \\
\hline $\begin{array}{l}\text { marital status } \\
\text { (\% without partner) }\end{array}$ & $42 \%$ & $39 \%$ & $40 \%$ & $n . s^{2}$ & $32 \%$ & $48 \%$ & $42 \%$ & n.s. ${ }^{2}$ \\
\hline
\end{tabular}

There appears to be a significant difference in age between the group who experience a relatively positive course of functioning and the group that experience a relatively negative course at the third assessment: in line with expectation 2.1, the first group is younger. At $t 4$ there is no significant difference, but the direction of the differences is similar. There are no significant differences with respect to sex and marital status. This accords with expectation 2.2 regarding sex but not with expectation 2.4 regarding marital status. The data on socio-economic status show a tendency in the expected direction (2.3): patients with a higher SES more often report a relatively positive course of functioning. For the long-term period $t 2-t 4$ this difference is statistically significant. 
In table 10.2 data are presented on the relationship of these social-demographic variables to actual changes in functioning over time. Here we see no significant differences at all between the groups. Age and socio-economic status may influence the way people evaluate the course of physical functioning when they look back, but they appear not to be related to actual changes over time, and thus not to have predictive value.

\subsubsection{Psychosocial functioning}

The relationship of the social-demographic variables to the course of psychosocial functioning can be drawn from tables 10.3 and 10.4. They are analogous to 10.1 and 10.2, but refer to psychosocial functioning.

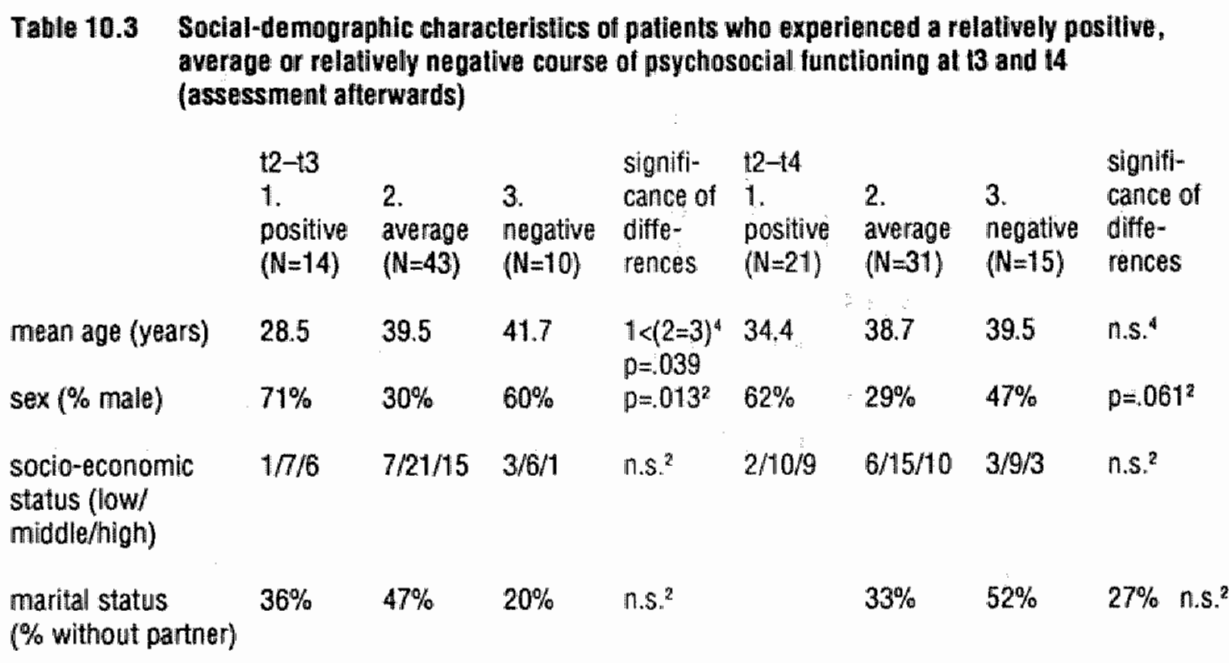

Table 10.4 Social-demographic characteristics of patients with a relatively positive, average or relatively negative course of psychosocial functioning (change over lime)

\begin{tabular}{|c|c|c|c|c|c|c|c|c|}
\hline & $\begin{array}{l}t 2-13 \\
1 . \\
\text { positive } \\
(N=23)\end{array}$ & $\begin{array}{l}2 . \\
\text { average } \\
(N=23)\end{array}$ & $\begin{array}{l}3 . \\
\text { negative } \\
(N=21)\end{array}$ & $\begin{array}{l}\text { signifi- } \\
\text { cance of } \\
\text { diffe- } \\
\text { rences }\end{array}$ & $\begin{array}{l}t 2-14 \\
1 . \\
\text { positive } \\
(\mathrm{N}=23)\end{array}$ & $\begin{array}{l}2 . \\
\text { average } \\
(N=19)\end{array}$ & $\begin{array}{l}3 . \\
\text { negatiwe } \\
(N=25)\end{array}$ & $\begin{array}{l}\text { signifi- } \\
\text { cance of } \\
\text { diffe- } \\
\text { rences }\end{array}$ \\
\hline mean age (years) & 36.4 & 36.4 & 40.0 & n.s." & 33.6 & 32.3 & 45.1 & $\begin{array}{l}(1=2)<3^{4} \\
p=.006\end{array}$ \\
\hline $\operatorname{sex}(\%$ male $)$ & $52 \%$ & $39 \%$ & $38 \%$ & $\pi . s^{2}$ & $48 \%$ & $37 \%$ & $44 \%$ & m.s. ${ }^{2}$ \\
\hline $\begin{array}{l}\text { socio-economic } \\
\text { status (low/ } \\
\text { middlle/high) }\end{array}$ & $4 / 10 / 9$ & $4 / 11 / 8$ & $3 / 13 / 5$ & $n . s^{2}$ & $5 / 11 / 7$ & $2 / 9 / 8$ & $4 / 14 / 7$ & n.s. ${ }^{2}$ \\
\hline $\begin{array}{l}\text { marital status } \\
\text { (\% withoul partner) }\end{array}$ & $48 \%$ & $35 \%$ & $38 \%$ & $n . s^{2}$ & $39 \%$ & $47 \%$ & $36 \%$ & $n . s^{2}$ \\
\hline
\end{tabular}


According to the figures, neither marital status nor socio-economic status show a relationship either with the experienced course of functioning afterwards or with actual changes over time.

There is an obvious relationship between age and both the experienced course of functioning afterwards and changes over time: the groups with a relatively positive course of functioning tend to be younger. The differences regarding age are only statistically significant for the short period in table 10.3 and for the long period in 10.4 , but the tendency is systematic. There is also a statistically significant difference in sex between the groups distinguished: the relatively positive groups in each table tend to contain more men. This is only significant in table 10.3, but in 10.4 the same tendency can be seen. We found a similar difference in the first phase of the study (tables 7.1 and 7.2). Interpretation of the sex differences is quite complicated, because in the relatively negative groups there are more men than in the average groups. This might indicate that women show a tendency to present an average course of psychosocial functioning and men are more subject to changes in this respect.

The figures in table 10.3, especially those regarding the first three months after discharge, might be influenced by differences in diagnostic distribution, since we did not succeed in creating groups with an equal distribution of diagnoses here. Looking separately at the figures for the three categories, however, they appear to show a largely similar pattern. In each category the relatively positive groups tend to be younger than the others and women prevail in the average group in each category.

\subsection{Characteristics of the disability related to the course of functioning}

\subsubsection{Physical functioning}

Table 10.5 gives the disability-related characteristics of the groups of patients who experienced a relatively positive, an average or a relatively negative course of physical functioning, three months after discharge ( 3 ) and at the last assessment (t4). The diagnosis is not included in the table because we eliminated differences in diagnosis between the groups distinguished (see chapter 9).

Table 10.5 shows that the groups distinguished do not differ significantly with respect to most of the disability-related characteristics studied either at the third or the fourth assessment. The only factor clearly related to the experienced course of functioning is the development of intercurrent diseases after discharge: patients in the relatively negative group at $t 4$ more often report 


\begin{tabular}{|c|c|c|c|c|c|c|c|c|c|}
\hline \multirow{2}{*}{\multicolumn{2}{|c|}{ Table 10.5}} & \multirow[b]{2}{*}{$\begin{array}{l}2-13 \\
\text { positive } \\
(N=28)\end{array}$} & \multirow[b]{2}{*}{$\begin{array}{l}2 . \\
\text { average } \\
(N=16)\end{array}$} & \multirow[b]{2}{*}{$\begin{array}{l}3 . \\
\text { negative } \\
(\mathrm{N}=23)\end{array}$} & \multirow[b]{2}{*}{$\begin{array}{l}\text { signifi- } \\
\text { cance of } \\
\text { diffe- } \\
\text { rences }\end{array}$} & \multirow[b]{2}{*}{$\begin{array}{l}12-14 \\
1 . \\
\text { positive } \\
(N=19)\end{array}$} & 8 & \multicolumn{2}{|c|}{$\begin{array}{l}\text { Ively positive, } \\
\text { dit fassessment }\end{array}$} \\
\hline & & & & & & & $\begin{array}{l}2 . \\
\text { average } \\
(N=26)\end{array}$ & $\begin{array}{l}3 . \\
\text { negative } \\
(N=22)\end{array}$ & $\begin{array}{l}\text { signifi- } \\
\text { cance of } \\
\text { diffe- } \\
\text { rences }\end{array}$ \\
\hline \multicolumn{2}{|c|}{$\begin{array}{l}\text { level of disability } \\
\text { (relatively high/ } \\
\text { modierate/low) }\end{array}$} & $11 / 6 / 11$ & $5 / 7 / 4$ & $8 / 6 / 9$ & $n . s^{2}$ & $9 / 2 / 8$ & $7 / 9 / 10$ & $8 / 8 / 6$ & $n . s^{2}$ \\
\hline \multicolumn{2}{|c|}{$\begin{array}{l}\text { duration of dis- } \\
\text { ability (in years) }\end{array}$} & 6.6 & 6.2 & 8.5 & m.s. ${ }^{4}$ & 6.0 & 8.3 & 6.9 & $\mathrm{n} . \mathrm{s}:{ }^{*}$ \\
\hline \multicolumn{2}{|c|}{$\begin{array}{l}\text { complicating } \\
\text { diseases (at t1) }\end{array}$} & $29 \%$ & $38 \%$ & $35 \%$ & n.s. ${ }^{2}$ & $37 \%$ & $35 \%$ & $27 \%$ & n.s. ${ }^{2}$ \\
\hline \multicolumn{2}{|c|}{$\begin{array}{l}\text { any other diseases } \\
\text { between } 12 \text { and } \\
13 / 22 \text { and } 14\end{array}$} & $29 \%$ & $38 \%$ & $39 \%$ & n.s. ${ }^{2}$ & $53 \%$ & $46 \%$ & $91 \%$ & $p=003^{2}$ \\
\hline
\end{tabular}

some other disease since discharge. The results in table 10.5 are in line with our expectation 2.5 regarding the level of disability. Expectation 2.6 about the duration of the disability is not supported by the data. Expectations $2.7 \mathrm{a}$ and $\mathrm{b}$ are largely confirmed. As expected, having other diseases or impairments at the time of admission to the rehabilitation centre is not related to the course of functioning. Intercurrent diseases after discharge are more frequent in the negative group at $t 4$, but not at $t 3$.

Now, table 10.6 gives the data on the relationships of these variables to actual changes over time. This table is identical to the previous one-only the groups compared are different.

Again we see that the course of functioning is not related to the level of disability. In contrast to what we saw before, there is also no significant relationship with having intercurrent diseases of impairments after discharge. There is a significant relationship between the course of functioning and the duration of the disability. As expected (2.6), the group with the positive course of functioning has a significantly shorter duration than the other groups. This is most clearly the case for the long-term course of functioning $(t 2-14)$. With respect to the period $2-13$, however, the average group has the longest duration. This finding is not in line with expectation 2.6 . 
Table 10.6 Disability-relaied characteristics of patients with a relatively posilive, average or relalively negalive course of physical functioning (change over time)

\begin{tabular}{|c|c|c|c|c|c|c|c|c|}
\hline . & $\begin{array}{l}12-13 \\
1 . \\
\text { positive } \\
(N=24)\end{array}$ & $\begin{array}{l}2 . \\
\text { average } \\
(N=18)\end{array}$ & $\begin{array}{l}3 . \\
\text { negative } \\
(N=25)\end{array}$ & $\begin{array}{l}\text { signifi- } \\
\text { cance of } \\
\text { diffe- } \\
\text { rences }\end{array}$ & $\begin{array}{l}t 2-14 \\
1 . \\
\text { positive } \\
(\mathrm{N}=22)\end{array}$ & $\begin{array}{l}2 . \\
\text { average } \\
(\mathrm{N}=21)\end{array}$ & $\begin{array}{l}3 . \\
\text { negative } \\
(\mathrm{N}=24)\end{array}$ & $\begin{array}{l}\text { signifl- } \\
\text { cance of } \\
\text { diffe- } \\
\text { rences }\end{array}$ \\
\hline $\begin{array}{l}\text { level of disability } \\
\text { (relatively high/ } \\
\text { moderate/low) }\end{array}$ & $10 / 7 / 7$ & $7 / 6 / 5$ & $7 / 6 / 12$ & $n .5^{2}$ & $9 / 7 / 6$ & $6 / 4 / 11$ & $9 / 8 / 7$ & $\mathrm{n}_{\mathrm{sin}} \mathrm{S}^{2}$ \\
\hline $\begin{array}{l}\text { duration of dis- } \\
\text { ability (inyears) }\end{array}$ & 4.4 & 11.4 & 6.8 & $\begin{array}{l}1<2^{4} \\
p=.040\end{array}$ & 2.9 & 8.2 & 10.3 & $\begin{array}{l}1<(2=3)^{4} \\
p=015\end{array}$ \\
\hline $\begin{array}{l}\text { complicating } \\
\text { diserses (att t1) }\end{array}$ & $21 \%$ & $50 \%$ & $32 \%$ & $n . s^{2}$ & $32 \%$ & $19 \%$ & $46 \%$ & $n . s{ }^{2}$ \\
\hline $\begin{array}{l}\text { any other diseases } \\
\text { between } 12 \text { and } \\
\text { t3t } 2 \text { and } 14\end{array}$ & $38 \%$ & $28 \%$ & $36 \%$ & n.s. ${ }^{2}$ & $64 \%$ & $52 \%$ & $71 \%$ & n.s. ${ }^{2}$ \\
\hline
\end{tabular}

Combination of the results in tables 10.5 and 10.6 does not lead to a selfevident conclusion. It is obvious that the course of physical functioning is not related to the level of disability, nor to having other diseases or impairments at the time of admission. The results concerning duration of the disability and intercurrent diseases after discharge, however, are less unequivocal. Duration of the disability does relate to changes in functioning, but not in a consistent way and it is not related to the assessment patients make afterwards. Intercurrent diseases are related to the assessment afterwards and not to changes over time. These somewhat contrasting findings suggest that the two approaches of the course of functioning chosen in this study are quite different. In chapter 8 we already saw that they are only moderately correlated: hence they are treated separately. The findings here suggest that the assessment of functioning afterwards is explained by factors other than changes over time. We shall certainly return to this later.

\subsubsection{Psychosocial functioning}

Tables 10.7 and 10.8 have exactly the same structure as 10.5 and 10.6 . They give analogous information, but now for psychosocial functioning.

There is a significant relationship between the experienced course of psychosocial functioning afterwards and the objective level of disability: people with a relatively severe disability tend to evaluate the course of functioning during the first three months after discharge more positively. This 
Table 10.7 Disability-related characteristics of patients who experienced a relatively positive, average or relatively ne gative course of psychosocial functioning of ts and t 4 (assessment afterwards)

\begin{tabular}{|c|c|c|c|c|c|c|c|c|}
\hline & $\begin{array}{l}t 2-t 3 \\
1 . \\
\text { positive } \\
(N=14)\end{array}$ & $\begin{array}{l}2 . \\
\text { average } \\
(\mathrm{N}=43)\end{array}$ & $\begin{array}{l}3 . \\
\text { negative } \\
(\mathrm{N}=10)\end{array}$ & $\begin{array}{l}\text { signiff- } \\
\text { cance of } \\
\text { diffe- } \\
\text { rences }\end{array}$ & $\begin{array}{l}12-4 \\
1 . \\
\text { positive } \\
(N=21)\end{array}$ & $\begin{array}{l}2 . \\
\text { average } \\
(\mathrm{N}=31)\end{array}$ & $\begin{array}{l}3 . \\
\text { negative } \\
(\mathrm{N}=15)\end{array}$ & $\begin{array}{l}\text { signif: } \\
\text { cance of } \\
\text { diffte- } \\
\text { rences }\end{array}$ \\
\hline $\begin{array}{l}\text { level of disability } \\
\text { (relatively high/ } \\
\text { moderate/low) }\end{array}$ & $8 / 2 / 4$ & $16 / 14 / 13$ & $0 / 3 / 7$ & $p=033^{2}$ & $11 / 5 / 5$ & $9 / 10 / 12$ & $4 / 4 / 7$ & n.s. \\
\hline $\begin{array}{l}\text { duration of dis- } \\
\text { ability (in years) }\end{array}$ & 3.1 & 8.8 & 5.8 & $\begin{array}{l}1<2^{4} \\
p=097\end{array}$ & 7.8 & 6.4 & 8.0 & n.s. \\
\hline $\begin{array}{l}\text { complicating } \\
\text { diseases (at } t 1 \text { ) }\end{array}$ & $29 \%$ & $35 \%$ & $30 \%$ & n.s. & $29 \%$ & $32 \%$ & $40 \%$ & n.s? \\
\hline $\begin{array}{l}\text { any other diseases } \\
\text { between } t 2 \text { and } \\
13 / 22 \text { and } 14\end{array}$ & $50 \%$ & $28 \%$ & $33 \%$ & $n . s^{2}$ & $57 \%$ & $58 \%$ & $80 \%$ & $n s^{2}$ \\
\hline
\end{tabular}

Table 10.8 Disability-re lated characteristics of pattents with a relalivelly posilive, average or relatively negalive course of psychosocial functioning (change over lime)

\begin{tabular}{|c|c|c|c|c|c|c|c|c|}
\hline & $\begin{array}{l}t 2-t 3 \\
1 . \\
\text { positive } \\
(N=23)\end{array}$ & $\begin{array}{l}2 . \\
\text { average } \\
(\mathrm{N}=23)\end{array}$ & $\begin{array}{l}3 . \\
\text { negative } \\
(N=21)\end{array}$ & $\begin{array}{l}\text { signifi- } \\
\text { cance of } \\
\text { diffe- } \\
\text { rences }\end{array}$ & $\begin{array}{l}12-14 \\
1 . \\
\text { positive } \\
(\mathrm{N}=23)\end{array}$ & $\begin{array}{l}2 . \\
\text { average } \\
(\mathrm{N}=19)\end{array}$ & $\begin{array}{l}3 \\
\text { negative } \\
(N=25)\end{array}$ & $\begin{array}{l}\text { signifil- } \\
\text { cance of } \\
\text { diffe- } \\
\text { rences }\end{array}$ \\
\hline $\begin{array}{l}\text { level of disability } \\
\text { (relatively high/ } \\
\text { moderate/low) }\end{array}$ & $8 / 5 / 10$ & $7 / 9 / 7$ & $7 / 5 / 9$ & n.s. ${ }^{2}$ & $9 / \pi / \pi$ & $4 / 7 / 8$ & $11 / 5 / 9$ & n.s. ${ }^{2}$ \\
\hline $\begin{array}{l}\text { duration of dis- } \\
\text { ability (in years) }\end{array}$ & 7.3 & 7.3 & 7.0 & n.s." & 4.9 & 6.7 & 9.6 & $n . s$ \\
\hline $\begin{array}{l}\text { complicating } \\
\text { diseases (at t1) }\end{array}$ & $17 \%$ & $35 \%$ & $48 \%$ & $n . s^{2}$ & $30 \%$ & $26 \%$ & $40 \%$ & $n \cdot s^{2}$ \\
\hline $\begin{array}{l}\text { any other diseases } \\
\text { between } t 2 \text { and } \\
13 / 2 \text { and } 14\end{array}$ & $30 \%$ & $22 \%$ & $52 \%$ & $p=.090^{2}$ & $61 \%$ & $53 \%$ & $72 \%$ & $\mathrm{n.s} \mathrm{s}^{2}$ \\
\hline
\end{tabular}

relationship is not significant at $t 4$, but a tendency in the same direction does exist. According to table 10.8 , level of disability is not related to change in psychosocial functioning over time. Similarly, there is no clear relationship between the duration of the disability and the course of psychosocial functioning. The data regarding the period $t 2-\mathrm{t} 3$ in table 10.7 and those regarding the period $\mathrm{t} 2 \mathrm{t} 4 \mathrm{in}$ table 10.8 show a tendency in the direction expected, but this is 
not systematic and not supported by the other data. Consistent with expectation $2.7 \mathrm{a}$, having complicating diseases at $\mathrm{t} 1$ is not significantly related to the course of functioning, although complicating diseases tend to prevail in the relatively negative groups. Patients with intercurrent diseases after discharge also tend to prevail in the relatively negative groups, most obviously in table

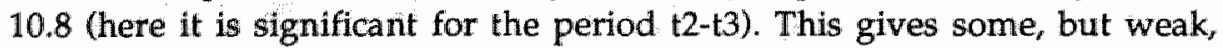
support for expectation $2.7 \mathrm{~b}$.

Combination of these results leads to the conclusion that the experienced course of psychosocial functioning afterwards is related to objective level of disability, but that this variable is not related to changes in functioning. It apparently has no predictive value. The other variables are not systematically related to the course of functioning. The results for $22-\mathrm{t} 3$ are not always consistent with those for the period $t 2-t 4$ and here as well there are differences between the relationships in both tables.

The interpretation of the figures with respect to duration of the disability in these tables, especially table 10.7, might be clouded by the fact that the RA group is overrepresented in the negative group, because we did not succeed in eliminating the diagnostic differences here (see chapter 9, page 111). Separate analysis of these figures for the diagnostic categories, however, suggests that they show a broadly similar pattern, except for the SC group (in this group al]. patients have a duration of less than 1 year).

\subsection{A summary and some conclusions}

In the preceding paragraphs many results were presented. This paragraph tries to summarise them in such a way that they can be carefully weighed up in relation to the expectations formulated. Table 10.9 gives a schematic summary of the findings in relation to the expectations.

From this table, it becomes clear that there is quite a difference between the results regarding physical and psychosocial functioning. There also appear to be important differences between the two approaches of the course of functioning: the evaluation afterwards and changes over time apparently relate to different variables. We now discuss the results for each variable separately.

Age (2.1)

Our expectation regarding age is affirmed by the results. There is a systematic tendency of the groups with a relatively positive course of functioning to be younger than the others. In three of the approaches this is statistically significant. 

disability-related characteristics in relation to the expectations

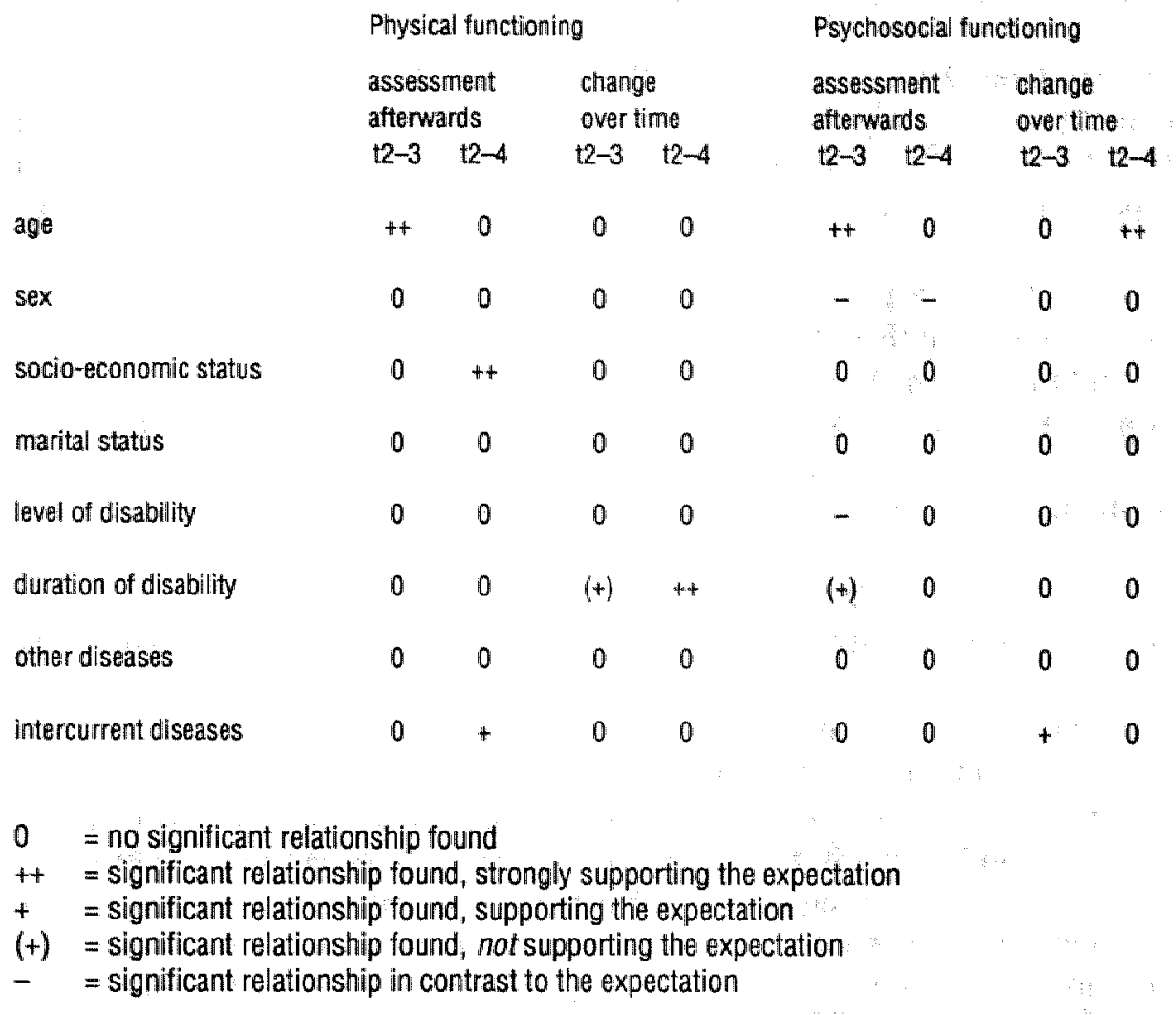

$\operatorname{Sex}(2.2)$

We expected that there would be no relation between sex and the course of functioning. With respect to physical functioning this expectation finds support in the data. For psychosocial functioning the expectation only partly holds: men tend to evaluate the course of functioning more positively than women retrospectively. This is true for the short period $t 2-t 3$ as well as for the longer period $12-14$. An interesting finding is that women show a more stable course of psychosocial functioning than men; they tend to predominate in the average groups.

Socio-economic status (2.3)

With respect to psychosocial functioning, the expectation that higher socioeconomic status would be related to a positive course is not supported. We found no significant relationship in any of the approaches and time-periods. 
With respect to physical functioning, the results are partially in line with the expectation: socio-economic status is related to the course of functioning as evaluated afterwards, but not to actual changes.

\section{Marital status (2.4)}

Our expectation regarding marital status is not affirmed by the results. We found no relationship between having a life partner or not and the course of functioning, neither for physical functioning or for psychosocial functioning.

\section{Objective level of disability (2.5)}

We expected that there would be no relationship between the level of disability and the course of functioning. For physical functioning this holds, in both approaches and for each time-period. For psychosocial functioning it only partly holds: patients with relatively severe disabilities evaluate retrospectively the course of psychosocial functioning more positively.

\section{Duration of disability (2.6)}

We expected long duration to be associated with a relatively negative course of functioning. The results presented only partly affirm this expectation. The relatively positive groups in most of the tables presented tend to have a more recent disability. This is statistically significant for actual changes in physical functioning during the first three months after discharge as well as during the longer period t2-t4. It is also significant for the experienced course of psychosocial functioning during the first three months. There is, however, a problem. In some of the tables it is the average group who has the longest duration. This is not in line with our expectation. It suggests that long duration increases the likelihood of functional stability.

\section{Complicating diseases (2.7)}

The results are in line with our expectation 2.7a that complicating diseases or impairments already present at the time of admission do not influence the course of functioning after discharge. The data on intercurrent diseases after discharge partly affirm our expectation $2.7 \mathrm{~b}$. The results are, however, not really consistent. 


\section{CHAPTER 11}

\section{Personal characteristics and the course of functioning}

This chapter deals with the relationship of the personal characteristics in the research model to the course of functioning after discharge. The structure of the chapter is essentially similar to that of chapter 10 , with the most important difference being the first paragraph which presents the scores of the research population on the measures used. This is done for the total group and for the diagnostic categories separately. We present data on personality traits, the health locus of control and self-image at the subsequent assessments in the study. This serves as background information for the analysis in the subsequent paragraphs. For a clear understanding of the relationships between these variables and the course of functioning it is necessary to know how stable these characteristics are. It also gives interesting information about how these variables develop during the two years the patients were followed. From paragraph 11.2 onwards, the same approach is followed as in chapter 10: 11.2 deals with the relationship of the variables distinguished to the course of physical functioning and 11.3 with psychosocial functioning. In both paragraphs we first investigate the relationship of the variables to the assessment of change afterwards, at $\mathbf{t} 3$ as well as at $t 4$. Secondly we investigate their relationship to changes in the evaluation of functioning over time. The chapter ends with a summary and some conclusions in paragraph 11.4 . 
11.1 Personality traits, health locus of control and self-image in a timeperspective

In table 11.1 the average scores on the subscales of the personality inventory at the time of the first and last assessment are presented. These scores seem to be quite stable during the two-year period: there are no significant differences in any of the groups on any of the scales. The correlation coefficients, however, indicate less stability. This means that personality traits are liable to change. Correlations between the scores of the total group at $t 1$ and $t 4$ range from .54 for self-recognition to .65 for rigidity.

The lowest correlations are seen in the SC group. For inadequacy and selfrecognition they are extremely low. The social inadequacy score for the SC group is remarkably stable. The AS group seems to have the most stable scores. This difference in stability between the groups might be explained by the fact that a spinal cord lesion causes sudden, mostly severe disabilities that

Table 11.1 Personality traits at 11 and 14 , for the total group and the diagnostic categories separalely

t1

inadequacy

sacial

inadequacy

rigidity

Self-recognition

total group
RA $(N=21)$
AS $(N=27)$
$S C(N=19)$

$-0.05(6)$

$0.50(3)$

$-0.58(1)$

$0.18(2)$

total group

$-0.13(6)$

$0.22(3)$

$-0.54(1)$

$0.12(2)$

RA

AS

SC

total group

$-0.44(6)$

$-0.39(3)$

$-0.73(1)$

$-0.06(2)$

total group

$0.31(6)$

$-0.22(3)$

RA.

AS

$S C$ t4

correlation

between

t1 and $t 4$

.55

.56

.71

.04

.56

.48

.67

.70

.65

.61

.79

.44

.54

.31

.78

.28 
can change life almost entirely. For ankylosing spondylitis this is different this has a gradual onset with initially mild disability and a smaller impact on daily life.

In table 11.2 the average scores of the total group and the three diagnostic categories on the three health locus of control scales at the subsequent assessments are given. The figures do not show dramatic changes over time in any of the groups. For the total group, there are no statistically significant differences between the scores at the subsequent assessments. This suggests that the scores are stable. The correlation coefficients between the subsequent scores, however, indicate that they are not really stable, especially not after discharge. For the total groups the correlations for the "internal" scale between $t 1$ and $t 2$, $\mathrm{t} 2$ and $\mathrm{t} 3$ and $\mathrm{t} 3$ and $\mathrm{t} 4$ are $.80, .79$ and .43 respectively. For the 'doctor' scale they are $.56, .63$ and .56 , and for the 'chance' scale $.73, .58$ and .41 . This indicates that, just like personality traits, the health locus of control is similarly liable to change. We tried to find out whether there were differences in stability between the diagnostic categories here as well, by computing the same correlation coefficients for each category separately. The result showed that the RA group especially has low correlations compared to the others. The correlation for the internal scale between $\mathrm{t} 3$ and $\mathrm{t} 4$ was -.13 . For the "doctor" and 'chance' scales this was .26 and .08 respectively. We have no explanation for this difference between the groups.

Table 11.2 Health locus of control at the subsequent assessments, for the total group and the diagnostic categorles separalely

\begin{tabular}{|c|c|c|c|c|c|}
\hline & & t1 & 12 & $\mathrm{t} 3$ & 14 \\
\hline \multirow[t]{4}{*}{ internal orientation } & total group & $22.1(2)$ & $21.6(11)$ & $21.6(9)$ & $21.1(3)$ \\
\hline & $\mathrm{RA}(\mathrm{N}=21)$ & $20.8(1)$ & $18.9(6)$ & $19.1(2)$ & $18.9(1)$ \\
\hline & $A S(N=27)$ & $22.2(1)$ & $22.3(3)$ & $21.8(5)$ & $21.4(1)$ \\
\hline & $S C(N=19)$ & 23.2 & $22.8(2)$ & $24.0(2)$ & $23.1(1)$ \\
\hline \multirow{4}{*}{$\begin{array}{l}\text { orientation on } \\
\text { doctors }\end{array}$} & total group & $18.7(5)$ & $18.1(9)$ & $17.7(9)$ & $17.5(4)$ \\
\hline & RA & $23.6(2)$ & $20.8(5)$ & $20.2(3)$ & $20.0(1)$ \\
\hline & SA & $15.8(1)$ & $16.7(3)$ & $15.8(4)$ & $16.7(1)$ \\
\hline & $\mathrm{SC}$ & $17.8(2)$ & $17.7(1)$ & $17.8(2)$ & $15.9(2)$ \\
\hline \multirow[t]{4}{*}{ chance-orientation } & total group & $19.6(7)$ & $19.7(10)$ & $19.9(12)$ & $18.4(6)$ \\
\hline & RA & $22.2(1)$ & $22.2(5)$ & $23.6(5)$ & $19.8(2)$ \\
\hline & $\mathrm{SA}$ & $18.1(2)$ & $17.7(3)$ & $18.0(5)$ & $17.0(2)$ \\
\hline & SC & $18.6(4)$ & $20.2(2)$ & $18.9(2)$ & $18.8(2)$ \\
\hline
\end{tabular}


In addition, with respect to score-differences between the diagnostic categories at each assessment, some differences appear. The RA group tends to have the lowest scores on the "internal' scale, while the SC group has the highest scores. On the 'doctor' scale and on the 'chance' scale the RA group scores highest at each assessment. These differences are statistically significant at $t 3$ and $t 4$ for the "internal' scale, at $t 1, t 2$ and $t 4$ for the "doctor" scale and at $t 1, t 2$ and $t 3$ for the "chance' scale (one-way analysis of variance).

These differences are in the direction that should be expected. The RA group is relatively old, and older people are known to be more externally oriented than younger people, especially when they have a history as a patient (Halfens, 1985; Halfens and Philipsen, 1988). The fact that we find these differences in a way that could be expected gives some confidence in the validity of the scales used, and makes it unlikely that the low stability of the scores described before is to be explained by unreliability of the instrument.

The data on the self-image at the subsequent assessments are presented in table 11.3. It is clear that the patients on average perceive themselves as damaged to a considerable extent. The self-image is apparently negatively influenced. The most interesting detail in this table is the relatively negative self-image of the total group at the third assessment. At $\mathrm{t} 3$ a relatively high percentage of damage to the self is reported, significantly higher than at $t 2$ (Ttest: $\mathrm{p}=.051$ ). The scores on the positive and negative scale derived from the semantic differential show a similar pattern: the 'positive' score at $t 3$ is significantly lower than at $\mathrm{t} 2$ and $t 4$ ( $T$-test: $\mathrm{p}=.017$ and .058 respectively) and the 'negative' score at $\mathrm{t} 3$ is significantly higher than at $\mathrm{t} 2$ ( $\mathrm{T}$-test: $\mathrm{p}=.008$ ). This 'dip' in the self-image is very similar to the dip in the self-assessment of functioning found in chapter 8 . This suggests that a relationship of self-image to the course of functioning will be found. When looking more closely at the score pattern in the distinct diagnostic categories, the dip in the percentage of self damaged appears to be present only in the RA group. For the positive and negative scales from the semantic differential it is consistent in each group.

There is a remarkable difference between the diagnostic groups regarding the percentage of the self damaged. The RA group reports a significantly higher percentage than the other groups at $t 2, \mathrm{t} 3$ and $t 4$. This indicates that they have a more negative self-image. However, the results from the semantic differential do not support this. At $t 1$ and $t 2$ they even score higher on the 'positive' scale. At the other assessments there are no significant differences between the diagnostic categories with respect to any of the scores in the table.

The fact that the scores on the personality inventory, the health locus of control scores as well as the self-image-scores are not really stable over time, made us 


\begin{tabular}{|c|c|c|c|c|c|}
\hline$\therefore$ & & $\mathrm{t1}$ & 12 & 4 & 14 \\
\hline \multirow{4}{*}{$\begin{array}{l}\text { percentage of self } \\
\text { damaged }\end{array}$} & total group & $31.5(7)$ & $34.6(8)$ & $429(7)$ & $38.7(3)$ \\
\hline & RA $(N=21)$ & $36.2(4)$ & $41.3(5)$ & $57.4(4)$ & $496(2)$ \\
\hline & $\mathrm{AS}(\mathrm{N}=27)$ & $25.7(3)$ & 23.3 & $26.9(1)$ & $28.7(1)$ \\
\hline & $S C(N=19)$ & $22.0(3)$ & $22.7(2)$ & 29.1 & \\
\hline \multirow[t]{4}{*}{ positive self-image } & total group & $35.8(10)$ & $35.5(6)$ & $34.3(6)$ & $35.2(5)$ \\
\hline & RA & $38.0(2)$ & $37.3(3)$ & $35.5(1)$ & $36.4(3)$ \\
\hline & SA & $35.4(1)$ & $36.1(2)$ & $34.9(3)$ & $35.5(2)$ \\
\hline & $\mathrm{SC}$ & $33.3(7)$ & $32.9(1)$ & $32 \|(2)$ & 33.7 \\
\hline \multirow[t]{4}{*}{ negative self-image } & total group & $18.4(8)$ & $17.8(6)$ & $19.3(6)$ & $18.4(5)$ \\
\hline & $\mathbb{R A}$ & $20.0(1)$ & $18.9(3)$ & $20.8(1)$ & $20.2(3)$ \\
\hline & SA & $18.0(2)$ & $16: 1(2)$ & $17.7(4)$ & $17.0(2)$ \\
\hline & SC & $16.6(5)$ & $18.9(4)$ & $19.8(1)$ & $18.5^{\circ}$ \\
\hline
\end{tabular}

decide to use the scores at $\mathrm{t} 3$ and $t 4$ when investigating the relationship of these variables to the evaluation patients make of the course of functioning when looking back at these assessments. When investigating the relationship of these variables to changes in functioning over time we use scores from $t 2$ as well as from $\mathbf{t} 3$ and/or $\mathbf{4}$, to get maximal insight. For the personality inventory we only have scores at $\mathrm{t} 1$ and $\mathrm{t} 4$. Here we use the score that was obtained at the closest point in time.

\subsection{Personal characteristics related to the course of physical functioning}

We now investigate the relationship of the personal characteristics described with the course of physical functioning. Firstly we deal with the assessment patients make of the course of functioning afterwards. In table 11.4 the personal characteristics of the groups of patients who experienced a relatively positive, an average or a relatively negative course of physical functioning at $\mathrm{t} 3$ and $\mathrm{t} 4 \mathrm{are}$ presented, for the third and fourth assessment respectively. 
Tabie 11.4 Personal characteristics at t3 and 14 of patients who experienced a relatively positive, average or relatively negative course of physical funetioning (assessmenl afterwards)

\begin{tabular}{|c|c|c|c|c|c|c|c|}
\hline $\begin{array}{l}2-13 \\
1 . \\
\text { positive } \\
(N=28)\end{array}$ & $\begin{array}{l}2 . \\
\text { average } \\
(N=17)\end{array}$ & $\begin{array}{l}3 . \\
\text { negative } \\
(N=23)\end{array}$ & $\begin{array}{l}\text { signiti- } \\
\text { cance of } \\
\text { differ- } \\
\text { ence" }\end{array}$ & $\begin{array}{l}12-14 \\
1 . \\
\text { positive } \\
(\mathrm{N}=19)\end{array}$ & $\begin{array}{l}2 . \\
\text { average } \\
(\mathrm{N}=26)\end{array}$ & $\begin{array}{l}3 . \\
\text { negative } \\
(\mathrm{N}=22)\end{array}$ & $\begin{array}{l}\text { signifi- } \\
\text { cance of } \\
\text { differ- } \\
\text { ence }\end{array}$ \\
\hline
\end{tabular}

Personality traits it *

$\begin{array}{llllllllll}\text { - inadequacy } & -0.5(4) & -0.1(1) & 0.5(2) & \begin{array}{l}1<3 \\ p=0.55\end{array} & -0.4(4) & -0.2(1) & 0.6(4) & \text { n.s. } \\ \begin{array}{l}\text { - social } \\ \text { inadequacy }\end{array} & -0.5(4) & -0.1(1) & 0.3(2) & 0.5 . & -0.8(3) & -0.3(1) & -0.1(4) & n . s . \\ \text { - rigidity } & -0.9(4) & 0.4(1) & -0.5(2) & \begin{array}{l}(1=3)<2 \\ p=.002\end{array} & -1.0(3) & -0.8(1) & -0.2(4) & \text { m.s. } \\ \text { - self-recognition } & 0.5(4) & 0.7(1) & -0.2(2) & \begin{array}{l}(1=2) \times 3 \\ p=.023\end{array} & 0.5(3) & 0.0(2) & -0.6(4) & \begin{array}{l}1>3 \\ p=.101\end{array}\end{array}$

Health locus of control

\begin{tabular}{|c|c|c|c|c|c|c|c|c|}
\hline $\begin{array}{l}\text { - internal } \\
\text { orlentation }\end{array}$ & $21.6(3)$ & $22.4(3)$ & $20.8(4)$ & n.s. & 22.7 & $20.4(11)$ & $20.4(2)$ & n.s. \\
\hline $\begin{array}{l}\text { - orientation on } \\
\text { doctors }\end{array}$ & $15.8(4)$ & $18.9(2)$ & $19.3(4)$ & $\begin{array}{l}1<(2=3) \\
p=0.061\end{array}$ & $15.0(1)$ & $17.4(1)$ & $19.9(2)$ & $\begin{array}{l}1<3 \\
p=.021\end{array}$ \\
\hline $\begin{array}{l}\text { - chance- } \\
\text { orientation }\end{array}$ & $18.7(5)$ & $17.3(4)$ & $23.1(4)$ & $\begin{array}{l}(1=2)<3 \\
p=026\end{array}$ & $18.2(1)$ & $18.3(2)$ & $18.8(3)$ & n.s. \\
\hline
\end{tabular}

Self-image

- positive

$34.6(1) \quad 35.3(2) \quad 33.1(4) \quad$ n.s. $\quad 34.9(1) \quad 35.8(1) \quad 34.8(3) \quad$ n.s.

- negative

$18.1(2) \quad 19.2(2) \quad 2 \% .0(3) \quad$ n.S.

$17.9(1) \quad 17.5(1) \quad 20.0(3) \quad$ n.s.

- percentage of self damaged

$\begin{array}{lll}31.0(4) \quad 43.9(3) \quad 55.2(1) \quad & 1<3 \\ p=017\end{array}$

27.6

$28.1(1) \quad 62.4(2) \quad(1=2)<3$ $p=000$

* one-way analysis of variance, using Scheffe's procedure for contrasts ( $p \leq 10)$.

* * scores at 11 for the period $t 2-13$; at 14 for $12-t 4$.

There are important differences in personality traits between the groups. At the third assessment there is a statistically significant difference in the scores on the inadequacy scale, the rigidity scale and the self- recognition scale: the relatively negative group scores higher on inadequacy than the positive group and lower on self-recognition than the positive and average groups. At $t 4$ a similar pattern exists, although this is not significant for the inadequacy scale. 
These findings are in line with expectations $3.1 \mathrm{a}$ and $\mathrm{c}$. The difference in the rigidity scores is not completely in line with our expectation formulated in chapter 4. We might, however, have expected such a difference: it is not surprising that patients with a high rigidity score report less change than others. Apparently this is not true for a longer period. We find no support for our expectation regarding social inadequacy: there is no significant difference, although a tendency in the expected direction is present at both assessments.

The relatively positive group has a significantly lower orientation on doctors at $\mathrm{t} 3$ as well as at $\mathrm{t} 4$. At $\mathrm{t} 3$ the relatively negative group has a higher chance-orientation. At $t 4$ this is not significant, but there is a slight tendency in the same direction. These differences are in line with expectation $3.2 \mathrm{~b}$. The results regarding the internal orientation are not in line with our expectation (3.2a), nor do they concur with the results found in the first phase of the study (table 7.4).

Expectation 3.3, regarding the self-image, is only partly supported by the data in table 11.4. The negative group experiences a significantly higher percentage of the self damaged than the other groups, at both assessments. The results of the scales derived from the semantic differential are not in line with the expectation: there is only a non-significant tendency of the relatively negative groups to score higher on the "negative' scale.

We now look at the relationships of the personal characteristics to actual changes over time. In table 11.5 the course of functioning during the period $\mathbf{t 2}$ t 3 is related to the scores at the second and the third assessment (for personality traits, the first), and the long-term course is related to scores at the second and fourth assessment.

The results here are very different from those in table 11.4. Only a few of the variables found to be related to the retrospective assessment of the course of physical functioning appear to have a relationship to changes over time and for some other variables the situation is reversed. The difference in the internal health locus of control scores for the period $\mathrm{t} 2 \mathrm{t} \mathrm{t} 3$ as well as that for the period t2-t4 does not support our expectation. The findings with respect to doctororientation partly affirm our expectation; the scores at $t 3$ and $t 4$ differ in the direction expected. The differences on the rigidity score regarding the period $\mathrm{t} 2-\mathrm{t} 3$ are in line with our expectation, but this is not very convincing.

Combination of the results in tables 11.4 and 11.5 is difficult. The general conclusion is that some of the personal characteristics investigated do r elate in a direction expected to the retrospective evaluation patients make of the course of physical functioning, but that they have no predictive value. In chapter 10 we already advanced the suggestion that the retrospective assess- 
Table 11,5 Personal characieristics of patients with a relatively postive, average or relatively nepative course of physical funetioning (change over time)

\begin{tabular}{|c|c|c|c|c|c|c|c|}
\hline $\begin{array}{l}12-43 \\
1 . \\
\text { posilive } \\
(\mathbb{N}=24)\end{array}$ & $\begin{array}{l}2 . \\
\text { average } \\
(\mathrm{N}=18)\end{array}$ & $\begin{array}{l}3 . \\
\text { negalive } \\
(N=25)\end{array}$ & $\begin{array}{l}\text { signifi- } \\
\text { cance of } \\
\text { difference* }\end{array}$ & $\begin{array}{l}12-i 4 \\
1 . \\
\text { posilive } \\
(N=22)\end{array}$ & $\begin{array}{l}2 . \\
\text { averaget } \\
(\mathbb{N}=21)\end{array}$ & $\begin{array}{l}3 . \\
\text { negatiwe } \\
(\mathrm{N}=24)\end{array}$ & $\begin{array}{l}\text { signillo- } \\
\text { cance of } \\
\text { differenco }\end{array}$ \\
\hline
\end{tabular}

Personally irails

- inadequacy

$0.1(2) \quad-0.3(3) \quad 0.0(1) \quad$ n.s.

$0.1 \quad-0.3(5) \quad-0.1(1)$

n.s.

-social inadequacy $-0.4(2) \quad-0.4(3) \quad 0.3(1) \quad$ nis.

$\begin{array}{llll}-0.3 & 0.2(5) \quad-0.2(1) \quad \text { n.s. }\end{array}$

- riglidity

$-0.9(2) \quad 0.0(3) \quad-0.3(1) \quad 1<2$

$\begin{array}{lll}-0.8 & -0.4(5) \quad 0.1(1)\end{array}$

n.s.

- self-recogition $\quad 0.2(2) \quad 0.7(3) \quad 0.2(1) \quad$ n.s.

$0.3 \quad 0.3(5) \quad 0.4(1)$

n.s.

Health locus of control

\begin{tabular}{|c|c|c|c|c|c|c|c|c|c|}
\hline \multirow[t]{2}{*}{$\begin{array}{l}\text { - Internal } \\
\text { orientation }\end{array}$} & 12 & $21.8(5)$ & $18.9(3)$ & $23.1(3)$ & $\begin{array}{l}2<3 \quad t 2 \\
p=.089\end{array}$ & $21.3(3)$ & $197(6)$ & 23.1 (2) & n.s. \\
\hline & 13 & $21.1(3)$ & $19.8(3)$ & $23.2(3)$ & n.s. & 22.0 & $18.8(1)$ & $22.3(2)$ & $\begin{array}{l}(1=3)<2 \\
p=.069\end{array}$ \\
\hline $\begin{array}{r}\text { - orientation } \\
\text { on doctors }\end{array}$ & t2 2 & $16.9(5)$ & $16.6(3)$ & $20.0(1)$ & m.s. & $18.7(2)$ & $15.3(6)$ & $19.5(1)$ & $\begin{array}{l}(1=3)>2 \\
p=.097\end{array}$ \\
\hline $2 \times 3$ & $\mathrm{t} 3$ & $15.4(4)$ & $19.4(2)$ & $18.7(3)$ & $\begin{array}{l}1<(2=3) \\
p=04 \pi\end{array}$ & 14 & 17.1 & $15.2(1)$ & $\begin{array}{l}20.2(3) \\
p=.010\end{array}$ \\
\hline
\end{tabular}

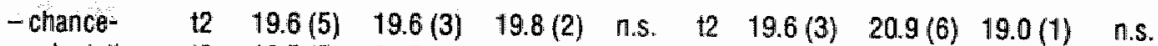
orientation t3 $18.5(5) \quad 21.5(4) \quad 20.1(3)$ n.s. $14 \quad 18.8(2) \quad 17.7(1) \quad 18.7(3)$ n.s.

\section{Self-image}

- positive t2 $35.3(2) \quad 36.9(3) \quad 34.9(1) \quad$ m.s. $\quad$ t2 $35.9(2) \quad 34.6(3) \quad 35.9(1)$ n.s. t3 $34.9(2) \quad 35.5(1) \quad 32.8(3) \quad n . s . \quad 14 \quad 35.1(1) \quad 34.8(2) \quad 35.7(2)$ n.s.

$\begin{array}{lllllllllll}- \text { negative } & \text { t2 } & 17.8(2) & 17.1(3) & 18.2(1) & \mathrm{n} . \mathrm{s} . & 12 & 17.1(11) & 18.7(3) & 17.6(2) & \mathrm{n.s} .\end{array}$ t3 $18.5(3) \quad 18.1(1) \quad 21.0(2)$ n.s. $t 4 \quad 18.2(1) \quad 18.2(2) \quad 18.7(2)$ n.s.

- percentage of t2 $30.1(4) \quad 37.9(2) \quad 36.2(2) \quad n . s . \quad$ t2 $37.4(2) \quad 34.9(3) \quad 31.7(3)$ n.s. self damaged t3 $37.0(2) \quad 43.4(3) \quad 48.3(2) \quad$ n.s. $\quad$ t4 $35.1 \quad 32.0(1) \quad 48.4(2) \quad$ n.s.

"one-way analysis of variance, using Scheffe's procedure lor contrasis $(0 \leq 10)$.

ment is explained by factors other than changes over time; now we must come to the same conclusion. This forces us to distinguish explicitly both approaches of the course of functioning in the subsequent analysis. 


\subsection{Personal characteristics related to the course of psychosocial}

functioning

This paragraph contains the investigation of the relationship of the personal characteristics studied to the course of psychosocial functioning. The approach is very similar to that in paragraph 11.2. Table 11.6 gives the necessary data on the course of functioning as perceived afterwards, while table 11.7 gives the relationships of the variables of interest to changes in functioning over time.

\section{Table 11.6 Personal characteristics at $t 3$ and $t 4$ of palients who experienced a relatively positive, average or relatively negative course of psychosocial functioning (assessment atterwards)}

\begin{tabular}{|c|c|c|c|c|c|c|c|}
\hline $\begin{array}{l}12-13 \\
1 .\end{array}$ & 2. & 3. & $\begin{array}{l}\text { signifi- } \\
\text { cance of }\end{array}$ & $\begin{array}{l}12-14 \\
1 .\end{array}$ & 2. & & $\begin{array}{l}\text { signifi- } \\
\text { cance of }\end{array}$ \\
\hline $\begin{array}{l}\text { positive } \\
(N=14)\end{array}$ & $\begin{array}{l}\text { average } \\
(N=43)\end{array}$ & $\begin{array}{l}\text { negative } \\
(N=10)\end{array}$ & difference * & $\begin{array}{l}\text { positive } \\
(N=21)\end{array}$ & $\begin{array}{l}\text { average } \\
(N=31)\end{array}$ & $\begin{array}{l}\text { negative } \\
(N=15)\end{array}$ & difteren \\
\hline
\end{tabular}

Personality irails

- inadequacy

$0.5(1) \quad-0.4(4) \quad 0.6$

$(1=3) \times 2$

$-0.3(2) \quad-0.2(5) \quad 0.7(2)$

n.s. $p=.059$

- sociall inadequacy

$-0.2(1)-0.2(4)-0.3$

n...

$-02(1)$

$-0.4(5) \quad-0.7(2)$

n.s.

- rigidily

$-1.0(1)-0.4(4) \quad 0.0$

m.S.

$-1.0(1) \quad-0.5(5) \quad-0.5(2)$

n.S.

- sell-recognition

0.4

0.5

$-0.6$

$(1=2)>3$

$p=.021$

$-0.1(2) \quad 0.4(5) \quad-0.8(2)$

23

Health locus of control

- internal orientation

$21.5(1)$

$22.6(7) \quad 18.1$

23

21.8

$20.2 \quad 21.9(1)$

n.s. $\mathrm{p}=0.045$

- orientation an

$16.4(1) \quad 18.0(7)$

18.7

n.s.

16.3

$17.8(3) \quad 18.7(1)$

n.s.

doclors

- chance-orientation

$20.3(2)$

$18.7(8) \quad 24.2(1) \quad 2<3$

$20.5(1) \quad 16.4$

$19.7(3)$

$(1=3)>2$ $p=0.079$ $p=.056$

Sell-image

- posilive

$33.2 \quad 35.0(4) \quad 33.0(1) \quad n .5$

339

$36.2(3) \quad 35.2(2)$

ก.ร.

- negalive

$20.2(1) \quad 18.1(4) \quad 22.9 \quad 2<3$

19.1

$17.2(3) \quad 19.9(2)$

ก.ร. $p=0.025$

- percentage ol sell

$40.4(2)$

$38.2(3)$

$66.7(1)$

$(1=2)<3 \quad 41.6$

$28.7(1) \quad 56.9(2)$

$2<3$ $p=0.027$

* one-way analysis of wariance, using Schelle's procedure lor contrasts lp s 10$)$. 
Table 11.7 Porsonal characteristics of paltents with a relatively positive, average or relatively negative course of psychosocial lunctioning (change over time)

\begin{tabular}{llllllll}
$12-13$ & \multicolumn{9}{c}{ signifi- } & $12-14$ & signifi- \\
1. & 2. & 3 & cance of & 1. & 2. & 3. & cance of \\
positive & average & negative & difference & positive & average & negative & difference* \\
$(N=23)$ & $(N=23)$ & $(N=21)$ & & $(N=23)$ & $(N=19)$ & $(N=25)$ &
\end{tabular}

\section{Personality traits}

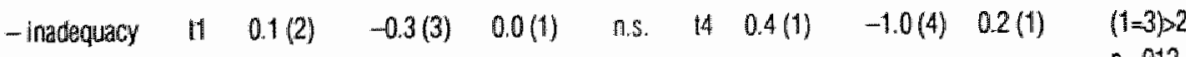

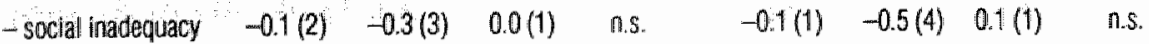

- rigidily $\quad-0.4(2) \quad-0.5(3) \quad-0.4(1) \quad n . s . \quad-0.5(1) \quad-0.7(4) \quad-0.3(1) \quad$ m.s.

$\begin{array}{llllllll}\text { - self-recognition } & 0.3(2) & 0.5(3) & 0.2(1) \quad \text { n.S. } & 0.0(1) & 0.9(4) & 0.2(1) & (1=3)<2\end{array}$ $\mathrm{p}=.046$

Health locus of control

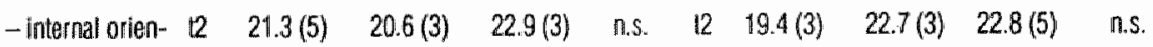

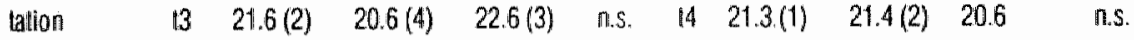

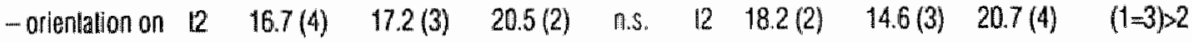
doctlors 13. $17.6(3) \quad 17.4(3) \quad 18.4(3)$ n.s. $\quad 14 \quad 15.6(1) \quad 16.5(2) \quad 20.0(1) \quad(1=2)<3$ $\mathrm{p}=.007$ $p=0.011$

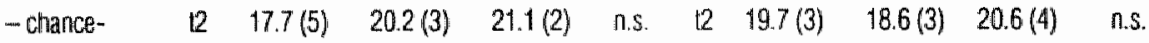
orientation $13 \quad 17.7(3) \quad 21.9(6) \quad 20.5(3)$ n.s. $14 \quad 17.3(2) \quad 18.8(3) \quad 19.1(1)$ n.s.

Self-image

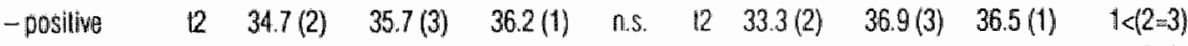

$13 \quad 35.2(2) \quad 34.4(1) \quad 33.1(3) \quad$ n.s. $14 \quad 34.0(1) \quad 36.8(2) \quad 35.3(2) \quad$ n.s.

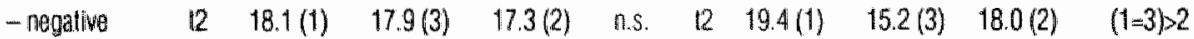
13- $17.7(2) \quad 10.1(1)-21.4(3)-1<\quad 14 \quad 18.6(1)-15.5(2) \quad 203(2) \quad(1-3 p 2$

13 $\quad 17.7(2) \quad 19.1(1) \quad 21.4(3) \quad 1<3 \quad 14 \quad 18.6(1) \quad 15.5(2) \quad 20.3(2) \quad(1-3)>2$ $p=075 \quad p=009$

- percentage of $12 \quad 33.8(2) \quad 36.0(3) \quad 34.1(3)$ n.s. 12 43.3.(5) $24.9(1) \quad 35.4(2)$ n.s.

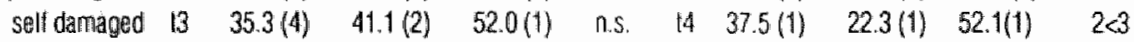

$p=.008$

* one-way analysis of variance, using Schefle's procedure Ior contrasts ( $\rho$ s. 10). 
The results in table 11.6 are only partially in line with our expectations. Insofar as it concerns the personality inventory, only the differences found on the selfrecognition scale go in the expected direction, at $t 3$ as well as at $t 4$. The significant difference on the inadequacy scale at $t 3$ is not in the right direction and not in line with previous results. The differences between the groups with respect to the internal orientation at $t 3$ weakly af firm expectation $3.2 \mathrm{a}$, but at $t 4$ this is not the case. The results regarding the orientation on doctors are in line with expectation $3.2 \mathrm{~b}$, but they are not statistically significant. The differences in chance-orientation at $t 3$ are broadly in line with our expectation, but this is not the case at $t 4$. The results regarding the self-image must lead to the conclusion that there is no clearly interpretable relationship between these characteristics and the experienced course of psychosocial functioning. Only the reported percentage of self damaged differs in the expected direction at $t 3$. At t 4 this is not systematically the case. The scores on the 'negative' scale also differ in a direction that gives some, but not very strong support for our expectation: the relatively negative group has a higher score on this scale than the average group. All in all, it gives only very weak support for expectation 3.3 with respect to psychosocial functioning.

In table 11.7 the scores at the time of the second and third respectively fourth assessment of the groups of patients with a relatively positive, average or negative course of functioning are presented, in order to investigate the relationships of the variables to changes in psychosocial functioning. This table gives no support for our expectations regarding the personality traits. With respect to the health locus of control, only the difference in doctor-orientation at $t 4$ between the groups with a relative positive, average or negative course of functioning goes in the expected direction. The difference between the same groups at $t 2$ does not support our expectation. The results regarding selfimage are also not very convincing. Only the relatively high score on the "negative' scale of the negative group in the period $t 2-t 3$ at $t 3$ and the relatively high percentage of the self damaged mentioned by the negative group in the period $12-\mathrm{t} 4$ give some support for our expectation.

\subsection{A summary and some conclusions}

Maybe even more clearly than in chapter 10 , the results in this chapter show a difference between the longitudinal and the retrospective approach of the course of functioning. It is obvious that the evaluation afterwards relates to variables other than change over time. Generally speaking most relationships are found with the retrospective approach: the personal characteristics investi- 
gated seem to relate to the assessment patients make of the course of functioning afterwards, but not as clearly in a prospective, predictive manner. Table 11.8 gives a schematic summary of the findings, related to the expectations. We now discuss the results regarding each variable separately.

\begin{tabular}{|c|c|c|c|c|c|c|c|c|}
\hline \multirow{2}{*}{ Table 11.8} & \multicolumn{8}{|c|}{$\begin{array}{l}\text { A schematic summary of the results on personal characteristics in retation to the } \\
\text { expectatlons }\end{array}$} \\
\hline & \multicolumn{4}{|c|}{ Physical functioning } & \multicolumn{4}{|c|}{ Psychosocial functioning } \\
\hline & & $\begin{array}{l}\text { assessment } \\
\text { afterwards }\end{array}$ & \multicolumn{2}{|c|}{$\begin{array}{l}\text { change } \\
\text { over time* }\end{array}$} & \multicolumn{2}{|c|}{$\begin{array}{l}\text { assessment } \\
\text { afterwards }\end{array}$} & \multicolumn{2}{|c|}{$\begin{array}{l}\text { change } \\
\text { over time* }\end{array}$} \\
\hline & $12-3$ & $t 2 \sim 4$ & t2-3 & $12-4$ & $12-3$ & $+2-4$ & $t 2-3$ & $12-4$ \\
\hline 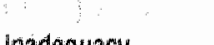 & & & & & & & & \\
\hline Intadequacy & ++ & 0 & 0 & 0 & $(+)$ & 0 & 0 & $(+)$ \\
\hline socilal inadequacy & 0 & 0 & 0 & 0 & 0 & 0 & 0 & 0 \\
\hline rigidity & $(+)$ & 0 & + & 0 & 0 & 0 & 0 & 0 \\
\hline self-recognition & ++ & t+ & 0 & 0 & ++ & + & 0 & $(+)$ \\
\hline internal orientation & 0 & 0 & -10 & $O /(+)$ & + & 0 & $0 / 0$ & $0 / 0$ \\
\hline doctor-orientation & +t & ++ & $0 /++$ & $(+) /+$ & 0 & 0 & $0 / 0$ & $(+1) /++$ \\
\hline chance-orlentation & ++ & 0 & $0 / 0$ & $0 / 0$ & + & $(t)$ & $0 / 0$ & $0 / 0$ \\
\hline positive self-image & 0 & 0 & $0 / 0$ & $0 / 0$ & 0 & 0 & $0 / 0$ & -10 \\
\hline negative self-imape & 0 & 0 & $0 / 0$ & $0 / 0$ & + & 0 & $0 /++$ & $(+) /(+)$ \\
\hline$\%$ of self damaged & ++ & $+t$ & 0.10 & $0 / 0$ & + & + & $0 / 0$ & $0 / t$ \\
\hline 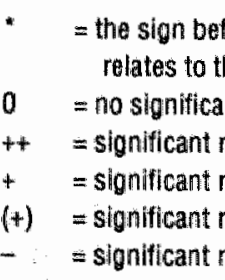 & $\begin{array}{l}\text { efore the slash re } \\
\text { those at } t 3 \text { and } \\
\text { ant relationship } \\
\text { relationship four } \\
\text { relationship four } \\
\text { relationship, no } \\
\text { relationship in }\end{array}$ & $\begin{array}{l}\text { es to th } \\
\text { aspecti } \\
\text { nd. } \\
\text { strong } \\
\text { suppo } \\
\text { pportit }\end{array}$ & $\begin{array}{l}\text { scores } \\
y \text {. } \\
\text { suppo } \\
\text { 19 the } \\
\text { the exi }\end{array}$ & $\begin{array}{l}2, \text { the } \\
\text { y the ex } \\
\text { ectation } \\
\text { tation. } \\
\text { ion. }\end{array}$ & $\begin{array}{l}\text { behin } \\
\text { ation. }\end{array}$ & e slash & & \\
\hline
\end{tabular}


Personality traits (3.1)

Our expectations regarding personality traits are to a limited extent affirmed by the results. Inadequacy is related to the experienced course of physical functioning in the expected direction, but not in the longitudinal analysis. Its relationship to the course of psychosocial functioning is unclear. Social inadequacy is not related to the course of physical or psychosocial functioning, neither retrospectively nor longitudinally. Our expectation regarding selfrecognition is quite systematically confirmed with respect to the experienced course of functioning afterwards, but not with respect to longitudinal changes. Rigidity is not convincingly related to the course of functioning in a way consistent with our expectation, although a tendency in the expected direction is present in most approaches: the relatively positive groups tend to have the lowest scores.

Although we did not include the other subscales of the Dutch Personality Inventory in our research model, we explored their relationship to the course of functioning. No significant differences were found in any of the approaches followed.

\section{Health locus of control (3.2)}

a. internal orientation:

We expected that a high internal health locus of control is related to a positive course of functioning. In the first phase of the study we did indeed find this relationship. In the present phase, however, no support was found for this expectation with respect to physical functioning. For the experienced course of psychosocial functioning during the first three months after discharge, a difference in the expected direction was found, but this was not true for the long-term period $t 2-t 4$. The internal orientation appears to have no predictive value.

b. doctor and chance-orientation:

A high doctor-oriented and chance-oriented health locus of control were expected to be related to a relatively negative course of functioning. For the experienced course of physical functioning afterwards the results are in line with this. Longitudinally, however, this is not the case. With respect to the experienced course of psychosocial functioning it is only partly the case: for the first three months after discharge a relationship with chance-orientation is found, but this is not true for the long period $12-t 4$. Longitudinally, only a relationship with doctor-orientation is found, but this is not supported by the other data. 
Self-image (3.3)

We expected that a positive self-image would be related to a positive course of functioning. Overall, the conclusion must be that this expectation is not supported as far as it concerns the scales derived from the semantic differential. The reported percentage of self damaged does differ in the expected direction in tables 11.4 and 11.6 , and partly in table 11.7. 


\section{CHAPTER 12}

\section{Social network characteristics and the course of functioning}

In this chapter we investigate the relationship of social network characteristics to the experienced course of functioning afterwards and to changes in functioning over time. Simillarly to chapter 11, the first paragraph describes how these network characteristics develop during the two years the patients were followed (12.1). Strictly speaking, this is beyond the research questions we want to answer, but it can be considered as necessary background information of a highly interesting nature, as will soon be clear. Paragraph 12.2 deals with the relationship between the network characteristics and the course of physical functioning. Paragraph 12.3 is about psychosocial functioning in relation to the network characteristics. The approach is similar to that in the previous two chapters: firstly the relationship of the variables of interest to the assessment of change afterwards and secondly their relationship to changes in functioning over time. Also similar to the preceding chapters, this chapter ends with a summary and some conclusions (12.4).

\subsection{Social networks in a time-perspective}

Table 12.1 presents the average network characteristics of the total group and the distinct diagnostic categories at the four subsequent assessments. 
Table 12.1 Social network characteristics at the sulisequent assessments, for the tolal group and the diagnostic categories separallely

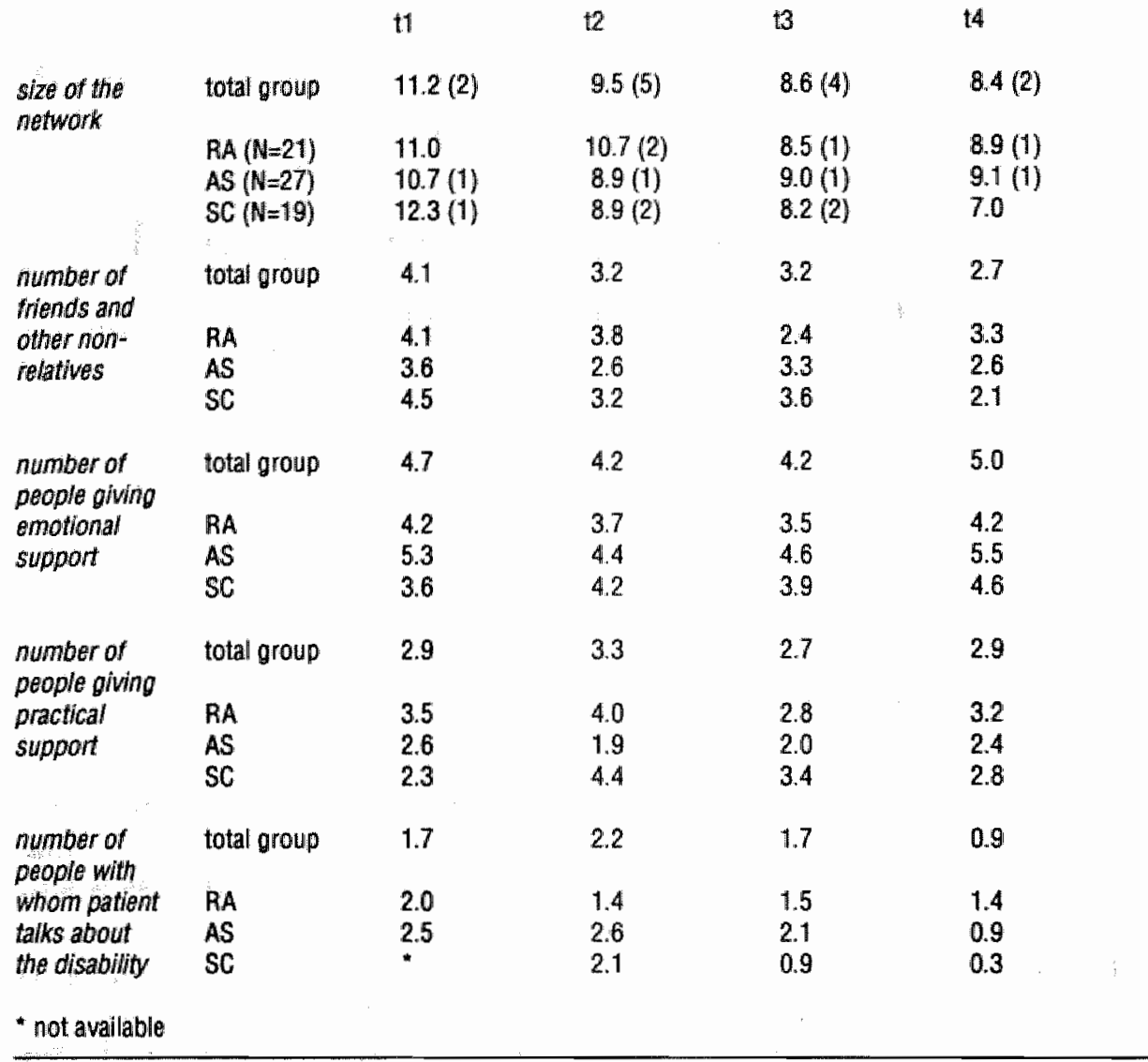

The figures show quite impressive changes in the networks over time: especially the size of the network and the number of friends and other non-relatives in the network decrease in each diagnostic category. This decrease is most obvious in the SC group. They 'lose' 5.3 people from their network over two years, especially non-relatives: about $45 \%$ of the people disappearing from the network are non-relatives, which means that they 'lose' more than half $(53 \%)$ of their friends and other non-relatives. For the other diagnostic categories the changes are less drastic $c_{n}$ but the decrease is obvious. For the total group, the decrease in size of the network between admission and discharge is statistically significant ( $T$-test: $p=002$ ); the later changes are not. The same goes for the decrease in the number of friends and non-relatives (T-test: $\mathrm{p}=.017$ ). The figures on emotional and practical support do not significantly change between the subsequent assessments. The number of people with 
whom the patients talk much about their disability decreases significantly after $\mathrm{t} 3$ (T-test: $\mathrm{p}=.061$ ), due largely to the decrease in the AS group.

There is only one statistically significant difference between the diagnostic groups at the different assessments: this concerns the number of people giving practical support. The AS group mentions fewer people (one-way analysis of variance: $\mathrm{p}=.067)$, which is understandable in view of their relatively mild disability.

\subsection{Social network characteristics related to the course of physical functioning}

The relationship of the social network characteristics to the retrospective assessment patients make of the course of physical functioning can be deduced from table 12.2. This gives the network characteristics of the groups of patients

Table 12.2 Social network characteristics al 13 and 14 of palients who experienced a relatively positive, average or negalive course ol physical lunctioning (assessment aflerwards)

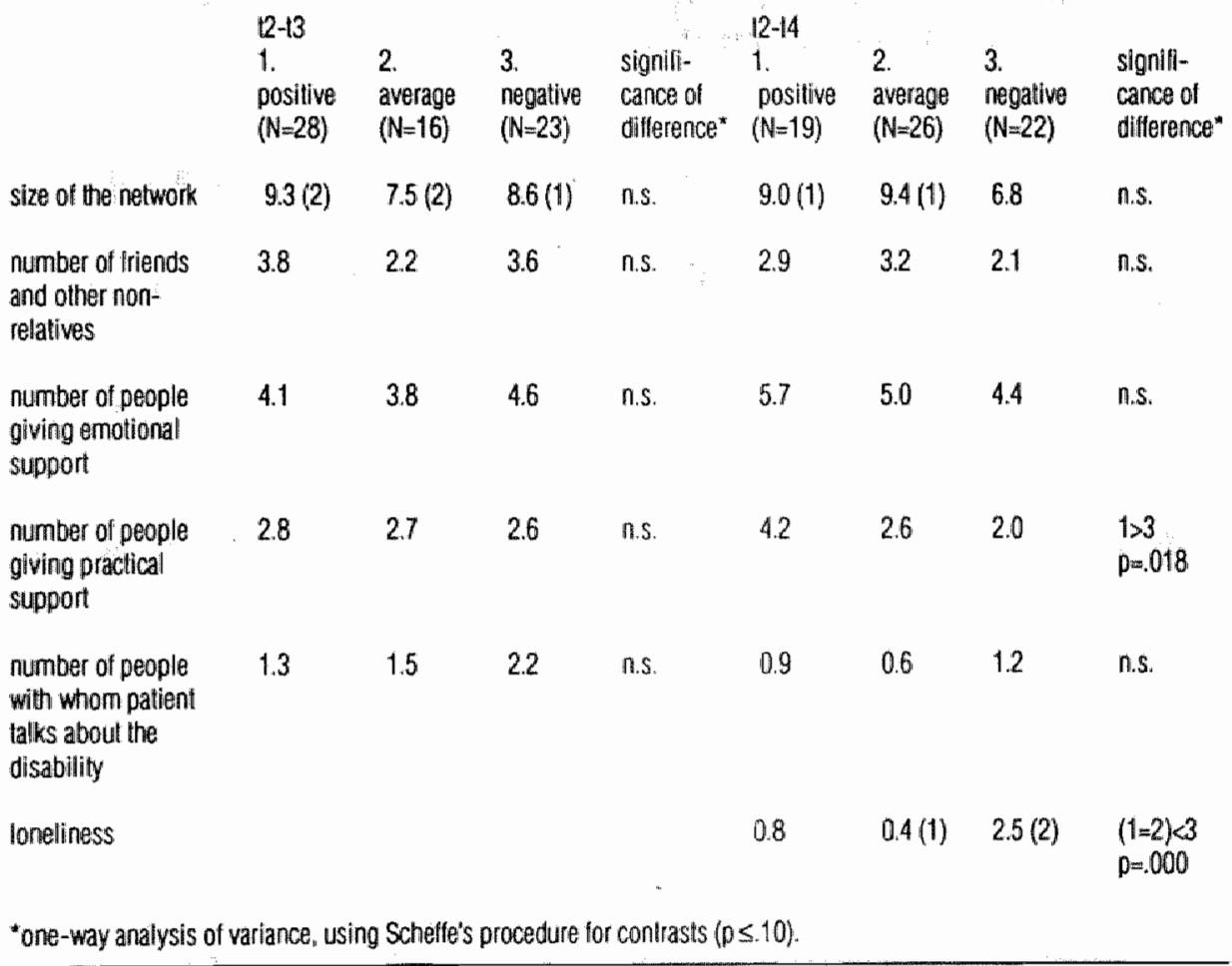


who experienced a relatively positive, average or relatively negative course of functioning at $t 3$ and at $t 4$. For $t 4$ the scores on the loneliness scale (see chapter 4, page 46) are presented as well. Unfortunately these are not available for the earlier assessments.

There appear to be very few significant differences between the groups distinguished. The network characteristics seem not to be r elated to the experienced short-term course of physical functioning ( $t 2-t 3)$. For the long-term course of functioning there is only a significant difference with respect to the number of people giving practical support to the patients and with respect to feelings of loneliness: the relatively negative group feels more lonely and has fewer people giving practical support than the other groups. The figures on emotional support and the size of the network at $t 4$ show a non-significant tendency in the same direction.

These results point in the direction that there is a relationship between social support and the experienced course of physical functioning over a longer period, which is in line with expectation 3.6. Expectations 3.4 and 3.5, regarding size of the network and number of non-relatives, are not supported by these results.

Table 12.3 Soclal network characteristics of patients with a relatively posilive, average or negalive course of physical functioning (change over time)

\begin{tabular}{|c|c|c|c|c|c|c|c|c|c|c|}
\hline \multirow{3}{*}{$\begin{array}{l}\text { size of the } \\
\text { nelwork }\end{array}$} & & $\begin{array}{l}12+13 \\
1 . \\
\text { posilive } \\
(\mathbb{N}=24)\end{array}$ & $\begin{array}{l}2 . \\
\text { average } \\
(\mathrm{N}=18)\end{array}$ & $\begin{array}{l}3 . \\
\text { negative } \\
(N=25)\end{array}$ & \multicolumn{2}{|c|}{$\begin{array}{l}\text { signifif- } \\
\text { cance of } \\
\text { difference* }\end{array}$} & $\begin{array}{l}12-14 \\
1 \\
\text { posilive } \\
(\mathrm{N}=22)\end{array}$ & $\begin{array}{l}2 . \\
\text { average } \\
(N=21)\end{array}$ & $\begin{array}{l}3 . \\
\text { negative } \\
(N=24)\end{array}$ & $\begin{array}{l}\text { signifi- } \\
\text { cance of } \\
\text { dilference" }\end{array}$ \\
\hline & 2 & $12.1(3)$ & $9.6(1)$ & $7.1(1)$ & $\begin{array}{l}1>3 \\
p=013\end{array}$ & 12 & 1118 & $8.0(4)$ & $8.4(1)$ & $\begin{array}{l}1>(2=3) \\
p=.059\end{array}$ \\
\hline & 13 & $9.4(3)$ & $9.1(1)$ & $7.6(1)$ & $\mathrm{ns}$ & 14 & 10.2 & $6.4(2)$ & 8.3 & $\begin{array}{l}1>2 \\
p=.055\end{array}$ \\
\hline $\begin{array}{l}\text { number of } \\
\text { Irienids and other }\end{array}$ & 12 & 3.7 & 4.4 & 2.0 & $\begin{array}{l}2>3 \\
p=.088\end{array}$ & 12 & 2.7 & 3.5 & 3.5 & n.s. \\
\hline non-relatives: & 13 & 3.2 & 3.9 & 26 & n.S. & 14 & 3.3 & 1.7 & 3.0 & n.s. \\
\hline $\begin{array}{l}\text { number of people } \\
\text { giving eminotional }\end{array}$ & 12 & 5.3 & 4.4 & $3: 3$ & a.s. & 12 & 4.1 & 3.8 & 4.8 & n.s. \\
\hline support & 13 & 5.4 & 32 & 3.9 & $\begin{array}{l}1>(2=3) \\
p=090\end{array}$ & 14 & 6.1 & 4.5 & 4.3 & n.S \\
\hline $\begin{array}{l}\text { number of people } \\
\text { giving practical }\end{array}$ & 12 & 3.3 & 4.2 & 3.6 & n.s. & 12 & 2.6 & 2.6 & 4.4 & n.s. \\
\hline support & 13 & 2.4 & 4.1 & 1.9 & $\begin{array}{l}(1=3)<2 \\
p=078\end{array}$ & 4 & 3.5 & 2.4 & 2.7 & n.s. \\
\hline $\begin{array}{l}\text { number of people } \\
\text { with whom peltient }\end{array}$ & & 2.9 & 1.5 & 2.0 & n.s. & 12 & 3.1 & 2.1 & 1.3 & n.s. \\
\hline $\begin{array}{l}\text { lalks about the } \\
\text { disability }\end{array}$ & $\$ 3$ & 1.1 & 2.1 & 1.9 & n.s. & 14 & 0.8 & 0.6 & 1.3 & n.s. \\
\hline
\end{tabular}


The relationship of these variables to longitudinal changes in functioning, shown in table 12.3 , presents a quite different picture. There is a statistically significant difference with respect to the size of the network at the time of discharge ( $t 2$ ) between the relatively positive and negative groups, for the period $t 2-t 3$ as well as for the longer period $t 2-t 4$. This provides strong support for expectation 3.4. At the later assessments this difference has decreased, but a tendency in the same direction is still present at t3. The number of nonrelatives in the network at $\mathrm{t} 2$ is also significantly different for the short period. For the longer period and at the later assessments there is no difference, however: there is, therefore, little support for expectation 3.5 in these results. The figures with respect to emotional support give some support for our expectation (3.6): the relatively positive group in the period $t 2-t 3$ mentions significantly more people giving emotional support than the other groups at the third assessment. At $t 2 a$ tendency in the same direction is present, and the same goes for the groups distinguished in the period $\mathrm{t} 2-\mathrm{t} 4$ at the last assessment.

A closer look at the data regarding the period $t 2-t 4$, permits an interesting tendency with respect to social support to be seen: the positive group mentions more people giving support at $t 4$ than at $\mathrm{t} 2$, while the negative group shows an opposite tendency. This suggests that changes in experienced support are related to changes in functioning. The direction of this relationship in unclear; are people with a positive course of functioning more able to mobilize support or does support positively influence functioning? As already discussed in chapters 2 and 7 , probably both explanations are true.

Althogether, the results in tables 12.2 and 12.3 lead to partial support for our expectations regarding social network characteristics. The size of the network is related to changes in physical functioning over time, in the direction expected, but not to the assessment afterwards. Social support (practical support and feelings of loneliness) is related to the retrospective assessment of the course of functioning at $t 4$, and also to changes over time in the first three months after discharge (emotional support): Moreover, changes in experienced support seem to be related to changes in functioning.

\subsection{Social network characteristics related to the course of psychosocial functioning}

Table 12.4 gives the data on the relationship of the social network characteristics to the course of psychosocial functioning as perceived afterwards. Table 12.5 does the same for changes in psychosocial functioning over time. 
Table 12.4 Sociall nelwork characteristics at t3 and 4 of patients who experienced a relatively positive, averape or negative course of psychosocial functioning (assessment afterwarus)

\begin{tabular}{|c|c|c|c|c|c|c|c|c|}
\hline & $\begin{array}{l}12-13 \\
1 . \\
\text { posilive } \\
(N=14)\end{array}$ & $\begin{array}{l}2 . \\
\text { average } \\
(N=43)\end{array}$ & $\begin{array}{l}3 \\
\text { negallive } \\
(N=10)\end{array}$ & $\begin{array}{l}\text { signifit- } \\
\text { cance of } \\
\text { difference* }\end{array}$ & $\begin{array}{l}12-14 \\
1 . \\
\text { positive } \\
(N=21)\end{array}$ & $\begin{array}{l}2 . \\
\text { average } \\
(N=31)\end{array}$ & $\begin{array}{l}3 . \\
\text { negative } \\
(N=15)\end{array}$ & $\begin{array}{l}\text { signifi- } \\
\text { cance of } \\
\text { diflerence }\end{array}$ \\
\hline size of the retwork & 11.6 & $7.6(4)$ & 8.6 & $\begin{array}{l}1>2 \\
p=051\end{array}$ & 9.7 & 83 & 6.9 & n.s. \\
\hline $\begin{array}{l}\text { number of iriends } \\
\text { and othur non- } \\
\text { relatives }\end{array}$ & 5.4 & 2.9 & 1.4 & $\begin{array}{l}1>2 \times 3 \\
p=015\end{array}$ & 3.4 & 2.9 & 1.5 & n.s. \\
\hline $\begin{array}{l}\text { number of people } \\
\text { giving emotional } \\
\text { support }\end{array}$ & 5.9 & 3.6 & 4.1 & $\begin{array}{l}1>2 \\
p=081\end{array}$ & 5.9 & 4.9 & 3.9 & n.s. \\
\hline $\begin{array}{l}\text { number of people } \\
\text { giving practical } \\
\text { support }\end{array}$ & 4.9 & 20 & 2.3 & $\begin{array}{l}1>(2=3) \\
p=011\end{array}$ & 4.0 & 2.0 & 2.9 & $\begin{array}{l}1>2 \\
p=.025\end{array}$ \\
\hline $\begin{array}{l}\text { number of peopla } \\
\text { willin whom patient } \\
\text { talks about the } \\
\text { disability }\end{array}$ & 21 & 1.3 & 2.3 & n.s. & 0.9 & 0.9 & 1.0 & n.s. \\
\hline loneliness & & & & & 0.5 & $1.2(2)$ & $2.1(1)$ & $\begin{array}{l}1<(2=3) \\
p=060\end{array}$ \\
\hline
\end{tabular}

The results in table 12.4 strongly support all our expectations regarding social network characteristics. The relatively positive group at $\mathrm{t} 3$ has larger social networks, with more friends and other non-relatives, and they report receiving more emotional and practical support. The figures regarding $t 4$ show an obvious systematic tendency in the same direction, although this is only significant for practical support. The relatively negative group at t4 has significantly more feelings of loneliness than the other groups, which is also in line with our expectations.

The results presented in this table must lead to the conclusion that the assessment patients make retrospectively of the course of psychosocial functioning is strongly related to social network characteristics.

In contrast to table 12.4 , table 12.5 shows no clear relationship of most of the network characteristics to longitudinal changes in psychosocial functioning. Only the groups distinguished with respect to the long-term course of func- 
tioning show a significant difference in network-size at the last assessment in the expected direction: the positive group has the largest networks at $t 4$. Similar to what we saw in chapter 11 with respect to the personal characteristics investigated, this leads to the conclusion that the network characteristics relate to the assessment patients make of the course of psychosocial functioning afterwards, but not in a prospective, predictive manner.

Table 12.5 does show the same tendency as described for 12.3: with respect to the period $t 2-t 4$, the positive group shows an increase of the number of people supporting them, while the opposite tendency is present in the negative group. Although this tendency is less obvious than in table 12.3, it also suggests a relationship between changes in experienced support and the course of functioning.

Table 12.5 Social network characteristics of patients with a relalively posilive, average or negalive course of psychosocial functioning (change over lime)

\begin{tabular}{|c|c|c|c|c|c|c|c|c|c|}
\hline \multirow{3}{*}{$\begin{array}{l}\text { size of the } \\
\text { network }\end{array}$} & & $\begin{array}{l}12-13 \\
1 . \\
\text { positive } \\
(N=23)\end{array}$ & $\begin{array}{l}2 . \\
\text { awerage } \\
(N=23)\end{array}$ & $\begin{array}{l}3 . \\
\text { negative: } \\
(N=21)\end{array}$ & $\begin{array}{l}\text { signifi- } \\
\text { cance of } \\
\text { difference }\end{array}$ & $\begin{array}{l}12-14 \\
1 . \\
\text { pasitive } \\
(N=23)\end{array}$ & $\begin{array}{l}2 . \\
\text { average } \\
(\mathrm{N}=19)\end{array}$ & $\begin{array}{l}3 . \\
\text { negative } \\
(\mathrm{N}=25)\end{array}$ & $\begin{array}{l}\text { signifi- } \\
\text { cance of } \\
\text { difference* }\end{array}$ \\
\hline & 12 & $10.0(2)$ & $7.2(2)$ & $11.3(1)$ & $\begin{array}{l}(1=3)>012 \\
p=059\end{array}$ & $9.1(1)$ & $10.8(2)$ & $8.9(2)$ & n.s. \\
\hline & $\mathbb{1 3}$ & $8.4(1)$ & $7.7(1)$ & $10.0(2)$ & n.s. 14 & 10.1 & $8.4(2)$ & 6.9 & $\begin{array}{l}1>3 \\
p=091\end{array}$ \\
\hline $\begin{array}{l}\text { number of } \\
\text { friends and other }\end{array}$ & $\mathrm{t} 2$ & 3.5 & 20 & 4.3 & n.s. & 23 & 4.2 & 3.4 & n.s. \\
\hline non-relativives & 13 & 2.6 & 2.6 & 4.6 & n.s. & 3.6 & 1.9 & 2.5 & n.s. \\
\hline $\begin{array}{l}\text { number of people } \\
\text { giving emotional }\end{array}$ & $\mathbb{2}$ & 4.6 & 3.8 & 4.5 & m.s. & 4.0 & 4.6 & 4.4 & n.s. \\
\hline Support & 13 & 4.1 & 3.6 & 5.1 & n.s. & 5.8 & 5.1 & 4.2 & n.s. \\
\hline $\begin{array}{l}\text { number of } \\
\text { people giving }\end{array}$ & 12 & 2.9 & 3.0 & 3.8 & n.s. & 2.5 & 3.7 & 3.7 & n.s. \\
\hline practical support & $\mathbf{B}$ & 2.7 & 2.6 & 2.7 & n.s. & 3.0 & 3.1 & 2.6 & n.s. \\
\hline $\begin{array}{l}\text { number of people } \\
\text { with whom patient }\end{array}$ & 2 & 2.7 & 1.3 & 2.4 & n.s. & 1.6 & 29 & 2.1 & n.s. \\
\hline $\begin{array}{l}\text { talks about the } \\
\text { disability }\end{array}$ & B & 1.7 & 1.3 & 2.0 & n.s. $\quad 14$ & 1.0 & 0.9 & 0.9 & n.s. \\
\hline
\end{tabular}




\subsection{A summary and some conclusions}

Just as in the two preceding chapters, the results in this chapter show important differences between the longitudinal and the retrospective approach of the course of functioning. Most significant relationships are found with the retrospective approach, especially with regard to psychosocial functioning. In table 12.6 the results are schematically summarised. The results regarding

\section{Talie 12.6 A schematic summary of the resulls on social network characteristics in relation to the expectations}

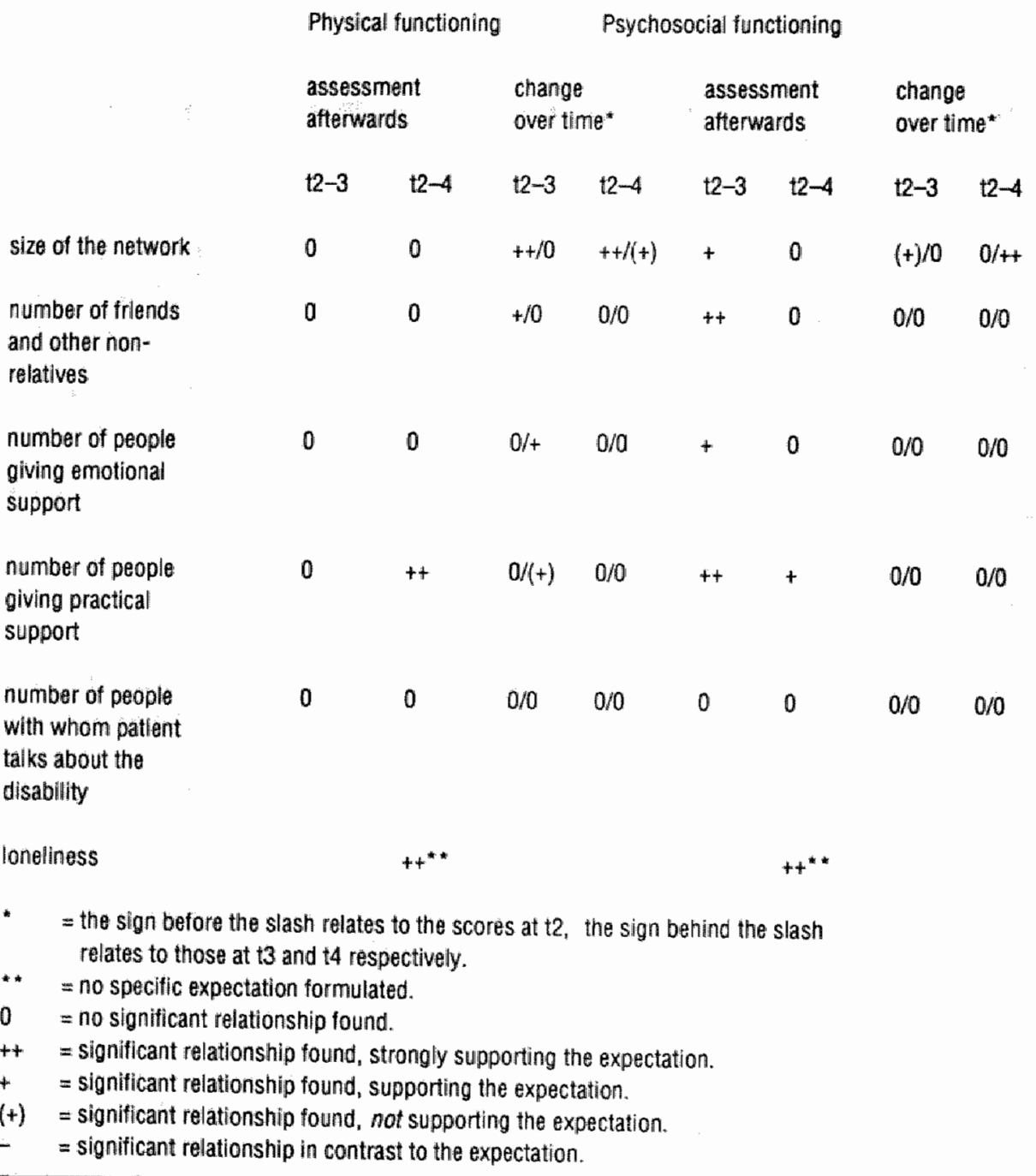


each variable separately are discussed below, from the perspective of the expectations.

\section{Size of the network (3.4)}

We expected that a large network would be related to a positive course of functioning. For physical functioning as well as for psychosocial functioning this expectation receives only partial support. The results regarding physical functioning show a relationship of network size with changes in functioning over time, but not with the assessment of the course of functioning afterwards, although a tendency in the same direction can be observed for the period $12-t 4$. For the course of psychosocial functioning the results mainly support the expectation for the assessment afterwards. The results regarding longitudinal changes are not unequivacal.

\section{Number of non-family members (3.5)}

With respect to physical functioning, the number of friends and other nonrelatives is only related to the course of functioning, in the way expected, during the first three months after discharge. The relationship found here is in no way supported by the results regarding $t 2-t 4$ or regarding the assessment of the course of functioning afterwards. We consider this only weak support for our expectation. For psychosocial functioning this is different. A large significant difference is found between the groups experiencing a relatively positive course of functioning and the other groups at $t 3$, and at $t 4$ a similar tendency is present. This supports our expectation as far as the assessment of the course of functioning afterwards is concerned.

\section{Social support (3.6)}

We expected that strong practical and emotional support is related to a positive course of functioning. With respect to the course of physical functioning the results give some support for this expectation, especially regarding practicall support. This is the case for the evaluation of the course of functioning at the last assessment and for longitudinal changes in the period $t 2-t 3$ (emotional support). Together with the results regarding loneliness, we consider this sufficient to conclude that social support is related to the experienced course of physical functioning afterwards. With respect to the course of psychosocial functioning the results are very clear: social support is related to the experienced course afterwards in the expected direction, but not to changes in functioning over time. The data with respect to changes over time suggest a relationship between changes in experienced support and the course of functioning, for physical as well as psychosocial functioning. The direction of this relationship is unclear. 



\section{CHAPTER 13}

\section{Continuity of professional care and the course of functioning}

The last group of independent variables in our research model to be discussed are the aspects of continuity of professional care distinguished in chapter 4 . In this chapter we investigate the relationship of these aspects to the course of functioning. Before doing so, however, we describe the results concerning continuity of care for the total group. In chapter 7 we concluded that there are problems in care after discharge. Tuning and coordination of care appeared to be less than optimal. In view of the scale of these problems, paragraph 13.1 is devoted to their analysis in the light of the results of the second phase of the study. Unlike all other results presented, this is done for the maximal available number of patients at $t 3$ and $t 4(N=85$ and 77 respectively). In paragraph 13.2 we investigate the relationship of continuity of care to the course of physical and psychosocial functioning. This is done for the 67 patients of whom all assessments are available. The approach is essentially similar to that in the foregoing chapters. The course of functioning during the first thr ee months is related to data on care during this period, while the long-term course is rellated to data on the period $t 2-t 4$. Paragraph 13.3 contains a summary and a discussion of the results in relation to the expectations. 


\subsection{Continuity of professional care after discharge}

In chapter 4 we distinguished four aspects in the operationalisation of continuity of professional care: coordinating contacts between care-providers, agreement on each others' tasks and duties, agreement between patient assessment and professional assessment of functioning and (patient) satisfaction with care (see paragraph 4.3.2.3). Results are now presented for these aspects separately.

\section{Coordinating contacts between care providers}

At the time the patients are discharged from the rehabilitation centre, the rehabilitation specialist sends a letter of discharge to the general practitioner and other medical specialists involved. Sometimes, when care by the community nurse is considered necessary, a special discharge form is send to the community nurse as well. This is the usual procedure in Dutch health care in general, including the field of rehabilitation. Looking at this procedure more in detail, it appears not to be without problems. First of all, the letter and the discharge form do not always reach the practitioner or nurse. Three months after discharge there were 6 of the 74 general practitioners interviewed who reported not having received any written information about the patient. For the community nurses this was so in 30 instances. Of the 23 cases in which there actually were contacts between community nurse and patient, only 11 had received information. Besides the fact that information does not always reach the care-providers involved, there is an even more important problem: most of the general practitioners admitted not having read the letter. They filed it in their archives and only read it if and when the patient came with a problem. Although written communication between professionals is very common, it appears to be less efficient than it ought to be. It does not obviously enhance continuity of care.

Besides the letter and discharge form there can be other ways of communication between professionals. To get an idea of the occurrence of other contacts, the general practitioners, community nurses and rehabilitation specialists in the study were asked at the third and fourth assessment whether they had had telephone or face-to-face contacts with other professionals involved in the three months before the interview and, if so, with whom, about what and on whose initiative the contact took place. In table 13.1 some of the results are summarised. This table shows that patients on the average have contacts with more than four different health professionals in the first three months after discharge. Later on this number decreases, but is still 3.1 in the three months before the last assessment. To give an idea of the necessity of coordinating 
contacts, the table indicates also the number of professionals contacted more than once during these three-month periods. We assume that, if two professionals have contacts with the patient more than once in three months, a contact between them is at least desirable. This basic assumption is used to compile the rest of table 13.1. Using this criterion, there appear to be 30 cases at t3 and 31 at $t 4$ in which no contacts were necessary. In 8 and 4 of these cases respectively there were, nevertheless, contacts between professionals. In nearly half of the cases in which a contact can be considered necessary, there was no single contact reported by any of the professionals interviewed with any other health professional (out of a list of 23). In only 28 cases at t3 and 24 cases at 44 was any contact reported. As already described in chapter 4 , we used very mild criteria to count these contacts. Any contact mentioned was considered to have taken place, even when it was not mentioned by the other professional involved. Because of the limited number of contacts reported we did not further distinguish the nature and contents of the contacts. Most of the contacts reported had the character of information-exchange. Discussion or policy-making was only rarely mentioned.

The number of contacts between rehabilitation centre and primary health care workers is strikingly low, especially in the first three months after discharge. Together with the findings regarding written information, this leads to the conclusion that one could hardly speak of transfer of care. The figures on

\section{Table 13.1 Coordination between care-providers}

\begin{tabular}{|c|c|c|}
\hline & $\begin{array}{l}12-t 3 \\
(N=85)\end{array}$ & $\begin{array}{l}t 3-t 4 \\
(N=77)\end{array}$ \\
\hline number of prafessionals involwed & $\begin{array}{l}4.4 \\
(0-9)\end{array}$ & $\begin{array}{l}3.1 \\
(0-8)\end{array}$ \\
\hline $\begin{array}{l}\text { number of protessionals contacted } \\
\text { more than once }\end{array}$ & $\begin{array}{l}2.6 \\
(0-7)\end{array}$ & $\begin{array}{l}2.2 \\
(0-6)\end{array}$ \\
\hline $\begin{array}{l}\text { coordinating contacts: } \\
\text { - } \quad \text { no contacts necessary } \\
\text { - } \quad \text { no contacts } \\
\text { - } \quad \text { some degree of communication } \\
\text { - } \quad \text { no information available: }\end{array}$ & $\begin{array}{r}30 \\
26 \\
28 \\
1\end{array}$ & $\begin{array}{r}31 \\
18 \\
24 \\
4\end{array}$ \\
\hline $\begin{array}{l}\text { number of cases in which there were } \\
\text { contacts between rehabilitation } \\
\text { centre and: }\end{array}$ & & \\
\hline - general practitioner & 3 & 8 \\
\hline
\end{tabular}


other coordinating contacts give reason to have doubts about the way the activities of the professionals involved in care are coordinated and integrated.

Agreement between care-providers on each others" tasks and duties

When everybody concerned knows what he or she has to do, and there is agreement upon that, it might be considered unnecessary to have coordinating contacts. The figures in table 13.2, however, show that there is very little agreement on tasks and duties between general practitioners and community nurses. This table gives the number of 'pairs' of general practitioners and community nurses pointing to the same person as primarily responsible for six different tasks. As already described in chapter 4, they had to make a choice out of four professionals. The answers were obtained at the time of the first assessment, hence before they had actually delivered (after)care to the patient. At the third assessment the same question was put to those professionals actually playing a role in the care for the patient after discharge. At t1 there were 65 pairs of professionals available, at $t 3$ only 17 . The results speak for themselves: only very rarely is a similar answer given.

The average number of tasks on which both professionals agree is only 0.7 out of these six at $t 1$. In more than half of the cases there is no agreement at all. The maximum number of tasks on which a pair agrees is 3 ; this occurs only

Table 13.2

Agreement on tasks and dulies between general practitioners and community nurses

Numbers of pairs pointing to the same professional as primarily responsible

$11(\mathrm{~N}=65)$

$13(N=17)$

guiding the patient through

health care and procedures

surveillance of care

arbitrating and helping with

agencies and difficult

procedures

counselling the tamily

counselling the patient

(atter discharge)

coordinating care after

discharge 
three times. At $t 3$ the results are not different: the average number of tasks on which both professionals agree is 0.9 , in 7 cases (out of 17) there is no agreement at all, the maximum agreement is 3 tasks, which occurs twice. Mostly both professionals admit responsibility, but not infrequently they both point to someone else or each other.

Together with the results on coordinating contacts presented before, these findings make it very unlikely that care after discharge is well coordinated and integrated. It is striking, moreover, that within each professional group there also appears to be a wide variety in answers (not presented). There certainly is no unanimous opinion about tasks and duties. This automatically means that there is also little agreement between the rehabilitation centre and the professionals in primary care. These results strongly reinforce the doubts formulated above, about the degree of coordination of activities of different professionals.

\section{Agreement between patient and care-providers about functioning}

The patients were asked at each assessment to assess different aspects of their own functioning. The professionals were asked how they thought the patient would answer these questions. In this way we can get an indication of how well the professionals know how the patient feels and thinks. In other wor ds, it gives an indication of the communicative distance between the patient and his professional care-providers. In chapter 9 as well as in chapter 6 we have already seen that the general practitioner and the patient make quite different assessments of the course of functioning. In chapter 7 we found little agreement between the assessments of patients, general practitioners and community nurses on the physical aspects of functioning. Now we investigate the degree of agreement between the assessment of the patients and the ideas of general practitioners and community nurses of how the patients assess their functioning. This is done for the physical aspects of functioning; as a basis we use the sumscore on physical functioning. Table 13.3 gives some figures regarding this aspect of continuity of care, three months after discharge and at the last assessment.

Twenty percent of the general practitioners who have had contact with the patient and for whom the measure could be computed report not having any idea about how the patient thinks about functioning. This percentage is about the same at both points in time. For the rest there is an average absolute score difference of about 2 scale points. The results for the community nurses are similar. The correlation coefficients indicate that both professionals have a reasonably good idea of how their patients would answer. The results are slightly more positive than those in chapter 7 . This might be expected because we now asked the professionals explicitly how the patient would answer, 
Table 13.3 Agreement between patients and caro-providers about functioning

$$
\mathrm{t} 3(\mathrm{~N}=85) \quad \mathrm{t}(\mathrm{N}=77)
$$

patient-general practitioner

number of cases in which there was no contact patient-general practitioner

number of general practitioners that have no idea

number of cases in which disagreement could not be computed *

average disagreement **

correlation coefficient

patient-community nurse

number of cases in which there was no contact patient-community nurse

number of community nurses

that have no idea

number of cases in which dis-

agreement could not be computed *

average disagreement * *

$1.9(\mathrm{~N}=16)$

$2.0(N=11)$

correlation coefficient

while in the first phase we only asked for their own assessment. We also computed the correlation coefficients between the patient-assessment and the assessments of general practitioners and community nurses. These are somewhat weaker indeed $(.52$ and .53 for the general practitioners at $t 3$ and $t 4$ respectively, .27 and .56 for the community nurses), and very similar to those in chapter 7 . 


\section{Satisfaction with care}

As a fourth aspect in the measurement of continuity of care, we measured the satisfaction of patients and social network members with care after discharge. In table 13.4 the results are summarised. The figures with respect to the social network members are the result of a combination of the two network members interviewed: when there were two, we averaged their answers; when there was only one, we used his/her answer.

\section{Table 13.4 Salisfaction of patients and network members with care since discharoe}

$\begin{array}{ll}t 2-t 3 & t 3-t 4 \\ (N=85) & (N=77)\end{array}$

Satisfaction with care *:

patient

social network

report mark for care:

patient

sociall network

number of report marks $\leq 6$ :

patient

sociall metwork

number of people having

complaints about care in

general/provision of aids

and adaptations:

patient

social network

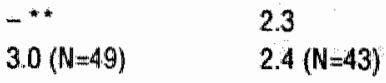

$-* *$

$7.4(\mathrm{~N}=62)$

$6.3(\mathrm{~N}=41) \quad 6.9(\mathrm{~N}=4.1)$

$\begin{array}{ll}-* & 17\end{array}$

2211

$15 / 12$

$28 / 12(N=60)$
7

11

\section{- 5-point rating scale: very satisfied (1) very dissatisfied (5)}

- not available

People are obviously not always satisfied with the care they received. Patients and especially social network members (mostly partners, parents, children) are only moderately satisfied with care, they give moderate report marks with a considerable number of unsatisfactory marks, and there are a considerable number of complaints about care. The content of these complaints is identical to those reported in chapter 7: an experienced lack of counselling and support, long and complicated procedures of the providing authorities, and a lack of adequate information. 
Taking all these findings together, we can only conclude that they coincide almost perfectly with those obtained in the first phase of our study. This must lead to the conclusion that coordination and tuning of care after discharge are far from perfect. The results show problerns regarding all the aspects of care distinguished. It becomes even questionable whether there are cases in which one could speak of 'continuity of care' according to our definition. In order to get an idea of this we created a global index in which we tried to combine the results on the four aspects of care distinguished for each patient/case. On the basis of the following criteria we gave a code 0 (neutral or negative) or 1 (positive) for each aspect.

- Coordination: any telephone or face-to-face contact mentioned by any of the professionals interviewed with any other professional resulted in a code 1 . For the period $t 2-t 3$ this was 28 times the case, for $t 2-t 426$ times.

- Agreement on tasks and duties: when general practitioner and community nurse agreed on one or more of the six tasks at $t 4$ and/or at $t 3$, a code 1 was given. This was 24 times the case.

- Agreement between the patient and care-providers: when there was a difference of less than 3 scale points between patient and general practitioner or between patient and community nurse, a code 1 was given. For the period $\mathbf{t} 2-\mathrm{t} 3$ this is 27 times the case, for $\mathrm{t} 2-\mathrm{t} 421$ times.

- Satisfaction with care: when the patient or the network members judged care as at least satisfactory or gave a report mark above 7 , this resulted in a code 1 . For the period $t 2-t 3$ this resulted in 11 cases in a code 1 , for the longterm period in 34 cases.

This index was created for the period $t 2-t 3$ and $t 3-t 4$ separately. For $t 3-t 4$ the agreement on tasks and duties was omitted, because this is only available for $\mathrm{t} 1$ and $\mathrm{t} 3$.

The criteria used are very rough, in order to create a maximum contrast. More strict criteria would lead to an almost negligible number of positive scores. Even when using these very mild criteria, the result is striking: with respect to the period $t 2-t 3$ there are 19 cases with a score of 0,15 cases with a score of 1,24 with a score of 2 and only 9 with a score of 3 . The score of 4 does not occur at all. More than half of the cases do not get a score higher than 1 on these four aspects. For the period $t 3-t 4$ the scores are as follows: 18 times 0,23 times 1, 18 times 2 and 8 times 3 .

These results leave no doubt: continuity of care as defined for this study does not really exist in the population studied. The consequences of this conclusion shall be further discussed in part IV of this book. For now it is important to state that these findings make it unlikely that clear relationships between these aspects of care and the course of functioning will be found. It is 
at least questionable whether the differentiation created in the previous tables is meaningful.

\subsection{Continuity of care related to the course of functioning}

The figures regarding the relationship of the aspects of continuity of care to the course of physical and psychosocial functioning are presented in appendix IV. They are rather disappointing. There are only very few significant and clearly interpretable relationships. Therefore the tables regarding the relationship between continuity of care and functioning are not presented in this chapter. The only conclusion from the analysis can be that patients experiencing a relatively negative course of functioning more often have contacts with more different heallth professionals, and that in these cases more coordinating contacts are necessary. It is also clear, however, that there are not relatively more coordinating contacts. The other figures reveal no clearly interpretable relationship of any of the aspects distinguished to the experienced course of physical and psychosocial functioning. The very few significant differences found are not convincing or not systematic, and not supported by the other data.

\subsection{A summary and some conclusions}

Summarising the results presented in this chapter is not difficult. With respect to the description of care after discharge we already formulated the conclusion that coordination and tuning of care after discharge is far from perfect. The findings are in line with those in the first phase of the study, which makes them very trustworthy and hard to neglect. In part IV of this book we return to this conclusion and try to formulate some recommendations.

With respect to the relationship of these aspects to the course of functioning, the summary is very easy: no clear relationship is found in any of the approaches followed. The only clear result is that patients with a relatively negative course of functioning (especially physical) tend to have more frequent contacts with more professionals. In these cases more coordination might be considered necessary, but according to our findings, this does not occur.

The interpretation and explanation of these findings regarding the relationship of continuity of care to the course of functioning is much less easy than summarising them. In paragraph 13.1 we already described that there were no 
cases in which one could with conviction speak of 'continuity of car $e^{\prime}$. We created maximal contrasts on the four aspects studied to get some dif ferentiation of the care-situations. The differentiation created may, therefore, be almost fictitious. We consider this the most probable explanation of the fact that no relationships are found.

The other explanation might of course be that there really is no relationship between continuity of care and functioning. On the basis of common sense alone this is hard to believe however. For our study this conclusion has important consequences. It means that continuity of care cannot, for statistical reasons, be included in the analysis of the factors explaining or predicting the course of functioning. Our expectation (3.7) regarding continuity of care cannot be tested in this study.

Finding no clear relationship between aspects of continuity of care and the course of functioning leads to another important conclusion, although this is beyond the questions we try to answer. It means that a negative course of functioning of the patient or a larger number of professionals involved do not lead to more coordinating activities between professionals. Apparently the number of contacts between professionals is not related to complexity and/or necessity of care. They almost seem accidental. 


\section{CHAPTER 14}

\section{A multivariate analysis: explaining the course of functioning}

One of the aims of this study is to explain differences in the course of functioning after discharge from rehabilitation, with the personal characteristics, social network characteristics and the aspects of continuity of care investigated as potential explanatory variables. In chapter 7 and in chapters 10 to 13 we studied the bivariate relationships of all the variables of interest to different measures of the course of functioning. We followed a rather straightforward approach for this analysis: on the basis of comparisons of groups of patients with a relatively positive, average or negative course of functioning, we investigated the differences or otherwise these groups showed on the variables subjected to analysis. In this way we gained insight into the bivariate relationships of these variables to the course of functioning. In this chapter we perform a multivariate analysis with a limited set of variables, selected on the basis of the results in the preceding chapters. We try to find out which variables have an independent significant relationship to the experienced course of functioning and which variables actually predict the course of functioning. The selection of the variables to be included in the analysis and the way the analysis is done, are discussed in paragraph 14.1. In paragraph 14.2 we discuss the relationships between the variables selected. In paragraph 14.3 we present 
the results regarding the course of physical functioning, with 14.4 focusing on psychosocial functioning. In these two paragraphs we try to answer our fourth research question, regarding the relative importance of the variables mentioned in explaining the course of functioning. In 14.5 we discuss some problems in the analyses performed that might have caused incorr ect interpretations, and describe an alternative analysis, intended as a check on the results in 14.3 and 14.4. Finally, in 14.6, we discuss the results and formulate some conclusions.

\subsection{A selection of the variables to be included in the multivariate analysis and a description of the method}

We want to explain or predict the dependent variable, i.e. the course of functioning, as accurately as possible with as small a number of variables as possible. Therefore we want to restrict the number of variables to be taken into account. The results presented in the preceding chapters $(7,10-13)$ make a selection possible. When combining the results in the summarising tables at the ends of these chapters, it is clear that some of the variables investigated are not related to the course of functioning in any of the approaches followed or in only one in an unclear or unsystematic way. This is the case for the following variables:

- sex

- marital status

- objective level of disability

- complicating diseases or impairments (at t1)

- the personality trait social inadequacy

- the self-image as measured with the semantic differential

- the number of people giving emotional support

- the number of people with whom the patient talks about the disability

- all the aspects of continuity of care

These variables are not included in the further analysis. The social network characteristic 'number of friends and other non-relatives' is also excluded from further analysis, because it correlates rather strongly with the size of the network: $55, .66$ and .66 at $t 2, t 3$ and $t 4$ respectively. Although socio-economic status is also significantly related to the course of functioning in only one of the approaches, we consider it theoretically too important to drop at this moment. It is likely to be related to the personal and social network characteristics, so that it might play an important role in a multivariate analysis.

Perhaps unnecessarily, we summarise the relationships of the remaining variables to the different approaches of the course of functioning in table 14.1. 


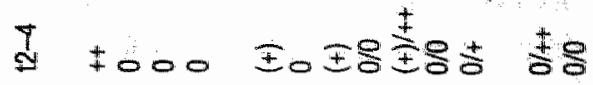

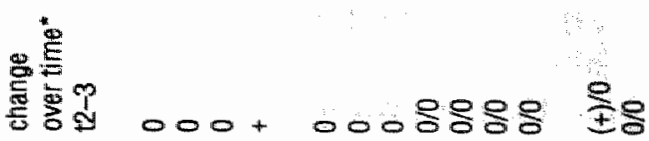

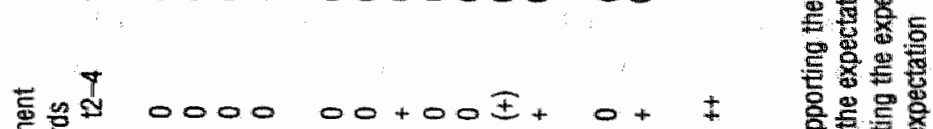

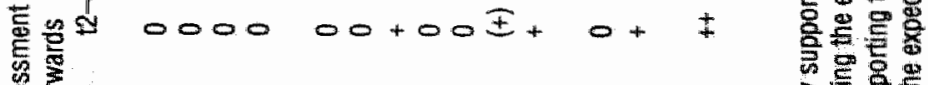
II $m$

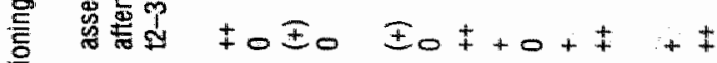

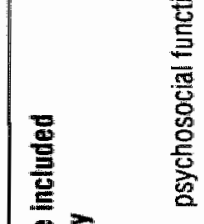

으롶

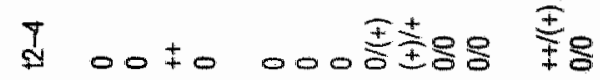

参 $\quad$ 总

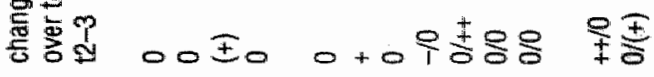

들 영

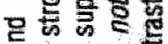
总证语 을를롤혼 드으은 응 현

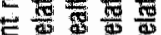
틀 影说

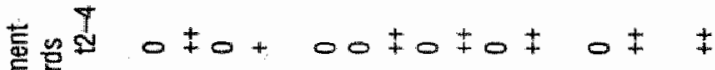

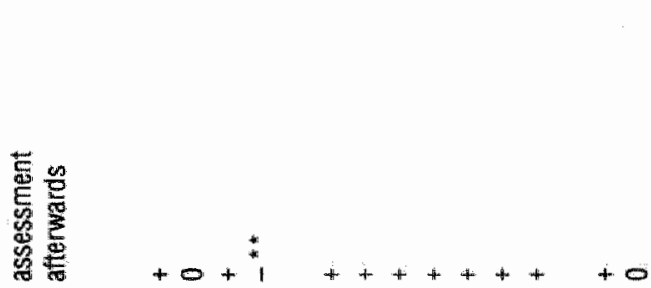

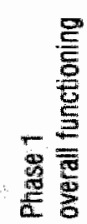

茞类

焉

$\stackrel{9}{\mathrm{~B}} \stackrel{\mathrm{a}}{\mathrm{w}}$

옹훙 号 
This is a combination of the tables $7.7,10.9,11.8$ and 12.6. In this table it is even more clearly visible than in the preceding chapters that most significant relationships are found with the retrospective approach of the course of functioning, and with respect to physical functioning. It is likely that the change-scores, especially those regarding psychosocial functioning, will remain largely unexplained in the analysis.

In an attempt to further reduce the number of variables, we performed a principal components analysis on the 7 personal characteristics selected, for each assessment separately. The results summarised in table 14.1 suggest that some of these characteristics tend to be associated. With this analysis we can investigate whether this is true. The results of the analysis are presented in table 14.2.

Table 14.2 Principal components analyses on the personal characteristics at 12 , $t 3$ and 14

12

factor 1 factor 2 factor 3 factor 1 factor 2 factor 1 factor 2 factor 3

\section{internal orientation} doctor-orientation chance-orientation inadequacy "

rigidity *

selt-recognition *

$\%$ damaged

Eigenvalue

$\%$ variance expl.

$\begin{array}{rrr}-.38 & .73 & .24 \\ .73 & .36 & .21 \\ .58 & .51 & .08 \\ .68 & -.34 & .04 \\ .35 & -.32 & .83 \\ -.58 & -.10 & .41 \\ .57 & .01 & -.23 \\ & & \\ 2.26 & 1.14 & 1.02 \\ 32.2 & 16.3 & 14.5\end{array}$

-.37
.53
.71
.68
.45
-.57
.55

2.21
31.6

.57
.61
.11
.30
.55
.53
.13
1.40
20.0

-.28
.44
.65
.72
.54
-.68
.73
2.49
35.6

$\begin{array}{rr}.59 & -.56 \\ .77 & -.12 \\ -.04 & .31 \\ -.20 & -.07 \\ .48 & .56 \\ .18 & .48 \\ -.19 & -.33\end{array}$

1.28

18.3

* for the analysis regarding $t 2$ and $t 3$, the scores from 11 are used. At $t 4$ the scores from $t 4$ are used.

These results show that most of these characteristics rather consistently tend to go together at each assessment. A high doctor-orientation, high chanceorientation, high inadequacy, low self-recognition and a high percentage of the self damaged strongly load on the first factor at each assessment. The internal orientation and rigidity have a somewhat less clear and consistent relationship to the other characteristics. Their loadings on the first factor are, however, sufficient, except for internal orientation at $t 4$. On the basis of these results we decided to combine the personal characteristics into a single new variable, being the factorscore on the first factor at each assessment separately. This new variable might be interpreted as 'being at a loose end' or $r$ as we term it, 'powerlessness'. People with a high score on this variable tend to be strongly doctor and chance-oriented, to have a high inadequacy score, a low self-recognition score and to have a negative self-image. They also tend to 
have a high rigidityscore and a low internal orientation.

A further reduction of the social network characteristics and the socialdemographic and disability-related characteristics is not meaningful. Thus, the variables to be included in the final analysis are:

- "powerlessness'

- size of the network

- number of people giving practical support

- loneliness (at $\mathbf{t} 4$ only)

- age

- socio-economic status

- duration of the disability

- intercurrent diseases after discharge

The technique selected for this purpose is a discriminant analysis, the most logical choice given our group-comparative approach. A discriminant analysis is performed for each of the approaches and time periods distinguished in the preceding chapters and in table 14.1. As discriminating variables we use the 8 variables listed above. With this technique it is possible to find the linear combination of variables that best discriminates between, or separates, the groups of patients with a relatively positive, average or negative (experienced) course of functioning, and it shows the relative importance of each variable in this respect. It is also possible to predict group membership on the basis of the discriminating variables.

For reasons of clarity we decided not to compare three groups of patients in one analysis, but to perform the analysis for the relatively negative and the relatively positive groups only. In this way only one discriminant function is computed, which greatly enhances a clear interpretation. Paragraph 14.5 discusses whether this omission of the average groups is likely to have influenced the results in such a way that wrong conclusions are drawn, and part of the results are checked by means of an alternative analysis technique.

A stepwise method is used, to find the smallest possible number of variables with maximal discriminating and predictive power. Statistical controls on stepping were SPSS-X default criteria (F-to-enter and F-to-remove of 1.0 and a tolerance level of .001; SPSS-X User's guide, 3rd.ed., 1988).

The number of cases available for these analyses is small: it varies between 21 and 44 . Although we have strongly restricted the number of independent variables, we have a cases to variables ratio of no more than 6 to 1 (4 to 1 in the worst case and 8 to 1 in the best case). We have not thoroughly checked the data for violations of assumptions. In most of the analyses, however, the groups analysed are about equally sized (except for the analysis regarding the assessment of the course of psychosocial functioning afterwards at 4 ), which 
considerably reduces concern about multivariate normality and homogeneilty of the variance-covariance matrices (Tabachnick and Fidell, 1983).

A special problem is that quite a number of cases are 'lost' in the analysis due to missing values on one or more of the discriminating variables. This tends to occur more often in the relatively negative groups, especially with respect to the long-term course of functioning. It is not possible to do anything about this; it can only be taken into account when interpreting the results.

\subsection{The relationships between the explanatory variables}

As basic information for the understanding of the results of the multivariate analysis to be presented, it is good to have insight into the relationships be-

Table 14.3 Correlations between the independent variables to be used in the discriminant anallyses

$\begin{array}{lllllll}2 . & 3 . & 4 . & 5 . & 6 . & 7 . & 8 .\end{array}$

second assessment (t2)

1. powerlessness

2. size of the network

$-.05$

.05

3. practical support

4. loneliness

5. age

6. socio-economic status

7. intercurrent diseases

8. duration of disability

$\begin{array}{ccccccc}-.05 & .05 & * & .35 & -.34 & * & .14 \\ & .41 & * & -.07 & .01 & * & -.09 \\ & & * & -.09 & -.01 & * & -.04 \\ & & * & * & * & * \\ & & & -.42 & * & .45 \\ & & & & * & -.02\end{array}$

third assessment (13)

1. powerlessness

2. size of the network

3. practical support

4. loneliness

5. age

6. socio-economic status

7. intercurrent diseases

8. duration of disability

$\begin{array}{rrrrrrr}-.07 & .07 & * & .34 & -.47 & .12 & .04 \\ & .50 & * & -.18 & -.14 & .07 & -.12 \\ & * & -.15 & -.01 & .07 & .07 \\ & & * & * & * & * \\ & & & -.42 & .08 & .45 \\ & & & & .10 & -.02 \\ & & & & & .01\end{array}$

fourth assessment (t4)

1. power ressness

2. size of the network

3. practical support

4. Ioneliness

5. age

6. socio-economic status

7. intercurrent diseases

8. duration of disabillty

$\begin{array}{rrrrrrr}-.10 & .05 & .31 & .25 & -.21 & .15 & -.03 \\ & .44 & .28 & -.16 & .12 & .00 & .00 \\ & -.11 & -.24 & .08 & -.12 & -.15 \\ & & .36 & -.35 & .10 & .01 \\ & & & -.42 & .05 & .45 \\ & & & & -.14 & -.02 \\ & & & & & -.03\end{array}$

- not available

* not relevant at 2 
tween the explanatory variables included in the analysis. Table 14.3 therefore gives the correlation matrices of the variables used, for each assessment separately. Statistically significant correlations $(p<.10)$ are italicized.

This table shows some potentially problematic correlations. Powerlessness appears to be connected with high age and low socio-economic status, high age tends to be associated with low socio-economic status and long duration of disability, and the amount of practical support received is connected with the size of the network. It is especially the connection between age and socioeconomic status, in combination with their opposite connection with powerlessness, which might cause some problems in the analysis.

\subsection{Explaining the course of physical functioning}

The final results of the series of discriminant analyses with respect to the course of physical functioning are presented in table 14.4. This table gives the standardised canonical discriminant function coefficients of the variables included in the discriminant function, as well as the structure coefficients (= the correlation of the original discriminating variable with the discriminant function) of all the variables included in the analysis. It also gives the canonical correlation coefficient, the eigenvalue and the percentage of cases classified correctly in the classification part of the analysis. Columns I and II in table 14.4 concern the assessment of the course of functioning when looking back in time at the third and fourth assessment. Here the discriminating variables are those obtained at $t 3$ and $t 4$ respectively. Columns III and IV concern the actual change-scores. Here the results of two different analyses are presented: once with discriminating variables from 12 (IIIA and IVA) and once with the same variables obtained at $t 3$ and $t 4$ respectively (IIIB and IVB). The reason for this 'double' analysis lies in the fact that personal characteristics and social network characteristics did not appear to be very stable in the preceding chapters. In this way we can get maximal insight.

In the analyses presented in table 14.4, age was not included as a discriminating variable. The reason for this is that in a first series of analyses age appeared to have a strongly negative canonical discriminant function coefficient which was in sharp contrast to the bivariate findings. This phenomenon - a 'simple' correlation and a significant discriminant function coef ficient with an opposite sign-, together with low structure-coefficients for age strongly $^{2}$ suggests that age is a so-called suppressor variable. This means that it 'suppresses' some variance in the other independent variables, caused by the fact that they are interrelated, and thus that it is wrongly included in the discriminant function. In table 14.3 we already saw that, in the total population in the 
study, age was negatively connected with socio-economic status and also positively connected with powerlessness. Looking at the within-groups correlation matrices of the independent variables for the groups included in the discriminant analyses, this appears to be even more clearly the case: age has strong negative correlations with socio-economic status in each analysis, and moderately positive correlations with powerlessness in the analyses regarding the actual change-scores (columns III and IV). This suggests that age is not a predictor of the course of functioning by itself, but that it acts through other variables, i.e. socio-economic status and powerlessness. In chapter 2 (paragraph 2.6) we already suggested that this might be the case. The phenomenon described occurred in five of the six analyses and in the sixth age appeared to play a minor role. Therefore age was left out of the final analysis.

In the analysis regarding the assessment of the course of functioning at $t 3$, a somewhat similar problem occurred. Here intercurrent diseases appeared to be a very important discriminating variable, which is in sharp contrast to the bivariate findings. This might also be caused by interrelations of the independent variables. In this case intercurrent diseases are related to socio-economic status and also weakly to powerlessness, two variables that are strongly (negatively) interrelated. For this reason the variable intercurrent diseases was also left out of the final analysis presented in column I of table 14.4. Its role in explaining the experienced course of physical functioning cannot be clearly interpreted.

We shall now discuss the results for each time-period investigated.

The first three months after discharge ( $t 2-t 3)$

The assessment patients make of the course of physical tunctioning when looking back at $\mathrm{t} 3$ (column I) appears to be largely explained by two variables: powerlessness and socio-economic status. These are the only two variables that significantly distinguish the patients with a relatively positive and negative assessment of the course of functioning, after adjusting for all other variables in the analysis. The patients in the relatively negative group feel more powerless or 'at a loose end' and are likely to have a lower socio-economic status. Powerlessness is the strongest predictor. On the basis of these two variables alone nearly $70 \%$ of the patients can be classified correctly into one of the groups. According to the structure coefficients none of the other variables contribute to the distinction of the groups. The role of age has already been discussed. In chapter 10 we found a significant difference in age between the groups distinguished, but this appeared to be an indirect relationship. High age increases the likelihood of having a low socio-economic status and is also related to powerlessness, but it is not directly related to the experienced 
Table 14.4 Discriminant analyses on the course of physical functioning (stepwlse method)

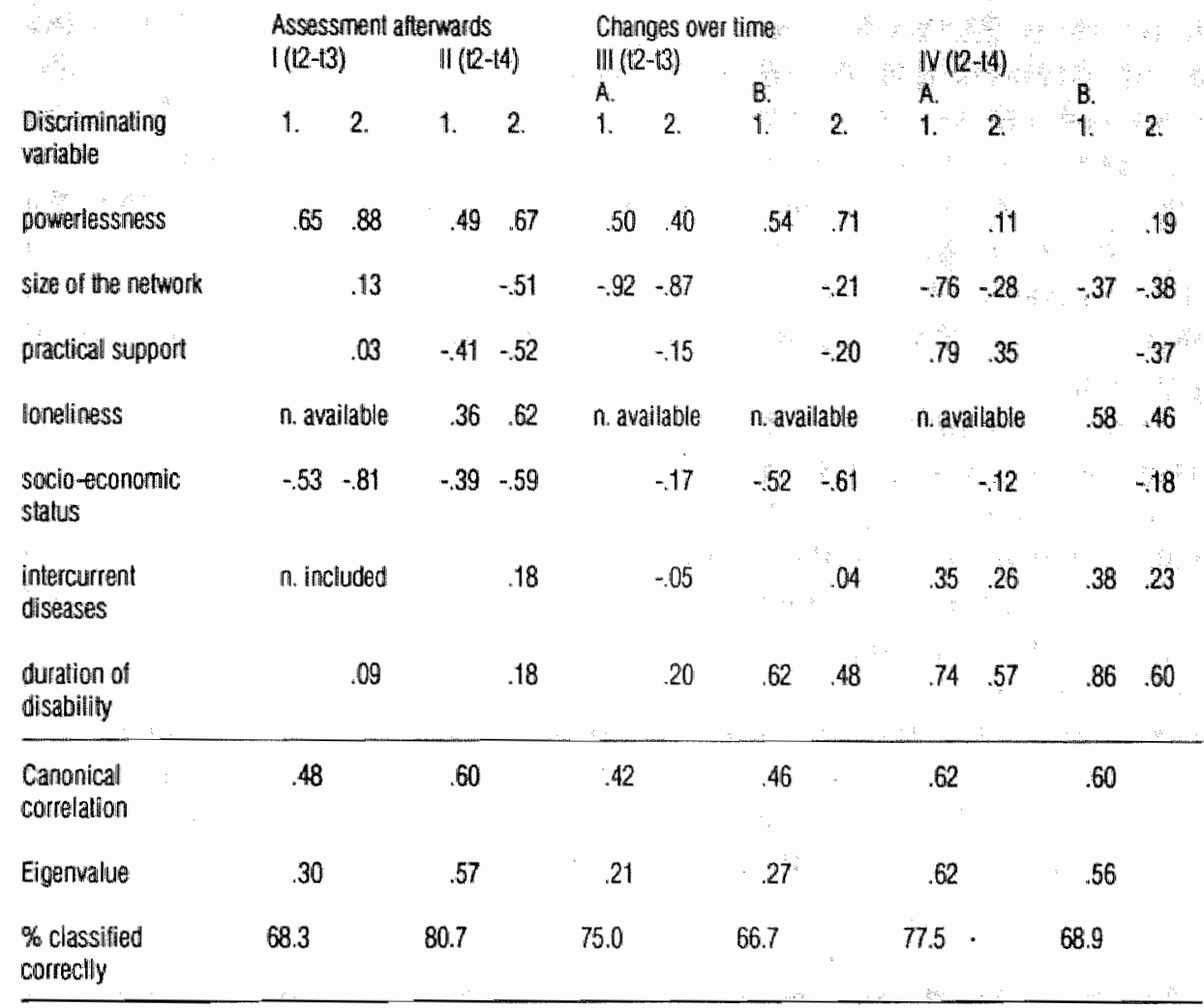

course of functioning. The occurrence of intercurrent diseases is, as already discussed, not likely to be related to the assessment patients make.

The results regarding changes over time are less clear. Using data from $\mathrm{t} 2$ as discriminating variables (column IIIA) leads to quite different results compared to using data from 13 (column IIIB). Consistent with the previously discussed analysis, powerlessness has a significant discriminating power in both analyses. At $t 2$ the size of the social network best distinguishes both groups of patients. The relatively negative group has small networks and scores high on powerlessness at the time of discharge. Three months later, the same two groups are best distinguished by duration of disability and socioeconomic status. The size of the network does not contribute to the distinction at that time. The relatively negative group is then characterized as follows: having a long duration of disability, a low socio-economic status and feeling powerless. The explanation of these seemingly contrasting findings can be 
found in tables 12.1 and 12.3 in chapter 12. In 12.1 we saw that the network tends to become smaller for the total patient population during the two years of the study. In 12.3 we presented the social network characteristics of the groups distinguished. The relatively negative group appeared to have an average network size of 7.1 at $t 2$ and 7.6 at $t 3$. For the positive group this figure changed from 12.1 at $t 2$ to 9.4 at $t 3$. Apparently the decline in network size takes place in those patients having a relatively large network, leading to a reduction of the differences between the groups with a relatively positive and negative course of functioning. At 3 this difference is no longer significant, so that other variables become more important in distinguishing the groups of patients.

The results of these analyses regarding changes over time must not be given too much weight, since the discriminant functions are not very strong. In a discriminant analysis following a direct method, which means that all the variables are forced into the discriminant function, the canonical correlation is not significant in either analysis. The reason for this might be the effect of regression to the mean, described in chapter 9 . We saw that the change-scores are strongly related to the initial scores at discharge. This means that group membership is partly predicted by initial scores, which clouds the results, especially since the initial scores are likely to be related to the independent variables as well. The regression-effect is not present with respect to the assessment of the course of functioning afterwards.

\section{The long-term course of functioning ( $t 2-t 4)$}

The results regarding the assessment patients make of the course of physical functioning since discharge at $\mathbf{t} 4$ (column II) are partly similar to those regarding the first three months. Powerlessness and socio-economic status are again variables that significantly distinguish both groups of patients, after adjusting for all the other variables. Powerlessness is, just as at $t 3$, the strongest predictor. The important difference is that at $t 4$ the social network characteristics also significantly contribute to the distinction of the groups: the group with a relatively negative course of functioning experiences less practical support and feels more lonely than the positive group. Apparently social support and loneliness carry considerable weight in the assessment of the long-term course of physical functioning. The four variables mentioned explain about $36 \%$ of the variability in the groups (canonical correlation .60) and it is possible to correctly classify $80 \%$ of the patients on the basis of them.

The importance of the social network characteristics in explaining the course of physical functioning is even clearer in the analyses regarding changes over time (colums IVA and B). When using data from $\mathrm{t} 2$ as discriminating variables, 
it appears that the following variables, in descending order, have a significant independent contribution to the distinction of the groups: practical support, size of the network, duration of the disability and intercurrent diseases. The group with a relatively negative course of functioning experiences more practical support at discharge, has smaller networks, a longer duration of disability and more often intercurrent diseases. The result regarding practical support is at first sight in contrast to what we expected (see chapter 3 , expectation 3.6). When looking at the results of the analysis on the basis of the data from $t 4$, however, it can be interpreted more clearly. The same group with a relatively negative course of functioning is then characterized by more feelings of loneliness and a small network, besides a long duration and more intercurrent diseases. The experienced amount of support does not play a significant role in the distinction of the groups. According to the structurecoefficient of -.37 it is negatively related to the course of functioning, which is in line with our expectation. Combination of the results from $t 2$ and $t 4$ strongly suggests that the relatively negative group has experienced a decline in the amount of practical support between discharge and 4 . In chapter 12 we indeed saw some evidence for this: in table 12.3 the number of people giving practical support in the relatively negative group appeared to be 4.4 at $t 2$ and 2.7 at $t 4$, while the same figures for the relatively positive group changed from 2.6 to 3.5. Thus, what at first sight appear to be contrasting results from analyses IVA and $B$, do in fact stress the importance of social support in explaining the course of physical functioning. On the basis of these dlata it is impossible to determine the causal direction of the relationship between social support and the course of functioning.

The results in columns IVA and B in table 14.4 are to a large extent similar, and lead to the same conclusion: social network characteristics (size and loneliness/practical support), duration of the disability and the occurr ence of intercurrent diseases are the most important variables in explaining the longterm course of physical functioning after discharge. In both analyses, the proportion of variance explained is considerable ( 36 and $38 \%$ ) with a fairly good classification result.

It is important to note that, unlike the results in column II regarding the assessment afterwards, powerlessness and socio-economic status appear not to be related to changes in functioning over time.

\subsection{Explaining the course of psychosocial functioning}

The final results of the series of discriminant analyses with respect to the course of psychosocial functioning are presented in table 14.5. This table is 
Taltie 14.5 Discriminant analyses on the course of psychosocial functioning

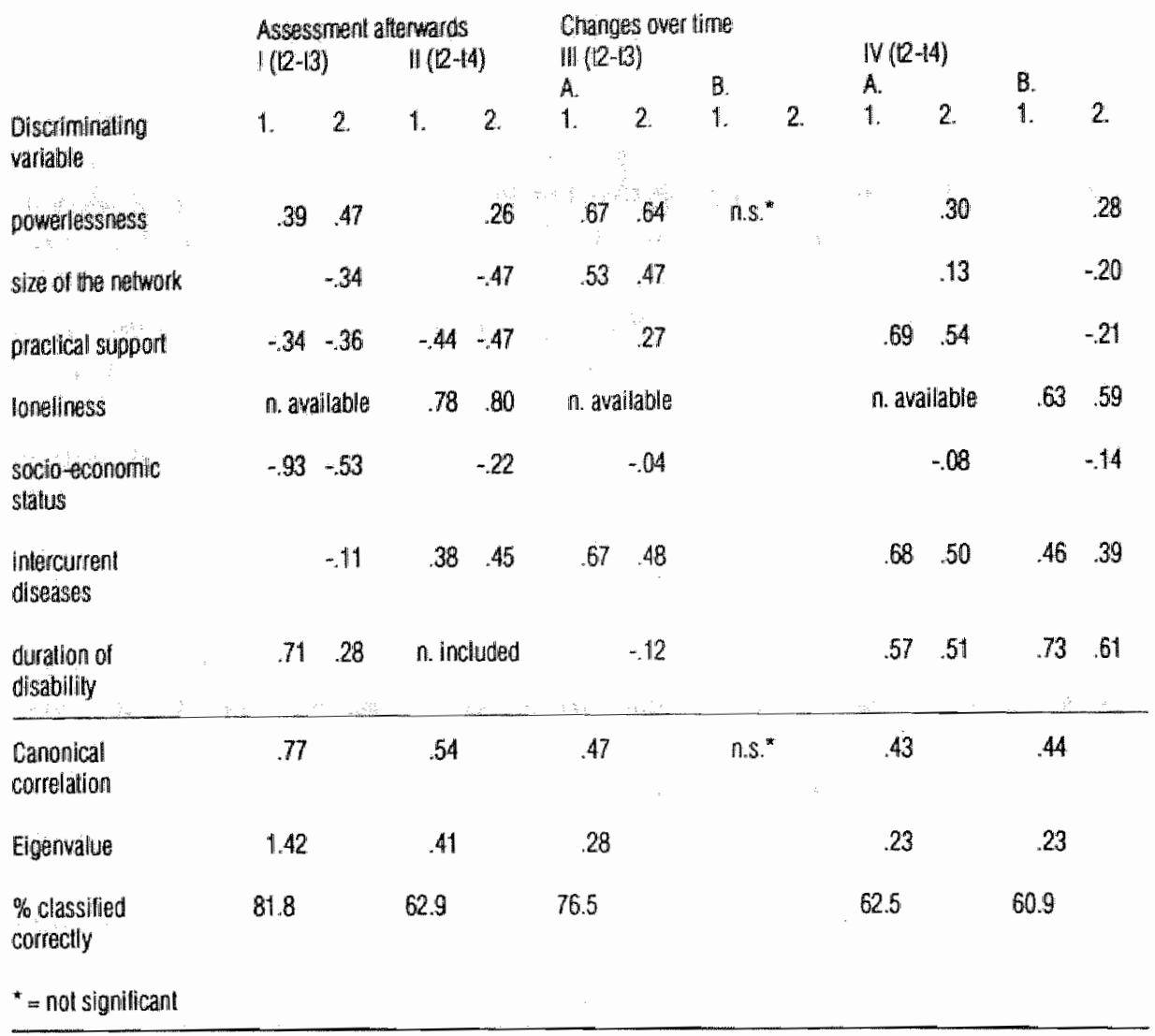

similar to 14.4. For the same reason as described in the previous paragraph, age was not included in the analysis.

As could be expected on the basis of the previous findings, the results regarding psychosocial functioning are quite different from those described in paragraph 14.3 for physical functioning. Nevertheless there are some corresponding results. We shall now discuss the results for each time-period separately.

\section{The first three months after discharge ( $12-13)$}

There appear to be four variables significantly contributing to the distinction of patients who experience a relatively negative course of psychosocial functioning from those who make a relatively positive assessment: low socioeconomic status, long duration of the disability, high powerlessness and little practical support. These variables together explain about $60 \%$ of the variance 
and make a good classification of the patients possible: over $80 \%$ ar e classified correctly.

The results regarding changes over time are less clear. Using data from t 3 (column IIIB) the canonical correlation is not statistically significant, which means that the discriminant function computed cannot be interpreted. It is therefore not presented in the table. On the basis of the data from $\mathrm{t} 2 \mathrm{a}$ rather weak discriminant function is computed. Powerlessness, inter current diseases and the size of the network significantly discriminate the groups distinguished. The relatively negative group can be characterized as follows: they feel powerless at discharge, they are likely to develop intercurrent diseases and they have relatively large social networks at discharge. The result with respect to network-size is in contrast to our expectation (3.4) and also to what was found in table 14.4. We have no explanation for this result; the data presented in chapter 12 give no clearly interpretable clue. The fact that a direct discriminant analysis, forcing all six variables into the discriminant function, just as was seen for physical functioning, gives no significant canonical correlation, suggests that these results should not be given too much weight. There was no bivariate significant difference in network size between the groups distinguished (see table 12.5). It seems better to conclude that changes in psychosocial functioning during the first three months after discharge cannot be clearly explained, nor predicted. Probably the regression-to-themean effect, discussed in chapter 9 , is confounding the results here as well.

\section{The long-term course of functioning ( $t 2-t 4)$}

Consistent with the findings regarding physical functioning, the social network characteristics play a more important role in explaining the long-term course of psychosocial functioning. Loneliness, practical support and the occurrence of intercurrent diseases are the variables that make a significant distinction between patients with a relatively positive and a relatively negative assessment afterwards. The negative group feels more lonely, experiences less practical support and more often has intercurrent diseases. Unlike the findings regarding physical functioning, powerlessness and socio-economic status do not contribute to the distinction.

Duration of the disability was left out of the analysis in column II of table 14.5 , because it got a strongly negative canonical discriminant function coefficient which was in contrast to the bivariate findings (see table 10.3). This suggests the same phenomenon as described above for age.

The discriminant function computed regarding the assessment afterwards is not strong. Although the canonical correlation coefficient is reasonable, the 
classification result is very meagre. Especially the relatively negative group is often wrongly classified: over $70 \%$ of this group is classified into the positive group. This means that the assessment of the course of functioning cannot be explained powerfully enough on the basis of the variables included.

The results regarding changes over time are very similar to those found for physical functioning. The only difference regards the network-size. The group with a relatively negative course experiences relatively much practical support at discharge, but at $t 4$ they are relatively lonely and practical support is negatively related to the discriminant function. Similar to what was found for physical functioning, this strongly suggests that an experienced decline in practical support is related to a more negative course of functioning. The figures presented in table 12.5 support this conclusion: the average number of people giving support mentioned by the relatively negative group is 3.7 at $t 2$ and 2.6 at $t 4$, while the figures for the positive group are 2.5 and 3.0 respectively. The other variables contributing to the distinction of the groups in these analyses are duration of the disability and intercurrent diseases. Patients who have already had their disability for a long time have a greater likelihood of showing a negative course of psychosocial functioning, especially when intercurrent diseases occur. Powerlessness and socio-economic status appear to play no role in explaining changes in psychosocial functioning over time.

As was already expected on the basis of table 14.1, both the discriminant functions regarding long-term changes over time are not very powerfull. Similar to the function for the assessment afterwards, they are not significant when using a direct method for the analysis. The classification result for both is meagre: only about $60 \%$ of the patients are classified correctly. This must lead to the conclusion that the long-term course of psychosocial functioning, as well as the assessment of it afterwards, cannot be explained nor predicted very powerfully on the basis of the variables included in the study.

\subsection{A check on the results and an alternative analysis}

The analyses presented so far reveal that the course of functioning can be, to a considerable extent, explained with the set of variables included in this study. There is, however, no single explanatory model for the course of functioning; the results are different for physical and psychosocial functioning, and also vary for the different measures of functioning used. Physical functioning can be explained much better than psychosocial functioning, and the assessment of the course of functioning as experienced afterwards can be explained better 
than changes in functioning over time. Nevertheless, the results allow some general conclusions when they are combined. In table 14.6 we summarise the results. Here the variables found to significantly distinguish the negative and positive groups in the different analyses are marked, without a rank-order.

It should be noted that the results regarding the course of psychosocial functioning, especially those regarding actual change over time are not very convincing. We have already concluded that these changes in psychosocial functioning can not be explained or predicted powerfully enough on the basis of the variables included in the study. To a certain extent, the same applies to the assessment patients make of the course of psychosocial functioning afterwards at t4. In spite of these poor results, they are presented in table 14.6 as well. They must not be given too much weight, however.

This table clearly shows the (relative) importance of the distinct variables in the explanation of the course of functioning. Unlike our expectation 4.1 , for-

Tahlle 14.6

A schematic summary of the results of the discriminant analyses performed: variables predicting relatively negative lunclioning

Physical functioning Psychosocial functioning

\begin{tabular}{|c|c|c|c|}
\hline $\begin{array}{l}\text { assessment } \\
\text { afterwardls }\end{array}$ & $\begin{array}{l}\text { change } \\
\text { over time }\end{array}$ & $\begin{array}{l}\text { assessment } \\
\text { afterwards }\end{array}$ & $\begin{array}{l}\text { change } \\
\text { over time }\end{array}$ \\
\hline t2-3 $12-4$ & $t 2-3$ t2-4 & $12-3 \quad 12-4$ & $t^{2}-3$ \\
\hline
\end{tabular}

high powerlessness

small size of the network

little practical support

high loneliness

low socio-economic status

more intercurrent diseases

long duration of disability

* a decline in experienced practical support appeared to be related to worse functioning.

* * the result here is in contrast to those regarding physical functioning and also in contrast to our expectations.

** not included in the analysis. 
mulated on the basis of the results in chapter 7 (page 90), the course of functioning is to a large extent explained by very basic variables, that are unchangeable characteristics of the patients: socio-economic status and duration of the disability (both related to age), together with the development of intercurrent diseases. This means that it is also possible to make a fairly good prediction at the time of discharge. Low socio-economic status (and thus high age) increases the likelihood of developing a negative course of functioning, especially during the first three months after discharge and more clearly for physical functioning. Long duration of the disability (also associated with high age) and the occurrence of other diseases after discharge are also related to a more negative course. This goes for physical as well as for psychosocial functioning. Intercurrent diseases especially influence the long-term course.

Powerlessness, which is characterised by a strong doctor-orientation, high inadequacy, low self-recognition and a negative self-image, is an important variable in the explanation/prediction of the course of functioning during the first three months.

Social network characteristics are especially important in the explanation/ prediction of the long-term course of functioning. Feelings of loneliness and experiencing little practical support or especially a decline in practical support appear to be strong predictors of a relatively negative course of both physical and psychosocial functioning. A small social network is also related to a negative course of functioning, but the results regarding this variable are not unequivocal.

These results might give important clues for the improvement of rehabilitation care and aftercare. Before elaborating on the possible consequences to be taken from these results, however, we have to discuss some problems in the analyses performed, that might have unintentionally influenced the results. This is necessary to check the correctness of the conclusions formulated. There are two problems to be dealt with:

1. the effect of omitting the 'average' groups in the discriminant analyses;

2. the possible influence of differences between diagnostic categories.

\section{The first problem}

The discriminant analyses were performed with only two of the three groups of patients distinguished. This makes the results clearly interpretable, but it has a disadvantage that not all the patients are used for the analysis and that the 'average' groups are simply omitted, as if nothing is known about them. In chapters 10 to 13 we already saw that the average group is sometimes very different from the other two groups with respect to a certain variable. In table 14.1 this is also clearly visible: the sign $(+)$ indicates that an unclear non-linear 
relationship between a variable and the course of functioning was found. Similar problems might appear with respect to powerlessness, which is a combination of all the personal characteristics.

In order to investigate to what extent this phenomenon has to be taken into account in interpreting the results, table 14.7 lists the average scores of the three groups of patients (positive, average and negative) on the variables found to be important predictors of the course of functioning. This is done for each time-period and measure of the course of functioning separately, for the variables marked in table 14.6. We consider it a problem when the 'average" group has an average score that is not between the average scores of the positive and negative group, and that is significantly different from one of these groups. When this is the case, it is marked in the table (italicized). Most of the data presented in table 14.7 have already been presented and discussed in the preceding chapters, but for reasons of clarity they are combined here.

This table shows that we have to be especially car efull with our conclusions regarding duration of the disability and network-size. The average group has the longest duration in two of the four approaches in which duration is an important explaining variable. This means that the conclusion must be somewhat nuanced. As was already seen in chapter 10, short duration does not differentiate clearly between the average and negative groups. With respect to the role of network-size in explaining long-term changes in physical functioning the conclusion might be that network-size differentiates between the 'positive' group and the other groups. Its role in explaining short-term changes in psychosocial functioning is unclear; the average group has smaller networks than the other groups. This means that network-size is not a useful predictor of the course of psychosocial functioning.

The general conclusions regarding the variables powerlessness, practical support, loneliness, socio-economic status and intercurrent diseases, do not seem to be in conflict with the data presented in table 14.7.

\section{The second problem}

In creating the groups to be used in the analyses (chapter 9), we tried to eliminate differences in the diagnostic distribution. This makes it unlikely that the results found are strongly influenced by differences in diagnosis, but we are not certain of it; the elimination did not succeed completely and some of the variables found to be important 'predictors' are closely related to certain diagnostic categories (low socio-economic status, high age and long diseaseduration are typically characteristics of rheumatoid arthritis patients; see chapter 5). For one of the explanatory variables - duration of the disability - we are certain that it cannot be important in the SC group, since there is practically no differentiation in duration in this group. 
Table 14.7 Average scores of the three groups of patients distinguished on the variables found to be predictors of vroup membership

Physical functioning

Assessment afterwards

powerlessness

practical support

loneliness

socio-economic status $2-t 3$

$\begin{array}{ccc}-0.5 & 0.3 & 0.4\end{array}$

12 not relevant

43. not relevant not relevant $2.4 \quad 2.1 \quad 2.0$

t2-t

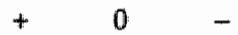

$\begin{array}{rrrr} & -0.3 & -0.2 & 0.6 \\ 12 & 2.8 & 2.9 & 4.1 \\ 44 & 4.2 & 2.6 & 2.0 \\ & 0.8 & 0.4 & 2.5 \\ & 2.5 & 2.2 & 1.9\end{array}$

Changes over tinne

powerlesiness
network-size
practical support
loneliness
socio-economic status
intercurrent diseases
duration of disability

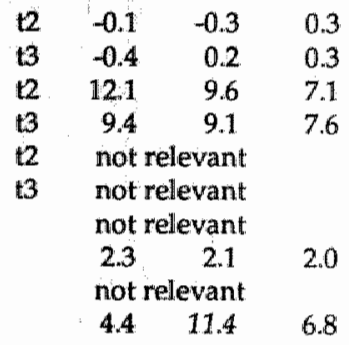

Psychosocial functioning

Assessment alterwards

powerlessness

practicall support

loneliness

soclo-economic status

intercurrent diseases

duration of disability

$\begin{array}{cccc} & -0.5 & 0.0 & 0.5 \\ \mathrm{t} 2 & 5.2 & 2.7 & 3.1 \\ \mathrm{t} 3 & 4.9 & 2.0 & 2.3 \\ & & \text { not relevant } & \\ & 2.4 & 2.2 & 1.8 \\ & \text { not relevant } & \\ & 3.1 & 8.8 & 5.8\end{array}$

Changes over time

powerlessness
network-size
practical support
loneliness
intercurrent diseases
duration of disability

$\begin{array}{cccc}\mathbf{t} 2 & -0.3 & -0.1 & 0.3 \\ \mathbf{t 3} & -0.2 & -0.1 & 0.3 \\ \mathbf{t} 2 & 10.0 & 7.2 & 11.3 \\ \mathbf{1 3} & \mathbf{8 . 4} & 7.7 & 10.0 \\ \mathbf{t 2} & \text { not relewant } & \\ \mathbf{t 3} & \text { not relewant } & \\ & \text { not relevant } \\ & 17 \% \quad 35 \% & 48 \% \\ & \text { not relevant }\end{array}$

12

14

t2

14

$\begin{array}{llll}\mathrm{t} 2 & 2.5 & 3.7 & 3.7\end{array}$

$\begin{array}{llll}4 & 3.0 & 3.1 & 2.6\end{array}$

$\begin{array}{lll}1.0 & 0.6 & 1.8\end{array}$

$30 \% \quad 26 \% \quad 40 \%$ 
In chapter 11 we saw that there are important and sometimes large differences between the diagnostic groups with respect to the personal characteristics (tables 11.1, 11.2 and 11.3). This means that even small differences in the distribution of the diagnostic categories in the groups compared might already lead to a distortion of the results regarding the personal characteristics, especially since they are all combined into one variable 'powerlessness'. At $t 3$ the average scores on powerlessness of the three diagnostic categories are as follows: RA 0.29 , AS -0.31 and SC 0.14 . At t4 these figures are $0.39,-0.27$ and .00 respectively. These differences are statistically significant (one-way analysis of variance; $p=.08$ and .09 respectively). For the interpretation of the results regarding social network characteristics differences in diagnosis do not seem to be potentially problematic; in chapter 12 only few significant differences between the diagnostic categories were found (table 12.1).

For these reasons we consider it necessary to perform an alternative analysis, controlling for the possible influence of diagnosis in a different manner. To check the results found so far, we decided to perform a muitiple regression analysis on the original 'rough' scores on the scales measuring the experienced course of functioning afterwards (see chapter 8, table 8.1), with the same variables and two dummy-variables for the diagnosis as predicting/explaining variables. In this way the influence of diagnosis as such on the course of functioning can be approached in a different way. Regrettably such an analysis is only possible with the scales measuring the experienced course of functioning afterwards as dependent variables. As predictor/explanatory variables we use the same set of variables as in the discriminant analyses, together with two dummy-variables for the three diagnostic categories. Age was left out of the analysis, for the same reasons described in paragraph 14.3. Thus, we have 8 predictors for the analysis regarding $\mathrm{t} 3$ and 9 for the analysis regarding t4, including the two dummy-variables. This brings the cases to variable ratio at a level of 7 to 1 and 6 to 1 respectively, which is low but acceptable for a standard multiple regression analysis.

In order to visualize the effect of diagnosis, we performed two parallel analyses: in the first we did not include the dummy-variables for diagnosis; in the second these dummy-variables were forced into the analysis in a first step, followed by the remaining variables together in a second step. The results of the series of analyses with respect to physical functioning are presented in table 14.8. This table gives three columns of figures for each time period investigated. The first column (A) gives the 'rough' correlation coefficients of the predictor variables with the assessment of the course of functioning. The second column (B) gives the Beta-weights from the analysis without the dummyvariables for diagnosis. The last column (C) finally gives the Beta-weights 


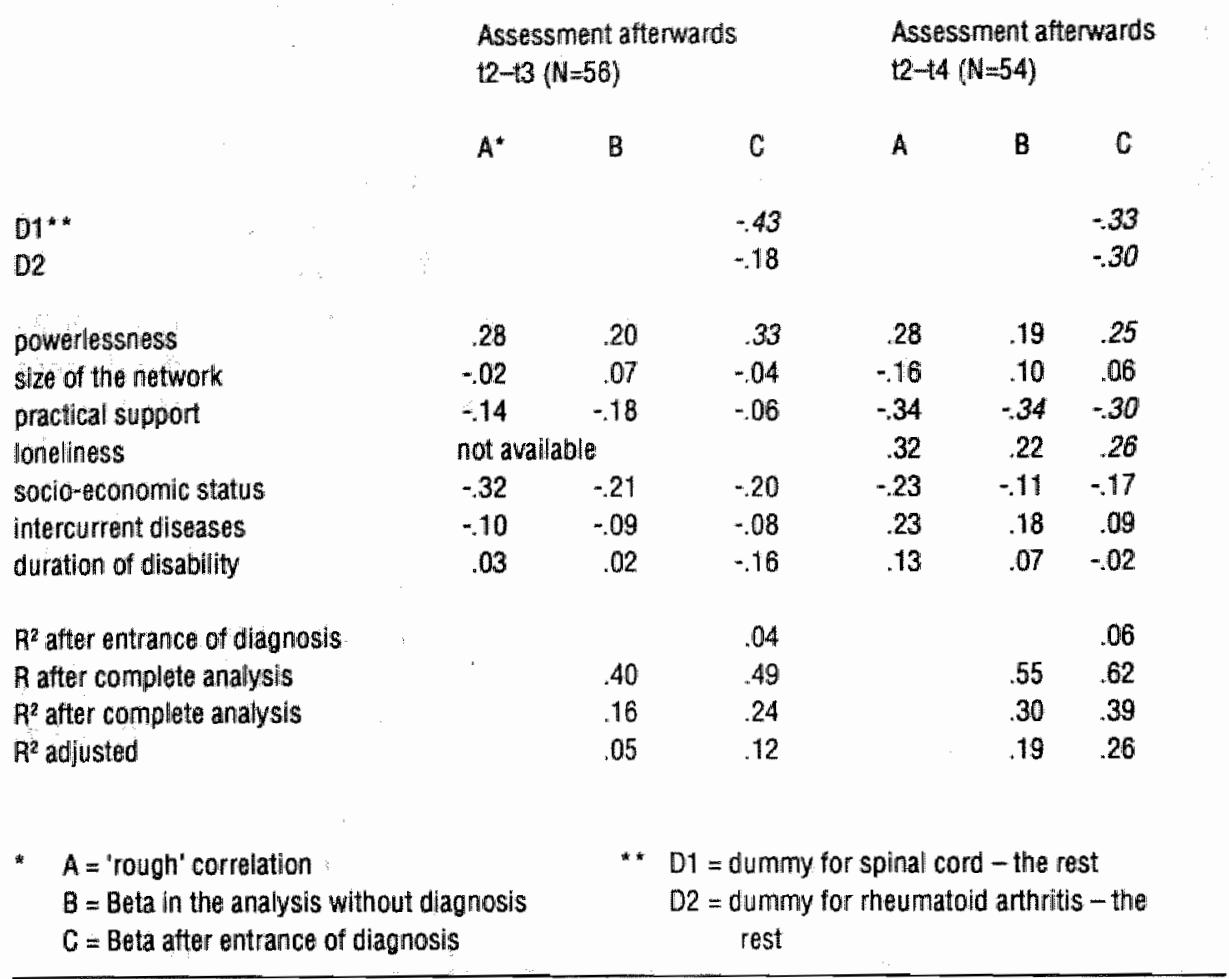

from the analysis in which diagnosis was forced into the analysis before the other variables. Significant Beta-weights $(p<10)$ are italicized in the table.

When comparing the results in both columns $C$ with those from the discriminant analyses, summarised in table 14.6 , it is clear that the results of both approaches are to a large extent similar. The variables that appeared to significantly discriminate between the groups distinguished in the discriminant analysis also have the highest Beta-weights in the multiple regression analysis, after controlling for diagnosis, although they are not all significant. In both analyses, diagnosis is significantly related to the assessment of the course of functioning, but it explains only a little of the variance. The other variables together explain much more variance. It must be noted that the multiple correlation in the analysis regarding $t 3$ is not very high. This means that these results must be interpreted with care.

These results together do confirm the conclusions from the discriminant analyses with respect to the assessment of the course of physical functioning afterwards. 
Table 14.9 gives the results of the analyses regarding the experienced course of psychosocial functioning afterwards. The lay-out of this table is identical to that of table 14.8 .

\section{Table 14:9}

\section{Multiple regression analysis on the assessment of the course of psychosocial functioning afterwards}

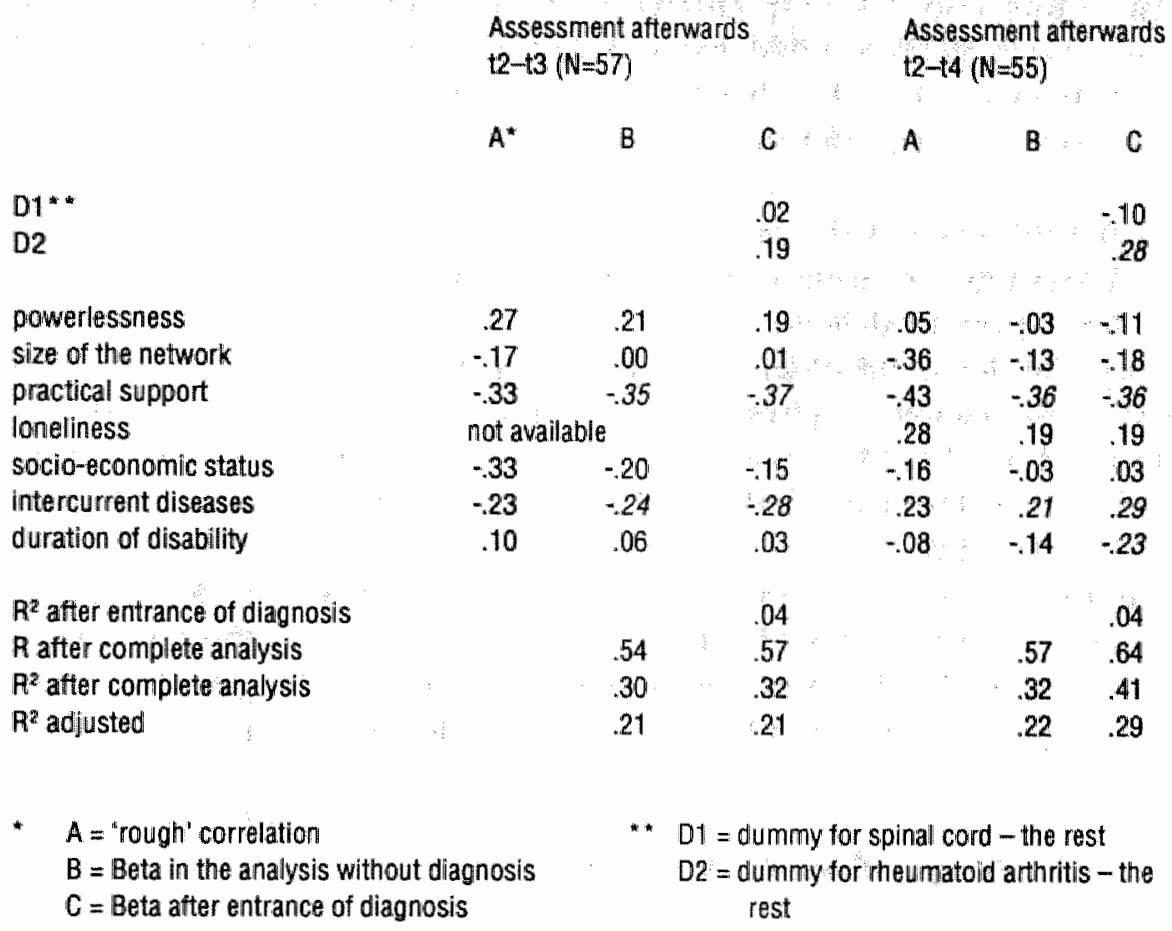

The results from these analyses are less consistent with the discriminant analyses than those in table 14.8. The most important dif ference is seen with respect to 3 . Here duration of the disability appears not to be related to the assessment patients make, while this was an important variable in the discriminant analysis. In table 14.7 , however, we already saw that the result of the discriminant analysis in this respect was doubtful. It therefore seems best to conclude that the role of duration of the disability in explaining the experienced course of psychosocial functioning is unclear. Another important difference between the two approaches regarding the assessment at $\mathrm{t} 3$ has to do with the role of intercurrent diseases. Having intercurrent diseases is related to a more positive assessment of the course of psychosocial functioning. This did not come out of the discriminant analysis and it is hard to explain or interpret this result. It is also in contrast to our expectation ( $2.7 \mathrm{~b})$. The results 
regarding the other variables in the analysis are globally consistent with those presented before. Especially the importance of practical support in explaining the assessment patients make is stressed.

The analysis regarding $t 4$ largely confirms the results from the discriminant approach; the variables that appeared to discriminate significantly between the groups compared, receive relatively high Beta-weights in a consistent direction. The only difference concerns duration of the disability, but we have already concluded that the role of this variable is unclear. The fact that its Beta-weight is higher than the rough correlation suggests that it acts as a suppressor variable, and therefore gives an extra reason to doubt the result.

We are not able to check the results of the discriminant analyses regarding the changes over time by means of an alternative technique. The multiple regression analysis presented, however, gives little reason to believe that differences in the distribution of the diagnostic categories have distorted the results with respect to the course of physical functioning. We consider the results as summarised in table 14.6 trustworthy, with of course the reservations mentioned before on the basis of table 14.7 with respect to network size and duration of the disability.

With respect to psychosocial functioning we have already concluded that the change-scores cannot be clearly explained or predicted on the basis of the variables included in the analysis. Another way of controlling for the influence of diagnosis would most likely not change this conclusion.

\subsection{A summary and some conclusions}

In this chapter we described a rather complicated series of analyses, together revealing which factors are important in the explanation of the course of functioning. Firstly, we described a series of discriminant analyses, and secondly we checked the results of part of them by means of a multiple regression technique. Although the results of different analyses using different measures of the course of functioning and different statistical techniques are not completely consistent and unequivocal, they do allow some general conclusions. In table 14.6 we summarised the results from the series of discriminant analyses. In paragraph 14.5 we found reasons to doubt part of these results, in the sense that they are probably distorted by differences in diagnosis between the groups compared in the discriminant analyses, but generally speaking, the results are consistent and thus seem to be trustworthy. The final conclusions can be summarised as follows. 
- Social-demographic variables play an important role in the explanation of the course of functioning. Patients with a low socio-economic status, which is closely related to high age, have a higher likelihood of developing a more negative course of functioning, especially during the first three months after discharge. This especially applies for physical functioning.

- Disability-related characteristics have a less important and less clear role in the explanation. The occurrence of other diseases after discharge increases the likelihood of a relatively negative course of functioning, especially with respect to psychosocial aspects, but this is not completely unequivocal. A short disease duration increases the chance of a relatively positive course of functioning, but a long disease duration does not mean a negative course; the average groups tend to have the longest disease duration.

- Powerlessness, which stands for the combination of the personal characteristics studied, plays a major role in the explanation of the course of physical as well as psychosocial functioning during the first three months after discharge. Patients who show a relatively negative course of functioning during this period score relatively high on the variable powerlessness, which means that they tend to have a strong doctor-orientation, a high inadequacy score, a low self-recognition and a negative self-image, together with a high chance-orientation, a low internal orientation and a high rigidity score. It is important to notice that this is not only the case when looking transversally, but that a high score on powerlessness at the time of discharge actually predicts the course of functioning. In explaining the long-term course of functioning, however, the role of powerlessness is much less important.

- Of the social network characteristics studied, the experienced amount of practical support and loneliness appear to be important 'predictors' of the long-term course of physical as well as psychosocial functioning. Feelings of loneliness and experiencing little practical support and especially a decline in practical support are strong 'predictors' of a relatively negative course of both physical and psychosocial functioning. The direction of this relationship is not clear. Size of the network is not a good predictor.

The consistency of the results from the discriminant and the regression approach means that we can be rather certain that these conclusions hold for all three diagnostic categories involved in the study.

In chapter 15 we shall discuss these conclusions in relation to the expectations formulated in chapters 3 and 7 . The expectations regarding the first three research questions in this study have already been tentatively discussed in chapters 7 and 10 to 13 on the basis of the bivariate analyses. The results of the 
multivariate analysis allow greater precision in the discussion of these expectations, and also of the expectations regarding the relative importance of the variables studied in explaining the course of functioning (chapter 7 , expectations $4.1,4.2$ and 4.3 ). This discussion is described in chapter 15, where the results from both phases of the study and from the bivariate and the multivariate analyses in phase 2 are combined. 


\section{PART IV}

\section{Conclusions, discussion and implications of the study}

The final part of this book contains a discussion of the results found in both phases of the study and the formulation of the conclusions.

The possible implications of the study are also discussed, in terms of recommendations for rehabilitation practice and suggestions for further research.

Finally, this part contains the summary.

Even the 'quick' reader must read this part. 



\section{CHAPTER 15}

\section{Conclusions}

In this chapter we discuss the results of both phases of the study and formulate the final conclusions. We start with a discussion in paragraph 15.1 of some important problems encountered in this study. This is done to place the results in a proper perspective before formulating conclusions and recommendations.

In paragraphs 15.2 to 15.4 we discuss the results and formulate the conclusions. Paragraph 15.2 is about the course of functioning after discharge (question 1, based upon chapters 6 and 8), while 15.3 deals with the role of personal characteristics, social network characteristics, social-demographic variables and characteristics of the disability in explaining the course of functioning (questions 2, 3 and 4, based upon chapters 7 and 10 to 14). This paragraph ends with a general hypothetical explanatory model of the course of functioning. Paragraph 15.4 is reserved for the findings with respect to continuity of professional care. This chapter ends with some suggestions for rehabilitation practice and recommendations for further research, in paragraphs 15.5 and 15.6 respectively. 
During this study we encountered some problems that have largely influenced the way we analysed the data. The most important problems are the relatively small number of patients that could be included in the longitudinal part of the study, together with the considerable drop-out during the study. This is especially problematic because we deal with three different diagnostic categories. We aimed at a number of at least 150 patients, about 50 in each category. Although this number was estimated on the basis of admission figures from the five years before the study, it appeared impossible to reach this number within the period available. The $39 \%$ drop-out further reduced the number available for analysis. Because of this small number it was impossible to perform separate analyses for the diagnostic categories: we were forced to perform an overall analysis, controlling for the possible influence of diagnosis by choosing a relative classification of the patients into groups with a relatively positive, average or negative course of functioning for each diagnostic category separately. This made us decide to follow a more complicated line of analysis. It was for instance the reason to perform two types of multivariate analyses in chapter 14 , in order to check whether this procedure of eliminating diagnosis was likely to have caused false results. The fact that the results of both types of analyses are generally consistent indicates that this was not the case.

Although a small number of cases strongly restricts the possibilities to use advanced statistical techniques, we performed multivariate analyses. In our opinion, these multivariate techniques have been handled with sufficient care: we reduced considerably the number of variables included and performed several parallel analyses.

Altogether we consider the limited number of patients in the study not really a problem after all, especially not since the results from the first phase of the study are generally consistent with those from the second phase. This makes a much stronger case: it gives little reason to doubt the validity of the results.

The problem of drop-out in the longitudinal phase of the study may be problematic in another sense than that it diminishes the number of patients. In chapter 5 we alreadly concluded that the drop-outs tend to be older and less educated, to have more complicating diseases and a more negative self-assessment of physical functioning than the patients completing the study. We also saw that one of the reasons for drop-out was illness or severe problems of the patients. There obviously is a selective drop-out: the population available for complete analysis consists of relatively 'good' patients. It is important to 
know how the drop-outs 'fit into the results'. Therefore we took a more detailed look at their characteristics at the first assessment. We already saw that they differ from the 'stayers' with respect to some social-demographic and disability-rellated characteristics. In table 15.1 we give a comparison of the drop-outs and the 'stayers' on the variables found to be important in explaining the course of functioning in chapter 14. We can only present these figures for the first assessment, as far as available.

Table 15.1

A comparison of drop-outs and the patients of whom lour assessments are avallable on the variables found to be important predictors of the course of functioning

$\begin{array}{ll}\text { drop-outs } & \text { remaining group } \\ (\mathbb{N}=42) & (\mathrm{N}=67)\end{array}$

wariables constituting 'powerlessness'

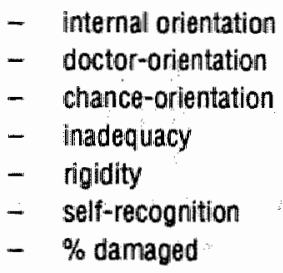

practical support

$\begin{array}{rr}22.3 & 22.0 \\ 19.4 & 18.7 \\ 25.0 & 19.6 \\ -0.1 & 0.0 \\ -0.4 & -0.1 \\ -0.1 & 0.3 \\ 49.1 & 31.5\end{array}$

4.0
22.0

18.7

19.6

0.0

0.1

31.5

This table shows that the drop-outs tend to have the characteristics that were found to predict a relatively negative course of functioning. If the variable 'powerlessness' were computed in the same way as for the data from 12 and later on in chapter 14, the drop-outs would obviously score higher than the 'stayers'. Together with their higher age and their lower level of education (and thus lower socio-economic status), these figures support the validity of the results found; we know that at least part of the drop-out is caused by a negative course of functioning, so one should expect that this gr oup has some of the characteristics predicting a negative course. The fact that this is indeed true makes it very likely that, if the drop-outs had completed the study, the results would have been similar.

A special problem to be discussed here is that of the regression-to-the-mean phenomenon, described in chapter 9 . There we concluded that long-term changes in functioning are rather strongly related to the initial functional level at discharge. This is most clearly the case for psychosocial functioning. For the first three months after discharge and for the retrospective approach to the 
course of functioning, we do not have to take this effect into account. We do not know if and how the regression effect influenced the results. Because of the small number of patients available for the analyses, it was impossible to control statistically for initial scores in the multivariate analyses. We consider it likely that it is one of the causes that relatively few significant relationships between the independent variables in the research model and changes in functioning over time were found in chapters 10 to 12 . The fact that the course of functioning is partly explained by the level of functioning at discharge at least clouds the results because initial functioning is likely to be related to the independent variables as well.

The last topic we want to discuss here regards the fact that we used different measures for the course of functioning: changes over time and a retrospective assessment, both for physical and psychosocial functioning. Moreover, the first three months after discharge and the long term period were analysed separately. This made the analysis rather complex: we performed four parallel analyses for each time-period distinguished. In chapter 8 the reasons why these distinctions had to be made were discussed. We considered it impossible to make a safe and well-founded choice for one of the approaches and exclude others. There is no obvious argument that one is the best or most valid; we consider them as equal indicators of the course of functioning. This means that the final conclusions have to be based upon a combination of the results of the parallel analyses. We only attach value to more or less consistent findings. When formulating the conclusions with respect to the explanation of the course of functioning, in paragraph 15.3, we shall not specifically distinguish the different approaches, but try to formulate general conclusions, carefully weighing the results from both phases of the study and the parallel analyses.

Although we consider the problems described not really problematic in the sense that they might lead to false results, they entail that the conclusions should be formulated with care. In this study we tried to get the maximum out of the data. According to a Dutch proverb, this entails a certain risk: "Wie het onderste uit de kan wil, krijgt de deksel op zijn neus". As careful researchers, it is therefore wise to state that the conclusions should be looked upon as valid hypotheses to be tested in further research. We consider some of the findings solid enough to formulate some recommendations for practice. 
The first question which this study was designed to answer concerns the course of functioning of patients in different diagnostic categories after their discharge from clinical rehabilitation. On the basis of reported experiences of patients and rehabilitation professionals we expected that a considerable number of patients would functionally deteriorate after discharge; not everyone will be able to keep the functional level reached during rehabilitation.

In both phases of the study this expectation is affirmed. In phase 1 , the transversal part of the study, about half of the patients interviewed appeared to have experienced some degree of physical deterioration against 35\% who had experienced an improvement. With respect to psychosocial functioning the results are more positive: about $20 \%$ reported a deterioration while $40 \%$ reported improvement. These figures were obtained about a half to one and a half years after discharge. There are slight differences between the two diagnostic categories involved in the first phase, the SC group being more positive, but in both groups deterioration as well as improvement are reported.

The longitudinal data from phase II of the study are very similar. When averaging the results from the three different measures used to describe the course of physical functioning, about $35 \%$ of all patients appeared to deteriorate during the first three months after discharge and a somewhat smaller percentage between discharge and the last assessment. This percentage is lower than that in phase $\mathrm{I}$, which can be explained by the fact that we used several measures and a stricter statistical criterion to consider a change in scores as 'real' change.

Just as in the first phase, the results on psychosocial functioning are more positive. When averaging the results from the three measures for this aspect of functioning, about $25 \%$ of all patients appeared to deteriorate after discharge. This figure is the same for the first three months as for the long term period.

The data regarding both physical and psychosocial functioning quite systematically show a "dip" in functioning three months after discharge. For the total group studied, there is a statistically significant improvement on each measure used between admission and discharge. After discharge there is a tendency towards deterioration in the first three months, followed by a tendency towards improvement again. We found some indications that the "dip' found in this study is likely to be a relatively positive representation of the 'dip' actually existing. These results indicate that the period shortly after discharge is a critical one; patients apparently encounter problems in keeping the functional level they had reached. Although there are differences between the diagnostic categories - just like in phase I the $\mathrm{SC}$ group shows the most positive course - this conclusion applies to each category studied. The fact that it 
appeared to be impossible for most people to keep a care-diary during the first three months fits in very well with the results described (see paragraph 4.2).

The selective drop-out during the longitudinal part of the study makes it likely that the "real' percentage of patients experiencing a deterioration after discharge is higher than mentioned above. As described in paragraph 15.1, the patients who were included in the analysis tend to be a positive selection. It is very likely that a relatively high percentage of the drop-outs would have shown a relatively negative course of functioning if they had completed the study.

Although the number of patients deteriorating is considerable, we think it is important to conclude that, on average, the (experienced) course of functioning in the total group after discharge is not negative. In both phases of the study most patients appear to succeed quite well in keeping and even improving their functional status. The group that does not succeed, however, certainly deserves special attention.

The second element of the first research question regards the extent in which the self-assessments of patients conform to professional assessments of the course of functioning and to assessments of relevant others. With respect to this question we found relatively strong correlations between patients and social network members in both phases of the study: correlation coefficients are between .61 and .89 for physical functioning (average .75) and between .26 and .53 for psychosocial functioning (average .44). The correlations between patients and professionals are lower. The average correlation between patients and general practitioners with respect to physical functioning is .40 and with respect to psychosocial functioning .03. For the community nurses these figures are 52 and .31 respectively. It could be argued that these relatively low correlation coefficients are a reason to doubt the credibility and maybe the validity of the assessments made by the patient, but the strong correlation between patients and social network members strongly contradicts this. The findings with respect to continuity of care, described in chapters 7 and 13 , make the conclusion that health professionals are insufficiently informed about how the patient functions and feels much more plausible. In phase II this is supported by the professionals themselves: about one third of the general practitioners reported having no idea about functioning of the patient.

\subsection{Explaining the course of functioning}

The second element of our central research question, formulated in the questions 2,3 and 4 in chapter 3 , concerns the explanation of the course of function- 
ing. We shall now confront the expectations formulated with the results of both phases of the study. We discuss the results with respect to each expectation separately. In fact this is a combination of the conclusions formulated in the chapters 7,10 to 13 , and 14 .

Age (2.1)

We expected that younger people would show a more positive course of functioning. This is clearly confirmed in both phases of the study and for physical as well as psychosocial functioning. The multivariate analyses in chapter 14 suggest that the influence of age is indirect; it is likely to act through socio-economic status and the personal characteristics (powerlessness).

$\operatorname{Sex}(2.2)$

We expected to find no relationship between sex and the course of functioning. In contrast to this expectation, we found that men experienced a more positive course of overall functioning in the first phase of the study. In phase II we found the same with respect to the experienced course of psychosocial functioning afterwards: men are more positive. With respect to physical functioning no relationship was found. This means that our expectation is only partly confirmed. Sex, however, appears not to play a very important role in the explanation. It was therefore not included in the multivariate analyses.

\section{Socio-economic status (2.3)}

We expected that people with a relatively high socio-economic status would show a more positive course of functioning. In phase I this expectation was not confirmed; no significant relationship was found. In the bivariate analysis in chapter 10 we also found only partial support for this expectation. Socioeconomic status only appeared to be significantly related to the evaluation of the course of physical functioning afterwards. On the basis of strong indications in the literature we nevertheless decided to include socio-economic status in the multivariate analyses in chapter 14. Here it appeared to be an important predictor of the course of physical as well as psychosocial functioning in the direction expected, especially during the first three months after discharge. These somewhat contrasting results indicate that the role of socioeconomic status is not completely unequivocal. It is likely to interact with other variables. In chapter 14 we saw that it is strongly connected with age and also with personal characteristics (powerlessness). It is not possible to precisely unravel these relationships, but it is clear that socio-economic status plays a role in the explanation of the course of functioning. We consider the results sufficiently evident to conclude that high socio-economic status is 
related to a positive course of functioning.

\section{Marital status (2.4)}

We expected that people who have a life partner would show a more positive course of functioning. In both phases of the study, however, we found no support for this expectation. The conclusion must be that marital status is not related to the course of functioning.

\section{Objective level of disability (2.5)}

We expected that the level of disability would not be connected with the course of functioning after discharge. In phase I no clear relationship was found and in phase II we only found that patients with relatively severe disabilities evaluate the course of psychosocial functioning during the first three months more positively, when looking back in time. Since all the other data are in line with our expectation, and do not show a clear tendency in any direction, we consider the expectation affirmed.

\section{Duration of the disability (2.6)}

Our expectation was that long duration would be related to a more negative course of functioning. The data in phase I confirm this expectation. In phase II, however, the results only partly affirm it. In the bivariate as well as the multivariate analyses there appeared to be a more complicated relationship of duration with the course of functioning: in some of the approaches followed in chapter 10 the group with an average course of functioning has the longest duration. The positive group systematically has the shortest duration, but long duration does not predict a negative course of functioning. A better expectation or hypothesis might be that short duration gives a better chance to experience a positive course, while long duration gives a greater chance of a stable or negative course of functioning.

\section{Complicating diseases or impairments (2.7)}

a. We expected that chronic diseases or impairments that already existed before admission to the rehabilitation centre would not be related to the course of functioning after discharge. In phase II this expectation is without doubt affirmed. In phase I we could not examine this.

b. Diseases and impairments developing after discharge were expected to negatively influence the course of functioning. In phase II we found partial support for this expectation. In phase I we did not distinguish between 'old' and 'new' complicating diseases. We found a relationship with the course of functioning. Because we found strong support for expectation $2.7 \mathrm{a}$ in phase II it is likely that the relationship found in phase I can be 
interpreted as affirmation of expectation $b$. These findings together are considered to be a sufficient indication that intercurrent diseases are important in explaining the course of functioning. In the multivariate analyses in chapter 14 we found that the occurrence of other diseases after discharge increases the chance of developing a relatively negative course of functioning, especially in psychosocial respect. This is not completely unequivocal, however.

\section{Personality traits (3.1)}

a. We expected high neuroticism to be related to a negative course of functioning. As an indicator of neuroticism the inadequacy scale of the Dutch Personality Inventory was used. The results in phase I clearly confirm the expectation. In phase II this is only partly the case; inadequacy is related to the assessment of physical functioning when looking back in time, but not to longitudinal changes. Its relationship with psychosocial functioning is unclear. In the multivariate analyses inadequacy was combined with other personal characteristics into the variable powerlessness. Thus, a specific pronouncement with respect to its role is impossible. Powerlessness is found to be a strong predictor of the course of functioning during the first three months after discharge.

b. High extraversion was expected to be related to a positive course of functioning. The results with respect to social inadequacy in phase I af firm this expectation, but in phase II no support at all was found. We consider this expectation not affirmed. Social inadequacy was therefore not included in the multivariate analyses.

c. High self-esteem was expected to be related to a positive course of functioning. As a measure of self-esteem the self-recognitionscale of the Dutch Personality Inventory was used. In both phases of the study, this expectation is quite systematically confirmed, as far as it concerns the experienced course of functioning afterwards. In the multivariate analyses self-recognition was, just like inadequacy, part of the variable powerlessness (a low score on self-recognition indicating powerlessness).

d. In chapter 4 we formulated the expectation that rigidity would be related to a negative course of functioning. In phase I this was af firmed. In phase II it was partly affirmed: only once there was a significant difference in the direction expected, but the relatively positive group quite systematically tends to have the lowest rigidity score. In the multivariate analyses rigidity was part of powerlessness (high rigidity indicating powerlessness), which was found to be an important predictor of functioning during the first three months. 


\section{Health locus of control (3.2)}

a. We expected that a strong internal locus of control would be related to a positive course of functioning. The results in the first phase of the study affirm this expectation, but this is only partly the case for phase II; only with the short-term course of psychosocial functioning (as experienced afterwards) was a relationship in the direction expected found. Although these results only partially affirm the expectation, we decided to include the internal orientation in the multivariate analyses, as an element of the variable powerlessness (low internal orientation indicating powerlessness).

b. We expected a strong external locus of control to be related to a negative course of functioning. The results with respect to doctor-orientation and chance-orientation in phase $I$ are in line with this expectation. The results in phase II are also generally in line with it, mainly with respect to the course of functioning as experienced afterwards, and more clearly for physical than for psychosocial functioning. Doctor-orientation has the strongest relationship with functioning. In the multivariate analyses both scores were included in the variable powerlessness.

\section{Self-image (3.3)}

We expected that a positive self-image would be related to a positive course of functioning. When using the percentage of self damaged as a measure of selfimage, this expectation is largely affirmed in both phases of the study. The scales derived from the semantic differential in phase II, however, give no support at all. The percentage damaged was included in the multivariate analyses as an element of powerlessness. The results with respect to powerlessness have been described already.

\section{Size of the network (3.4)}

We expected that a large social network would be related to a positive course of functioning. In phase I this is affirmed. The bivariate analysis in chapter 12 also largely supports this expectation, but the results are not completely unequivocal. In the multivariate analyses in chapter 14 network size appeared to be not a good predictor, because the average group has the smallest network size in some of the approaches. This means that our expectation is not unequivocally affirmed; the relationship of network size with the course of functioning apparently is more complex than expected.

\section{Number of non-family members (3.5)}

A network with relatively many non-family members was expected to be related to a positive course of functioning. The data in phase I af firm this 
expectation. In phase II it is only clearly affirmed as far as the assessment of the course of psychosocial functioning afterwards is concerned.

Although we considered these results sufficient evidence that the number of non-family members plays a role in the explanation of the course of functioning, it was not included in the multivariate analyses, because of its strong correlation with network size.

\section{Social support (3.6)}

We expected that strong practical and emotional support would be related to a positive course of functioning. In the first phase of the study we found no support for this expectation. In phase II the experienced amount of practical support and feelings of loneliness appeared to be strong predictors of the long term course of physical as well as psychosocial functioning. Emotional support is not strongly related to the course of functioning. The results with respect to longitudinal changes in both the bivariate and multivariate analyses strongly suggest that a decline in the experienced amount of practical support is related to a negative course of functioning. The causal direction of this relationship is not clear.

\section{Continuity of care (3.7)}

We expected that continuity of professional care would be related to a positive course of functioning. In phase I as well as in phase II we found no clearly interpretable relationship between aspects of continuity and the different measures of the course of functioning. Patients with a relatively negative course of functioning tend to have more frequent contacts with more professionals, but there are no differences with respect to coordination and tuning of care. It is most probable that the fact that no relationship was found is explained by a lack of differentiation: there are almost no cases in which one could speak of continuity of care, according to our definition. The conclusion must be that it is not possible to pronounce upon the correctness of our expectation.

In the model shown in figure 15.1 the conclusions described above are schematically summarized. This model can be seen as a hypothetical explanatory model of the (experienced) course of functioning. The variables of which the results rather firmly indicate that they play a role are italicized. The results with respect to the other variables are not entirely unequivocal. In this model we do not distinguish between physical and psychosocial functioning and we also make no distinction between the longitudinal and retrospective approach; it is a model representing the overall conclusions. The figure indicates the variables predicting a relatively negative course of functioning. 


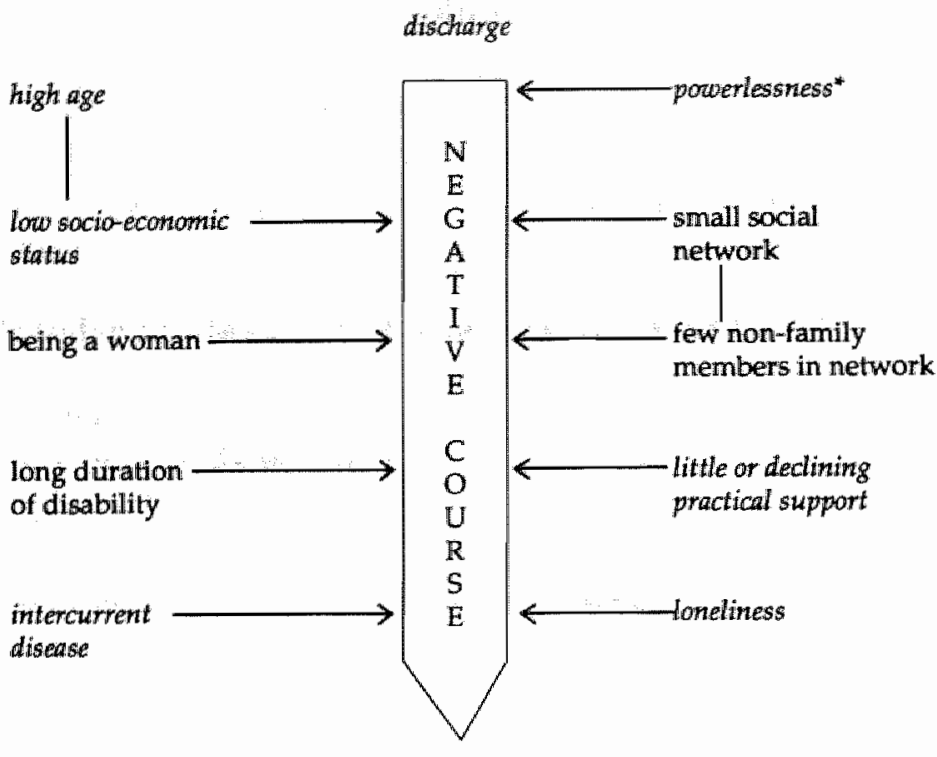

long-term

"powerlessness = strong doctor-and chance-orientation, high inadequacy, low self-recognition, negative self-image, high rigidity, low internal locus of controt.

The answer to the fourth research question, regarding the relative importance of the factors studied in explaining the course of functioning, is also visible in this model. The answer depends on the time period studied. With respect to the first three months after discharge, the personal characteristics and socialdemographic variables play a central role in the explanation, while the social network characteristics become more important when explaining the long term course.

The expectations formulated on the basis of the first phase of the study in chapter 7, regarding the fourth research question, are only partly affirmed in phase II. They at least have to be nuanced. The results in phase I gave reason to expect that social-demographic variables would play a minor role in explaining the course of functioning (expectation 4.1). As far as the long term course is considered, this expectation is affirmed. Socio-economic status (together with age), however, plays an important role in predicting the short term course.

The results in phase I also gave reason to expect that disability-related characteristics would play a minor role (expectation 4.2). The results in phase II show a somewhat more important, but not unequivocal role of these characteristics. It is important to conclude that the level of disability is not related 
to the course of functioning. It is also important to conclude that the results found are independent of the diagnosis. This is generally in line with findings of for example Cassileth et al. (1984) and Pollock et al. (1990), who found psychological status among physically chronically ill to be independent of diagnosis.

Expectation 4.3, regarding the importance of personal and social network characteristics, is clearly affirmed, but has to be nuanced as already indicated above: personal characteristics are most important with respect to the short term; social network characteristics are most important with respect to the long term.

At this point we want to stress again the fact that the causal direction of the relationship between social network characteristics and functioning is not unequivocal. As already discussed in earlier chapters and as was clearly shown in chapter 12, social networks change as a result of disability. The results of this study also indicate that network characteristics influence the course of functioning. Probably the best way to look upon the relationship between the social network and functioning is to consider it to be a functional relationship, in the sense that both causal directions exist. This stresses the clinical importance of social network characteristics, because such a functional relationship easily becomes a downgoing spiral: dysfunctioning negatively influences the network, less support from a smaller network negatively influences functioning, and so forth.

With respect to the personal characteristics, the relationship to functioning is less complicated. Powerlessness as measured in this study almost has the character of a personality trait, although more socially embedded characteristics are incorporated as well. This makes it likely that powerlessness is causally related to the course of functioning, which is supported by the fact that the score on the variable powerlessness at the time of discharge was found to have predictive value for actual changes in functioning after discharge in chapter 14.

\subsection{Continuity of professional care}

Continuity of professional care was included in the study as one of the factors possibly explaining or predicting the course of functioning. In both phases of the study no clear relationship with the course of functioning was found, however. Nevertheless, the results regarding continuity of care give rise to some important conclusions. In both phases we found very similar and consistent indications that coordination and tuning of care after discharge is far from 
perfect. This applies to coordination between the rehabilitation centre and primary health care as well as for coordination within primary care. The most important findings are summarised below:

- Information-exchange between professionals when a patient leaves a hospital or other facility most commonly takes place by means of letters or special discharge-forms. A letter of discharge to the general practitioner and other medical specialists involved, and, if necessary, a discharge-form to the community nurse, are considered standard in the rehabilitation centre where this study took place. This study, however, revealed that the letter is sometimes late and sometimes does not reach the general practitioner at all. Those who had received it had not always read it: most of them said they put it away in their archives and only read it when the patient comes with a problem. With respect to community nurses, only about half of those who were actually involved in the care process, had received any kind of information about the patient. It is clear that this kind of written communication does not contribute much to a good handing over and coordination of care.

- Besides the written information-exchange, there are very few telephone or face-to-face contacts between members of the rehabilitation team and professionals in primary health care. Of the more than 120 cases studied, there were only 11 in which such a contact in the first three months after discharge was mentioned. Some of these concerned the same patient. Together with the findings regarding written information this leads to the conclusion that one could hardly speak of transfer of care.

- Apart from the line rehabilitation centre - primary care there are also only a few contacts between professionals involved. The patients on average have contacts with about four different professionals in the first three months after discharge, and the number that they see more than once averages at two and a half. In nearly half of the cases in which we considered some contact necessary, that is if there were two or more professionals with whom the patient had contact more than once, there was no single contact reported by any of the professionals interviewed with any other professional. As far as contacts were reported, they almost always had the character of information-exchange; discussion or policy-making was only rarely mentioned. The figures are similar in both phases of the study.

- The data for phase II show that there is very little agreement between general practitioners and community nurses about who is primarily responsible for different aspects of care. Out of a list of six tasks, including coordination and surveillance of care, the average number of tasks on which both professionals agree is less than one. Three months after discharge agreement is not better than at the time of admission. It is not 
uncommon to find that two professionals both expect that the other coordinates care, or that they both say they do it. It is most likely that uncoordinated care is the result.

Within each professional group there is a wide variety of opinions on tasks as well. This means that there is also little agreement between the rehabilitation centre and the professionals in primary care.

- In both phases there are only moderate or even low correlations between professional assessments of functioning and the assessment of patients themselves. When professionals are asked how they think the patients would assess their functioning, the correlations are somewhat stronger, but a considerable number of the professionals (about 20\%) then report not knowing how the patient assesses his functioning. These figures indicate that there is only limited agreement between professionals and patients about the situation of the patients.

- Patients and especially their social network members (mostly partners, parents or children) are only moderately satisfied with care after discharge. They mention a considerable number of complaints about care, mostly regarding an experienced lack of counselling and support, the relevant authorities' long and complicated procedures for providing aids and house-adaptations, and a lack of adequate information.

In sum, we can only conclude that coordination and tuning of care after discharge is far from perfect. Continuity of care as defined for this study does not really exist in the cases studied. This is the most probable explanation why no relationship with the course of functioning was found. Probably, the influence of continuity of care on the course of functioning can only be studied with an experimental design, introducing continuity-enhancing procedures in the regular care-process. In paragraph 15.5 we return to this.

Finding no relationship between aspects of continuity of care and the course of functioning leads to another conclusion. It means that deterioration of the patient's condition does not lead to more contacts between professionals. It does lead to more contacts with the patient, but apparently it is not a reason to consult or inform others.

Our findings are not unique. In chapter 2 we have already described continuity of care as an issue that receives considerable attention in the literature regarding health care. A recent study by Van Wijk (1989) and a study by Breuer (1989) support our findings with respect to discharge from rehabilitation. There is growing evidence that continuity of care is problematic in other areas of health care as well (e.g. Philipsen, 1990; Van den Bos, 1989; Engelsman and 
Riewald, 1988; Kerkstra et al., 1990; Wiegers and Kersten, 1990). Although there is no real proof that this has negative consequences for patients, it does call for action. Health professionals should seriously undertake the work of continuity of care or otherwise explain what they mean by saying that it is an important element of their task. In this respect we agree with the title of a brochure about coordination of care, published by the association ATIS in 1988: 'Coordination of Care. Do not claim it but do it' ("Coördinatie van Zorg. Niet opeisen maar aanpakken').

\subsection{Possible implications for rehabilitation practice}

Although we stated that the results of this study should be looked upon as valid hypotheses to be tested in further research, they might have consequences for daily practice in rehabilitation. We see consequences in three fields.

1. The results of this study make it possible to identify patients with a relatively high risk of deterioration after discharge at an early stage. Low socio-economic status, which is related to high age, together with high powerlessness are good predictors of the course of functioning during the first three months after discharge. Socio-economic status and age already belong to the 'standard' information obtained when a patient is admitted to a rehabilitation centre. Powerlessness could be measured quite easily. It must be possible to develop a short questionnaire on the basis of the instruments used in this study and combined in the variable powerlessness, which would give a good impression of the level of powerlessness.

Patients identified as potential 'risk-patients' should be given special attention and treatment. Around the time of discharge special arrangements could be made to ensure a better continuity of care and to bridge the gap between the centre and the home environment. For example, gradually decreasing outpatients' treatment, therapy and training in the home environment before discharge, etc. During rehabilitation specific attempts could be made to influence positively the health locus of control and/or the self-image. These characteristics can potentially be influenced, although specific treatments still have to be developed.

Lökk (1990) recently reported an interesting experiment in this area. He performed a study on elderly handicapped people in a day-care unit. It was hypothesised that passivity and lack of possibility to influence treatment inhibit progress in therapy. The experimental programme was devised in collaboration with the patients in order to ameliorate the passivity factor in treatment. There was a-significant improvement in perceived 
health and life satisfaction in the experimental group. Taylor (1986) described very similar results from several studies conducted in nursing homes. People were given experimentally more control and influence on decisions about certain facilities and services, while others were given no control. Those who had more control felt better and were more active than those with less control. Such studies show clearly that very simple nonspecific control interventions can achieve a substantial and long-term impact on health outcomes.

In the field of patient education there is a growing experience with interventions aimed at the increase of control (Kok, 1988). For the development of rehabilitation-specific interventions these might serve as examples to build upon further.

2. The importance of social support in predicting the long-term course of functioning calls for interventions that enhance the maintenance of support from the social network. The drastic changes in the networks of especially the spinal cord group might be reason enough to pay special attention to this aspect. At least two different approaches can be distinguished: training and support of network members in dealing with the disabled and training of social skills of patients. Both approaches can reinforce each other. Strengthening of social networks might become an important goal in physical rehabilitation. Efforts in this direction are likely to enhance long-term success in living with a disability.

In several areas of health care examples of techniques and programmes aimed at the development or strengthening of social networks can be found. Israel (1983) gave some examples in the field of health education, while Gottlieb (1985) described examples in the field of community mental health. Andersson reported the results of an intervention programme against loneliness in elderly women (1985). He demonstrated that an intervention consisting of a series of small group meetings did lead to less feelings of loneliness, less feelings of meaninglessness, more social contacts and higher self-esteem in a group of elderly women. On the basis of experiences in such fields rehabilitation-oriented programmes can be developed. An example of such a programme in the field of rehabilitation is reported by Mulders et al. (1989). They developed an after-care programme for stroke patients and their partners and found rather promising effects on social functioning.

A first basic step, that can be implemented without many problems, is the more active and intensive involvement of partners and other close social network members in rehabilitation treatment. The social network members interviewed in this study unanimously report the absence of support for themselves. Maybe the patient is too central. 
3. The results with respect to continuity of care strongly call for changes in the standard discharge-procedure (letter of discharge and/or discharge-form). First of all, it is clear that written information alone is insuf ficient to ensure coordinated care. The following changes might improve the effectiveness of these written methods of communication:

- The content of letters and discharge-forms should be the reflection of engagements between professionals and others involved, rather than an attempt to make engagements. This means that the rehabilitation team should have contact with the professionals and non-professionals that will be involved after discharge, in an early stage before discharge. In this way it becomes clear for everyone, including the patient, who is responsible for what aspect of care, and nobody is charged with tasks he or she does not agree on. Of course this means that everyone involved should receive a copy of the letter or discharge-form. It might also be fruitful to appoint someone to coordinate care after discharge, on the basis of the engagements made.

- A second aspect regards promoting expertise of primary care workers and non-professionals. One of the reasons for the problems described is probably the fact that there are relatively few patients who are admitted to a rehabilitation centre, and that it often concerns a relatively rare diagnosis. A general practitioner, for example, is not likely to have many patients with a spinal cord lesion in his practice. It can hardly be expected that he provides the care the rehabilitation centre expects, without specific information and/or training.

- The last suggestion regards the involvement of 'experienced' patients in the care process. Health professionals might be unable to support patients in all respects. They especially do not know the consequences of certain diseases for daily life. This is a field in which well-trained 'experienced' patients can play a very important role, filling part of the gap experienced by patients and their social network members.

Patient associations may be very meaningful in this respect. A good example is the Dutch association of patients with neuromuscular diseases (VSN, Vereniging Spierziekten Nederland). In a nationwide study among patients with neuromuscular diseases, Terpstra et al. (1990) found that this association was one of the most important sources of information for patients and their parents. 
1. The first recommendation for further research is to test the results of this study in new studies, regarding the same diagnostic categories as well as other categories. The precise role of the structural social network characteristics, sex and duration of the disability have to be further analysed and studied. The same goes for the direction of the relationship between social support and the course of functioning.

Some recent studies in the field of physical chronic diseases strongly support our findings with respect to the importance of social relationships for functioning and well-being, and suggest that social support and social contacts have a causal influence on functioning (e.g. O'Reilly and Thomas, 1989; Fitzpatrick et al., 1988). Further research is necessary, however.

A long-term prospective cohort study on a larger population of chronically ill patients might offer the best chance to answer these questions.

2. In this study we tried to determine some of the factors playing a role in the explanation of the course of functioning. We did not fully study the interrelationships of the variables found to be important. For a better understanding of the process leading to a certain degree of experienced handicap and a certain level of functioning it is necessary to study these interrelationships further in future projects. It might also be advantageous to add new elements to the hypothetical explanatory model developed, in or der to improve the explanatory power. One such element could be coping strategy.

3. In our opinion one of the central goals of rehabilitation research in the near future should be to study the relationships between the different levels at which consequences of disease can occur: impairment, disability and handicap. The central question should focus on the way in which these levels are related to each other and especially on the identification of factors which intervene in the relationships between them. Why does person $A$ in our example in the introduction of this book feel more handicapped than person B? And why are some people more severely disabled than others with the same impairment? The results of this study can be seen as a partial answer to such questions, as far as the relationship disability-experienced handicap is concerned. For the further development of rehabilitation theory and practice we consider elaboration of this model essential. Such research largely depends on the quality of the measurement instruments used. In this respect there is still work to be done, especially regarding the measurement of handicap. Recent developments in the field of quality of life might be a fruitful ground to build upon. 
4. Our fourth recommendation is to start applied experimental projects aimed at evaluating the effectiveness of intervention strategies developed in response to the suggestions in paragraph 15.5: strategies to influence powerlessness, to strengthen social networks and social skills of patients, and new procedures that enhance continuity of care. Probably such experiments are the best way to test the results of this study, while in the mean time already improving care. This is especially important for continuity of care. In this study it appeared to be impossible to investigate the relationship between continuity of care and the course of functioning, most probably because there is insufficient differentiation in the degree of continuity of care. Field experiments with, for example, case management or other procedures enhancing coordination of care are the most suitable answer to this problem.

5. The fact that we found little differentiation in continuity of care might also be explained by the fact that we did not fully succeed in operationalising and measuring the concept. As described in chapter 4, we initially wanted to use a care diary as the method to obtain information about the care process, but this appeared to be impossible for many patients. Regrettably, we were therefore only able to use indirect measures as indicators of the degree of continuity of care. We suggest the planning of a prospective cohort study, using more refined measures of continuity of care, based upon a care diary.

6. We measured the course of functioning in different ways. Patients were asked to assess the course of functioning retrospectively and we gathered longitudinal information about changes in functioning over time. These different approaches led to different results, although the general conclusions are in line with each other. The retrospective approach appeared to give the best interpretable results. It was less problematic in the analysis. We consider it worthwhile to add this approach to future longitudinal research, and to study further its validity as a measure of change. Such an approach in longitudinal studies, together with 'real' longitudinal datta, might solve some of the problems of longitudinal research. It is also theoretically interesting to study the discrepancy between the longitudinal and the retrospective approaches. On the basis of Thomas' famous theorem 'if men define a situation as real, it is real in its consequences" (see Zijderveld, 1974), one could argue that the retrospective assessment is likely to have more consequences for future functioning of patients than longitudinal assessments, and that it should therefore be a central approach in future research. 


\title{
CHAPTER 16
}

\author{
Summary
}

This book is the report of a study into the course of functioning in different patient categories after discharge from clinical rehabilitation in a rehabilitation centre. The purpose of this study was to describe the course of functioning after discharge. We wanted to know to what extent patients, in their own perception, succeed in keeping the functional level they reached in the rehabilitation centre. In addition we sought an explanation of why some people show a more positive course of functioning than others. The study is specifically focused on the role of personal characteristics, social network characteristics and continuity of professional care around and after discharge in explaining the course of functioning. We wanted to gain insight into the relative importance of these factors, in addition to certain social-demographic and disability-related characteristics. A distinction is made between the short term course (the first three months after discharge) and the long term course (until one to one and a half years after discharge). Patient categories included in the study are rheumatoid arthritis, ankylosing spondylitis and patients with a spinal cord injury. 
The book is divided into four parts. The first part consists of five chapters, which describe the background of the study, the research questions to be answered and the way the study was planned and carried out. Chapter 1 gives a short introduction. Chapter 2 contains an overview of the literature relevant within the framework of the study. The chapter starts with the description of a focus of measurement of rehabilitation outcome. Reasons are given for the decision to focus on the course of functioning in terms of reported actual behaviour or activities in daily life, in combination with an evaluation of functioning by the patients themselves. In the later paragraphs of chapter 2 the variables to be included in the research model are determined and what is known or can be expected about their relationship to the course of functioning is discussed. On the basis of the results in chapter 2, we formulate some more explicit research questions, a research model and a set of expectations in chapter 3 . The variables included as explanatory variables in the research model are: personality traits, health locus of control, self-image, size of the social network, number of friends and other non-relatives in the network, practical and emotional support, continuity of professional care, age, sex, socio-economic status, marital status, objective level of disability, complicating diseases and duration of the disability. Continuity of care is defined as the degree to which professional care is provided as a coordinated and uninterrupted succession of activities, in accordance with (experienced) patient needs.

The way the course of functioning and the explanatory variables mentioned above are operationalised and measured is described in chapter 4 . This chapter also gives a description of the design of the study and the methods of data gathering. The study is divided into two phases. The first phase has a retrospective transversal design. The second, much larger and more extensive phase has a longitudinal design. In phase I we included 37 patients with a spinal cord lesion or rheumatoid arthritis, who had been discharged from the rehabilitation centre between a half and one and a half years before. In the second phase we approached every newly admitted patient with a spinal cord lesion, rheumatoid arthritis or ankylosing spondylitis for the study. In the period available for the study there were 109 patients willing to cooperate. These patients were followed for 2 years. In these two years there were four assessments: the first as soon as possible after admission, the second at the time of discharge, the third three months after discharge, and the fourth two years after the first. At each assessment information was gathered not only from the patient, but also from professional helpers and persons from the social network. In addition to the patient, the following persons were approached at each assessment: the rehabilitation specialist or rheumatologist, the rehabilitation nurse who was closest to the patient, the general practitio- 
ner, the community nurse and the two people from the social network who were, according to the patient, the most important at the time of assessment. The information needed was mainly gathered by means of prestructured personal interviews and partly by means of self-administered questionnaires.

The last chapter in part $\mathrm{I}$, chapter 5, describes the populations of patients, professional workers and social network members participating in both phases of the study. It also deals with matters of non-response and drop-out during the study. An important conclusion from chapter 5 is that there is a selective drop-out in the longitudinal part of the study. Only $62 \%$ of the starting population of patients were available for the longitudinal analysis. This is a positive selection: at least part of the drop-out is explained by illness or other problems of the patient.

Part II of the book gives the results from the first phase of the study. It consists of only 2 chapters. Chapter 6 describes the results regarding the experienced course of functioning after discharge. Almost half of the 37 patients involved in this phase reported some degree of physical deterioration and about $20 \%$ some degree of psychosocial deterioration. Health professionals and social network members reported similar figures. In chapter 7 the group of deteriorated patients is compared with the non-deteriorated patients, with respect to all the possible explaining variables in the research model. For this analysis physical and psychosocial functioning are combined into one measure for overall functioning. The results in chapter 7 clearly reveal that patients experiencing a deterioration are in many respects different from those who give a more positive assessment of the course of functioning. Personal characteristics and social network characteristics especially appear to be important predictors of the course of functioning. In the main, the results are in line with the expectations formulated in chapter 3 . Another important conclusion from the results in chapter 7 is that there appear to be problems in the continuity of care after discharge. Tuning and coordination of care are far from perfect. A judgement of the importance of these problems for the course of functioning of patients is not possible on the basis of the data from the first phase of the study.

Part III of the book gives the results from the second, longitudinal phase of the study. This part consists of 7 chapters. The first of these, chapter 8, deals with the course of functioning after discharge, measured in different ways. Unlike in chapter 6 , we make a distinction between physical and psychosocial functioning in this chapter. Within these two dimensions three different measurement approaches are used: an assessment of the course of functioning by the patients themselves afterwards (at the third and fourth assessment), longitu- 
dinal changes in reported activities and behaviour (measured with the Sickness Impact Profile) and longitudinal changes in the self-assessment of functioning.

The results in chapter 8 are largely in line with those in chapter 6 . When averaging the results of the three measures of the course of functioning, about $35 \%$ of the total group of patients deteriorate during the first three months and a somewhat smaller percentage when looking at the long term. For psychosocial functioning these percentages are lower: at the third as well as at the fourth assessment about $25 \%$ of the patients deteriorated in comparison to the time of discharge. Because of the selective drop-out during the study, it is likely that the 'real' percentages of deteriorated patients are higher. The figures differ for the different diagnostic categories, but in each category the number of deteriorating patients is considerable.

Just like in chapter 6 , assessments of the patients are to a large extent supported by assessments of people who know the patient well, and to a lesser extent by the professionals involved.

The data show an obvious 'functional dip' three months after discharge: for both dimensions of functioning there is a tendency of deterioration during the first three months, followed by a slight tendency of improvement again. This indicates that the first few months after discharge form a very critical period.

In chapter 9 we create groups of patients to be compared in the analysis of the factors related to the course of functioning in the chapters further on. These groups are created in such a way that the diagnostic categories are about equally represented. This is done because of the differences between these categories found in chapter 8. For each time-period to be studied (short term and long term) and for physical and psychosocial functioning separately, groups of patients with a relatively positive, an average and a relatively negative course of functioning are created: once on the basis of the retrospective assessment of the patients themselves afterwards (this approach is very similar to that in the first phase of the study) and once on the basis of actual changes over time in the self-assessment of functioning and in reported acitivities and behaviour. The latter two measures are combined into one, in order to reduce the number of different approaches. The result of these operations is that we follow 8 parallel approaches for the analysis of the factors related to the course of functioning: short term and long term, physical and psychosocial functioning, assessment afterwards and changes over time.

Besides the creation of these groups of patients, chapter 9 deals with the phenomenon of regression to the mean in the longitudinal approach. It appears to be rather strongly present with respect to the long term course on the basis of longitudinal change-scores. Here it is likely to influence the results of the analysis. 
The remaining 5 chapters in part III (10-14) deal with the explanation of the course of functioning. Chapters 10 to 13 each deal with the relationship of one group of variables with the 8 different measures of the course of functioning distinguished in chapters 8 and 9 . In each of these chapters only bivariate relationships are described; the groups of patients created are compared with respect to the variables of interest. Except for chapter 10, each of these chapters starts with a description of the explanatory variables and, if relevant, changes in these variables over time. Then, the differences between the different groups of patients are described. Finally, the results from the 8 parallel approaches are discussed in relation to the expectations formulated in chapter 3. Chapter 10 is about social-demographic and disability-related characteristics. Chapter 11 deals with the personal characteristics studied. In chapter 12 social network characteristics are at issue, while chapter 13 deals with continuity of care. The data presented in these chapters make it possible to make a selection of the variables that are most important in explaining the course of functioning; some of the variables studied appear to have no relationship to any of the measures of the course of functioning distinguished, or in an unclear or unsystematic way.

The selection of the variables that have a more or less consistent relationship with some of the approaches followed is the basis for the final analysis in chapter 14. Here we describe a series of multivariate analyses with this limited selection of the variables studied in the chapters 7 and 10 to 13 . The techniques used are discriminant and multiple regression analyses. For these analyses the personal characteristics selected are combined into one overall variable, because they appeared to form one factor in a principal components analysis. This variable is called 'powerlessness'. The variables finally included in the analyses in chapter 14 are: powerlessness, size of the social network, number of people giving practical support, loneliness, age, socio-economic status, duration of the disability and intercurrent diseases after discharge. The analyses presented in chapter 14 lead to the following conclusions:

- Social-demographic variables play an important role in the explanation of the course of functioning. Patients with a low socio-economic status, which is closely related to high age, have a greater chance to develop a more negative course of functioning, especially during the first three months after discharge. This especially applies to physical functioning.

- Disability-related characteristics have a less important and less clear role in the explanation. The occurrence of other diseases after discharge gives a greater chance to develop a relatively negative course of functioning, especially in psychosocial respect, but this is not completely unequivocal. A short disease-duration gives a higher chance to develop a relatively positive course of functioning, but a long disease-duration does not mean a 
negative course; the average groups tend to have the longest disease-duration.

- Powerlessness, which stands for the combination of the personal characteristics studied, plays a major role in the explanation of the course of physical as well as psychosocial functioning during the first three months after discharge. Patients who show a relatively negative course of functioning during this period score relatively high on the variable powerlessness, which means that they tend to have a strong doctor-orientation, a high inadequacy-score, a low self-recognition and a negative self-image, together with a high chance-orientation, a low internal orientation and a high rigidity-score. It is important to notice that this is not only the case when looking transversally, but that a high score on powerlessness at the time of discharge actually predicts the course of functioning. The role of powerlessness in explaining the long-term course of functioning is much less important.

- Of the social network characteristics studied, the experienced amount of practical support and loneliness appear to be important 'predictors' of the long-term course of physical as well as psychosocial functioning. Feelings of loneliness and experiencing little practical support and especially a decline in practical support are strong 'predictors' of a relatively negative course of both physical and psychosocial functioning. Size of the network is not a good predictor.

These conclusions hold for all three diagnostic categories involved in the study.

The results presented in the chapter 11,12 and 13 do not only contribute to the answer to the question of what factors explain the course of functioning after discharge. In these chapters we also describe the explanatory variables and their development over time. These descriptions lead to some important conclusions of their own. The most important concern the social network characteristics and continuity of care.

In chapter 12 it becomes clear that the social networks changed quite impressively in the two-year period of the study. The size of the network and the number of friends and other non-relatives in the network decrease in each diagnostic category. This decrease is most obvious for patients with a spinal cord lesion: they 'lose' more than half of their friends and other non-relatives.

The results in chapter 13 strongly underline those in chapter 7 with respect to continuity of care around and after discharge. Tuning and coordination of care after discharge is far from perfect. The results show problems regarding all aspects of care distinguished. It is even questionable whether continuity of care as defined for this study exists in practice. This is the most probable 
explanation why no relationship of aspects of continuity of care with the course of functioning is found. The most important findings are:

- Written information-exchange between rehabilitation centre and primary health care does not contribute much to a good handing over and coordination of care. Letters or discharge-forms are sometimes late, do not always reach the general practitioner, and often do not reach the community nurse. Insofar as they are received, they are mostly not read.

- Telephone or face-to-face contacts between professionals involved in the care for a patient are rare. As far as contacts take place, they almost always only have the character of information exchange.

- There is very little agreement between professionals about who is primarily responsible for different aspects of care.

- There is only limited agreement between professionals and patients about the situation of the patients.

- Patients and especially their social network members are only moderately satisfied with care after discharge. They mention a considerable number of complaints about care, mostly regarding an experienced lack of counselling and support, the relevant authorities' long and complicated procedures for providing aids and house-adaptations, and a lack of adequate information.

Part IV of the book contains a discussion of the results found in both phases of the study and the formulation of the conclusions. In chapter 15 we first discuss some important problems encountered in this study: the limited number of patients available, selective drop-out, regression to the mean and the fact that several parallel approaches were followed in the analysis. Although we consider these problems not really problematic in the sense that they might have lead to false results, we conclude that it is best to look upon the conclusions as valid hypotheses to be tested in future research. After this discussion the final conclusions are formulated, the contents of which have already been described earlier in this summary.

Chapter 15 ends with some recommendations for rehabilitation practice and suggestions for further research. The practical recommendations concern the development of interventions aimed at positively influencing the characteristics combined in the variable powerlessness, especially the health locus of control and self-image, and the development of interventions that enhance the maintenance of support from the social network. The latter could be done in two different ways: training and support of social network members in dealing with the handicapped and training of social skills of patients. The third practical recommendation regards the problems in continuity of care. We suggest the development of a discharge-procedure that ensures clarity and 
agreement upon tasks and duties of professionals and non-professionals in the care-process, and the appointing of one of the people involved to coordinate care. We also suggest the promotion of expertise in primary care workers and non-professionals with respect to rehabilitation in general as well as in specific cases. The last suggestion concerns the involvement of 'experienced' patients in the care process. These might play a very important role in supporting patients and especially in providing information about living with a disability'. 


\section{References}

Adams, B.N.

Interaction theory and the social network. Sociometry 1967; 30: 64-78.

Ajzen, I. and M. Fishbein

Understanding attitudes and predicting social behaviour. Englewood Cliffs, NJ: Prentice-Hall, 1980.

Andersson, K. and S. Berg

The relationship between some psychological factors and the outcome of medical rehabilitation. Scand. J. Rehab. Med., 1975, 7, 166-170.

Andersson, L.

Intervention against loneliness in a group of elderly women: an impact evaluation.

Soc. Sci. Med. 1985, 20, 355-364.

Andrews, F.M. S.B. Withey

Social indicators of well-being: America's perception of life quality. New York, Plenum Press, 1976.

ATIS: Vereniging Algemene Thuiszorg in Samenwerking

Coördinatie van zorg. Niet opeisen maar aanpakken. 1988.

Bangma, B.D.

Revalidatiegeneeskunde. Ontwikkelingen in de laatste tien jaar. Medisch Contact $1984,36,1149-1152$.

Bangma, B.D.

Revalidatiegeneeskunde. Methodologie en praktische uitvoering. Van Gorcum, Assen/Maastricht, 1989. 
Becker, M.H.

The health belief model and sick role behavior. Health Education Monographs, $1974,2,409-419$.

Becker, M.H., R.H. Drachman and I.P Kirscht

A field experiment to evaluate various outcomes of continuity of physician care. Am. J. Public Health, 1974, 64, 1062-1070.

Ben-Sira, $Z$.

The structure of readjustment of the disabled: an additional perspective on rehabilitation. Social Science and Medicine, 1981 15A, 565-580.

Ben-Sira, $Z$.

Affective and instrumental components in the physician-patient relationship: an attitudinal dimension of interaction theory. J. of Health and Social Behaviour, 1980, $21,170-180$.

Ben-Sira, $Z$.

Lay evaluation of medical treatment and competence development of a model of the function of the physician's affective behavior. Soc. Sci. Med., 1982, 16, 1013-1019.

Ben-Sira, $Z$.

Disability stress and readjustment: the function of the professional"s latent goals and affective behavior in rehabilitation. Soc. Sci. Med., 1986, 23 (1), 43-55.

Biergner, M. R.A. Bobbitt, W.E. Pollard, D.P. Martin \& B.S. Gilson

The Sickness Impact Profile: validation of a health status measure. Medical Care, $1976 \mathrm{a}, 14,57-67$.

Bergner, M., R.A. Bobbitt, S. Kressel, W.E. Pollard, B.S. Gilson \& J.R. Morris

The Sickness Impact Profile: conceptual formulation and methodology for the development of a health status measure.

International Journal of Health Services, vol. 6, no. 3, 1976b, 393-414.

Bergner, M. \& B.S. Gilson

The Sickness Impact Profile: The relevance of social science for medicine. In:

L. Eisenberg \& A. Kleinman (Eds.). The Relevance of Social Science for Medicine.

Dordrecht. D. Reidel Publishing Company, 1980, 135-150.

Bergner, M., R.A. Bobbitt, W.B. Carter \& B.S. Gilson

The Sickness Impact Profile: development and final revision of a health status measure. Medical Care, 1981, 19, 787-805.

Berkman, L., S.L. Syme

Social networks, host resistance and mortality; a nine-year follow-up study of

Alameda County Residents. Am. J. of Epidem. 1979; vol. 109: 186-204.

Bloom, S.W.

The doctor and his patient. Free Press, New York, 1965.

Bos van den, G.A.M.

Zorgen van en voor chronisch zieken. Bohm, Scheltema \& Holkema. Utrecht/ Antwerpen, 1989.

Brever, $P$.

Samenhangende zorgstructuren in de revalidatie. Nationaal Ziekenhuisinstifuut, Utrecht, 1989.

Broadhead, W.E., B.H. Kaplan, S.A. James, E.H. Wagner, VI. Schoenbach, R. Grimson, S. Heyden, G. Tibblin, S.H. Gehlbach

The epidemiologic evidence for a relationship between social support and health. Am. J. of Epidem., 1983, 117 (5), 521-537. 
Broese van Groenou, M.I.

Changes in personal relations following divorce; theoretical and methodological design.

Paper presented to the "Onderzoeksgroep sociale netwerk analyse van de NWOwerkgemeenschap SoMo', Amsterdam, 25 jan. 1989.

Bruhn, J.G.

Effects of chronic illness on the family. The Journal of family practice 1977; vol. 4 . nr. 6: $1057-1060$.

Bruin de, A.F, L.P. de Witte, F. Stevens, J. Diederiks

Sickness Impact Profile the state of the art of a generic functional status measure. Submitted, 1990.

Burink-Withaar, Jansen, Jonkers and Pruyn

Mentioned by R. Jonkers, M. Rutten, T. Ronner, IJ. Alleyn and T. v.d. Horde,

Omgaan met borstkanker: een samenwerkingsproject van de Provinciale Kruisvereniging Zuid-Holland te Den Haag en het Studiecentrum Sociale Oncologie te Rotterdam van de stichting Koningin Wilhelmina Fonds: eerste onderzoeksverslag april 1981.

Buys, P.C.

Curatieve gezondheidszorg, ziekteverzuim en arbeidsongeschiktheid. Proefschrift, Rotterdam, 1984.

Caplan, G. (ed.)

Support systems and community mental health; lectures on concept development. New York, 1974; Behavioral publications.

Cassee, E.Th.

Kommunikatie en therapeutisch gedrag. In: E.Th. Cassee en C.J. Lammers Mensen in het ziekenhuis. Nieuwe vormen van leidinggeven en kommunikatie. WoltersNoordhoff, 1971.

Cassel, J.

The contribution of the social environment to host resistance. Am. J. of Epidem. $1976 ; 104$ (2): 107-123.

Carter, W.B., R.A. Bobbitt, M. Bergner \& B.S. Gilson

Validation of an Interval Scaling: The Sickness Impact Profile. Health Services Research, 1976, 516-527.

Cassileth, B.R., E.J. Lusk, T.B. Strouse, D.S. Miller, L.L. Brown, P.A. Cross, A.N. Tenaglia Psychosocial status in chronic illness. New England Journal of Medicine 1984, 311, 506-511.

Charmaz, K.

Loss of self: a fundamental form of suffering in the chronically ill. Sociology of Health and Illness, 1983, $5(2), 168-195$.

Cobb, S.

Social support as a moderator of life stress. Psychosomatic Medicine, $1976 ; 38$ (5): 300-314.

Cohen, J.

Statistical power analysis for the behavioral sciences. Academic Press, New York and London, 1969.

Cohen, J.

Statistical power analysis for the behavioral sciences (Rev. Ed.). Academic Press, New York and London, 1977. 
Cohen, S. and S.L. Syme (eds.)

Social support and health. Orlando (FI), Academic Press, 1985.

Cohen, S, and T.A. Wills

Stress, social support, and the buffering hypothesis. Psychological Bulletin, 1985, $98(2), 310-357$.

Colleman J.S.

Social capital in the creation of human capital.

American Journal of Sociology, 1988, vol. 94, no. supplement, 595-5120.

Coolen, J.A.I.

De integratie van een voorzieningensysteem. Een onderzoek naar coür dinatie en integratie in de gezondheids-en welzijinszorg voor oude mensen.

Proefschrift Twente, 1986.

Croog, S.H. and S. Levine

The heart patient recovers; social and psychological factors. Human Sciences Press, New York/London, 1977.

Dew, M.A.

A causal analysis of factors affecting adjustment to spinal cord injury. Rehab. Psychology, 1985, 30 (1), 39-46.

Deyo, R.A., T.S. Inui, J.D Leininger and S.S. Overman

Measuring functional outcomes in chronic disease: a comparison of traditional scales and a selfadministered health status questionnaire in patients with rheumatoid arthritis. Medical Care, 1983 (21), 180-192.

Deyo, R.A. \& T.S. Inui

Toward clinical applications of health status measure: sensitivity of scales to clinically important changes. Health Services Research, 1984, 19, 275-289.

Diener, $\mathbf{E}$.

Subjective well-being. Psychological Bulletin, 1984, 95 (3), 542-575.

Dijkstra, A.

Stigmatisering. Maatschappelijke gevolgen van een afwijkend uiterlijk.

Rotterdam, Lemniscaat b.v., 1979

DiMatteo, M.R. and O.D. DiNicola

Achieving patient compliance. Pergamon Press, New York, 1982.

Eijk, van I.

De verwerking van enkele levensgebeurtenissen en steun uit sociale netwerken.

Gezondheild en Samenleving, 1980; 1 (2), 83-101.

Ejlertsson, G., S. Berg

Continuity of care measures. Med. Care 1984, 22, 231-239.

Engelsman, C., M. Riewald

Continuäteit van zorg bij poliklinische chemotherapie. Medisch Contact, 1988, 43 (45), $1377-1380$.

Eriksson, E.A., L.G. Mattsson

Quantitative measurements of continuily of care. Med. Care 1983, 21, 858-875.

Fieigenson, J.S., F.H. McDowell, P. Meese, M.L. McCarthy, S.D. Greenberg

Factors influencing outcome and length of stay in a stroke rehabilitation unit.

Part 1. Analysis of 248 unscreened patients - medical and functional prognostic indicators. Stroke, 1977, 8: 651-656.

Finlayson, A.

Social networks as coping resources: lay help and consultation patterns used by women in husbands' post-infarction career. Social Science and Medicine, 1976, 10, $97-103$. 
Finlayson, A. and J. McEwen

Coronary heart disease and patterns of living. London: Croom Helm, 1977

Fitzpatrick, R, S. Newman, R. Lamb, M. Shipley

Social rellationships and psychological well-being in rheumatoid arthritis. Soc. Sci.

Med. 1988, 27, 399-403.

Flap, H.D.

De theorie van het sociale kapitaal.

Antropologische verkenningen, 1987, vol. 6, 14-27.

Fugl-Meyer, A.R.

Post-stroke hemiplegia-occupational status. Scand. J. Rehab. Med., 1982, 14 (supplement), 167-171.

Gehandicaptenraad

Thuishulp aan mensen met een handicap. Een overzicht van de bestaande situatie en voorstellen tot oplossing van knelpunten. Nota van de Werkgroep Thuishulp. Utrecht, oktober 1986.

Gillson, B.S., J.S. Gilson, M. Bergner e.a.

The Sickness Impact Profile: Development of an outcome measure of health care.

American J. Publ. Health, 1975, 65, 1304-1310.

Gogstad, A.C., A.M. Kjellman

Rehabilitation prognosis related to clinical and social factors in brain injured of different etiology. Soc. Sci. Med, 1976, 10, 283-288.

Gottlieb, B.H.

Social support and community mental health. In: Cohen, S. and S.L. Syme. Social support and health. Academic Press, 1985.

Grol, R., A. Smits, H. Fransen, C. van Weel

Continuiteit in de huisartsgeneeskunde. Huisarts en Wetenschap 1987, 30, 275-279.

Halfens, R.

Locus of control: de beheersingsorientatie in relatie tot ziekte- en gezondheidsgedrag. Proefschrift, Rijksuniversiteit Limburg, Maastricht, 1985.

Halfens, R. and H. Philipsen.

Een gezondheidsspecifieke beheersingsorientatieschaal. Validiteit en betrouwbaarheid van de MHLC. Faculteil der Gezondheidswetenschappen, Rijksuniversiteit Limburg, Maastricht, 1988.

Haynes, R.B., D.W. Taylor, D.L. Sackett

Compliance in health care. Baltimore: John Hopkins University, 1979.

Huygen, F.J.A.

"De gehandicapte thuis". In: A. Verkuyl (red.). Gehavend en wel. Psychosociale aspecten van revalidatie. Alphen aan de $\mathbb{R} i j n$, Samson, 1977.

Hyman, M.D.

Social isolation and peer performance in rehabilitation. Journal of chronic diseases, $1972,25,85-97$.

IJzerman, C.J., S.K. Oskam

Continuiteỉt in de huisartspraktijk gemeten. Huisarts en Wetenschap 1990, 33, 51-56.

Israel, B.A.

Social networks and health status: linking theory, research and practice. Patient Counselling and Health Education, 1983, $4(2), 65-79$. 
Jacobs, H.M. and R.A. de Melker

Samenwerking tussen hwisartsen en specialisten in relatie tot de kwaliteit van de hulpverlening: een literatuurstudie in het kader van een onderzoek naar de kwaliteit van de hulpverlening op het grensvlak van de eerste en tweede lijn. Vakgroep Huisartsgeneeskunde Rijksuniversiteit Utrecht, 1983.

Jansen, H.F.A., C.P.C. Breemer ter Stege en F. Doeleman

Samenhang in de zorgverlening: alstemming binnen het primaire proces van de gezondheidszorg. M. en O., 1985, 5, 339-355.

Janssen, M. H. Phulipsen, R. Halfens

Personal networks of chronically ill people. Paper presented at the fifth international conference on personal relationships. Oxford, 15-20 july 1990.

jette, A.M.

Functional status index: Reliability of a chronic disease evaluation instrument.

Arch. Phys. Med. Rehabil. 1980; 61: 395-401.

Jong-Gierveld, J. de \& F. Kamphuis

The development of a Rash-type loneliness scale.

Applied Psychological Measurement, 1985, 9, 3, 289-299.

Jong-Gilerveld, J. de

Eenzalamheid: een meersporig onderzoek.

Van Loghum Slaterus, Deventer, 1984:

Katz, S, A.B. Ford, R.W. Moskowitz, B.A. Jackson, M.W. Jaffe

Studies of illness in the aged. The index of ADL: a standardized measure of biological and psychosocial function ${ }_{n}$ JAMA 1963; 185: 914-919.

Katz, S., S. Hendrick, N.S. Henderson

The measurement of long-term care needs and impact. Health Med. Care Serv. Rew. $1979 ; 2: 1-21$.

Kerkstra, A., R.A. Verheij, M. Foets, J. van der Velden

Behoefte aan nazorg en verleende nazorg na ontslag uit het ziekenhuis. T. Soc.

Gezondheidszorg 1990, 68, 346-354.

Kok, G.J.

Gedragsmodellen in patientenvoorlichting.

In: Damoiseaux, V. en Visser, A. Ph. (red.). Patientenvoorlichting, Een interdisciplinaire benadering. Van Gorcum, Assen/Maastricht, 1988.

Larson, $\mathbf{R}$.

Thirty years of research on the subjective well-being of older Americans. Journal of Gerontology, 1978, 33, 109-125.

Lefcourt, H.M. (ed)

Research with the Locus of Control construct. Volume 1, assessment methods.

Academic Press, Toronto, 1981.

Lehmann, J.F, B.J. Delateur, R.S. Fowler, C.G. Warren, R. Arnold, G. Schertzer, R. Hurka, J.T. Whitmore, A.J. Masock, K.H. Chambers

Stroke rehabilitation: outcome and prediction. Arch. Phys. Med. Rehabil. 1975, 56, 383-389.

Levenson, $H$.

Differentialing among internality, powerful others, and chance. In: Lefcourt, H.M (ed.) Research with the Locus of Control construct. Volume 1, assessment methods. Academic Press, 1981. 
Lin, $N$.

Social resources and instrumental action. In: Marsden PV. and Lin N. (eds). Social Structure and Network Analysis. Beverly Hills, 1985, Sage Publications.

Lin, N., W.M. Ensel, R.S. Simeone, W. Kuo

Social support, stressfull life events and illness. A model and an emperical test. J. of Health and Social Behaviour 1979; vol. 20" 108-119.

Litman, T.J.

The influence of self conception and life orientation factors in the rehabilitation of the orthopedically disabled. Journal of Health and Human Behavior, 1962, 249-257.

Litman, T.J.

The family and physical rehabilitation. Journal of chronic diseases, 1966, 19, 211-217.

Lökk, J.

Emotional and social effects of a controlled intervention study in a day-care unit for elderly patients. Scand. I. Prim. Health Care 1990, 8, 165-172.

Luteijn, F s $_{v}$. Starren \& H. v. Dijk

Nederlandse Persoonlijkheidsvragenlijst; Handleiding. Swets en Zeitlinger, Lisse, 1975.

Luteijn, F., J. Starren \& H. van Dijk

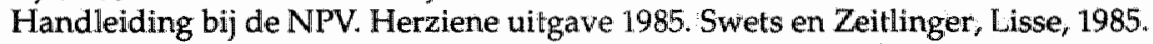

Luttik, A. H.M. Jacobs \& L.P de Witte

De Sickness Impact Profile: een meetintrument waarmee de invloed van ziekte en/ of gezondheidsklachten op het dagelijks functioneren kan worden vastgesteld.

Nederlandse versie.

Vakgroep Huisartsgeneeskunde. Rijksumiversiteit Utrecht, maart 1985.

MacKenzie, C.R., M.E. Charlson, D. Digioia \& K. Kelley

Can the Sickness Impact Profile measure change? an example of scale assessment. Journal of Chronic Diseases, 1986, vol. 39, no. 6, 429-438.

MacKenzie, E.J., S. Shapiro, R.T Smith, J.H. Siegel, M. Moody, A. Pitt

Factors influencing return to work following hospitalisation for traumatic injury.

Am. J. Public Health, 1987, 77, 329-334.

McDowell, I. and C. Newell

Measuring Health: a guide to rating scales and questionnaires. Oxford University Press, New York, 1987.

Meddin, J.R.

Sex differences in depression and satisfaction with self: findings from a United

States national survey. Soc. Sci. Med. 1986, 22 (8), 807-812.

Melker, de R.A.

Ziekenhuispatiant, huisarts, huisgezin. Dissertatie, Nijmegen, 1973.

Melker de, R.A., F. Touw-Otten, H.M. Jacobs, A. Luttik

De waarde van de 'sickness impact profile' als uitkonstmeting. Ned. T. w. Geneesk. $1990,134(19), 946-948$.

Ministry for Social Affairs and Employment

Note on income policy, 1989. Lower House, 1988-1989, 20808, nrs. 1-2.

Moskowitz, E. and C.B. McCann

Classification of disability in the chronically ill and aging. J. Chron. Dis. 1957; 5:

342-346. 
Mulders, A., L. de Witte, J. Diederiks

Evaluation of a rehabilitation after-care programme for stroke patients. Int. J. of Reh. Sciences $1989,2,97-103$.

Norbeck, J.S., A.M. Lindsey \& V.L. Carrieri

The development of an instrument to measure social support.

Nursing Research, 1981, 30, 264-269.

Nuckolls, K.B., J. Cassel and B.H. Kaplan

Psychosocial assets, life crisis and the prognosis of pregnancy. Am. J. of Epidem., $1972,100(5), 431-441$.

O'Reilly, P, H.E. Thomas

Role of support networks in the maintenance of improved cardiovascular health status. Soc. Sci. Med. 1989, 28, 249-260.

Osgood, C.E., G.J. Suci \& P.H. Tannenbaum

The measurement of meaning.

Urbana: University of Illinois Press, 1957.

Patrick, D.L., M. Morgan, J.R.H. Charlton

Psychosocial support and change in the health status of physically disabled people.

Soc. Sci. Med. 1986, 22, 1347-1354.

Philipsen, $\mathbb{H}$.

Rationaliteit en ons oordeel over de verdwijnende patient. Gezondheid en Samenleving, 1985,6 (3), 142-151.

Philipsen, $\mathbb{H}$.

Gezondheidszorg als project en bejegening. Waarden ten aanzien van ziekte, gezondheid en samenleving. Rijksuniversiteit Limburg, 1988.

Philipsen, $\mathrm{H}$.

De invloed van continuâteit van zorg op de kwaliteit van leven. Voordracht

Conferentie "Gezondheidszorgonderzoek bij Chronische Ziekten". Rhenen, 1 november 1990.

Pollard, W.E., R.A. Bobbitt, M. Bergner, D.P. Martin \& B.S. Gilson

The Sickness Impact Profile: reliability of a health status measure. Medical Care, 1976,14 , no. $2,146-155$.

Pollock, S.E., B.J. Christian, D. Sands

Responses to chronic illness: analysis of psychological and physiological adaptation. Nursing Research 1990, 39 (5), 300-304.

Ris, B.G.M. and J.P.M. Diederiks

Een kritische analyse van interdisciplinaire samenwerking in de hulpverlening.

T. Soc. Geneesk, 1974, 52, 553-560.

Ropes, M.W., G.A. Benner, S. Caleb, et al

Revision of diagnostic criteria for rheumatoild arthritis. Bull. Rheum. Dis. 1958; 9: 175-6.

Rotter $_{\text {f J.B., M. Seeman and S. Liverant }}$

Internal versus external control of reinforcements: a major variable in behavior theory. Decisions, Values and Groups 2, 1962, 473-516.

Schoemakers-Salkinoja, I., J. Hessing-Wagner

Samenhang in de zorg voor lichamelijk gehandicapten. Sociaal en Cultureel Planbureau, 1987.

Schoening, H.A., L. Anderegg, D. Bergstrom, M. Fonda, N. Steinke, P. Ulrich

Numerical scoring of self-care status of patients. Arch. Phys. Med. Rehabil. 1965; 46: 689-697. 
Smith, R.T.

Disability and recovery process: role of social networks. In: E Gartly Jaco (ed.) Patients, physicians, and illness. A sourcebook in behavioral science and health. The free Press, New York, 1979.

Soeters, I.

Patient, gezondheidszorg en langdurige ziekte. Proefschrift Maastricht, 1983.

SPSSX Users Guide. Third Edition.

SPSS Inc., Chicago, 1988.

Starfield, B.H., D.W. Simborg, S.D. Horn and S.A. Yourtee

Continuity and coordination in primary care: their achievement and utility. Medical Care, $1976,14(7), 625-636$.

Steen, van der J.J.

Terugkomtrouw in de huisartspraktijk. Proefschrift Leiden, 1987.

Steinbricker, O., C.H. Traeger \& R.C. Batterman

Therapeutic criteria in rheumatoid arthritis. JAMA, 1949, 140,659

Tabachnick, B.G., F.S. Fidell

Using Multivariate Statistics. Harper \& Row, New York, 1983.

Taylor, S.E.

Health Psychology. New York, Random House, 1986.

Teasdale, G., A. Skene, L. Parker, B. Jennet

Age and outcome of severe head injury. Acta Neurochir. 1979, 28 (supplement), 140-143.

Terpstra, S.J., L.P. de Witte, F.G. van der Horst, D.J.P. Tilli

Leven met een neuromusculaire aandoening ( $)$ : een onderzoek bij leden van de Vereniging Spierziekten Nederland. Instituut voor Revalidatie-vraagstukken, Hoenstroek, 1990.

Tilburg, T.G. van

Verkregen en gewenste ondersteuning in het licht van eenzaamheidservaringen.

Proefschrift Vrije Universiteit Amsterdam, 1988.

Verkuyl, A.

De patient die uit een revalidatiecentrum terugkomt. In: Kompas voor de huisarts.

Utrecht ${ }_{r}$ Bohm ${ }_{r}$ Scheltema en Holkema, 1981.

Visser, A.Ph.

De beleving van het verblijf in het algemene ziekenhuis: tevredenheid, kennis en emotionele toestand van ziekenhuispatienten: meting, inhoud en determinanten. Proefschrift Vrije Universiteit, Amsterdam, 1984.

Wallston, B.S., S.W. Alagna, B. McEvoy DeVellis and R.F. DeVellis

Social support and physical health. Health Pychology, 1983, 2 (4), 367-391.

Wallston, K.A. and B.S. Wallston

Health locus of control scales. In: H.M. Lefcourt (ed.). Research with the locus of control construct, volume 1: Assessment methods, 189-243. Academic Press, New York, 1981.

Wallston, K.A., B.S. Wallston \& R. DeVellis

Development of the multidimensional health locus of control (MHLC) scales.

Health Education Monographs, 1978, 6, 160-169.

Waltz, M.

Marital context and post-infarction quality of life: is it social support or something more? Soc. Sci. Med. 1986, 22 (8), 791-805. 
Wiegers, T.A., T.M.I.M.T. Kersten

Problemen bij de overdracht van nazorgpatienten. De continuiteit onderzocht.

TvZ/Vakblad voor verpleegkundigen $1990,728-733$.

Wijk van, $Y$.

De afstemmingsproblematiek tussen de klinische revalidatiezorg en de thuiszorg

Technische Universiteit Twente, 1989.

Willde, G.J.S.

Neurotische labiliteit gemeten volgens de vragenlijstmethode. Van Rossum, Amsterdam, 1970.

Witte de, L., E. van der Horst, J. Joosten, H. Philipsen, P. Bakker

Continuiteit van zorg na ontslag uit een revalidatiecentrum. TSG 1986; 64 nr.17 $567-572$

Witte, L. de, H. Jacobs, F. van der Horst, A. Luttik, J. Joosten \& H. Philipsen

De waarde van de Sickness Impact Profile als mat voor het functioneren van patienten.

Gezondheid en Samenleving, jrg. 8 , no. $2,1987,120-127$.

Witte, L.P. de, D.J.P. Till, A.J.G. Ticheler, B.A.C. Winants, F.G. van der Horst \& Sj. van der Linden

Leven met een reumatische aandoening. Een onderzoek naar de ervaren kwaliteit van het leven bij 372 mensen met een reumatische aandoening.

Instituut voor Revalidatievraagstukken, Hoensbroek, 1989.

World Health Organisation

International Classification of Impairments, Disabilities and Handicaps. A manual of classification relating to the consequences of disease. WHO, Geneva, 1980.

Wortman, C., T. Conway

The role of social support in adaptation and recovery from physical illness. In:

Cohen S. and Syme S.. Social support and health. Academic Press 1985, Orlando (FI).

Yarkony, F.M., E.J. Roth, A.W. Heinemann, L.L. Lovell

Spinal cord injury rehabilitation outcome: the impact of age. $J$. Clin. Epidemiol. $1988,41(2), 173-177$.

Zijderveld, A.C.

De relativiteit van kennis en werkelijkheid. Inleiding to de kennissociologie. Boom, Meppel, 1974

Zijderveld, A.C.

De culturele factor. Een cultuursociologische wegwijzer. VUGA, Den Haag, 1983. 
Appendices 


\section{Appendix I}

Scores of the total groups of patients involved in the study on the most central variables*

( $N=37$ for phase I and 67 for phase II)

$\begin{array}{llll}\begin{array}{l}\text { number } \\ \text { of items }\end{array} & \begin{array}{l}\text { maximal direction } \\ \text { range }\end{array} & \begin{array}{l}\text { average } \\ \text { score * }\end{array} & \begin{array}{l}\text { standland } \\ \text { deviation }\end{array}\end{array}$

Sickness Impact Profile

- physical subscore

very good

$35.0 / 19.7 \quad 17.4 / 14.3$

-very bad

- psychosocial subscore

48

$\begin{array}{rr}0-100 \% & \text { very good } \\ & \text {-very bad }\end{array}$

$13.0 / 9.2 \quad 12.6 / 9.2$

-very bad

Self-assessment of functioning

- physical functioning

$4-20$

very good

$13.7 / 10.9 \quad 3.7 / 3.0$

-wery bad

- psychosocial functioning

$5-25$

very good

$-/ 9.6$

$-/ 2.7$

-very bad

Self-assessment of change in functioning since discharge

- physicall functioning

$3 / 4^{* * *} \quad 3-15 / 4-20 \quad$ much better

$8.6 / 12.3 \quad 3.0 / 2.4$

-much worse

- psychosocial functioning

$2 \quad 2-10$

much better

$6.3 / 5.9$

$11.4 / 0.9$

-much worse

Personality traits

- inadequacy

21

$-3-3$

very low-

very high

$-0.2 /-0.1 \quad 1.6 / 1.5$

- social inadequacy

$15 \quad-3-3$

very low-

$-0.0 /-0.1 \quad 1.5 / 1.4$

- rigidity

25

$-3-3$

very high

very low-

$0.1 /-0.4 \quad 1.2 / 1.2$

- self-recognition

19

$-3-3$

very high

very low-

very high

$-0.1 / 0.3 \quad 1.2 / 1.2$ 
Healith locus of control

- internal orientation

6

6-36 How-hioh

$20.0 / 21.6 \quad 5.6 / 5.7$

- doctor orientation

6

$6-36$

Now-high

$20.7 / 18.1$

$6.5 / 6.1$

- chance orientation

6

6-36

low-high

$23.2 / 19.7$

$6.3 / 6.3$

Self-image

- percentage damaged

1

$0-100 \%$

not-severily

$49.5 / 34.6 \quad 37.0 / 30.5$

damaged

- positive self-evaluation

9

$9-45$

negative-

$-/ 35.5$

$-/ 5.1$

pasitive

8

$8-40$

pasitive-

negative

$-/ 17.8$

$-/ 5.2$

- negative self-evaluation

Social network characteristics

- size

$-\quad 0-20$

$9.3 / 9.5$

$5: 1 / 5.7$

- number of friends and other non-relatives.

$-\quad 0-20$

$4.2 / 3.2$

$3.5 / 3.7$

- number of people giving emotional support

- $\quad 0-20$

3.7. 3.3

$3.8 / 3.8$

- number of people giving practical support

$-\quad 0-20$
$-\quad 0$

$4.9 / 4.2$

$3.7 / 3.6$

- number of people with whom patient talks about disability

$-\quad 0-20$

$-12.2$

- loneliness

11

$0-11$

not-extremely

$-/ 1.2$

$-/ 1.9$

Ionely

- With respect to phase $\mathrm{II}$, the scores at the second assessment (discharge) are presented, except for the self-assessment of change in functioning. Here the scores from 13 are presented.

* The figures before the slash regard phase I of the study, those behind the slash phase II.

* * In phase II this scale consisted of 4 items, in phase 1 onily 3. 


\section{Appendix II}

\section{The items of the health locus of control scales (in Dutch)}

\section{Intermal orientation}

2. Als ik ziek ben ligt het aan mijzelf hoe snel ik beter word.

6. Als ik goed voor mijzelf zorg, kan ik ziektes voorkomen.

8. Als ik ziek word dan is dat mijn eigen schuld.

11. Mijn gezondheid wordt in de eerste plaats bepaalid door wat ik zelf doe.

14. Ik heb milin gezondheid in eigen hand.

17. Het ligt vooral aan mijzelf hoe snel ik van een ziekte zal genezen.

\section{Doctor-orientation}

4. Als ik van een ziekte herstell, heb ik dit toch wooral te danken aan milin arts.

5. Als ik me niet goed voel, moet ik eigenlijk een arts raadplegen.

7. Wat betreft mijn gezondheid kan ik alleen maar doen wall de dokter zegt.

9. Artsen hebben er veel inwloed op of ik gezond bilif of niet.

13. Artsen bepalen mijn gezondheid.

15. De beste manier voor mij om ziektes te voorkomen is regelmatig de huisarts te raadplegen.

\section{Chance-orientation}

1. Wat ik ook doe, ziek word ik waarschijnlijk toch.

3. Miln goede gezondheid is grotendeels een kwestie van aanleg of geluk.

10. Hoe snel ik van een ziekte zal genezen, wordt grctendeels door geluk bepaald.

12. De meeste dingen waardoor ik zilek word overkomen mij bij toeval.

16. Of ik gezond blif is een kwestie van toevallige gebeurtenissen.

18. Als ik ziek word dan word ik het toch, daar kan niemand lets aan doen.

Each item has six answering possibilities, ranging from 'strongly agree' to 'strongly disagree' (beslist mee eens, mee cens, enigszins mee cans, enigszins mee oneens, mee oneens, beslist mee oneens). 


\title{
Appendix III
}

\section{The items of the scales measuring aspects of the sell-matre (w Dist)}

\author{
Positive evaluation \\ kinderlijk - volwassen \\ regelmatig - onregelmatig \\ verleden - toekomst \\ mooi-lelijk \\ agressief - verzoenend \\ bedreigend - beschermend \\ soepel-star \\ tijgelijk - blijuend \\ hard-zacht
}

\author{
Negative evaluation \\ goed - slecht \\ sterk - zwak \\ waardevol - waardejoos \\ snel - langzaam \\ harmonieus - konkliktueus \\ anhandig - handig \\ groot - klein \\ actief - passief
}

For each pair of adjectives there are 5 answering possibilities. The direction of coding is towards the italicized adjectives. The positive scale has a theoretical range from 9 to 45 , while the negative scale ranges from 8 to 40 . 


\section{Appendix IV}

Aspects of continuity of care related to the course of functioning: tables

\section{Appendix IV, Tabie 1}

Aspects of continuity of care in the periods: 12-13 and 12-14 for patients who experienced a relalively posilive, average or negative course of physical tunctioning (assessment afterwards)

\begin{tabular}{llllll}
$12-13$ & & \multicolumn{5}{c}{$12-14$} & & \\
1. & 2 & 3. & 1. & 2. & 3. \\
positive & average & negallive & positive & average & regative \\
$(\mathbb{N}=28)$ & $(N=16)$ & $(N=23)$ & $(N=19)$ & $(N=26)$ & $(N=22)$
\end{tabular}

number of professionals

involved

\begin{tabular}{|c|c|c|c|c|c|c|c|}
\hline 4.2 & 4.7 & 4.5 & n.S. ${ }^{4}$ & 25 & 2.9 & 39 & $\begin{array}{l}(1=2)<3 \\
p=.071^{4}\end{array}$ \\
\hline 2.2 & 2.9 & 2.7 & n.s. & 1.6 & 2.1 & 3.0 & $\begin{array}{l}(1=2) \times 3 \\
0=.037^{4}\end{array}$ \\
\hline 14 & 6 & 6 & A.S. ${ }^{2}$ & 10 & 11 & 4 & $p=.0600^{2}$ \\
\hline 6 & 5 & 8 & n.s. ${ }^{2}$ & 2 & 6 & 8 & n.s. ${ }^{2}$ \\
\hline 7 & 5 & 9 & & 6 & 6 & 10 & \\
\hline 1 & - & - & & 1 & 3 & - & \\
\hline
\end{tabular}

agreement on tasks and duties at it

at 13

$\begin{array}{llllllll}7 & 7 & 6 & n . s^{2} & 7 & 6 & 5 & n^{2} .^{2} \\ (N=14) & (N=14) & (N=10) & & (N=11) & (N=15) & (N=12) & \\ 3 & 2 & 2 & n . s .^{2} & 1 & 3 & 3 & n . .^{2} \\ (N=3) & (N=4) & (N=3) & & (N=2) & (N=4) & (N=4) & \end{array}$

agreement between palient and professionals about functioning

palient - general practitioner

number of cases in which

there was no contact.

patient - general pract.

923

average disagrement

$$
\begin{array}{lll}
2.0 & 1.6 & 2.5 \\
(N=12) & (N=10) & (N=15)
\end{array}
$$

n.s. ${ }^{2} \quad 8$

12

1

$0=004^{2}$

number of general practi-

tioners that have no idea

432

1.7

n.s."

number of cases in which

disagreement could not

be compulad 


$\begin{array}{llllll}12-13 & & & 12-14 & & \\ 1 . & 2 . & 3 . & 1 . & 2 . & 3 \\ \text { positive } & \text { average } & \text { negative } & \text { positive } & \text { average } & \text { negative } \\ (\mathrm{N}=28) & (\mathrm{N}=16) & (\mathrm{N}=23) & (\mathrm{N}=19) & (\mathrm{N}=26) & (\mathrm{N}=22)\end{array}$

patient - community nurse

number of cases in which

there was no contact

patient - community nurse

$10-17$

$17-n s^{2}-15$

$25 \quad 15 \quad p=0.038^{2}$

average disagreement

$3.0 \quad 1$

$1.8 \quad 0.7$

$0.7 \quad p=0.085^{4}$

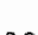

18

n.s. ${ }^{4}$

$(\mathrm{N}=2) \quad(\mathrm{N}=5) \quad(\mathrm{N}=4) \quad 1>3$

$(\mathrm{N}=3)$

$(N=6)$

number of community nurses.

that have no idea

2

number of cases in which

disagreement could not

be computed

2

salistaction of patients and

network members with care

pallient: dissatisfied not available for 13
average
salisfied

\section{network}

members

dissalisfied
average
satisfied

$\begin{array}{lll}3 & 2 & 4 \\ 8 & 3 & 8 \\ 3 & 5 & 3\end{array}$

$\begin{array}{llll}1 & 2 & 3 & \\ 8 & 11 & 9 & \text { n.s. } \\ 9 & 11 & 10\end{array}$

number of people lhawing complaints about care (at i3)

(in general/provision of aids)

\begin{tabular}{|c|c|c|c|c|c|c|c|c|}
\hline patient: & $3 / 4$ & $4 / 3$ & $6 / 3$ & $\begin{array}{l}\text { n.s. } \\
\text { n.s.? }\end{array}$ & $2 / 3$ & $4 / 4$ & $7 / 3$ & $\begin{array}{l}\text { n.s.l } \\
\text { n.s.?. }\end{array}$ \\
\hline rellwork & & & & & & & & \\
\hline members: & $\begin{array}{l}11 / 5 \\
(N=20)\end{array}$ & $\begin{array}{l}4 / 4 \\
(N=11)\end{array}$ & $\begin{array}{l}11 / 4 \\
(N=17)\end{array}$ & 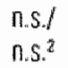 & $\begin{array}{l}8 / 3 \\
(N=13)\end{array}$ & $\begin{array}{l}11 / 5 \\
(N=21)\end{array}$ & $\begin{array}{l}7 / 2 \\
(N=14)\end{array}$ & $\begin{array}{l}n .5 . / \\
n . s_{0}^{2}\end{array}$ \\
\hline
\end{tabular}

* no cases lell 


\section{Appendix IW, Hable 2}

Aspects of continuity of care in the periods $12-13$ and $2-14$ for patients with a relatively positive, average or negalive course of physical functioning (change over time)

$\begin{array}{llllll}12-13 & & & 12-14 & & \\ 1 . & 2 . & 3 . & 1 . & 2 & 3 . \\ \text { positive } & \text { average } & \text { negalive } & \text { positive } & \text { average } & \text { negative } \\ (N=24) & (N=18) & (N=25) & (N=22) & (N=21) & (N=24)\end{array}$

\begin{tabular}{|c|c|c|c|c|c|c|c|c|}
\hline $\begin{array}{l}\text { number of prote } \\
\text { involved }\end{array}$ & 4.4 & 4.7 & 4.2 & $n$ n. $^{4}$ & 28 & 2.6 & 3.8 & $\begin{array}{l}(1=2)<3 \\
p=096^{4}\end{array}$ \\
\hline \multicolumn{9}{|l|}{ number of professionais } \\
\hline conlacled more than once & 2.1 & 2.9 & 2.6 & n.S. & 2.0 & 2.1 & 2.7 & $n . S_{n}^{4}$ \\
\hline \multicolumn{9}{|l|}{ coordinaling contacts } \\
\hline no contacis necassary & 13 & 4 & 9 & n.s. & 10 & 9 & 6 & $n . s^{2}$ \\
\hline no contacls & 5 & 5 & gi & ก. $5^{2}$ & 4 & 3 & 9 & $n s^{2}$ \\
\hline some degree ol coordination & 6 & 8 & 7 & & 6 & 8 & 8 & \\
\hline no informalion available & - & 1 & - & & 2 & 1 & 1 & \\
\hline \multicolumn{9}{|l|}{ agreement on tasks and duties } \\
\hline at n & $\begin{array}{l}5 \\
(N=10)\end{array}$ & $\begin{array}{l}5 \\
(N=12)\end{array}$ & $\begin{array}{l}10 \\
(\mathrm{~N}=16)\end{array}$ & f.S. ${ }^{2}$ & $\begin{array}{l}6 \\
(N=12)\end{array}$ & $\begin{array}{l}4 \\
(N=9)\end{array}$ & $\begin{array}{l}10 \\
(N=17)\end{array}$ & n.s..$^{2}$ \\
\hline at 13 & $(N=1)$ & $\begin{array}{l}6 \\
(N=6)\end{array}$ & $\begin{array}{l}0 \\
(N=3)\end{array}$ & $p=.007^{2}$ & $\begin{array}{l}1 \\
(N=1)\end{array}$ & $\begin{array}{l}3 \\
(N=4)\end{array}$ & $\begin{array}{l}3 \\
(N=5)\end{array}$ & $n \cdot s^{2}$ \\
\hline
\end{tabular}

agreement between patient and

professionals about functioning

patient - general pracilioner

number of cases in which

there was no contacl

palient - general pract.

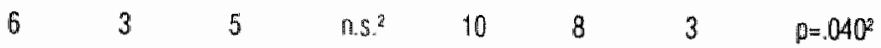

avarage disagrement

$\begin{array}{llllllll}2.1 & 1.6 & 2.4 & n .5 . & 2.6 & 2.3 & 1.8 & \text { n.s." } \\ (N=14) & (N=10) & (N=13) & & (N=9) & (N=6) & (N=13) & \end{array}$

number ol general practi-

lioners that have no ddea

44

2

5

number of cases in which disagreement could not be computted

3

25 


$\begin{array}{llllll}2-13 & & & 12-14 & & \\ 1 . & 2 . & 3 & 1 . & 2 . & 3 \\ \text { positive } & \text { average } & \text { negalive } & \text { posilive } & \text { average } & \text { negative } \\ (N=24) & (N=18) & (N=25) & (N=22) & (N=21) & (N=24)\end{array}$

patienfli-community nurse

number of cases in which

there was mo contact

patient communily nurse

$\begin{array}{llllllll}19 & 11 & 19 & \text { n.s. }{ }^{2} & 19 & 19 & 17 & \text { n.s. }\end{array}$

average disagreement

$2.5 \quad 1.3 \quad 1.0$

n.s.

$1.7 \quad 2.0 \quad 2.8 \quad$ n.s."

$(\mathbb{N}=2) \quad(N=6) \quad(N=3)$

$(\mathbb{N}=3) \quad(\mathbb{N}=1) \quad(\mathbb{N}=5)$

number of community nurses

that have no idea

1

number of cases in which

disagreement could not

be computed

$2 \quad-\quad 2$

salisfaction of patients and

nelwork members with care

patient: $\begin{aligned} & \text { dissatisfied } \\ & \text { average } \\ & \text { satisflied }\end{aligned}$

$\begin{array}{llll}2 & 0 & 4 & \\ 7 & 12 & 9 & \text { n.s. } \\ 12 & 7 & 11\end{array}$

\section{network}

members: dissatisfied average

$\begin{array}{lll}5 & 1 & 3 \\ 4 & 7 & 8 \\ 2 & 4 & 5\end{array}$

$\begin{array}{llll} & 2 & 1 & 1 \\ \text { n.s. } & 4 & 10 & 7 \\ & 6 & 3 & 6\end{array}$

$n . s^{2}$

number of people having complaints about care (at t3)

(in general/provision of aids)

\begin{tabular}{|c|c|c|c|c|c|c|c|c|}
\hline patient: & $3 / 4$ & $5 / 3$ & $5 / 3$ & $\begin{array}{l}\text { n.s./ } \\
\text { n.s.? }\end{array}$ & $4 / 3$ & $2 / 4$ & $7 / 3$ & $\begin{array}{l}\text { m.s. } \\
\text { m.s.". }\end{array}$ \\
\hline network & & & & & & & & \\
\hline members: & $\begin{array}{l}10 / 3 \\
(\mathbb{N}=15)\end{array}$ & $\begin{array}{l}7 / 3 \\
(N=15)\end{array}$ & $\begin{array}{l}9 / 4 \\
(N=18)\end{array}$ & $\begin{array}{l}\text { m.S./ } \\
\text { m.S. }\end{array}$ & $\begin{array}{l}11 / 3 \\
(H=16)\end{array}$ & $\begin{array}{l}8 / 4 \\
(N=17)\end{array}$ & $\begin{array}{l}7 / 3 \\
(N=15)\end{array}$ & $\begin{array}{l}\text { A.s. } \\
m . s^{2}\end{array}$ \\
\hline
\end{tabular}




\section{Appendix IV, table 3}

Aspacts of continuity of care in the periods $12-13$ and $12-14$ for patients who experienced a relatively positive, average or negative course of psychosocial functioning (assessment aflerwards)

\begin{tabular}{llllll}
$12-13$ & & \multicolumn{5}{c}{$2-14$} \\
1. & 2. & 3. & 1. & 2. & 3. \\
positive & average & negative & positive & average & negative \\
$(N=14)$ & $(N=43)$ & $(N=10)$ & $(N=21)$ & $(N=31)$ & $(N=15)$
\end{tabular}

\begin{tabular}{|c|c|c|c|c|c|c|c|c|}
\hline $\begin{array}{l}\text { number of professionals } \\
\text { involved }\end{array}$ & 4.6 & 4.3 & 4.5 & n.s. & 3.0 & 2.9 & 3.7 & n.s. ${ }^{4}$ \\
\hline \multicolumn{9}{|l|}{ number ol prolessionals } \\
\hline contacted more than once & 2.9 & 2.3 & 2.8 & n.s. ${ }^{4}$ & 2.0 & 2.3 & 2.5 & ns." \\
\hline \multicolumn{9}{|l|}{ coordinating contacts } \\
\hline no contacts necessary & 5 & 19 & 2 & $n: s^{2}$ & 9 & 11 & 5 & n.s..$^{2}$ \\
\hline no contacits & 4 & 10 & 5 & $n . s^{2}$ & 3 & 10 & 3 & n.s. ${ }^{2}$ \\
\hline some degree oll coordination & 4 & 14 & 3 & & 8 & 9 & 5 & \\
\hline no inlormalion available & 1 & - & - & & 1 & 1 & 2 & \\
\hline \multicolumn{9}{|c|}{ agreement on lasks and duties } \\
\hline allit & $\begin{array}{l}4 \\
(N=9)\end{array}$ & $\begin{array}{l}13 \\
(N=24)\end{array}$ & $\begin{array}{l}3 \\
(N=5)\end{array}$ & n.s. ${ }^{2}$ & $\begin{array}{l}7 \\
(N=13)\end{array}$ & $\begin{array}{l}10 \\
10(N=17)\end{array}$ & $\begin{array}{l}3 \\
(N=8)\end{array}$ & n.s. ${ }^{2}$ \\
\hline al 13 & $\begin{array}{l}1 \\
(\mathrm{~N}=2)\end{array}$ & $\begin{array}{l}5 \\
(N=6)\end{array}$ & $\begin{array}{l}1 \\
(N=2)\end{array}$ & n.S. ${ }^{2}$ & $\begin{array}{l}1 \\
(N=2)\end{array}$ & $\begin{array}{l}4 \\
(N=5)\end{array}$ & $(\mathbb{N}=3)$ & $n . s^{2}$ \\
\hline
\end{tabular}

agreement between patient and protessionals about functioning

pallent - general praclilioner

number ol cases in which

there was no contacl.

pallenl - aeneral prat.

average disagreement

210

2

n.s. ${ }^{2} \quad B$

13

2

ต..$^{2}$

$\begin{array}{llllllll}2.1 & 1.7 & 3.6 & 0=040^{4} & 2.5 & 1.4 & 2.3 & n . s^{4} \\ (\mathrm{~N}=9) & (\mathbb{N}=23) & (\mathrm{N}=5) & (1=2) \times 3 & (\mathrm{~N}=11) & (\mathrm{N}=7) & (\mathbb{N}=10)\end{array}$

number of general praciltioners that have no idea

17

3

5

number ol cases in which disagrement could not be compuled

$2 \quad 2$

$1 \quad 6 \quad 3$




$\begin{array}{llllll}12-13 & & & 0 & 2-14 & \\ 1 . & 2 . & 3 & 1 . & 2 . & 3 \\ \text { positive } & \text { average } & \text { negative } & \text { positive } & \text { average } & \text { negative } \\ (N=14) & (N=43) & (N=10) & (N=21) & (N=31) & (N=15)\end{array}$

patient - community nurse

number of cases in which

there was no contact

patient - communily nurse

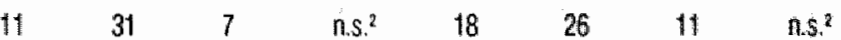

average disagreement

$\begin{array}{lll}3.0 & 1.4 & 1.0 \\ (\mathrm{~N}=1) & (\mathrm{N}=8) & (\mathrm{N}=2)\end{array}$

n.s.

3.5

$(\mathbb{N}=2) \quad(\mathbb{N}=3) \quad(N=4)$

number of community nurses

that have no idea

21

number of cases in which

disagreement could not

be computed

$\begin{array}{lll}- & 3 & 1\end{array}$

2

satistaction of patients and

network members with care

patient: dissatisfied not available for t3

$\begin{array}{lll}2 & 1 & 3 \\ 8 & 14 & 6 \\ 10 & 15 & 5\end{array}$

$n s^{2}$

network

$\begin{array}{lllllllll}\text { members: dissatisfied } & 1 & 8 & 0 & & 2 & 1 & & \\ \text { average } & 5 & 11 & 3 & \text { n.s. } & 9 & 8 & 4 & \text { n. }{ }^{2} \\ \text { salisfied } & 1 & 8 & 2 & & 3 & 10 & 2 & \end{array}$

number of people having

complaints aboul care (at 13 )

(in general/prowision of aids)

$\begin{array}{lllllllll}\text { pallient: } & 4 / 3 & 6 / 7 & 3 / 0 & \begin{array}{l}\text { n.s./ } \\ \text { n.s. }\end{array} & 4 / 4 & 4 / 7 & 5 / 2 & \text { n.s.l }\end{array}$

nelwork

$\begin{array}{llllllll}7 / 3 & 15 / 6 & 4 / 4 & \text { n.s.t } & 10 / 5 & 12 / 3 & 4 / 2 & \text { n.s. }\end{array}$

$(\mathbb{N}=10) \quad(N=32) \quad(N=6) \quad n . s^{2} \quad(N=15) \quad(\mathbb{N}=24) \quad(N=6) \quad n . s^{2}$




\section{Appendix IV, table 4}

Aspects of continuity of care in the perlods $12-13$ and t2-14 for patients with a relatively positive, average or negative course of psychosocial functioning (change over time)

\begin{tabular}{llllll}
$12-13$ & & \multicolumn{5}{l}{$1-14$} \\
1. & 2. & 3. & 1. & 2 & 3. \\
positive & average & negative & positive & average & negalive \\
$(\mathbb{N}=23)$ & $(N=23)$ & $(N=21)$ & $(N=23)$ & $(N=19)$ & $(N=25)$
\end{tabular}

number oll prolessionals

involved

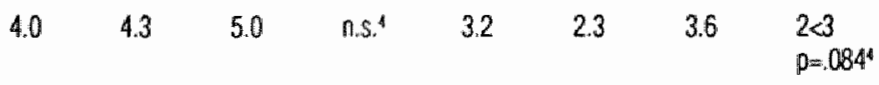

number of prolessionals.

conlicted more than once

$2.7 \quad 1.9 \quad 3$.

n.s.4

20

2.0

2.7 n.s.

coordinating contacts

no contacts necessary

mo contacts

812

some degree of coordination

no informalion available

855

ก.s..$^{2}$

$8 \quad 8$

8

9 n.s. ${ }^{2}$

59

n.s..$^{2}$

5

11

agreement on lasks and duties

at 11

al t 13

$\begin{array}{llllllll}3 & 9 & 8 & n . s^{2} & 6 & 6 & 8 & n . s^{2} \\ (N=11) & (N=15) & (N=12) & & (N=13) & (N=12) & (N=13) & \\ 2 & 3 & 2 & n . s^{2} & 1 & 3 & 3 & n . s^{2} \\ (N=3) & (N=4) & (N=3) & & (N=2) & (N=4) & (N=4) & \end{array}$

agresment between patient and

professionals aboul functioning

pattient - general practilioner

number ol cases in which

there was no contacl

patienl - general pract.

average disagrement

B

62

$2 \quad$ n.s. $\quad 6$

$\begin{array}{lll}2.3 & 1.7 & 2.3 \\ (N=14) & (N=13) & (N=10)\end{array}$

n.s.4

2.

$(N=11)$

$2.0 \quad 1.7 \quad$ n.S.

number of general pracli-

tloners thall have no idea

234

2

4

2

number of cases in which

disagreement could hat

be computed

1

1

5

4

51 


$\begin{array}{llllll}12-13 & & & & & \\ 1 . & 2 . & 3 . & 1 . & 2 & 3 . \\ \text { positive } & \text { average } & \text { negative } & \text { positive } & \text { average } & \text { negalive } \\ (\mathrm{N}=23) & (\mathrm{N}=23) & (\mathrm{N}=21) & (\mathrm{N}=23) & (\mathrm{N}=19) & (\mathrm{N}=25)\end{array}$

patienl - community nurse

number of cases in which there was no contact

patient communily nurse

average disagreement

$\begin{array}{lll}1.3 & 1.8 & 1.3 \\ (\mathbb{N}=4) & (N=4) & (N=3)\end{array}$

n.s.

$\begin{array}{llll}19 & 19 & 17 & \quad p=0.023^{2}\end{array}$

n.s.
$27 \quad-* \quad 22 \quad$ nis:
$(\mathrm{N}=3) \quad(\mathrm{N}=6)$

number of community nurses

that have no idea

1

number of cases in which

disagreement could not

be computed

$2 \quad 1 \quad 1$

$1 \quad-\quad 1$

satisfaction of patients and

network members with care
patient: dissalislied not available lor t3
average
salisfied

$\begin{array}{lll}1 & 0 & 5 \\ 9 & 10 & 9 \\ 13 & 6 & 11\end{array}$

n.s. ${ }^{2}$

network

members:

$\begin{array}{lll}\text { dissalistied } & 4 & 2 \\ \text { average } & 3 & 8 \\ \text { satistied } & 4 & 3\end{array}$

$$
\begin{aligned}
& 3 \\
& 8
\end{aligned}
$$

$\begin{array}{llll} & 0 & 2 & 2 \\ B^{2} & 4 & 8 & 9 \\ & 7 & 2 & 6\end{array}$

$n . s^{z}$

number of people having complainis about care (at t3)

(in general/provision of aids)

\begin{tabular}{|c|c|c|c|c|c|c|c|c|}
\hline patient: & $4 / 3$ & $4 / 4$ & $5 / 3$ & $\begin{array}{l}n . s . / \\
n . s^{2}\end{array}$ & $6 / 7$ & $2 / 1$ & $5 / 2$ & $\begin{array}{l}n: s . J \\
p=035\end{array}$ \\
\hline network & & & & & & & & \\
\hline members: & $\begin{array}{l}10 / 5 \\
(N-15)\end{array}$ & $\begin{array}{l}8 / 2 \\
(N=18)\end{array}$ & $\begin{array}{l}8 / 3 \\
(\text { h } /=15)\end{array}$ & $\begin{array}{l}n . s . / \\
n . s^{2}\end{array}$ & $\begin{array}{l}10 / 3 \\
(N=15)\end{array}$ & $\begin{array}{l}9 / 4 \\
(N=16)\end{array}$ & $\begin{array}{l}7 / 3 \\
(N=17)\end{array}$ & $\begin{array}{l}n . s . / \\
n . s^{2}\end{array}$ \\
\hline
\end{tabular}

* no cases left 


\section{Appendix V}

Social-demographic and disability-related characteristics

of the two subgroups of RA patients in phase II of the study

\begin{tabular}{|c|c|c|c|}
\hline & $\begin{array}{l}\text { RA rehab. } \\
\text { centire } \\
(\mathrm{N}=21)\end{array}$ & $\begin{array}{l}\mathrm{RA} \\
\text { clinic } \\
(N=18)\end{array}$ & Total \\
\hline mean age & 50.5 & 53.6 & 51.9 \\
\hline$\%$ male & $43 \%$ & $17 \%$ & $31 \%$ \\
\hline \multicolumn{4}{|l|}{$\%$ married and/or } \\
\hline living together & $62 \%$ & $88 \%$ & $71 \%$ \\
\hline \multicolumn{4}{|l|}{ mean educational } \\
\hline lewel & 2.3 & 1.8 & 2.1 \\
\hline mean family income & 1869 & $2069,-$ & 1954,- \\
\hline $\begin{array}{l}\text { mean duration of } \\
\text { disease (weeks) }\end{array}$ & 690 & 350 & 530 \\
\hline $\begin{array}{l}\% \text { with any compli- } \\
\text { cating disease }\end{array}$ & $43 \%$ & $28 \%$ & $36 \%$ \\
\hline level of disability & 14.0 & 13.0 & 13.6 \\
\hline
\end{tabular}




\section{Samenvatting in het Nederlands}

Dit boek vormt het verslag van een onderzoek naar het functioneren van patiënten na ontslag uit klinische revalidatie. Het eerste doel van het onderzoek betreft een beschrijving van het beloop van het functioneren na ontslag. We wilden weten in hoeverre patiënten er, in hun eigen beleving, in slagen het functionele niveau te behouden dat zij tijdens de opname ber eikt hebben. Een tweede doel van het onderzoek betreft de verklaring van verschillen in de mate van succes in dit opzicht; welke factoren verklaren dat sommige revalidanten een positiever beloop ervaren dan andere? Het onderzoek is specifiek gericht op de rol van persoonsgebonden kenmerken, kenmerken van het sociaal netwerk en continuiteit van de professionele zorg rond en na ontslag, in de verklaring van het functionele beloop. Met dit onderzoek wilden we inzicht krijgen in het relatieve belang van deze factoren, naast enkele sociaaldemografische variabelen en kenmerken van de aandoening. Er wordt een onderscheid gemaakt tussen het beloop op korte termijn (de eerste drie maanden na ontslag) en het beloop op lange termijn (tot één à ander half jaar na ontslag). Het onderzoek heeft betrekking op patiẻnten in drie diagnosegroepen: reumatoide arthritis, spondylitis ankylopoetica en dwarslaesies. 
Het boek bestaat uit 4 delen. Het eerste deel bestaat uit 5 hoofdstukken. Deze beschrijven de achtergrond van het onderzoek, de vraagstellingen en de wijze waarop het onderzoek is opgezet, gepland en uitgevoerd. Hoofdstuk 1 betreft de inleiding. In hoofdstuk 2 wordt een overzicht gegeven van binnen het kader van dit onderzoek relevante literatuur. Dit hoofdstuk begint met een discussie over de vraag waar bij de meting van revalidatiesucces de nadruk moet liggen. De nadruk is gelegd op dagelijks functioneren in termen van gerapporteerde activiteiten en gedrag, in combinatie met een subjectief oordeel van de patient over zijn eigen functioneren. In de overige paragrafen van hoofdstuk 2 beschrijven we de keuze van de in het onderzoeksmodel op te nemen variabelen en geven we aan wat er bekend is over de relatie tussen deze variabelen en het beloop van het functioneren. Op basis van dit overzicht worden in hoofdstuk 3 de vraagstellingen specifieker uitgewerkt, samen met een onderzoeksmodel en een aantal verwachtingen met betrekking tot de te onderzoeken samenhangen. De volgende variabelen zijn als verklarende variabelen in het onderzoeksmodel opgenomen: persoonlijkheidskenmerken, de gezondheidsgerelateerde beheersingsoriëntatie (health locus of control), zelfbeeld, omvang van het sociaal netwerk, aantal vrienden en andere nietfamilieleden in het netwerk, praktische en emotionele steun, continuiteit van de professionele zorg, leeftijd, geslacht, sociaal-economische status, burgelijke staat, het objectieve niveau van de fysieke beperkingen, de aanwezigheid van complicerende ziekten en de duur van de beperkingen. Continuiteit van zorg wordt gedefiniëerd als de mate waarin zorg geboden wordt als een gecoördineerde, ononderbroken opeenvolging van activiteiten, in overeenstemming met de (ervaren) behoeften van de patient.

De manier waarop het functioneren en de genoemde verklarende variabelen geoperationaliseerd en gemeten zijn, wordt beschreven in hoofdstuk 4 . Dit hoofstuk geeft ook een beschrijving van de opzet van het onderzoek en de gebruikte methoden. Het onderzoek is opgezet in twee fasen. De eerste fase is retrospectief en transversaal: het betreft een eenmalige meting waarbij terug gekeken wordt in de tijd. De tweede fase, die veel omvangrijker en uitgebreider is, heeft een longitudinaal design. Fase I betreft 37 patiënten met een dwarslaesie of reumatoïde arthritis, die een half tot anderhalf jaar tevoren uit het revalidatiecentrum ontslagen waren. In de tweede fase werden alle nieuw opgenomen patiënten met een dwarslaesie, reumatoïde arthritis of spondylitis ankylopoetica benaderd voor het onderzoek. In de beschikbare periode bleken 109 patiënten bereid mee te werken. Dit is drie kwart van het aantal opgenomen patiënten. Deze 109 mensen werden gedurende twee jaar gevolgd. In deze twee jaar waren er vier metingen: de eerste zo snel mogelijk na opname, de tweede op het moment van ontslag, de derde drie maanden na ontslag, en de vierde twee jaar na de eerste. Bij elke meting werden gegevens 
gevraagd aan de patient, aan betrokken professionele hulpverleners en aan leden van het sociaal netwerk van de patient. Naast de patient werden steeds de volgende personen benaderd: de revalidatie-arts/reumatoloog, de verpleegkundige in het revalidatiecentrum die het meest contact had met de patient, de huisarts, de wijkverpleegkundige, en de twee mensen uit het sociaal netwerk die, volgens de patient, op dat moment het belangrijkst war en. De benodigde informatie werd grotendeels verkregen met behulp van gestructureerdle mondelinge interviews en deels met schriftelijke vragenlijsten.

Het laatste hoofdstuk in deel I van het boek is hoofdstuk 5 . Hier wordt, voor beide fasen in het onderzoek, de onderzochte patiëntenpopulatie beschreven, samen met de geïnterviewde professionele hulpverleners en netwerkleden. Ook wordt ingegaan op de non-respons en de uitval gedurende het longitudinale deel van het onderzoek. Een belangrijke conclusie in hoofdstuk 5 is dat er in de tweede fase sprake is van selectieve uitval. Slechts $62 \%$ van de beginpopulatie is beschikbaar voor de longitudinale analyse. Dit is een positieve selectie: ten minste een deel van de uitval wordt veroorzaakt door ziekte of andere problemen van patiënten.

In deel II van het boek worden de resultaten van de eerste fase van het onderzoek beschreven. Het bestaat uit twee hoofdstukken. Hoofdstuk 6 beschrijft de resultaten met betrekking tot het ervaren beloop van het functioneren na ontslag. Bijna de helft van de 37 patiënten in deze fase rapporteerde een achteruitgang in fysiek functioneren en ongeveer $20 \%$ een achteruitgang in psychosociaal functioneren. Professionele hulpverleners en mensen uit het sociaal netwerk rapporteerden vergelijkbare gegevens. In hoofdstuk 7 wordt de groep patiënten die een achteruitgang rapporteerden vergeleken met hen die geen achteruitgang rapporteerden, wat betreft alle verklarende variabelen in het onderzoeksmodel. Voor deze analyse zijn de gegevens over het fysieke en het psychosociale functioneren samengevoegd tot één maat voor 'overall' functioneren. De resultaten in hoofdstuk 7 laten zien dat beide groepen in vele opzichten van elkaar verschillen. Vooral de persoonsgebonden kenmerken en de kenmerken van het sociaal netwerk blijken belangrijke voorspellers te zijn van het ervaren functionele beloop. Globaal gesproken zijn de resultaten in overeenstemming met de in hoofdstuk 3 geformuleerde verwachtingen. Een belangrijke conclusie op basis van de gegevens in hoofdstuk 7 is dat er problemen bestaan op het terrein van continuiteit van de zorg na ontslag. Afstemming en coördinatie van de zorg laten veel te wensen over. Een oordeel over het belang hiervan voor het functioneren van patiënten is op grond van deze gegevens niet mogelijk. 
Deel III van het boek beschrijft de resultaten van de tweede, longitudinale fase van het onderzoek. Dit deel bestaat uit 7 hoofdstukken. Hoofdstuk 8 gaat over het functioneren na ontslag, gemeten op verschillende manieren. Anders dan in hoofdstuk 6, wordt hier wel een onderscheid gemaakt tussen fysiek en psychosociaal functioneren. Elk van deze dimensies wordt op drie verschillende manieren gemeten: een beoordeling van het beloop achteraf (bij de derde en vierde meting), longitudinale veranderingen in gerapporteerde activiteiten en gedrag (gemeten met de Sickness Impact Profile) en longitudinale veranderingen in het eigen oordeel over het functioneren. De resultaten in hoofdstuk 8 komen in hoofdlijnen overeen met die in hoofdstuk 6 . Als de resultaten van de drie meetinstrumenten voor het functionele beloop gemiddeld worden, blijkt ongeveer $35 \%$ van de totale patiëntengroep gedurende de eerste drie maanden achteruit te gaan, en liets minder als gekeken wordt op lange termijn. Voor het psychosociale functioneren is dit percentage iets lager: op het moment van zowel de derde als de vierde meting functioneert ongeveer $25 \%$ van de patiënten slechter dan op het moment van ontslag. Vanwege de selectieve uitval tijdens het onderzoek, is het waarschijnlijk dat het 'echte' percentage patiënten dat functioneel achteruit gaat hoger is.

De resultaten zijn verschillend voor de verschillende diagnosegroepen, maar in elke groep is er een aanzienlijk aantal patiënten dat achteruit gaat. Globaal gesproken is het beloop bij de dwarslaesiepatiënten het meest positief en dat bij de spondylitispatiënten het minst.

Evenals in hoofdstuk 6, worden de antwoorden van de patiënten in belangrijke mate bevestigd door beoordelingen van de mensen uit het sociaal netwerk, en ook, zij het in iets mindere mate, door beoordelingen van professionele hulpverleners.

De gegevens laten een 'dip' in het functioneren zien drie maanden na ontslag: voor zowel fysiek als psychosociaal functioneren is er een tendens naar achteruitgang gedurende de eerste drie maanden, gevolgd door een lichte tendens naar verbetering. Dit geeft aan dat de eerste paar maanden na ontslag een kritieke periode vormen.

In hoofdstuk 9 worden groepen van patiënten samengesteld die in de latere hoofdstukken vergeleken worden in het kader van de analyse van de factoren die met het functionele beloop samenhangen. Deze groepen zijn zodanig samengesteld dat de drie diagnosegroepen in ongeveer gelijke mate vertegenwoordigd zijn. Dit is nodig vanwege de in hoofdstuk 8 gevonden verschillen in beloop tussen deze groepen. Voor de korte en de lange termijn én voor fysiek en psychosociaal functioneren apart, worden steeds drie groepen patiënten gevormd: een groep met een relatief positief beloop, een groep met een relatief negatief beloop en een 'gemiddelde' groep. Dit gebeurt steeds twee keer: een keer op basis van het retrospectieve oordeel van patiënten 
achteraf (dit lijkt erg op de benadering in hoofdstuk 7 ) en een keer op grond van een combinatie van longitudinale veranderingen in gerapporteer de activiteiten en gedrag (de SIP) en in het eigen oordeel over het functioneren. Het resultaat van al deze bewerkingen is dat bij de analyse van de samenhangen van de verklarende variabelen met het beloop, acht parallelle benaderingen onderscheiden worden: korte en lange termijn, fysiek en psychosociaal functioneren, oordeel achteraf en veranderingen in de tijd.

Naast het samenstellen van deze groepen wordt in hoofdstuk 9 ingegaan op het fenomeen regressie naar het gemiddelde in de longitudinale benadering. Met name bij de veranderingsscores met betrekking tot het beloop op lange termijn blijkt dit fenomeen duidelijk te bestaan. Het is waarschijnlijk dat de desbetreffende analyse erdoor vertekend wordt.

De resterende hoofdstukken in deel III $(10 \mathrm{t} / \mathrm{m} \mathrm{14})$ gaan over de verklaring van het beloop van het functioneren. In de hoofdstukken 10 tot en met 13 wordt steeds de relatie van een groep variabelen uit het onderzoeksmodel met de 8 maten voor het functioneren onderzocht. In elk van deze hoofdstukken worden alleen bivariate samenhangen beschreven: de in hoofdstuk $9 \mathrm{ge}$ creëerde groepen worden vergeleken wat betreft de te onderzoeken variabelen. Met uitzondering van hoofdstuk 10 begint elk hoofdstuk met een beschrijving van de scores op de verklarende variabelen en, waar dat relevant is, een beschrijving van longitudinale veranderingen daarin. Daarna worden de verschillen tussen de gecreëerde groepen besproken. Tenslotte worden de resultaten van de 8 parallelle benaderingen besproken in relatie tot de in hoofdstuk 3 geformuleerde verwachtingen. Hoofdstuk 10 gaat over sociaaldemografische variabelen en kenmerken van de aandoening. Hoofdstuk 11 gaat over de persoonsgebonden kenmerken, terwijl in hoofdstuk 12 het sociaal netwerk centraal staat. Hoofdstuk 13 gaat over de continuilteit van de zorg. De gegevens in deze hoofdstukken maken een selectie mogelijk van de variabelen die de belangrijkste rol spelen bij de verklaring van verschillen in beloop; een deel van de variabelen hangt met geen enkele van de onderscheiden maten voor het functioneren samen, of op een onduidelijke of niet systematische wijze. De selectie van die variabelen die een min of meer consistente samenhang vertonen met enkele van de gebruikte maten, vormt de basis voor de analyses in hoofdstuk 14 . Hier wordt een serie multivariate analyses beschreven met deze beperkte selectie van variabelen. Het gaat om discriminant analyses en multiple regressie analyses. Voor deze multivariate analyses worden de geselecteerde persoonsgebonden variabelen gecombineerd in één samengestelde variabele 'machteloosheid'. Dit is mogelijk omdat deze variabelen bij een principale componenten analyse één duidelijke factor bleken te vormen. De variabelen die uiteindelijk in de analyses in hoofdstuk 14 betrokken worden zijn: machteloosheid, omvang van het sociaal netwerk, 
het aantal mensen waarvan de patient praktische steun krijgt, eenzaamheid, leeftijd, sociaal-economische status, duur van de beperkingen en het ontstaan van andere ziekten na ontslag. De analyses in hoofdstuk 14 leiden tot de volgende conclusies:

- Sociaal-demografische variabelen spelen een belangrijke rol in de verklaring van het beloop van het functioneren. Patiënten met een lage sociaaleconomische status, hetgeen nauw gerelateerd is aan een hoge leeftijd, hebben een grotere kans op een relatief negatief beloop, vooral gedurende de eerste drie maanden na ontslag. Dit geldt het duidelijkst voor fysiek functioneren.

- Kenmerken van de beperking spelen een minder belangrijke rol in de verklaring van het beloop. Het optreden van andere ziekten na ontslag geeft een grotere kans op een relatief negatief beloop, vooral in psychosociaal opzicht, maar dit is niet geheel eenduidig. Een korte duur van de aandoening geeft een grotere kans op een relatief positief beloop, maar een lange duur betekent niet dat het beloop negatief zal zijn; de 'gemiddelde' groep heeft de aandoening het langst.

- Machteloosheid, hetgeen staat voor de combinatie van de persoonsgebonden kenmerken, speelt een hoofdrol in de verklaring van het beloop van zowel het fysieke als het psychosociale functioneren gedurende de eerste drie maanden na ontslag. Patiënten met een relatief negatief beloop scoren relatief hoog op de variabele machteloosheid. Dit betekent dat zij neigen in de richting van een sterke arts-oriëntatie, een hoge inadekwatiescore, een lage zelfwaardering en een negatief zelfbeeld, samen met een hoge kans-oriëntatie, een lage interne oriëntatie en een hoge rigiditeitscore. Het is van belang te constateren dat dit niet alleen in een transversale analyse zo is, maar dat een hoge score op machteloosheid op het moment van ontslag het beloop daadwerkelijk voorspelt. De rol van machteloosheid voor de verklaring van het functioneren op lange termijn is veel minder belangrijk.

- Van de onderzochte kenmerken van het sociaal netwerk blijken vooral de ervaren hoeveelheid praktische steun en eenzaamheid belangrijke "voorspellers' te zijn van het beloop van fysiek en psychosociaal functioneren op lange termijn. Gevoelens van eenzaamheid en het ervar en van weinig steun, en vooral een afname van de hoeveelheid steun zijn sterke 'voorspellers' van een relatief negatief beloop in fysiek en psychosociaal opzicht. Omvang van het netwerk is geen goede voorspeller van het beloop.

Deze conclusies gelden voor elk van de drie diagnosegroepen die in dit onderzoek betrokken zijn. 
De resultaten in de hoofdstukken 11,12 en 13 geven niet alleen een antwoord op de vraag welke factoren van belang zijn voor de verklaring van het functionele beloop na ontslag. De beschrijving van de verklarende variabelen in deze hoofdstukken leidt ook tot enkele belangrijke andere conclusies. De belangrijkste hebben betrekking op het sociaal netwerk en op de continuiteit van de zorg.

In hoofdstuk 12 wordt duidelijk dat sociale netwerken sterk veranderen gedurende de twee jaar dat patiënten gevolgd zijn. De omvang van het netwerk en het aantal vrienden en andere niet-familieleden nemen in elke diagnosegroep af. Dit is het duidelijkst in de dwarslaesiegroep: deze patiënten 'verliezen' gemiddeld meer dan de helft van hun vrienden en andere nietfamilieleden.

De resultaten met betrekking tot de continuiteit van de zorg rond en na ontslag in hoofdstuk 13, geven een sterke bevestiging van die in hoofdstuk 7. Afstemming en coördinatie van de zorg blijken verre van optimaal. Er blijken problemen te bestaan op alle onderscheiden aspecten van de zorg. Men kan zich zelfs afvragen of continuilteit van zorg zoals voor dit onderzoek gedefinieerd, in de praktijk bestaat. Dit is de meest waarschijnlijke verklaring voor het feit dat geen enkele relatie gevonden wordt tussen aspecten van continuiteit en het functioneren van patiënten. De belangrijkste bevindingen zijn:

- Schriftelijke informatie-uitwisseling tussen revalidatiecentrum en eerstelijns gezondheidszorg draagt weinig bij aan een goede overdracht en coördinatie van zorg. Ontslagbrieven en -formulieren zijn soms laat, bereiken de huisarts niet altijd en de wijkverpleegkundige vaak niet. Voorzover ze aankomen, worden ze meestal niet gelezen.

- Telefonische of mondelinge contacten tussen bij de zorg voor een patient betrokken hulpverleners zijn zeldzaam. Voorzover er contacten zijn, gaan die bijna nooit verder dan informatie-uitwisseling.

- Er is zeer weinig overeenstemming tussen hulpverleners over de vraag wie primair verantwoordelijk is voor verschillende aspecten van de zorg.

- Er is slechts in beperkte mate overeenstemming tussen professionele hulpverleners en patiënten over de situatie van de patiënten.

- Patiënten en vooral mensen uit hun sociaal netwerk zijn niet meer dan matig tevreden over de zorg na ontslag. Zij noemen een belangrijk aantal klachten, die vooral betrekking hebben op een gebrek aan begeleiding en ondersteuning, lange en gecompliceerde procedures bij de verstrekkende instanties voor hulpmiddelen en woningaanpassingen, en een gebrek aan adekwate informatie. 
In deel IV van het boek worden de resultaten van beide fasen wan het onderzoek besproken en worden de conclusies geformuleerd. In hoofdstuk 15 worden eerst enkele problemen van dit onderzoek besproken: het beperkte aantal patiënten dat voor de analyse beschikbaar was, de selectieve uitval, regressie naar het gemiddelde en het feit dat er verschillende parallelle analyses gedaan werden. Geconcludeerd wordt dat deze problemen waarschijnlijk niet tot foutieve resultaten hebben geleid, maar dat het voorzichtigheidshalve verstandig is de conclusies te beschouwen als valide hypothesen, die in toekomstig onderzoek getoetst moeten worden. Na deze discussie worden de conclusies beschreven. De inhoud hiervan is eerder in deze samenvatting al weergegeven.

Hoofdstuk 15 eindigt met een aantal aanbevelingen voor de revalidatiepraktijk en enkele suggesties voor verder onderzoek. De praktische aanbevelingen hebben betrekking op de ontwikkeling van interventies gericht op het positief beïnvloeden van de persoonsgebonden kenmerken die in de variabele machteloosheid zijn samengevoegd. Het gaat daarbij vooral om de beheersingsoriëntatie en het zelfbeeld. Ook wordt aanbevolen interventies te richten op de instandhouding van sociale steun vanuit het sociaal netwerk. Dit laatste kan in principe op twee manieren: training en ondersteuning van mensen in het netwerk in het omgaan met de revalidant en training van de sociale vaardigheden van de revalidant. De derde aanbeveling betreft de problemen op het gebied van continuiteit van de zorg. Aanbevolen wordt ontslagprocedures te ontwikkelen die meer duidelijkheid en overeenstemming garanderen over taken en verantwoordelijkheden van professionele en niet-professionele hulpverleners in het zorgproces. Een belangrijk element daarvan zou kunnen zijn het expliciet aanwijzen van een van de betrokkenen als zorg-coördinator. De laatste aanbevelingen betreffen het bevorderen van de deskundigheid van professionele hulpverleners en andere betrokkenen, en het betrekken van 'ervaren' patiënten bij de zorg. Ervaren patiënten kunnen een belangrijke rol spelen in de ondersteuning van patiënten, vooral door het geven van informatie over 'het leven met een chronische aandoening'. 


\section{Curriculum vitae}

Ik ben geboren op 28 juni 1959 te Beek. Na de lagere school aldaar doorliep ik van 1971 tot 1977 het Atheneum-B aan het St. Michiel lyceum te Geleen. Aansluitend studeerde ik, na de nodige keuzeproblemen, Geneeskunde in Maastricht. Tijdens deze studie was ik langdurig lid van de universiteitsraad en van enkele studentenorganisaties. Gedurende anderhalf jaar had ik tevens een halftijds aanstelling als beleidsmedewerker bij de grif fie van de universiteitsraad.

Het arts-diploma kreeg ik in november 1983. Ik werkte toen al enkele maanden bij de vakgroep Gezondheidsvoorlichting en -opvoeding van de RL, ten behoeve van een onderzoek naar GVO in de eerstelijns gezond heidszor g. Op basis van de gegevens uit een keuzeblok dat ik tijdens het laatste studiejaar had gedaan, werkte ik samen met enkele collega's het onderzoeksplan uit waarop dit proefschrift gebaseerd is. Voor de uitvoering van dat plan werd ik per 1 februari 1985 aangesteld bij de vakgroep Medische Sociologie van de RL, en van daaruit gedetacheerd naar het Instituut voor Revalidatie-Vraagstukken in Hoensbroek. Naast het promotie-onderzoek raakte ik daar allengs betrokken bij een groeiend aantal projecten, deels als projectleider en deels als medeuitvoerder of adviseur. Speciale aandachtspunten in mijn onderzoeks- 
activiteiten zijn: afstemming en coördinatie van zorg, nazorg, gevolgen van chronische aandoeningen voor het dagelijks leven en kwaliteit van leven.

Naast het onderzoekswerk heb ik een dag per week wisselende onderwijstaken binnen de facullteit der Gezondheidswetenschappen.

Behalve belangstelling voor mijn werk heb ik veel aandacht voor muziek, zich onder andere uitend in ruim 15 jaar kerkelijk orgelspel. De piano staat echter voorop.

Bij de beschrijving van mijn levensloop hoort zeker ook het feit dat ik sinds 1985 getrouwd ben en iets minder lang de vader van twee kinderen. 